INSTITUTO DE PESQUISAS ENERGÉTICAS E NUCLEARES

Autarquia associada à Universidade de São Paulo

\title{
ESTUDO DO EFEITO DA TENSÃO RESIDUAL NA MICRODEFORMAÇÃO DA REDE CRISTALINA E NO TAMANHO DE CRISTALITO EM AÇO Cr-Si-V JATEADO COM GRANALHAS DE AÇO
}

RENE RAMOS DE OLIVEIRA

Tese apresentada como parte dos requisitos para a obtenção do grau de Doutor em Ciências na área de Tecnologia Nuclear Materiais

Orientador:

Prof. Dr. Nelson Batista de Lima

\section{SÃO PAULO}


INSTITUTO DE PESQUISAS ENERGÉTICAS E NUCLEARES

Autarquia associada à Universidade de São Paulo

\section{ESTUDO DO EFEITO DA TENSÃO RESIDUAL NA MICRODEFORMAÇÃO DA REDE CRISTALINA E NO TAMANHO DE CRISTALITO EM AÇO Cr-Si-V JATEADO COM GRANALHAS DE AÇO}

RENE RAMOS DE OLIVEIRA

Orientador:

Prof. Dr. Nelson Batista de Lima

SÃO PAULO

2016 


\section{AGRADECIMENTOS}

Aos técnicos do CCTM: Celso Vieira de Morais, Nildemar Aparecido Messias Ferreira, Glauson Aparecido Ferreira, Olandir Vercino Correia, Mariano Castagnet.

A mestranda Gleicy de Lima Xavier

Ao Pesquisador Bruno Geoffroy Scuracchio.

Ao assistente técnico da W Abrasives Evandro Lemes.

Ao técnico da Thyssenkrupp Bilsten Brasil Alisson Denis Carros Nizes.

Ao Sr. Edson Togni do SENAI Nadir Dias Figueiredo

Ao Professor Dr. Garabed Kenchian do Instituto Federal de São Paulo

Em especial a minha família:

A minha esposa Olivia Cristina Passos Oliveira;

A minha mãe Hilda Giovannini de Oliveira;

Em memória de meu pai Martinho Ramos de Oliveira 


\section{ESTUDO DO EFEITO DA TENSÃO RESIDUAL NA MICRODEFORMAÇÃO DA REDE CRISTALINA E NO TAMANHO DE CRISTALITO EM AÇO Cr-Si-V JATEADO COM GRANALHAS DE AÇO}

\section{RESUMO}

No presente trabalho foram estudados alguns efeitos causados pelo jateamento por granalhas no aço Cr-Si-V, processo que tem por objetivo aumentar a resistência à fadiga. Para este estudo a variação de parâmetros no processo são ferramentas para melhor compreender os mecanismos que influenciam esta propriedade. Os parâmetros utilizados neste trabalho foram a variação da granalha e o pré tensionamento das amostras aplicados em lâminas utilizadas em feixe de molas automobilísticas de aço de liga cromo silício vanádio (SAE 9254+V). Inicialmente foi realizada a avaliação do perfil de tensão residual, efetuada por difração de raios- $x$ pelo método do $\operatorname{sen}^{2} \Psi$ ao longo da espessura na região onde a tensão é compressiva. Nos resultados nota-se um efeito anômalo em relação ao perfil característico da distribuição de tensão residual com a perda de compressão nas camadas iniciais em relação à superfície jateada. Com o uso da microscopia eletrônica de varredura foi observado a região afetada pelo jateamento por granalhas notando que as regiões plasticamente deformadas se encontram nas mesmas regiões onde ocorre a diminuição da tensão residual compressiva. O perfil obtido pela difração de raios-x fornece as informações necessárias com o propósito de conjugar os efeitos que a microtensão (microdeformação) influenciam na macrotensão (tensão residual). Esta relação foi comprovada pela sobreposição dos resultados encontrados na distribuição da microdeformação da rede cristalina com a tensão residual ao longo da espessura na região plasticamente deformada. Os resultados dos perfis das difrações de raios-x mostraram a existência de anisotropia de tensões entre os planos, geradas por defeitos de empilhamento e pela densidade de discordâncias. Assim sendo, para obter os valores das microtensões devem ser considerados os fatores das constantes elásticas (conforme o módulo das direções) 
e dos planos cristalográficos. O método aplicado foi o Williamson-Hall modificado. Além deste método outros também foram utilizados, tais como: método de WarrenAverbach e o método Single Line, este aplicando a série de Fourier, porém, ao observar os resultados, nota-se a diferença entre os valores obtidos nas deformações, tanto aos métodos quanto aos planos cristalográficos, porém a ênfase deste trabalho foi dada às características dos perfis da distribuição e não aos valores absolutos. Somando a isto, foi proporcionado o estudo da distribuição do tamanho médio de cristalito ao longo da espessura no perfil das difrações de raios- $\mathrm{x}$ e os resultados mostraram que esta distribuição varia de forma inversa a microdeformação. A relação entre o tamanho médio de cristalito e a variação das distâncias interplanares corresponde diretamente a alterações das densidades de discordâncias ocorridas no material que por sua vez estão ligadas às microdeformações da rede cristalina. Como complemento ao trabalho foram analisados o fator de concentração de tensão e ensaios de fadiga do material. $O$ fator de concentração de tensão não variou conforme a utilização das granalhas S330 e S390, ambas sendo aplicadas no mesmo regime de jateamento. Os ensaios de fadiga indicaram que o pré tensionamento aumenta a vida útil nas tensões cíclicas do material estudado. 


\title{
STUDY OF THE EFFECT OF RESIDUAL STRESS ON THE MICROSTRAIN OF THE CRYSTALLINE LATTICE AND ON THE CRYSTALITE SIZE OF STEEL Cr- Si-V BY SHOT PEENING
}

\begin{abstract}
In the present work, some effects caused by jateamento por granalhas on Cr-Si-V steel have been studied, a process that aims to increase fatigue resistance. For this study the variation of parameters in the process are tools to better understand the mechanisms that influence this property. The parameters used in this work were the variation of the grit and the pre-tensioning of the samples applied in leafs used in automotive springs of chrome silicon vanadium alloy steel (SAE $9254+\mathrm{V}$ ). Initially the evaluation of the residual stress profile was performed by $\mathrm{x}$-ray diffraction using the $\operatorname{sen}^{2} \Psi$ method along the thickness in the region where the stress is compressive. The results show an anomalous effect in relation to the characteristic profile of the residual stress distribution with the decrease of compression in the initial layers in relation to the blasted surface. With the use of scanning electron microscopy, the region affected by grit blasting was observed, noting that the plastically deformed regions are located in the same regions where the compressive residual stress decrease. The profile obtained by $\mathrm{X}$-ray diffraction provides necessary information with the aim of combining the effects of microstress (microstrain) on macrostress (residual stress). This relationship was confirmed by the overlap of the results found in the distribution of the microstrain of the crystalline lattice with the residual stress along the thickness in the plastically deformed region. The results of the $\mathrm{x}$-ray diffraction tests show an existence of tensile anisotropy between the planes generated by stacking faults and the dislocations density. Therefore, to obtain the values of the microstress must be considered the factors of the elastic constants and the crystallographic planes. The method applied was the modified Williamson-Hall. Beyound this method, others were also used, such as: Warren-Averbach method and the Single Line method, this applying the Fourier series, however, when observing
\end{abstract}


the results, we can notice the difference between the values obtained in the deformations, however, the emphasis of this work was on the characteristics of the distribution profiles and not on the absolute values. In addition, the study of the distribution of the mean crystallite size along the thickness of the X-ray diffraction profile was provided and the results showed that this distribution varies inversely with microstrain. The relationship between the mean crystallite size and the variation of the interplanar distances corresponds directly to changes in the densities of dislocations occurring in the material, which in turn are linked to the microstrain of the crystalline lattice. As a complement to the work, the stress concentration factor and fatigue tests of the material were analyzed. The stress concentration factor did not change according to the use of the $S 330$ and $S 390$ grit, both being applied in the same blasting regime. Fatigue tests indicated that pretensioning increases the useful life of the cyclic stresses of the material studied. 


\section{SUMÁRIO}

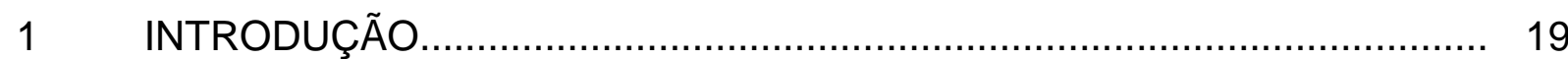

2 OBJETIVO

3 REVISÃO DA BIBLIOGRAFIA......................................................... 22

3.1 A aplicação do vanádio no aço.......................................................... 22

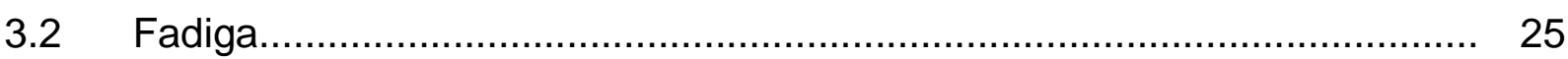

3.2.1 Tensões cíclicas...................................................................... 30

3.2.2 Curva de Wöhler (S-N) ............................................................... 33

3.2.3 Análise de Weibull.......................................................................... 35

3.3 Fator de concentração de tensão.......................................................... 37

3.4 Microdeformação da rede cristalina e tamanho de cristalito....................... 41

3.4.1 Método de Sherrer.................................................................... 42

3.4.2 Método Williamson-Hall..................................................................... 43

3.4.3 Série de Fourier.......................................................................... 54

3.4.4 Estudo do perfil das difrações............................................................... 58

3.4.5 Método Warren-Averbach............................................................. 64

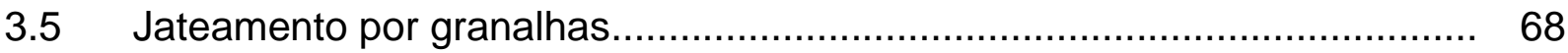

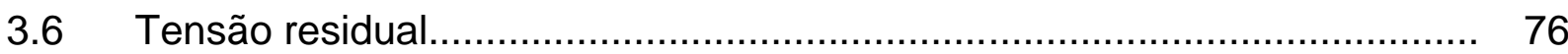

3.6.1 Medidas de tensão residual por raios-X................................................. 79

4 MATERIAIS E MÉTODOS................................................................. 83

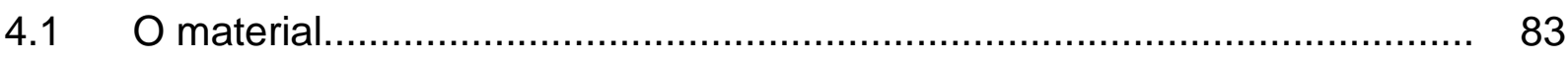

4.2 Conformação do material................................................................ 84

$4.3 \quad$ Tratamento térmico................................................................... 84

4.4 Aplicação do Jateamento por granalhas.............................................. 85

4.5 Análise de tensão residual em profundidade ao longo da espessura......... 86

4.6 Medidas de microdeformação e tamanho médio de cristalito..................... 87

4.7 Determinação do fator de concentração de tensão.................................... 88

4.8 Caracterização da seção transversal..................................................... 88

$4.9 \quad$ Ensaio de fadiga......................................................................... 89 


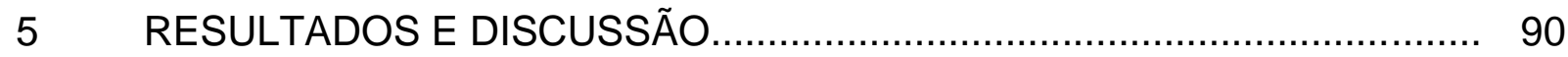

$5.1 \quad$ Distribuição de tensão residual........................................................... 90

5.2 Resultados do fator de concentração de tensão........................................ 95

5.3 Microdeformação da rede cristalina e tamanho médio de cristalito............. 99

$5.4 \quad$ Ensaio de fadiga.......................................................................... 135

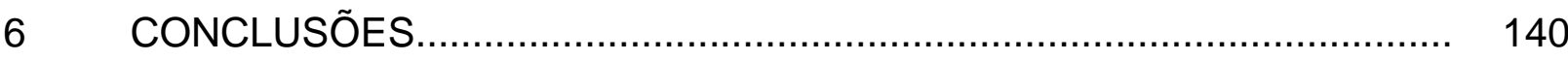

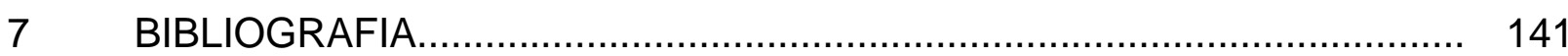




\section{LISTA DE FIGURAS}

Figura 1 Precipitado de carbonitreto de vanádio no ferro austenítico (Gallego et al., 2002)

Figura 2 Comparativo entre amostras contendo: (a) 0,1\% de vanádio e (b) 0,03\% de nióbio (Mitchell, 2001).

Figura 3 Solubilidade do nitreto de vanádio em relação a temperatura.

Figura 4 Nucleação de trinca por fadiga nas bandas de deslizamento, ilustrando o mecanismo de formação de extrusões e intrusões (Dieter, 1981)

Figura 5 a) Deformação estática, b) deformação cíclica originando intrusões e extrusões, Fuchs e Stephenns (1980) e imagens obtidas em MEV mostrando em c) intrusões e d) extrusões (Ruchert, 2007)

Figura 6 Propagação da trinca conforme a orientação dos grãos (Miller, 1993).

Figura 7 Aspectos macroscópicos a), microscópicos b) da superfície de fratura por fadiga evidenciando estrias (Ruchert, 2007)................. 28

Figura $8 \quad$ Superfície de fratura por fadiga (Ruchert, 2007).......................... 28

Figura 9 Representação de um dos modelos de propagação de trinca por fadiga. (Miller 1993)

Figura 10 Carregamento cíclico: Carregamento flutuante, regular e assimétrico (Callister, 2001)

Figura 11 Carregamento cíclico: Carregamento alternado, regular e simétrico(Callister, 2001).

Figura 12 Curva S-N característica para aços em geral

Figura 13 Comportamento das curvas dos parâmetros de forma em relação a probabilidade de falha (Ronniger, 2012)

Figura 14 Representação de uma placa de comprimento infinito submetida a tensão de tração com uma trinca de dimensão 2a (Anderson).

Figura15 Tensões próxima a ponta da trinca (Anderson). 
Figura 16 Picos de difração - (a) Representação de um pico de um cristal livre de deformações - (b) Representação de um pico de um cristal deformado (Cullity, 1978).

Figura 17 Metodologia para a determinação da microdeformação da rede cristalina e tamanho médio de cristalito

Figura 18 Fator de contraste correspondente a $\bar{C}_{h 00}$ para CFC hélice (a), CFC cunha (b), CCC hélice (c) e CCC cunha (d) na função da anisotropia elástica $A_{i}$ e em razão das constantes elásticas $\frac{C_{12}}{C_{44}}$

Figura 19 Parâmetro $q$ como função da anisotropia elástica $A_{i}$ e a razão da constante elástica $\frac{C_{12}}{C_{44}}$ : (a) no caso do sistema CFC nas discordâncias hélice e cunha em $\frac{C_{12}}{C_{44}}=1$; (b) no caso do sistema CCC nas discordâncias hélice e cunha em $\frac{C_{12}}{C_{44}}=1$; (c) no caso do sistema CCC na discordância cunha em diferentes razoes de $\frac{C_{12}}{C_{44}}$ (Ungar e Borbély, 1996).

Figura 20 Gráfico aplicado a equação de Williamson-Hall (a) e Aplicado na equação modificada (b) (Sato et al., 2013)

Figura 21 Gráfico da função para obtenção de $q$ para a função de $\Delta K^{2}$ em relação a $H^{2}$ (Ungar e Borbély, 1996).

Figura 22 Exemplo de um sinal discreto (Ichikawa, 2013).

Figura 23 Razão do alargamento integrado das componentes de Cauchy e Gaussiana $\frac{\beta_{C}}{\beta} \mathrm{e} \frac{\beta_{G}}{\beta}$, como função de $\frac{2 w}{\beta}$ (Langford, 1978).

Figura 24 Gráfico baseado nos coeficientes de Fourier para obtenção do Tamanho Médio de Cristalito e Microdeformação na Rede.

Figura 25 Gráfico dos coeficientes de Fourier $A_{L}^{S}$ em função de $L$. O intercepto da tangente fornece o tamanho médio do cristalito.

Figura 26 Demonstração do impacto da esfera sobre uma superfície (MIC, 2013)

Figura 27 Sistema de jateamento pressurizado (Poloar, 2016)...

Figura 28

Sistema de jateamento centrífugo (Rosler, 2016).

Figura 29 Distribuição de tensões após a aplicação do jateamento por granalhas (MIC, 2013).

Figura 30 Perfil típico de tensões residuais (Torres, 2002). 
Figura 31 Padrão de formas para jateamento, (MIC, 2013)........................... 75

Figura 32 Tensão residual induzida pela deformação plástica (Cullity e Stock, 2001)

Figura 33 Nomenclatura das direções das tensões em eixos e chapas (Wulpi, 1985)

Figura 34 O espaçamento interplanar $d_{0}$ é o mesmo para todas as famílias de planos, em qualquer direção, quando o material está livre de tensões, (François at al., 1996).....

Figura $35 \quad$ O espaçamento interplanar varia em todas as direções na presença de uma tensão, (François at al., 1996)

Figura 36 Direções da tensão e deformação principais, (Rigaku, 2003).

Figura 37 Conformação por laminação à quente (Thyssenkrupp Bilsten Brasil)....

Figura 38 Tratamento térmico (Thyssenkrupp Bilsten Brasil)...

Figura 39 Aplicação do jateamento por granalhas (IKK do Brasil).

Figura 40 Difratômetro utilizado nas medidas de tensão residual (IPENCNEN/SP)

Figura 41 Difratômetro utilizado nas medidas de microdeformação da rede e tamanho médio de cristalito (IPEN-CNEN/SP).

Figura 42 Parâmetros utilizados nos ensaios de fadiga (Scuracchio, 2012).......

Figura 43 Distribuição de tensão residual da amostra jateada em granalhas S330 sem tensionamento (TR1), S330 com tensionamento (TR2) e S390 com tensionamento (TR3).

Figura 44 Micrografias das amostras TR2 (a) e TR3 (b) na região superficial jateada.

Figura 45 Modelamento para o estudo do efeito do jateamento (Meguid et al., 1998)

Figura 46 Resultado obtido por modelamento em jateamento com esfera de aço: Analisado no centro das esferas (a) e analisado abaixo da linha de centro das esferas (b) (Meguid et al., 1998).

Figura 47 Micrografias representativas das regiões superficiais das amostras TR2 (a) e TR3 (b) (IPEN-CNEN/SP). 
Figura 48 Dados representativos obtidos no rugosímetro para obtenção do fator de concentração de tensão das amostras TR2 (a) e TR3 (b).....

Figura 49 Vista vertical da idealização de um elemento finito mostrando a zona de indentação em uma superfície livre Li et al. (1992)...

Figura 50 Refinamento dos picos de difração da amostra jateada com S330 sem pré tensionamento.

Figura 51 Figura 51: Gráfico de aproximação do alargamento do pico padrão de Si para determinação do $\mathrm{Fe}$ - CCC

Figura 52 Gráfico para a determinação da microdeformação e tamanho médio de cristalito da amostra 1

Figura 53 Deslocamento dos perfis de difração de um material CCC na presença de falhas de empilhamento.

Figura 54 Refinamento do pico 200 da amostra jateada com S330 sem tensionamento ampliada da figura 50 .

Figura 55 Refinamento do pico 200 da amostra jateada com S330 sem tensionamento

Figura 56 Gráfico para a determinação da microdeformação e tamanho médio de cristalito da amostra jateada com a granalha S330 na superfície.

Figura 57 Gráfico para a determinação de $q$ da amostra jateada com a granalha S330 na superfície

Figura 58 Gráfico para a determinação da microdeformação e tamanho médio de cristalito pelo método de Willianson-Hall modificado.

Figura 59 Gráficos da distribuição da microdeformação em relação a profundidade das amostras 1, 2 e 3 pelo método de Willianson-Hall modificado

Figura 60 Gráfico comparativo entre a tensão residual e a microdeformação da rede da amostra 1 pelo método Willianson-Hall modificado

Figura 61 Gráfico comparativo entre a tensão residual e a microdeformação da rede da amostra 2 pelo método Willianson-Hall modificado.

Figura 62 Gráfico comparativo entre a tensão residual e a microdeformação da rede da amostra 3 pelo método Willianson-Hall modificado 
Figura 63 Deslocamentos dos átomos em relação a tensão residual (a) e a microdeformação da rede cristalina (b).

Figura 64 Gráficos da distribuição do alargamento integrado em relação a profundidade da amostra 2

Figura 65 Gráficos da distribuição do alargamento integrado em relação a profundidade da amostra 3

Figura 66 Gráfico comparativo entre a tensão residual e o alargamento integrado da amostra 2 .

Figura 67 Gráfico comparativo entre a tensão residual e o alargamento integrado da amostra 3

Figura 68 Gráficos da distribuição da microdeformação da rede cristalina em relação a profundidade da amostra 2 pelo método Single Line por distribuição.

Figura 69 Gráficos da distribuição da microdeformação da rede cristalina em relação a profundidade da amostra 3 pelo método Single Line por distribuição.

Figura 70 Gráfico comparativo entre a tensão residual e a microdeformação da rede da amostra 2 pelo método Single Line

Figura 71 Gráfico comparativo entre a tensão residual e a microdeformação da rede da amostra 3 pelo método Single Line

Figura 72 Gráfico da distribuição da microdeformação em relação a profundidade da amostra 2 pelo método Warren-Averbach por distribuição.

Figura 73 Gráfico da distribuição da microdeformação em relação a profundidade da amostra 3 pelo método Warren-Averbach por distribuição.

Figura 74 Gráfico comparativo entre a tensão residual e a microdeformação da rede da amostra 2 pelo método Warren-Averbach por distribuição.

Figura 75 Gráfico comparativo entre a tensão residual e a microdeformação da rede da amostra 3 pelo método Warren-Averbach por distribuição. 
Figura 76 Gráfico para obtenção dos valores do tamanho médio do cristalito obtidos pelo método Single Line pela inclinação.

Figura 77 Gráficos da distribuição do tamanho médio dos cristalitos em relação a profundidade da amostra 2 pelo método Single Line pela inclinação.

Figura 78 Gráficos da distribuição do tamanho médio dos cristalitos em relação a profundidade da amostra 3 pelo método Single Line pela inclinação.

Figura 79 Gráficos comparativos entre a tensão residual e tamanho de cristalitos da amostra 2 pelo método Single Line pela inclinação.......

Figura 80 Gráficos comparativos entre a tensão residual e tamanho de cristalitos da amostra 3 pelo método Single Line pela inclinação.......

Figura 81 Gráfico para obtenção dos valores do tamanho médio do cristalito obtidos pelo método Warren-Averbach pela inclinação.

Figura 82 Gráfico da distribuição do tamanho médio dos cristalitos em relação a profundidade da amostra 2 pelo método Warren-Averbach pela inclinação.

Figura 83 Gráfico da distribuição do tamanho médio dos cristalitos em relação a profundidade da amostra 3 pelo método Warren-Averbach pela inclinação.

Figura 84 Gráfico comparativo entre a tensão residual e tamanho de cristalitos da amostra 2 pelo método Warren-Averbach pela inclinação.

Figura 85 Gráfico comparativo entre a tensão residual e tamanho de cristalitos da amostra 3 pelo método Warren-Averbach pela inclinação.

Figura 86 Gráfico para obtenção dos valores do tamanho médio dos cristalitos pelo método Single Line por distribuição

Figura 87 Gráficos da distribuição do tamanho médio dos cristalitos em relação a profundidade da amostra 2 pelo método Single Line pela distribuição. 
Figura 88 Gráficos da distribuição do tamanho médio dos cristalitos em relação a profundidade da amostra 3 pelo método Single Line pela distribuição.

Figura 89 Gráficos comparativos entre a tensão residual e tamanho de cristalitos da amostra 2 pelo método Single Line por distribuição........

Figura 90 Gráficos comparativos entre a tensão residual e tamanho de cristalitos da amostra 3 pelo método Single Line por distribuição........

Figura 91 Gráfico da distribuição do tamanho médio dos cristalitos em relação a profundidade da amostra 2 pelo método Warren-Averbach por distribuição.

Figura 92 Gráfico da distribuição do tamanho médio dos cristalitos em relação a profundidade da amostra 3 pelo método Warren-Averbach por distribuição.

Figura 93 Gráficos comparativos entre a tensão residual e tamanho de cristalitos da amostra 2 pelo método Warren-Averbach por distribuição.

Figura 94 Gráficos comparativos entre a tensão residual e tamanho de cristalitos da amostra 3 pelo método Warren-Averbach por distribuição.

Figura 95 Posições em $2 \theta$ para $\Psi=0^{\circ}$ das amostras 2 e 3

Figura 96 Comparativo entre a tensão residual e os parâmetros em $\Psi=0^{\circ}$ da amostra 2 .

Figura 97 Comparativo entre a tensão residual e os parâmetros em $\Psi=0^{\circ}$ da amostra 3

Figura 98 Gráfico gerado pela análise de Weibull da amostra 1

Figura 99 Gráfico gerado pela análise de Weibull da amostra 2.

Figura 100 Gráfico gerado pela análise de Weibull da amostra 3. 


\section{LISTA DE TABELAS}

Tabela 1 Dados de difusão do vanádio na ferrita e na austenita (Woodhead, 2000)

Tabela 2 Valores dos parâmetros $a, b, c$ e $d$ para os resultados de $\bar{C}_{h 00}$ nas discordâncias do tipo cunha para sistema CFC.

Tabela 3 Valores dos parâmetros a,b,c e $d$ para os resultados de $\bar{C}_{h 00}$ nas discordâncias do tipo cunha para sistema CCC

Tabela 4 Valores dos parâmetros $a, b, c$ e $d$ para os resultados de $q$ nas discordâncias do tipo cunha para sistema CFC

Tabela 5 Valores dos parâmetros $a, b, c$ e $d$ para os resultados de $q$ nas discordâncias do tipo hélice para sistema CCC.

Tabela 6 Valores dos parâmetros $a, b, c$ e $d$ para os resultados de $q$ nas discordâncias do tipo cunha para sistema CCC

Tabela 7 Relação da razão entre alargamento e integral do alargamento com a proporcionalidade entre as funções Cauchy e Gaussiana (Langford, 1978).

Tabela 8 Composição química do material em \% de massa.......................... 83

Tabela 9 Análise microestrutural do material................................................ 83

Tabela 10 Análise de dureza, estrutura e descarbonetação do material pela norma DIN e NBR.

Tabela 11 Resultados da tensão residual das amostras TR1, TR2 e TR3...... 91

Tabela 12 Especificação das granalhas (IKK do Brasil).................................. 93

Tabela 13 Relação das granalhas e pressão de jateamento para cálculo de energia cinética e momento linear.

Tabela 14 Resultados dos fatores de concentração obtidos em relação ao regime de pressão e carregamento das amostras jateadas com a S330 e S390.

Tabela 15 Alargamento dos picos a meia altura referentes aos planos do padrão do $\mathrm{Fe}$ - CCC.

Tabela 16 Planos individuais analisados por difração de raios- $x$ 
Tabela 17 Valores de $H^{2}$ para os planos (hkl) - CCC.................................... 105

Tabela 18 Resultados em porcentagem da deformação na rede cristalina...... 108

Tabela 19 Distribuição das posições em $2 \theta$ para $\Psi=0^{\circ}$ das amostras 2 e $3 . . \quad 131$

Tabela 20 Resultados em ciclos para o ensaio de fadiga das amostras $1,2 \mathrm{e}$

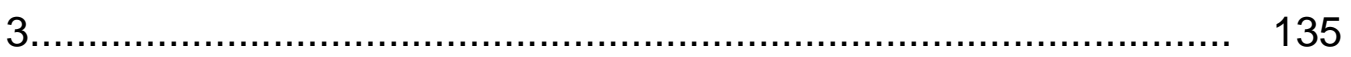

Tabela 21 Vida em fadiga B50 das amostras e valores de $\beta \ldots \ldots \ldots \ldots \ldots \ldots \ldots \ldots \ldots . . . . .139$ 


\section{INTRODUÇÃO}

O jateamento por granalhas é o método mais amplamente utilizado para introduzir tensão residual compressiva na superfície de um componente, aumentando sua vida em fadiga. Embora a grande aplicação do jateamento por granalhas na indústria existe a cerca de um século, os princípios do mecanismo para introdução de tensão residual não estão completamente compreendidos (Gonzales et al., 2009). Ohara (1999) entende que o jateamento por granalhas é considerado como um tratamento de superfície de benefícios questionáveis em relação a carregamento cíclico quando se é levado em conta a rugosidade gerada no material. Esta afirmação contraditória parte devido à ignorância do efeito do processo e em parte da falta de conhecimento suficiente que permita a caracterização do papel das modificações na superfície produzido pelo jateamento em danos por fadiga.

Procura-se compreender os parâmetros que controlam o desempenho de jateamento por granalhas, tais como os parâmetros de jateamento e as características das granalhas, surgindo uma nova designação, a de jateamento por granalhas controlado. O jateamento por granalhas controlado é um processo mecânico no qual as granalhas chocam com a superfície do material sob controle cinético e condições de impacto dando maior atenção às modificações de superfície produzidos pelo tratamento, sendo, a rugosidade da superfície, o aumento da densidade de discordâncias próximo às camadas da superfície, e o desenvolvimento de um perfil característico de tensão residual e microtensões da rede cristalina (Wagner e Lütjering, 1981; Turnbull et al., 1998). Eis que surgem as divergências, pois em termos de perdas em fadiga, a rugosidade na superfície irá acelerar a nucleação e início propagação de trincas, porém o endurecimento por deformação irá retardar a propagação, aumentando a resistência à deformação plástica e o perfil de tensão residual será de fornecer uma tensão de fechamento correspondente, que irá reduzir a força motriz para a propagação de trincas (Turnbull et al., 1998). Considerando o relaxamento do perfil de tensão residual causado por um determinado nível de tensão aplicado ou temperatura, é necessário supor que o desempenho do jateamento por granalhas dependerá do equilíbrio entre seus efeitos benéficos e prejudiciais nas propriedades em fadiga. Sendo assim, para que 0 
material obtenha um desempenho favorável, o papel dos efeitos tem de ser analisado e compreendido e para alcançar este objetivo é essencial conhecer simultaneamente a sua interação com outros parâmetros, tais como o tipo de material e as condições de carregamento.

A iniciação da trinca é um assunto que gerou diferentes teorias (Forsyth, 1957; Cottrell e Hull, 1957) e na maioria dos casos ocorre quase que imediatamente quando o componente é carregado acima do limite de fadiga (Miller, 1993), assim, o estágio de iniciação da trinca pode ser visto como a propagação de uma fissura com início em micro-defeitos (Kitagawa e Takahashi, 1976; Curtis et al., 2003) e com base nas observações acima fica evidente que a propagação constante de uma trinca vai definir a expectativa da vida do componente.

É bem conhecido que os materiais não falham por fadiga quando testado em tensões abaixo do limite de fadiga e hoje a compreensão do limite é considerado como o nível de tensão máxima abaixo do qual uma rachadura existente como defeito não irá propagar para falha dentro de um predeterminado período de vida, com a constatação de que as contornos de grãos e outras características microestruturais agem como barreiras para evitar a sua propagação (Blom et al., 1986; de los Rios e Navarro,1990). De acordo com Navarro e de los Rios (1992), o aprisionamento das trincas ocorre quando a ponta localizada na zona plástica é envolvida por barreiras e a tensão no local nas barreiras à frente da trinca impede a propagação da trinca além dessas barreiras.

A microdeformação na rede pode ser a causa da existência destas barreiras à propagação das trincas. Neste aspecto o estudo da microdeformação e perfil de tensão residual pela técnica de difração de raios-x em conjunto com microscopia eletrônica e ensaios de fadiga podem ajudar a esclarecer o mecanismo de aprisionamento das trincas.

O ponto inédito deste trabalho está no fato da inserção de informações relacionados a microdeformação da rede cristalina em sua influência nas propriedades de fadiga, correlacionando com informações de valores das tensões residuais distribuídas ao longo da espessura das amostras, dos tamanhos de cristalitos distribuídos ao longo da espessura somadas ao fator de concentração de tensão resultante do processo de jateamento por granalhas em liga de aço Cr-Si-V, recentemente implantada nas linhas de produção em elementos da suspensão em veículos automobilísticos. 


\section{OBJETIVO}

Determinar por meio da difração de raios-x os efeitos da tensão residual na microdeformação da rede cristalina e no tamanho de cristalitos após o jateamento por granalhas de aço em molas planas utilizadas em veículos automobilísticos e comparar os métodos de análise de perfil. 


\section{REVISÃO DA BIBLIOGRAFIA}

\subsection{A aplicação do vanádio no aço}

Nos aços, o vanádio forma compostos estáveis com o carbono e com o nitrogênio, (carbonetos, nitretos e carbonitretos) elementos que interagem determinando propriedades específicas, apresentando maior solubilidade na austenita (Frohberg e Graf, 1960) e na ferrita (Ohtani e Hillert, 1991), comparado aos outros elementos como $\mathrm{NbC}, \mathrm{NbN}$ e ao TiC, durante a processos de conformação, devido a dissolução dos carbonetos e carbonitretos de vanádio ocorrer totalmente a temperaturas entre $1150{ }^{\circ} \mathrm{C}$ a $1250 \stackrel{\circ}{\circ}$ (Canaan, 2007).

O resultado ao final deste processo é o endurecimento do material, extremamente útil quando se tem por objetivo o aumento da resistência mecânica (Glodowski, 2000).

A tabela 1 mostra os valores da energia de ativação $(Q)$ e da constante de difusão $\left(D_{0}\right)$.

Tabela 1: Dados de difusão do vanádio na ferrita e na austenita (Woodhead, 2000).

\begin{tabular}{|c|c|c|}
\hline & $Q\left(\frac{\mathrm{kJ}}{\mathrm{mol}}\right)$ & $D_{0}\left(\frac{m m^{2}}{s}\right)$ \\
\hline Ferrita ( $\alpha)$ & $242+/-2$ & $398+/-75$ \\
\hline Austenita ( $(\mathrm{)})$ & $293+/-4$ & $365+/-140$ \\
\hline
\end{tabular}

$\mathrm{Na}$ transformação da austenita para a ferrita, conforme a diminuição da temperatura proporciona a redução na solubilidade, resultando na precipitação dos compostos de vanádio no aço. Satoh, (1999) sugere que o inicio da precipitação aumenta pela presença de um substrato adequado conforme mostra micrografia apresentada na figura 1 onde o carbonitreto de vanádio foi precipitado no aço. 


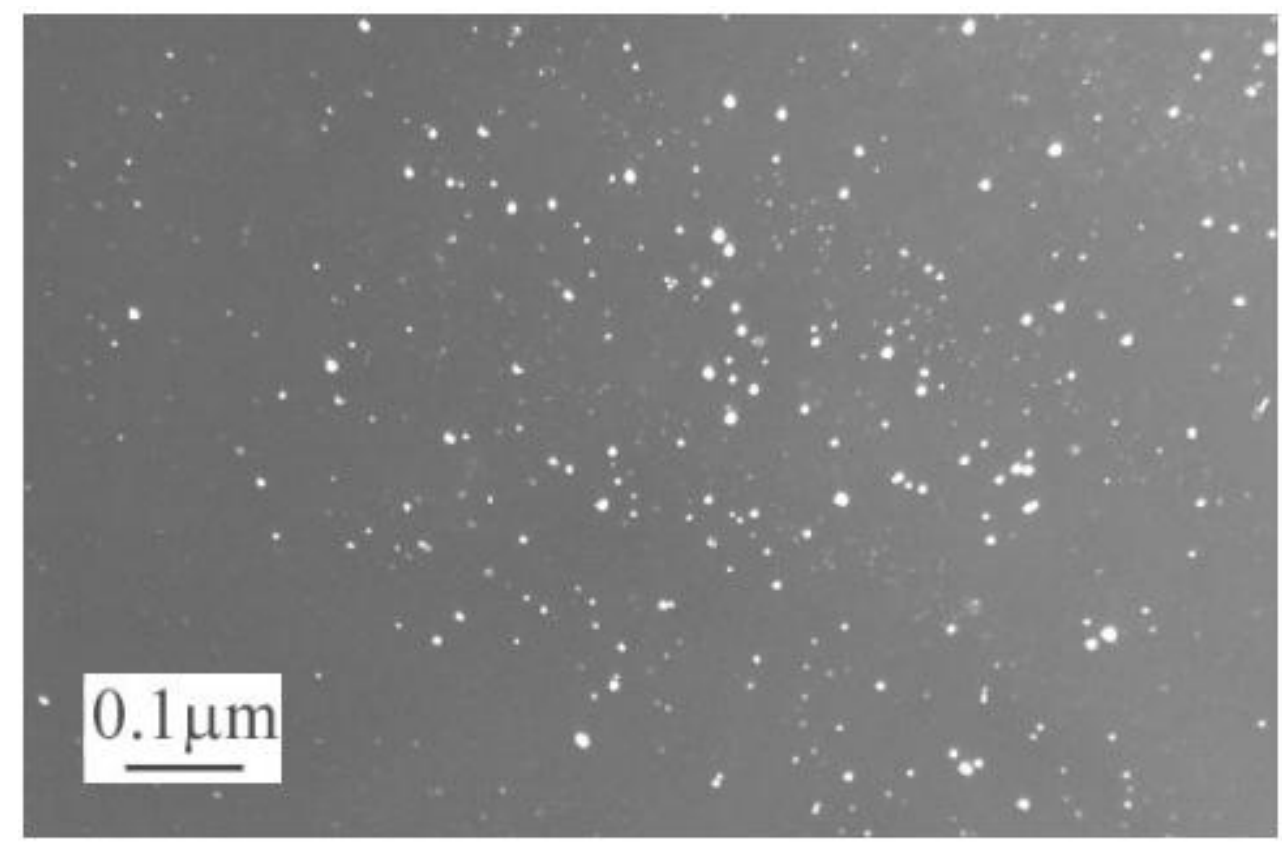

Figura 1: Precipitado de carbonitrato de vanádio no ferro austenítico (Gallego et al., 2002).

Durante a fusão, um dos tipos mais comuns de defeitos que podem ocorrer é conhecido como craqueamento transversal. Este defeito ocorre em aços microligados, em particular aos microligados de nióbio sendo o resultado da falta de ductilidade na região que se encontra acima do temperatura da qual ocorre as transformações de austenita para ferrita durante o resfriamento. Se é aplicada uma tensão, no momento do vazamento contínuo, enquanto a temperatura do aço está dentro da região crítica, podem ocorrer trincas, sendo estas normalmente transversal à direção do fluxo de fundição. Crowther et al. (1998) demonstraram por testes com o controle de arrefecimento na temperatura de fundição e analisaram a susceptibilidade do aparecimento de trincas de aço contendo vanádio e nióbio.

A figura 2 apresenta uma comparação da extensão de trincas obtidas em aço contendo $0,1 \%$ em massa de vanádio e outro com $0,03 \%$ de nióbio e nota-se claramente a diferença entre ambos. 


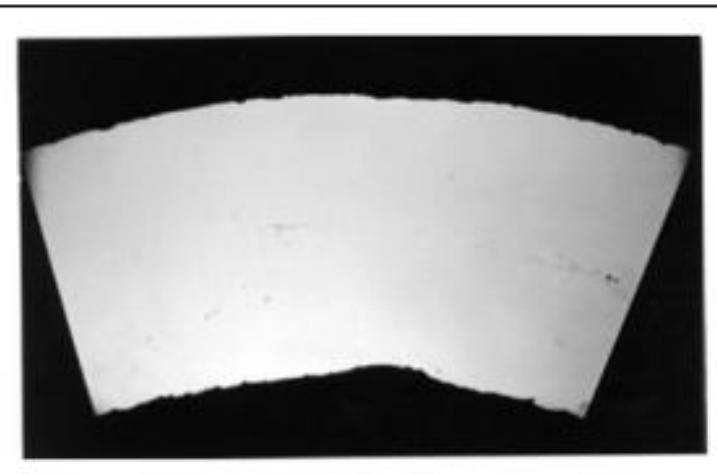

a

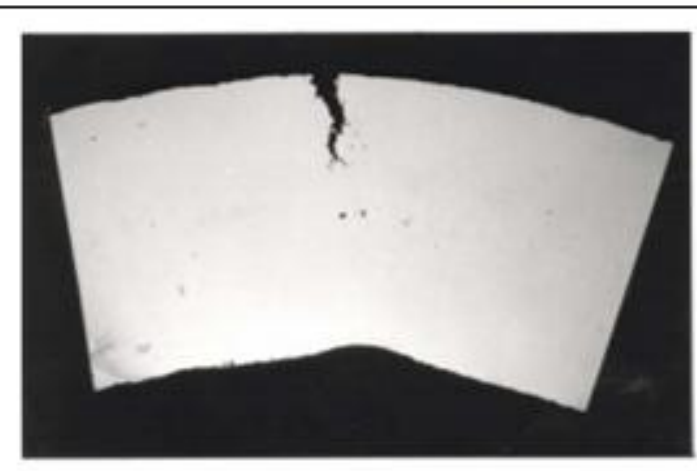

b

Figura 2: Comparativo entre amostras contendo: (a) $0,1 \%$ de vanádio e (b) $0,03 \%$ de nióbio, em massa (Mitchell, 2001).

Fica evidente que a trinca do aço contendo nióbio é maior do que a amostra contendo vanádio encontrados quanto à propagação ao longo do contorno de grão. A figura 3 ilustra a temperatura do equilíbrio de solubilidade para os aços contendo vanádio com diferentes porcentagens de nitrogênio.

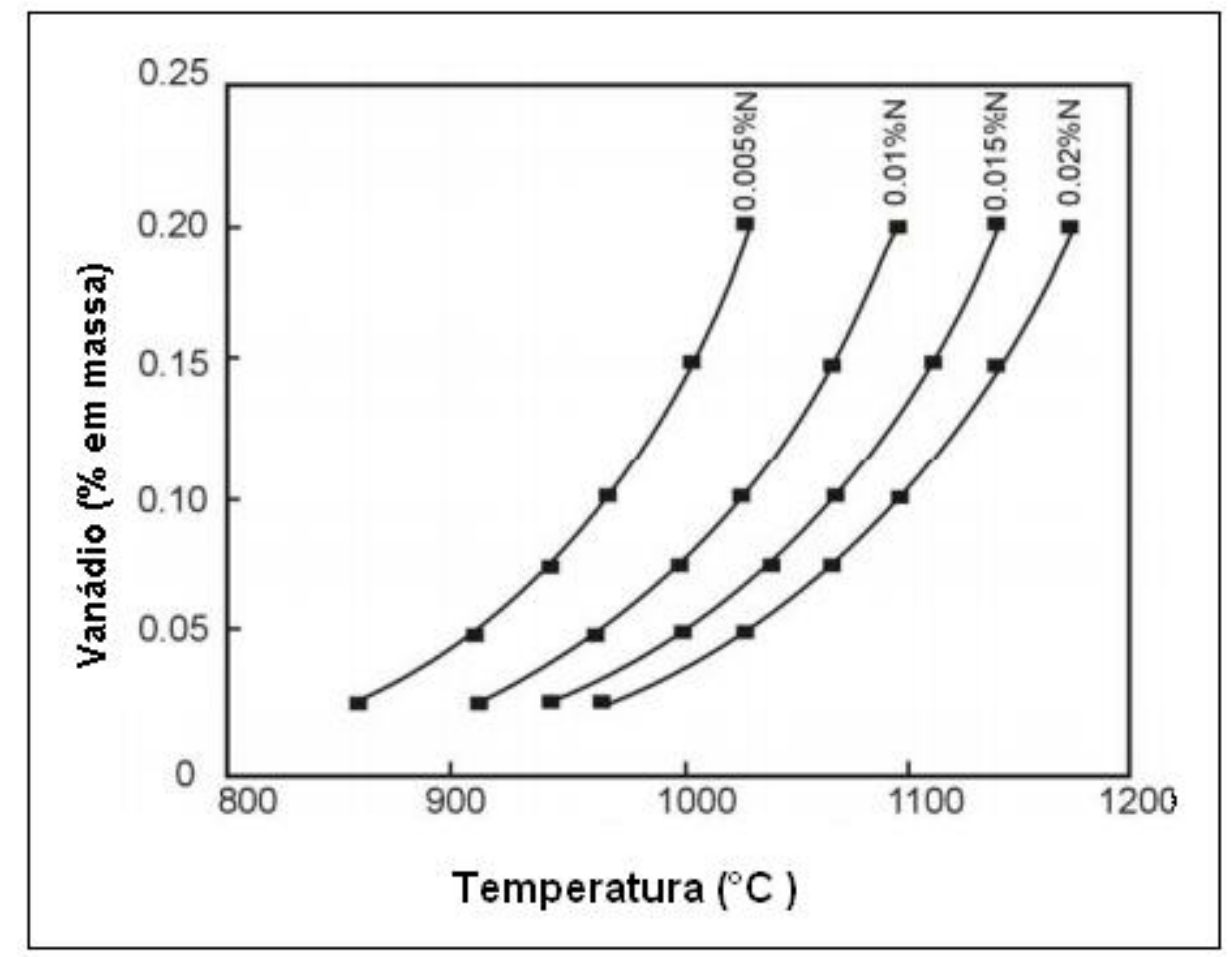

Figura 3: Solubilidade do nitreto de vanádio em relação a temperatura (Mitchell, 2001).

Pode-se observar que o aço que contém $0,1 \%$ de vanádio e 0,02\% de nitrogênio (ambos em \% de massa), considerada como combinação ideal, a temperatura da solução de equilíbrio será de aproximadamente $1100{ }^{\circ} \mathrm{C}$. Esta 
temperatura permite a utilização de energia eficiente com pouca ou nenhuma perda de capacidade de formação de precipitação do vanádio nos aços, portanto muito importante visto que a temperatura para a fundição está na faixa de $1150^{\circ} \mathrm{C}$ a 1200 ${ }^{\circ} \mathrm{C}$ (Mitchell, 2001).

Algumas propriedades mecânicas das ligas estão relacionadas aos mecanismos de endurecimento, no caso dos aços microligados, as resultantes deste processo estão no refino do grão ferrítico, favorecido pela precipitação dos carbonitretos formados no tratamento térmico (Deardo, 2001). O mecanismo do endurecimento por precipitação ocorre quando as partículas se formam nos contornos dos grãos, criando tensões que bloqueiam a movimentação das discordâncias, impedindo o crescimento dos grãos, deste modo obtendo aumento na resistência mecânica com a formação dos carbonetos e carbonitretos após a transformação da austenita para a ferrita (Honeycombe, 1988).

\subsection{Fadiga}

A fadiga tem como definição um processo de acúmulo de dano permanente, progressivo e localizado, que ocorre em componentes ou materiais sujeitos à condições dinâmicas de carregamento ou tensões cíclicas, que produzem tensões e deformações flutuantes podendo culminar em trincas e fraturas (ASTM E1820).

É considerada como uma falha gradativa de um componente submetido a solicitações mecânicas cíclicas, sendo estas alternadas, pulsantes ou flutuantes (Forrest, 1970), podendo o material se romper a uma tensão inferior à necessária para ocasionar fratura quando aplicada estática ou monotônica (Dieter, 1981).

O mecanismo de fadiga pode ser observado na diminuição da carga máxima, sob aplicação cíclica da carga, sendo que em cada ciclo se produzem pequenas deformações não reversíveis que culminará em uma ruptura que segue as seguintes etapas, sendo a primeira que o tensionamento cíclico causam deformação a frio e escorregamento localizados. A segunda etapa mostra que a gradual redução de ductilidade nas regiões encruadas resulta na formação de trincas microscópicas e por fim que o efeito do entalhe das trincas concentram tensões até que ocorra a ruptura completa, portanto considera-se que o critério para a falha por fadiga envolve a ação conjunta de fatores como tensões geradas por flexão ou torção, que 
no fim tornam-se tensões trativas, tensões cíclicas e deformação plástica (Madayag, 1969 ).

A nucleação da trinca é onde ocorre o seu início, pelas descontinuidades e tendendo a propagar-se ao longo dos planos das quais se encontram na superfície ou próxima a mesma, de caráter estrutural, como inclusões, geometria da peça ou imperfeições na superfície.

Geralmente uma trinca por fadiga se inicia em uma imperfeição livre (sendo raras as incidências no interior do material) onde sempre existe uma interface envolvida, no fato de a deformação plástica ser mais fácil de ocorrer nesta região, por encontrar-se num estado plano de tensões (Ruchert, 2007).

As intrusões e extrusões podem ser responsáveis pelo inicio de trincas ou podem interagir com os defeitos estruturais ou geométricos existentes (Meyers,1982). Alguns danos estruturais apresentados podem ser removidos por tratamento térmico e mecânico adequado.

A formação de intrusões e extrusões foi proposta por Dieter (1981), que depende da presença de dois sistemas de deslizamento cruzados que operam simultaneamente, conforme apresentado na figura 4:

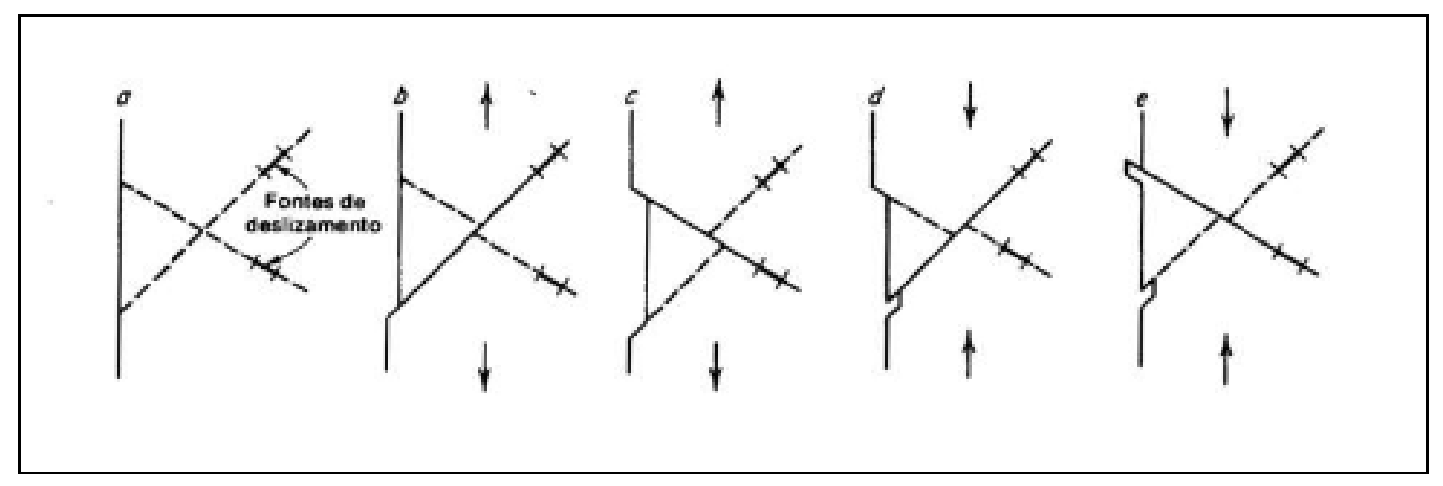

Figura 4: Nucleação de trinca por fadiga nas bandas de deslizamento, ilustrando o mecanismo de formação de extrusões e intrusões (Dieter,1981).

Dieter (1981), também propôs que a formação de extrusões e intrusões baseia-se em pequenos movimentos de deslizamento de vai e vem, originando entalhes ou ressaltos, conforme figura 5. 


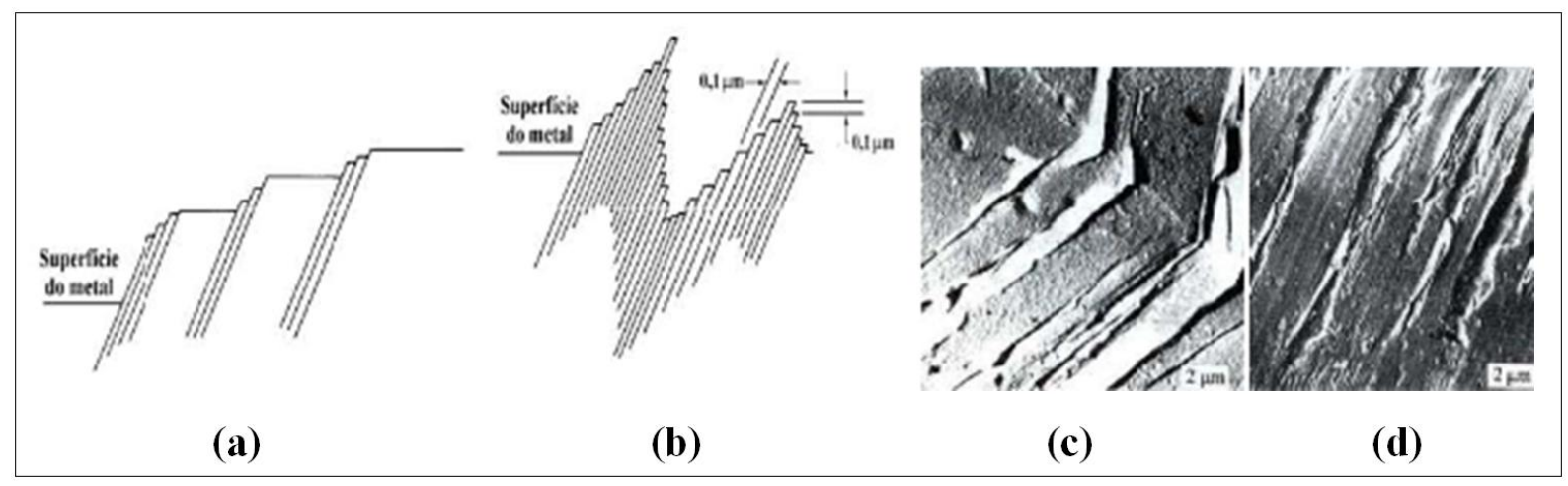

Figura 5: a) Deformação estática, b) deformação cíclica originando intrusões e extrusões, (Fuchs e Stephenns, 1980) e imagens obtidas em MEV mostrando em c) intrusões e d) extrusões (Ruchert, 2007).

O crescimento da trinca em bandas de deslizamento corresponde ao aprofundamento da trinca inicial nos planos de alta tensão de cisalhamento seguindo a orientação preferencial do grão, conforme ilustrado na figura 6.

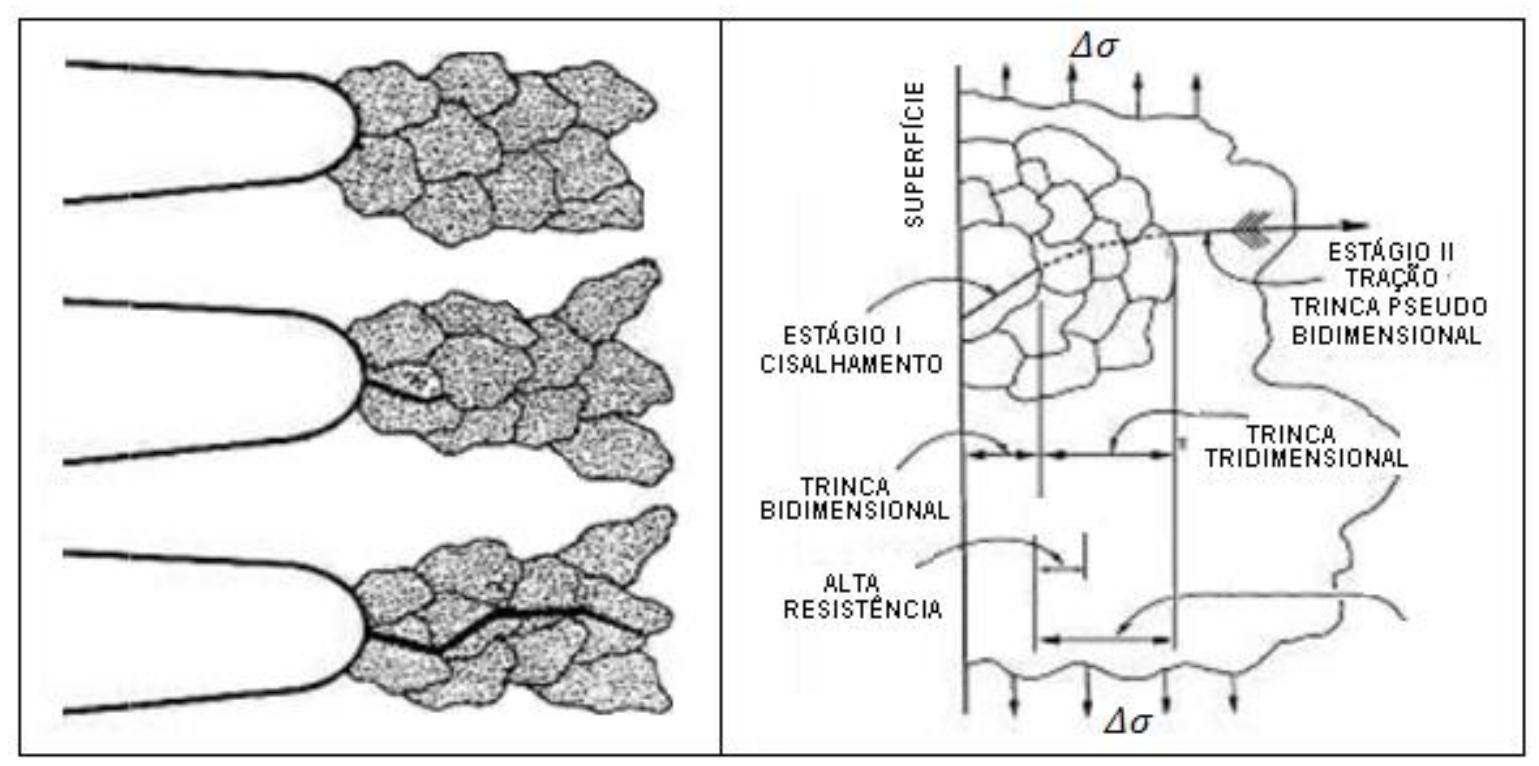

Figura 6: Propagação da trinca conforme a orientação dos grãos (Miller,1993)

Conforme observado, a propagação da trinca ocorre de modo transgranular e perpendicular à direção de carregamento. $O$ crescimento da trinca nos planos de tração corresponde a propagação que ocorre em um plano perpendicular à direção de máxima tensão de tração. Tem por característica a ocorrência de escorregamentos em planos diferentes devido ao aumento de intensidade da tensão próxima à ponta da trinca, possuindo características macroscópicas, sendo observada como uma região lisa, devido a fricção que se verifica entre as superfícies 
durante a propagação da trinca (Ruchert, 2007). Microscopicamente ocorre a presença de estrias na superfície da fratura, observada nas figuras 7a e 7b:

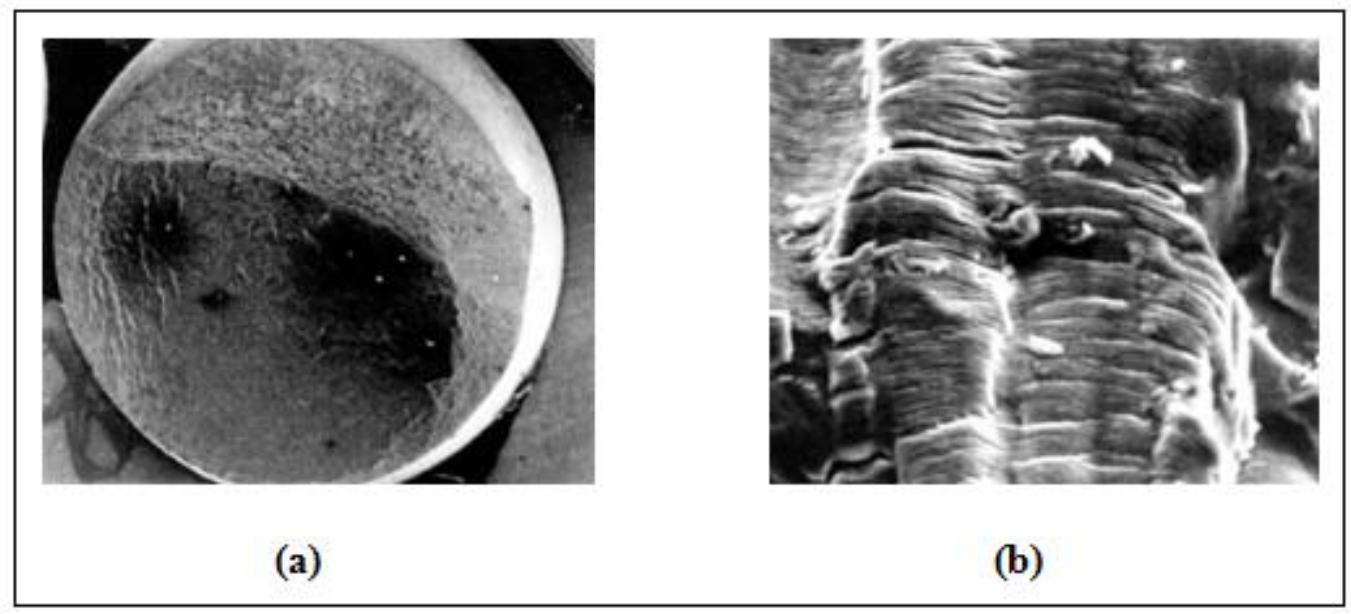

Figura 7: Aspectos macroscópicos a), microscópicos b) da superfície de fratura por fadiga evidenciando estrias (Ruchert, 2007).

A ruptura final é caracterizada pela fratura brusca e frágil pelo ponto de vista macroscópico e a ductilidade e a deformação plástica poderão ser evidenciadas por análises microscópicas, figura 8.

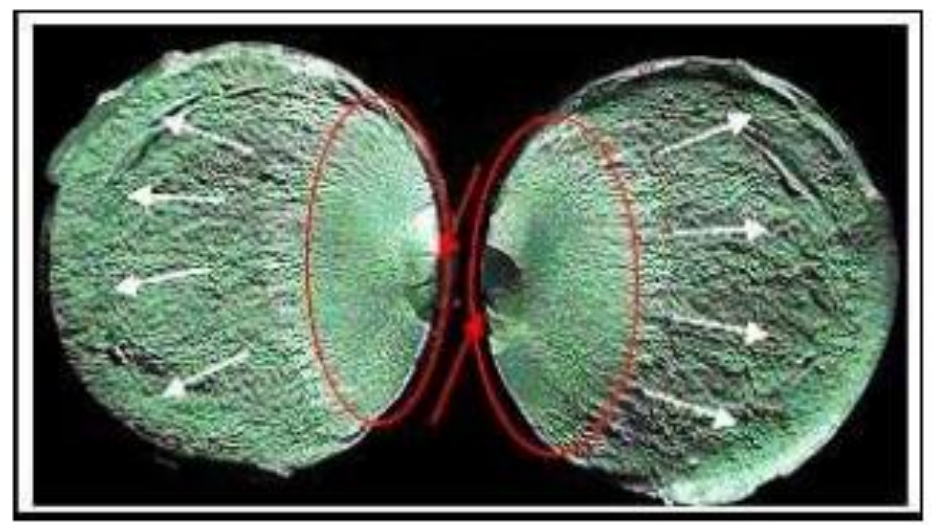

Figura 8: Superfície de fratura por fadiga indicando o local da nucleação (Ruchert, 2007)

$\mathrm{Na}$ figura 8 observa-se uma superfície fraturada por fadiga onde as setas indicam o local da nucleação da trinca e as setas em branco indicam o sentido de propagação da trinca. A região brilhante corresponde à propagação estável e a rugosa a instável.

Portanto, de forma resumida podemos afirmar que a primeira fase da ruptura por fadiga (figura 6) possui características microestruturais e a velocidade de sua 
propagação depende da barreira microestrutural dominante. À medida que a trinca avança, ela continua a ser desacelerada ao se aproximar de novas barreiras, mas em menor grau, até o ponto em que ela se torna insensível a novas barreiras microestruturais, atingindo o segundo estágio de propagação. A continuidade da tensão trativa implica no crescimento e por fim na ruptura do material. Miller (1993) ainda demonstra um modelo de crescimento de trinca causada por fadiga composta de 6 etapas, conforme figura 9 :

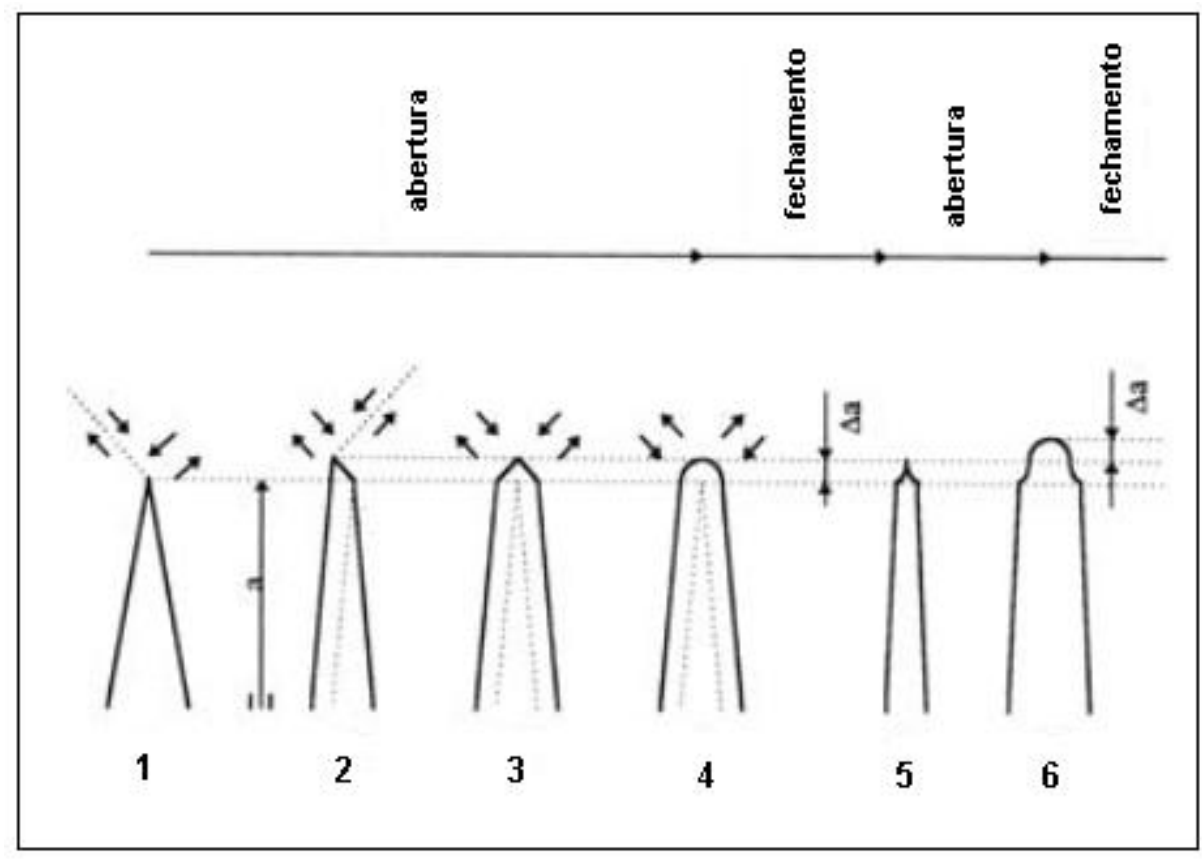

Figura 9: Representação de um dos modelos de propagação de trinca por fadiga (Miller 1993).

Etapa 1 - Planos de deslizamento preferenciais na direção de máxima tensão de cisalhamento;

Etapa 2 - A trinca abre e estende-se em comprimento;

Etapa 3 - Deslizamento acontecendo em outros planos;

Etapa 4 - O aumento da tensão ativa em novos planos e arredondamento da ponta da trinca.

Etapa 5 - Há deformação plástica em uma pequena região.

Etapa 6 - Embotamento da trinca.

Assim sendo, o tamanho de grão e o número de sistemas de escorregamento influenciam diretamente no crescimento de trinca e quanto mais numeroso o sistema 
de escorregamento e maior tamanho de grão, poucos obstáculos serão oferecidos e a trinca se desenvolverá com maior rapidez (Miller, 1993).

\subsubsection{Tensões cíclicas}

Como mostrado, a fadiga é definida como uma alteração estrutural progressiva, localizada e permanente em materiais submetidos a deformações flutuantes e repetidas ou tensões nominais, normalmente inferiores ao limite de escoamento do material em carregamento estático que pode culminar em trincas ou completa fratura após um número suficiente de flutuações (ASTM E 1823).

Entende-se por progressiva como um processo que ocorre ao longo do tempo ou uso, como localizada pois a falha por fadiga acontece em pontos específicos de uma estrutura, o termo permanente implica que o processo é irreversível e por fim a palavra flutuante indica que o processo envolve tensões ou deformações cíclicas.

Estes testes envolvem ciclos, máximos e mínimos de tensões que compõem as constantes denominadas como amplitudes de tensão constante.

A faixa de tensão, denominado por $\Delta \sigma$ é determinada pela diferença entre o valor máximo ( $\left.\sigma_{\max }\right)$ e o valor mínimo de tensão $\left(\sigma_{\min }\right)$.

$$
\Delta \sigma=\sigma_{\max }-\sigma_{\min }
$$

Calcula-se o valor de tensão média para o carregamento:

$$
\sigma_{m}=\frac{\sigma_{\max }+\sigma_{\min }}{2}
$$

$\mathrm{Na}$ prática este valor tem de ser diferente de zero, sendo em um carregamento flutuante, conforme mostrado na figura 10: 


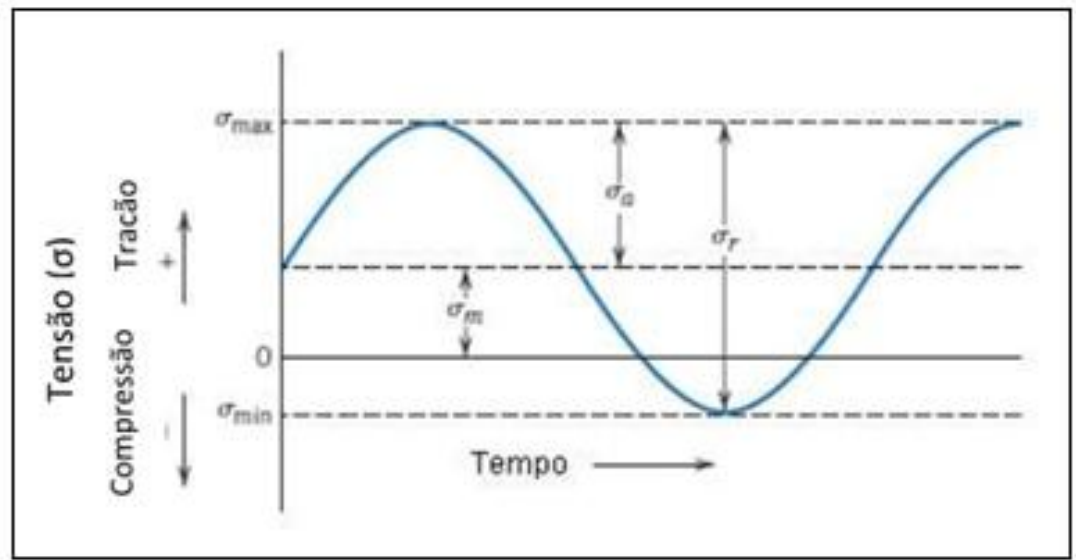

Figura 10: Carregamento cíclico: carregamento flutuante, regular e assimétrico (Callister, 2001).

Porém, a tensão média pode ser igual a zero como em um carregamento alternado na figura 11:

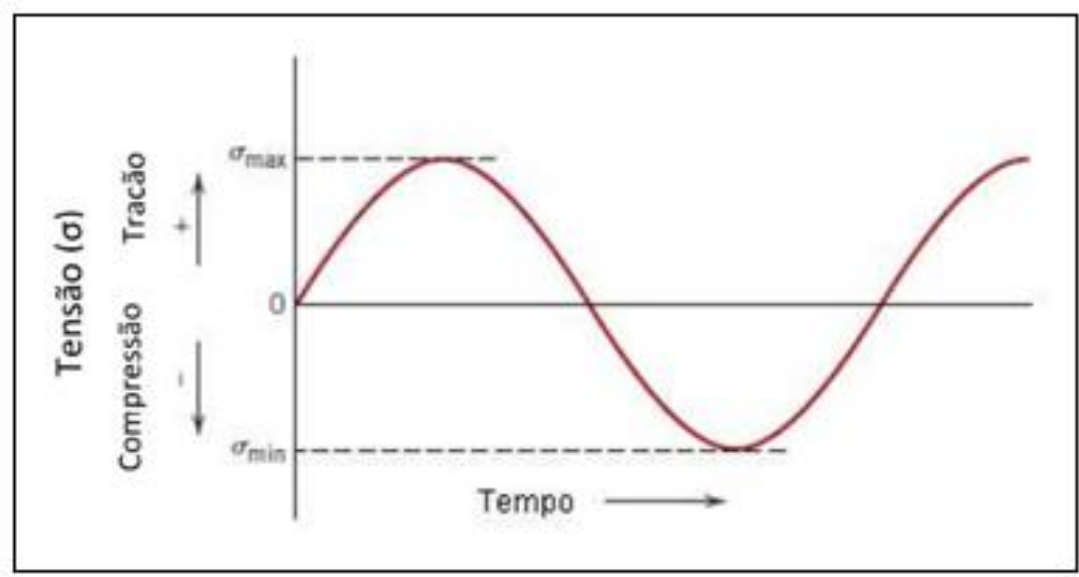

Figura 11: Carregamento cíclico: carregamento alternado, regular e simétrico (Callister, 2001).

Define-se a amplitude de tensão $\sigma_{\mathrm{A}}$ como a metade da faixa de tensão, correspondente parte da tensão flutuante ao longo do tempo sobre a tensão média.

$$
\sigma_{A}=\frac{\Delta \sigma}{2}=\frac{\sigma_{\max }-\sigma_{\min }}{2}
$$

As razões entre tensões máximas e mínimas e alternadas e médias podem ser definidas como:

$$
R=\frac{\sigma_{\min }}{\sigma_{\max }}
$$


e:

$$
A=\frac{\sigma_{A}}{\sigma_{m}}
$$

Afim de se aplicar o tipo de carregamento, os valores de R e A podem ser utilizados, sendo:

$$
\sigma_{m}=\frac{\sigma_{\max }+\sigma_{\min }}{2}
$$

Portanto,

$$
\sigma_{m}=\frac{\sigma_{\max }}{2}(1+R)
$$

E,

$$
\sigma_{A}=\frac{\Delta \sigma}{2}=\frac{\sigma_{\max }-\sigma_{\min }}{2}
$$

Assim sendo:

$$
\sigma_{A}=\frac{\Delta \sigma}{2}=\frac{\sigma_{\max }}{2}(1-R)
$$

Descrevendo os termos $\mathrm{R}$ e A como função em comum:

$$
\begin{aligned}
& R=\frac{1-A}{1+A} \\
& A=\frac{1-R}{1+R}
\end{aligned}
$$




\subsubsection{Curva de Wöhler (S - N)}

O método com que se representam resultados para um ensaio de fadiga é a curva de Wöhler ou curva S-N, onde S é a amplitude de tensão aplicada e N é o número de ciclos onde ocorre a iniciação da trinca no ensaio.

$\mathrm{O}$ ensaio de fadiga que gera a curva $\mathrm{S} \times \mathrm{N}$ está padronizado pela ASTM $\mathrm{E}$ 466-82. Neste ensaio a principal característica está no fato de que a tensão limite de resistência à fadiga, $\sigma_{a L R F}$, consiste no valor de tensão abaixo do qual o material não se fratura por fadiga, no caso dos aços, representada na figura 12

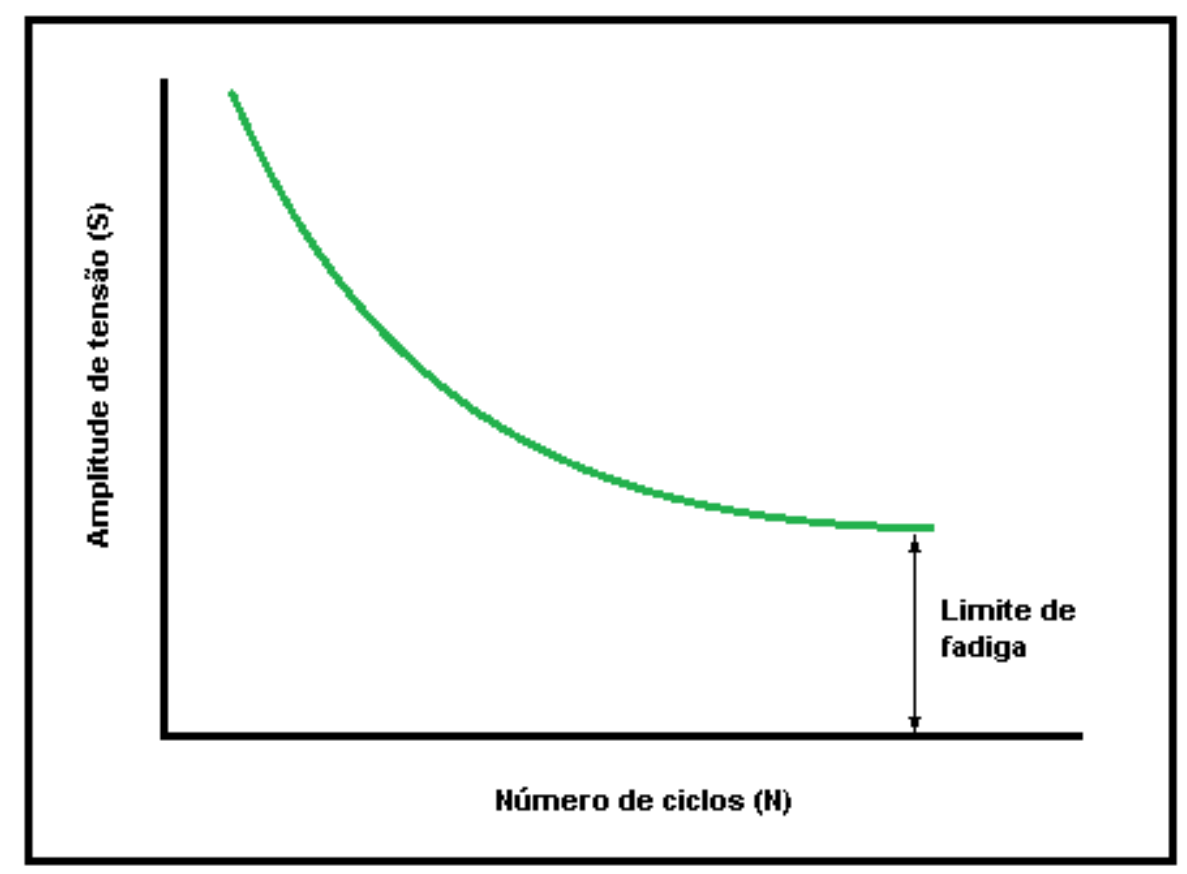

Figura 12: Curva S-N característica para aços.

A curva S-N é composta por inúmeros ensaios cujo objetivo é determinar a vida de um componente ou corpo de prova pela verificação da amplitude de tensão aplicada, sendo possível notar a relação da qual demonstra que para uma menor amplitude de tensão (S), maior será o número de ciclos suportados pelo material. $\mathrm{O}$ valor de tensão aplicada que resulta em uma determinada vida $\mathrm{N}$ do componente, é chamada de resistência à fadiga.

Ao observar que a curva S-N se torna horizontal, onde a amplitude de tensão fica abaixo do limite de fadiga dá se ao componente a denominação de vida infinita, 
ou seja, nessa amplitude por mais que se aumente o número de ciclos, não ocorrerá a formação de trincas que por sua vez levariam o material a ruptura.

Por meio de dados experimentais, aplicados a um ensaio de fadiga uniaxial, é gerado um gráfico S-N, representado por uma escala log-linear, cuja aproximação é dada pela equação 12, ou também em escala logarítmica (log-log) onde a equação final é representada pela equação 16.

$$
S_{A}=\sigma_{A}=C+D \cdot \log \left(N_{f}\right)
$$

Onde C e D são parâmetros constantes. Esta equação pode ser reescrita, sendo:

$$
\sigma_{A}=A \cdot N_{f}^{B}
$$

Os parâmetros A e B podem ser escritos como:

$$
A=2^{b} \cdot \sigma_{f}
$$

e,

$$
B=b
$$

Desta forma a equação 16 pode ser demonstrada na sua forma mais conhecida, chamada equação de Basquin:

$$
\sigma_{A}=\sigma_{f}\left(2 N_{f}\right)^{b}
$$

Onde $\sigma_{f}$ é o coeficiente de resistência à fadiga e $b$ é o expoente de resistência à fadiga ou expoente de Basquin. Estes valores são obtidos através de ensaios uniaxiais em corpos de prova entalhados (Malcher, 2006). 


\subsubsection{Análise de Weibull}

A distribuição de Weibull foi proposta originalmente por Waloddi Weibull em 1954 em estudos relacionados a probabilidade contínua em relação a falha devido a fadiga de metais. Este é um método para modelagem de dados que contém conjuntos de valores superiores a zero possibilitando prever a vida de um componente.

Quando se tem por objetivo a prevenção de falhas mostra-se indispensável a utilização de ferramentas quantitativas capazes de mensurar o seu risco de falha. Assim sendo define-se o índice de confiabilidade, matematicamente definido como:

$$
C(t)=1-\int_{0}^{t} f(t) d t
$$

Onde $C$ é a confiabilidade, $f(t)$ é a função da densidade de probabilidade e $t$ é o período de vida útil. Na distribuição de Weibull é aplicada no estudo da confiabilidade e análise de sobrevivência, utilizando os parâmetros dada pela equação 18:

$$
f(t)=\frac{\beta}{\eta}\left(\frac{t-\gamma}{\eta}\right)^{\beta-1} e^{-\left(\frac{t-\gamma}{\eta}\right)^{\beta}}
$$

Onde $t>0 ; \beta>0$ e $\eta>0$, e sendo $t$ a variável que define o ciclo, $\beta$ é o parâmetro de forma, $\eta$ é o parâmetro de escala e $\gamma$ é o parâmetro de posição. Sendo o parâmetro $\gamma$ como a vida inicial , pode ser desprezado. Assim a equação ficará:

$$
f(t)=\frac{\beta}{\eta}\left(\frac{t}{\eta}\right)^{\beta-1} e^{-\left(\frac{t}{\eta}\right)^{\beta}}
$$

Substituindo a equação 17 pela equação 19:

$$
C(t)=1-\int_{0}^{t}\left[\frac{\beta}{\eta}\left(\frac{t}{\eta}\right)^{\beta-1} e^{-\left(\frac{t}{\eta}\right)^{\beta}}\right] d t
$$


Que, calculando a integral:

$$
C(t)=e^{-\left(\frac{t}{\eta}\right)^{\beta}}
$$

O parâmetro $\beta$ é um número adimensional que interfere na função de densidade de probabilidade. Se $\beta<1$ a função de probabilidade de falha apresenta frequências elevadas na parte inicial da vida, denominadas falhas prematuras, quando $\beta=1$ tem-se a distribuição exponencial, indicando falha aleatória. Quando $\beta>1$ a taxa de falhas aumenta com o tempo. Ainda assim para $\beta=2$ a distribuição tem a forma log-normal e para $\beta=3$ a distribuição assume a forma normal. (Colosimo e Giolo, 2006); (Scuracchio, 2012). A figura 13 mostra o comportamento das curvas dos parâmetros de forma em relação a probabilidade de falha (Ronniger, 2012).

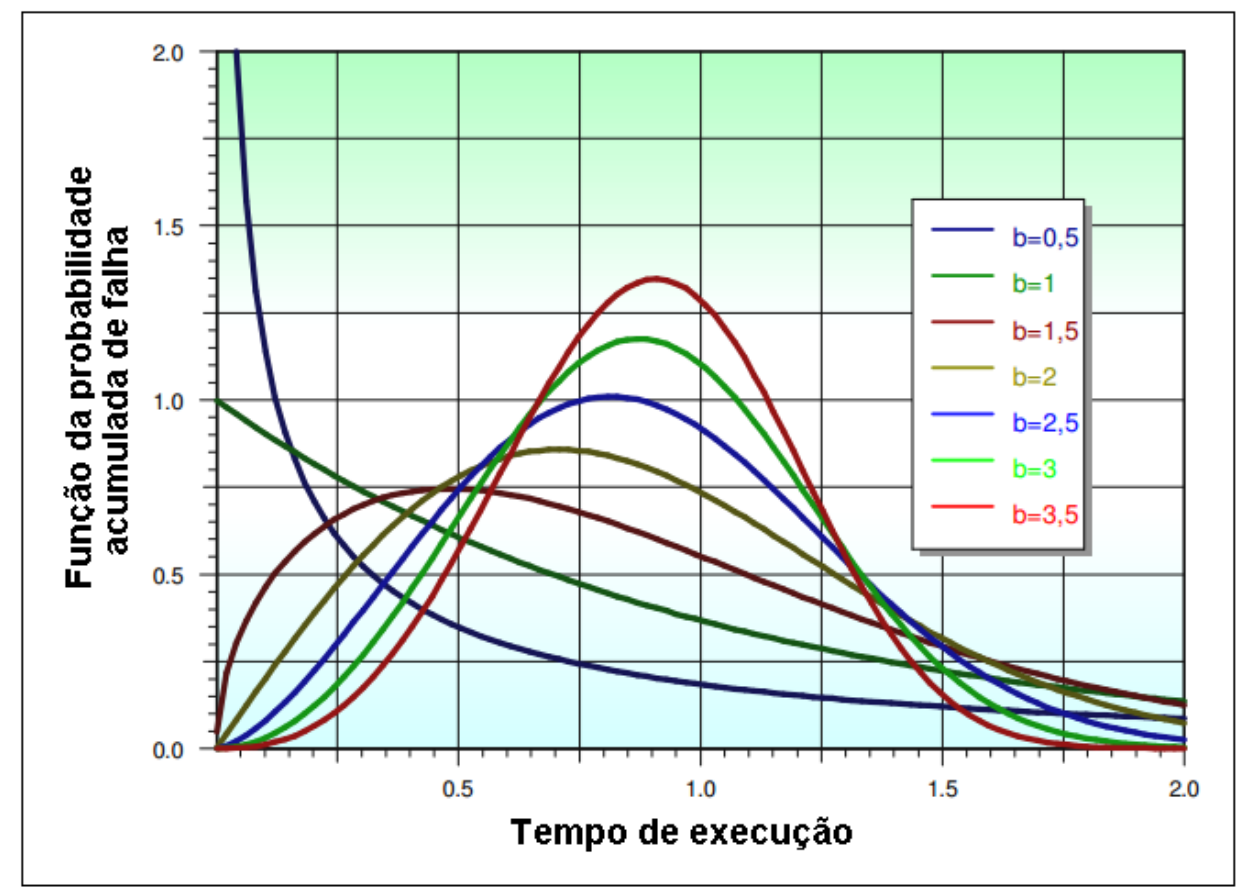

Figura 13: Comportamento das curvas dos parâmetros de forma em relação a probabilidade de falha (Ronniger, 2012).

Como forma de descrever e representar uma distância, tempo ou ciclo transcorrido desde o início até o momento da falha utiliza-se o parâmetro de escala (n), associado à vida característica de um determinado componente. 
Se $\eta$ é aumentado enquanto $\beta$ é mantido constante a distribuição tende-se a alargar, diminuindo a altura. Se $\eta$ é diminuído enquanto $\beta$ é mantido constante a distribuição tende a estreitar-se para dentro e para a esquerda (origem zero ou y) aumentando a sua altura.

O parâmetro $\eta$ é calculado na seguinte equação:

$$
\eta=\left[\sum_{i=1}^{\mathrm{n}} \frac{\mathrm{t}_{\mathrm{i}}^{\beta}}{\mathrm{n}}\right]^{\frac{1}{\beta}}
$$

Se $\eta=\mathrm{t}$, obtém-se:

$$
\mathrm{F}(\mathrm{t}=\eta)=1-\mathrm{e}^{-1}=63,2 \%
$$

Desta forma, a quantidade de ciclos para cada distribuição de Weibull corresponde a $63,2 \%$, determinada como vida característica, válida para qualquer valor de $\beta$ (Scuracchio, 2012).

\subsection{Fator de concentração de tensão.}

Na seleção de um determinado material, em se tratando de projetar o cálculo de tensão, constata-se que um material é considerado adequado quando sua resistência é maior do que a tensão aplicada prevista. Esta abordagem tem como objetivo proteger a estrutura do material contra a fratura frágil através da imposição de um fator de segurança sobre a tensão, combinado com os requisitos mínimos de tração de alongamento no material. A trinca ocorre quando a energia disponível para seu surgimento é suficiente para superar a resistência do material, o que inclui a energia de superfície, sua plasticidade e outros tipos de dissipação de energia associados com a propagação da trinca (Anderson, 2005).

Griffith (1920) foi o primeiro a propor o critério de energia de fratura. Irwin (1956) desenvolveu a versão atual desta abordagem. Inicialmente, Griffith estabeleceu uma relação entre tensão de fratura e tamanho da trinca, conhecida como balanço de energia de Griffith sendo este o ponto inicial para o 
desenvolvimento da mecânica da fratura, demonstrando qualitativamente que a resistência à tração dos materiais frágeis era menor que o seu valor teórico e que os materiais frágeis continham defeitos microscópicos, dos quais funcionam como concentradores de tensão, iniciadores de microtrincas no interior do material.

A taxa de liberação de energia, $\mathcal{G}$, é definida como a taxa de variação da energia potencial com a área da trinca para um material elástico linear. No momento da fratura, $\mathcal{G}=\mathcal{G}_{c}$, sendo esta a taxa de liberação de energia crítica, que é uma medida da tenacidade à fratura.

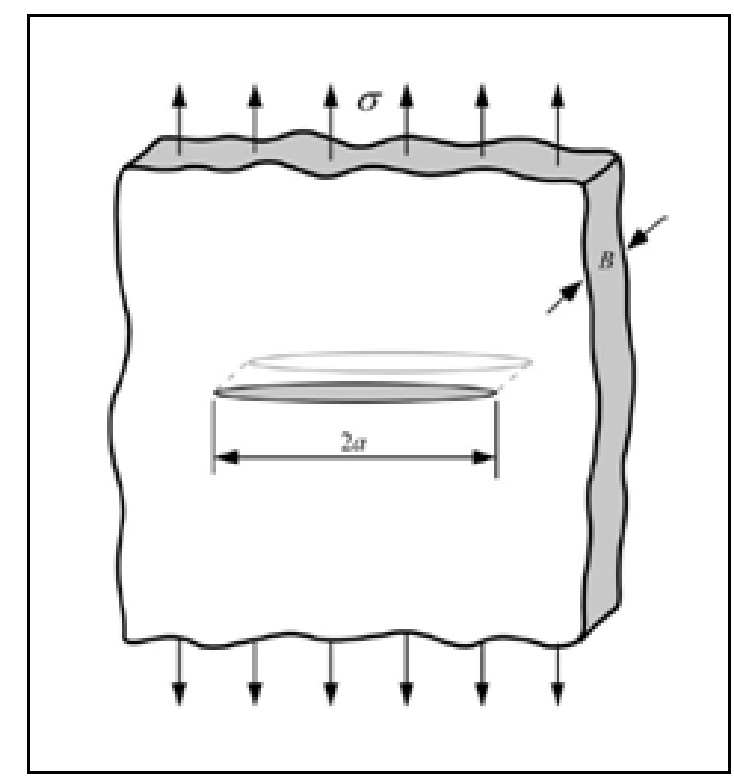

Figura 14: Representação de uma placa de comprimento infinito submetida a tensão de tração com uma trinca de dimensão 2a (Anderson, 2005).

Para uma trinca de comprimento $2 \mathrm{a}$, mostrada na figura 14 , a taxa de liberação de energia é dada por:

$$
\mathcal{G}=\frac{\pi \sigma^{2} a}{E}
$$

Onde $E$ é o módulo de Young, $\sigma$ é a tensão aplicada à distância, e a é o comprimento da metade da trinca. Na fratura $\mathcal{G}=\mathcal{G}_{c}$, a equação 25 descreve a combinação da tensão crítica e o tamanho da trinca:

$$
\mathcal{G}_{c}=\frac{\pi \sigma_{f}^{2} a_{c}}{E}
$$


Nota-se que para uma constante $\mathcal{G}_{c}$, a falha por tensão $\sigma_{f}$, varia de acordo $\operatorname{com} \frac{1}{\sqrt{a}}$. A taxa de liberação de energia $\mathcal{G}$ é a força motriz da fratura, enquanto que $\mathcal{G}_{c}$ é a própria resistência à fratura deste material.

Analogicamente a tensão de tração é também utilizada para demonstrar o conceito de similitude, sabendo que dado valor de tensão de escoamento medido experimentalmente pode também ser aplicado a grandes estruturas, pois a mesma independe do tamanho da amostra contanto que a mesma seja homogênea. Tal similitude também se aplica a tenacidade à fratura (no caso, $\mathcal{G}_{c}$ ), da qual independe do tamanho e geometria da amostra trincada (Anderson, 2005).

A figura 15 mostra esquematicamente um elemento próximo à ponta de uma trinca em um material, junto a um plano de tensão neste elemento. Nota-se que cada componente de tensão é proporcional a uma constante simples $\left(K_{I}\right)$. Se esta constante é conhecida, toda distribuição de tensão na ponta da trinca poderá ser calculada, conforme as equações $26 \mathrm{a}, 26 \mathrm{~b}$ e $26 \mathrm{c}$.

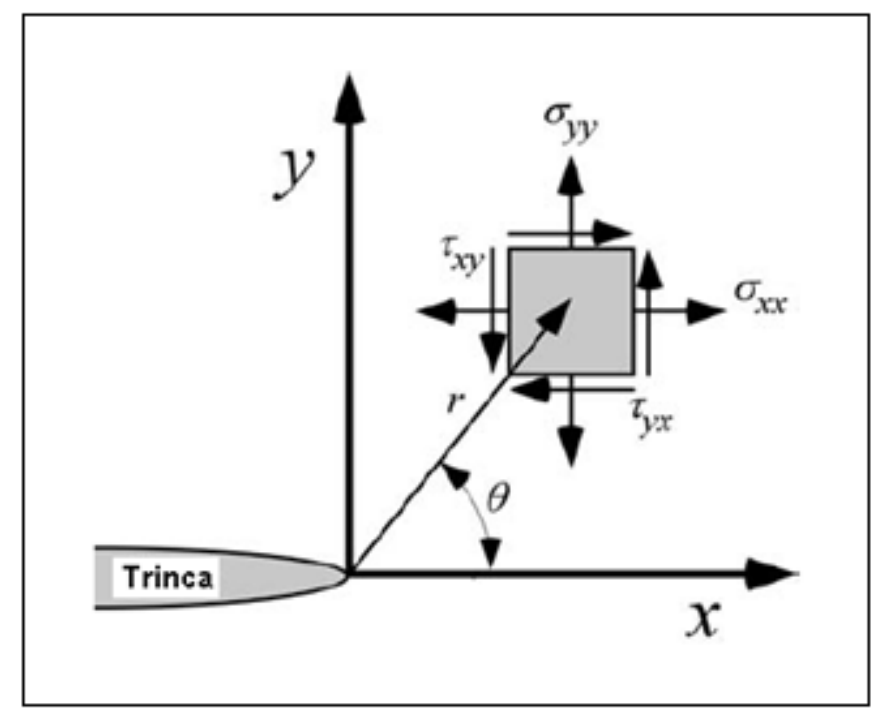

Figura15: Tensões próxima a ponta da trinca (Anderson, 2005).

$$
\begin{aligned}
& \sigma_{x x}=\frac{K_{I}}{\sqrt{2 \pi r}} \cos \left(\frac{\Theta}{2}\right)\left[1-\operatorname{sen}\left(\frac{\Theta}{2}\right) \operatorname{sen}\left(\frac{3 \Theta}{2}\right)\right] \\
& \sigma_{y y}=\frac{K_{I}}{\sqrt{2 \pi r}} \cos \left(\frac{\Theta}{2}\right)\left[1+\operatorname{sen}\left(\frac{\Theta}{2}\right) \operatorname{sen}\left(\frac{3 \Theta}{2}\right)\right]
\end{aligned}
$$




$$
\tau_{x y}=\frac{K_{I}}{\sqrt{2 \pi r}} \cos \left(\frac{\Theta}{2}\right) \operatorname{sen}\left(\frac{\Theta}{2}\right) \cos \left(\frac{3 \Theta}{2}\right)
$$

A esta constante dá-se o nome de fator de intensidade de tensão, da qual se caracteriza completamente às condições na ponta da trinca em um material linear elástico.

Assumindo que o material falha localmente em uma combinação entre a tensão e a deformação, então esta fratura ocorrerá em uma intensidade crítica de tensão $\left(K_{I C}\right)$, esta, uma unidade alternativa de tenacidade à fratura.Para uma placa, assim mostrada na figura 14, o fator de intensidade de tensão é dado por:

$$
K_{I C}=\sigma \sqrt{\pi a}
$$

A falha ocorre quando $K_{I}=K_{I C}$, neste caso, o $K_{I}$ é a força motriz da fratura e $K_{I C}$ é uma propriedade do material que não depende do tamanho ou geometria.

Assim sendo, a relação entre $K_{I C}$ e $\mathcal{G}_{c}$ será:

$$
\mathcal{G}_{c}=\frac{K_{I}^{2}}{\mathrm{E}}
$$

Esta mesma relação também se aplica para $\mathcal{G}_{c}$ e $K_{I C}$ (Anderson, 2005).

O efeito sobre a rugosidade da superfície provocada pelo jateamento exerce forte influência no perfil da resistência a fadiga, criando pontos de tensões, que variam de acordo com a profundidade do material. $\mathrm{O}$ aumento destes pontos reflete na disposição do material à diminuição da resistência da corrosão sob tensão e consequentemente à redução da resistência à fadiga.

Li et al. (1992) propôs que a concentração de tensão introduzida por vários pontos de impacto dependem da relação entre a profundidade e a largura impressa na superfície do material. A este fator é dado a concentração de tensão $K_{t}$, dado por:

$$
K_{t}=1+2,1 \frac{R_{t}}{S}
$$


Onde os parâmetros $R_{t}$ e $S$ são, respectivamente a média da altura em relação às medidas pico a vale e os espaçamentos dos picos adjacentes, sendo este o diâmetro da indentação provocada pelo impacto da granalha no material.

\subsection{Microdeformação da rede cristalina e tamanho de cristalito.}

A difração de raios-x é um método muito propício para análise de tamanho de cristalito e microdeformação em materiais metálicos e vale notar que a precisão da medição é fundamental para o resultado da análise, que toma por base a alteração da largura dos perfis de difração. Para uma reflexão individual, a variação no valor da largura do pico deverá ser extremamente baixa, sendo aconselhável utilizar uma baixa velocidade de varredura, esta em torno de $0,1^{\circ}$ por minuto, a fim de garantir a precisão das medições (He e Schoenung, 2002).

O resultado da difração em um cristal livre de deformações é um pico bem definido e intenso, e conforme o material é deformado, os campos de compressão e tração fazem com que haja um deslocamento do pico $2 \Theta$ para a direita tanto para a esquerda, ocorrendo assim a diminuição da intensidade e o alargamento do pico (Cullity, 1978), conforme figura 16a e 16b:

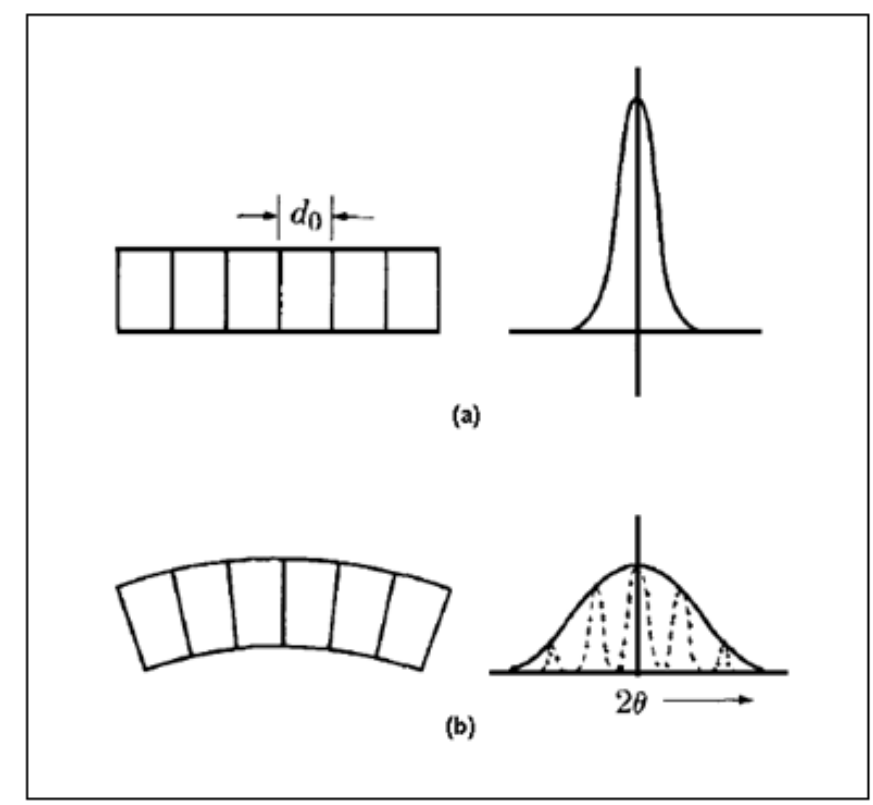

Figura 16: Picos de difração - (a) Representação de um pico de um cristal livre de deformações - (b) Representação de um pico de um cristal deformado (Cullity, 1978). 


\subsubsection{Método de Scherrer}

O cristalito é um termo dado a um conjunto de células sistematicamente agrupadas para formar um domínio coerente de difração (Jenkins e Snyder, 1996). O grão de um material policristalino é constituído por diversos cristalitos agrupados com diferentes orientações sendo o tamanho de cristalito e a microdeformação responsáveis pelo alargamento do pico de difração.

Diversas formulações foram desenvolvidas para o cálculo de tamanho de cristalito e microdeformação com base nos perfis de difração de raios- $x$, entre elas, a equação de Scherrer.

Se a origem física do alargamento das reflexões de difração de raios-x for associado com o tamanho de cristalito individual, a relação entre o tamanho de grão (D) e a largura do pico a meia altura, representada por $\Delta(2 \theta)$, a equação de Scherrer (Scherrer, 1918) será expressa por:

$$
D=\frac{0,9 \lambda}{\Delta(2 \theta) \cos \theta}
$$

Onde $\lambda$ é o comprimento de onda do anodo utilizado para a geração de raios$x$, e $\theta$ o ângulo de difração. O alargamento real do pico, $\Delta(2 \theta)$, pode ser obtido utilizando a equação:

$$
\Delta(2 \theta)=\left\{\left[\Delta(2 \theta)_{h}\right]^{2}-\left[\Delta(2 \theta)_{g}\right]^{2}\right\}^{\frac{1}{2}}
$$

Onde $\Delta(2 \theta)_{h}$ é a largura do pico a meia altura do perfil medido e $\Delta(2 \theta)_{g}$ é a largura do pico a meia altura do efeito instrumental que é obtido a partir do perfil de uma amostra padrão para a mesma reflexão.

O tamanho do cristalito obtido com a descrição da equação de Scherrer é, portanto, o volume médio em uma direção perpendicular ao plano de difração (He e Schoenung, 2002).

Entretanto, quanto a determinação do nível de deformação, uma outra abordagem deverá ser utilizada, designada de "linear fitting". 
Assumindo que, em geral, o perfil das reflexões de difração de raios-x é formado por dois componentes (tamanho de cristalito e microdeformação), estas devem ser estudadas separadamente, sendo assim, o alargamento do pico resultante da microdeformação, $\Delta(2 \theta)_{s}$, pode ser expresso como:

$$
\Delta(2 \theta)_{s}=2 \varepsilon \cdot \tan \theta
$$

Onde $\varepsilon$ é a microdeformação (Jeffery, 1971; Suryanarayana e Norton,1998).

\subsubsection{Método Williamson-Hall}

O que segue é a forma de interpretação da metodologia para determinação da microdeformação e tamanho médio de cristalitos de um material.

Este método, proposto por G. K. Williamson e W. H. Hall em 1953, permite a separação das contribuições relacionadas ao tamanho médio de cristalitos e a microdeformação da rede cristalina utilizando-se do perfil da difração obtido experimentalmente. O método Williamson-Hall é baseado no uso das informações constituídas pelo gráfico obtido pela equação:

$$
\beta \cos \theta=\frac{k \lambda}{D}+\eta \operatorname{sen} \theta
$$

Onde $\beta$ é a largura do pico a meia altura já considerado os efeitos instrumentais $\Delta(2 \theta), \lambda$ é o comprimento de onda da radiação, $D$ é a estimativa do tamanho médio dos cristalitos e $\eta$ é a estimativa da microdeformação da rede cristalina.

Pela construção do gráfico na figura 17 , o tamanho de cristalito pode ser determinado pelo intercepto no eixo das ordenadas $(\beta \cos \theta)$ e a microdeformação da rede cristalina pelo coeficiente angular da reta $(\eta)$. 


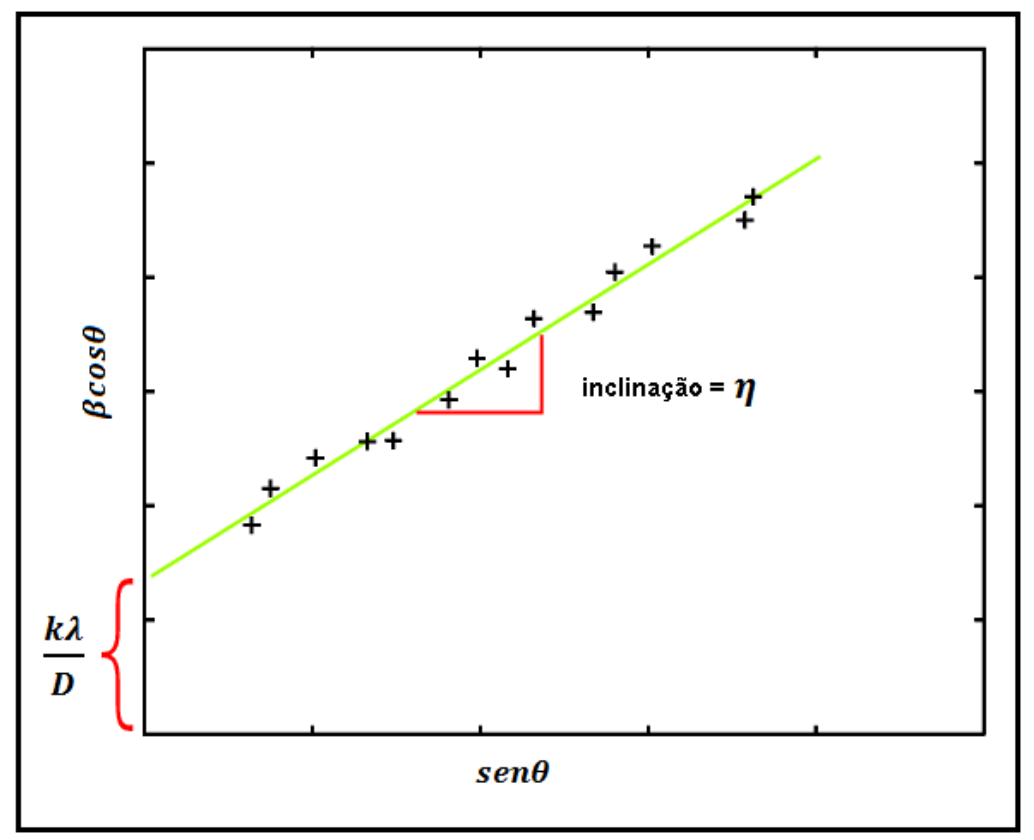

Figura 17: Metodologia para determinação da microdeformação da rede cristalina e do tamanho médio dos cristalitos (http://pd.chem.ucl.ac.uk/pdnn/peaks/sizedet.htm).

Basicamente, a equação de Williamson-Hall, não prevê o deslocamento dos picos causados pela densidade de discordâncias apresentados no material deformado. A deformação anisotrópica que se apresenta em um material pode ser representada por um modelo que ocorre nas discordâncias geradas por esta deformação. Por meios práticos pode-se definir um fator de contraste (definido por fator $C$ ), que por sua vez está relacionado pelo vetor de Burgers, pelo perfil obtido pela difração e pelas discordâncias que posteriormente geram outro fator importante definido por fator de contraste médio $(\bar{C})$, este obtido experimentalmente, que permite identificar o tipo de discordância, com o obtenção de parâmetros relacionados às constantes elásticas do material (fator q) (Ungár et al., 1999), pois sabe-se que 0 alargamento anisotrópico gerado pelo perfil da difração de raios- $x$ indica que a largura do pico a meia altura, sua integral ou mesmo o coeficiente de Fourier do perfil não são funções monótonas de um vetor de difração (Williamson e Smallman, 1955; Caglioti et al., 1958; Warren e Averbach, 1952; Warren, 1959).

Para o refinamento por Rietveld, diversas soluções tem sido sugeridas: (Suortti, 1993; Latroche et al., 1995; Stephens, 1999; Scardi, 1998; Popa, 1998) dentre os métodos propostos, o modelo de discordâncias pela deformação quadrática média $\left(\left\langle\varepsilon_{g, L}^{2}\right\rangle\right)$, onde $L$ é o comprimento de Fourier (Warren, 1959) e $\varepsilon_{g}$ é o componente do tensor de distorção na direção $g$ (Klimanek e Kuzel, 1989; Ungár e 
Borbely, 1996; Révész et al., 1998; Ungár e Tichy, 1999; Wu et al., 1998). Este modelo é baseado no contraste de discordâncias, variando com a orientação relativa de Burgers, na linhas dos vetores das discordâncias e com o vetor de difração ( $b$, le $g$, respectivamente). Resultados similares também são obtidos por microscopia eletrônica de transmissão (Hirsch et al., 1965).

O fator de contraste das discordâncias, para sua definição, será necessário inicialmente obter o coeficiente de Fourier do perfil da difração dado pelo produto dos coeficientes do tamanho pela distorção, $A_{L}^{S}$ e $A_{L}^{D}$, respectivamente (Warren, 1959), sendo:

$$
A_{L}=A_{L}^{S} \cdot A_{L}^{D}
$$

Onde $L$ é o comprimento de Fourier, definido por $L=n a_{3}$ onde $n$ é um número inteiro e $a_{3}$ é a unidade de comprimento de Fourier na direção do vetor de difração $g$ , sendo:

$$
a_{3}=\frac{\lambda}{\left[2\left(\operatorname{sen} \theta_{2}-\operatorname{sen} \theta_{1}\right)\right]}
$$

Onde o perfil é medido de $\theta_{1}$ a $\theta_{2},(\Delta \theta)$ e $\lambda$ é o comprimento de onda dos raios-x. Warren(1959) mostrou que o coeficiente de Fourier pode ser escrito como:

$$
\ln A_{L}(g) \cong \ln A_{L}^{S}-2 \pi^{2} L^{2} g^{2}\left\langle\varepsilon_{g}^{2}\right\rangle
$$

Onde $\left\langle\varepsilon_{g}^{2}\right\rangle$ é a deformação média quadrática na direção do vetor de difração, sendo este avaliado para os diversos tipos de defeitos, especialmente para as discordâncias (Wilkens, 1970; Groma et al., 1988; Krivoglaz, 1996), sendo:

$$
\left\langle\varepsilon_{g, L}^{2}\right\rangle \cong\left(\frac{\rho C b^{2}}{4 \pi}\right) \ln \left(\frac{R_{e}}{L}\right)
$$

Onde $\rho$ é a densidade das discordâncias, $R_{e}$ é o raio de corte externo, $b$ é o valor absoluto do vetor de Burgers e $C$ é o fator de contraste das discordâncias. 
Portanto, para discordâncias, $\left\langle\varepsilon_{g, L}^{2}\right\rangle$ depende de $L$ e o fator de contraste depende da orientação relativa da linha e do vetor de Burgers, da discordância e do vetor de difração. Se considerar a discordância como uma linha reta e paralela ao eixo $z$ de um sistema cartesiano, o campo de deslocamento de cada discordância pode ser dada pela coordenada polar j,r em um plano $x, y$. Desta forma o fator de contraste $C$ pode ser dado por:

$$
C=\left(\frac{1}{\pi}\right) \int_{0}^{2 \pi} d \varphi K^{2}(\varphi)
$$

Sendo:

$$
k(\varphi)=\sum_{i=1}^{3} \sum_{j=1}^{2} \gamma_{i} \gamma_{j} \beta_{i j}(\varphi)
$$

e:

$$
\begin{array}{r}
\beta_{i j}=\frac{2 \pi r}{b} \frac{\partial_{u_{i}}}{\partial_{x_{j}}} \\
i=1,2,3 \text { e } j=1,2
\end{array}
$$

Onde $k(\varphi)$ é um polinomial trigonométrico, $\gamma_{i}$ e $\gamma_{j}$ são os cossenos da direção do vetor de difração nos planos $x y, \frac{\partial_{u i}}{\partial_{x j}}$ é o tensor de distorção, $u_{i}$ é o campo de deslocamento da discordância e $r$ é o comprimento variável no sistema de coordenada polar.

" $C$ " pode ser obtido numericamente utilizando as constantes elásticas devido à superposição dos campos de deslocamento das discordâncias e do fator de contraste correspondente ao sistema de discordância. Assim obtém-se por uma superposição linear de um fator de contraste individual como média ponderada (Wilkens, 1970).

O fator de contraste médio das discordâncias, $(\bar{C})$, em cristais cúbicos é uma função linear de quarta ordem dos índices $h k l$ em diferentes reflexões (Ungar e Tichy, 1999). 
Onde:

$$
\bar{C}=A-B \frac{\left(h^{2} k^{2}+h^{2} l^{2}+k^{2} l^{2}\right)}{\left(h^{2}+k^{2}+l^{2}\right)^{2}}
$$

Onde $A$ e $B$ são valores dependentes da constante elástica do cristal. O valor de $A$ é o valor de contraste médio correspondente à reflexão h00, ou seja:

$$
\bar{C}_{h 00}=A
$$

Se a razão de quarta ordem da equação acima for denotada por $H^{2}$, a mesma poderá ser reescrita como:

$$
\bar{C}=\bar{C}_{h 00}\left(1-q H^{2}\right)
$$

Onde:

$$
q=\frac{B}{A}
$$

Assim sendo, o fator de contraste médio poderá ser obtido se $\bar{C}_{h 00}$ e $q$ forem conhecidos. Cabe uma observação para o fato de que em casos em que ocorra um alto grau de textura para sistemas de escorregamento por discordâncias, será necessária a avaliação da deformação anisotrópica por fatores de contraste individual a cada plano.

$\mathrm{Na}$ equação 45, nota-se que a estrutura em relação a $C$ depende da razão das constantes elásticas $C_{11}, C_{12}$ e $C_{44}$ para definir a anisotropia elástica;

$$
A_{i}=2 \frac{C_{44}}{\left(C_{11}-C_{12}\right)}
$$

e a razão entre $\frac{C_{12}}{C_{44}}$, ou seja, dos 3 parâmetros iniciais, pode-se reduzir para 2.

Os valores de $\bar{C}_{h 00}$ tanto para o sistema CCC e CFC foram amplamente estudados por Honeycomb (1984) e conforme a equação 43 os dois parâmetros 
para a sua determinação prática em relação ao fator $\bar{C}$ para a função de $H^{2}$ são $\bar{C}_{h 00}$ e $q$ e que os valores de $\bar{C}_{h 00}$ tanto para discordâncias do tipo cunha quanto ao tipo hélice poderão ser obtidos pela média aritmética dos valores individuais, parametrizadas por:

$$
\bar{C}_{h 00}=a\left[1-\exp \left(-\frac{A_{i}}{b}\right)\right]+c A_{i}+d
$$

A tabela 2 mostra os parâmetros a,b,c e $d$ para os resultados de $\bar{C}_{h 00}$ nas discordâncias do tipo cunha para os sistemas CFC e a tabela 3 mostra os resultados para o sistema CCC (Ungár et al. ,1999).

Tabela 2: Valores dos parâmetros $a, b, c$ e $d$ para os resultados de $\bar{C}_{h 00}$ nas discordâncias do tipo cunha para sistema CFC.

\begin{tabular}{|l|c|c|c|}
\hline & $\frac{\boldsymbol{C}_{12}}{\boldsymbol{C}_{\mathbf{4 4}}}=\mathbf{0 , 5}$ & $\frac{\boldsymbol{C}_{12}}{\boldsymbol{C}_{\mathbf{4 4}}}=\mathbf{1}$ & $\frac{\boldsymbol{C}_{12}}{\boldsymbol{C}_{\mathbf{4 4}}}=\mathbf{2}$ \\
\hline $\boldsymbol{a}$ & 0,1312 & 0,1687 & 0,2438 \\
\hline $\boldsymbol{b}$ & 1,4284 & 2,0400 & 2,4243 \\
\hline $\boldsymbol{c}$ & 0,0201 & 0,0194 & 0,0172 \\
\hline $\boldsymbol{d}$ & 0,0954 & 0,0926 & 0,0816 \\
\hline
\end{tabular}

Tabela 3: Valores dos parâmetros a,b,c e $d$ para os resultados de $\bar{C}_{h 00}$ nas discordâncias do tipo cunha para o sistema CCC.

\begin{tabular}{|c|c|c|c|}
\hline & $\frac{\boldsymbol{C}_{12}}{\boldsymbol{C}_{\mathbf{4 4}}}=\mathbf{0 , 5}$ & $\frac{\boldsymbol{C}_{12}}{\boldsymbol{C}_{\mathbf{4 4}}}=\mathbf{1}$ & $\frac{\boldsymbol{C}_{12}}{\boldsymbol{C}_{\mathbf{4 4}}}=\mathbf{2}$ \\
\hline $\boldsymbol{a}$ & 1,4948 & 1,6690 & 1,4023 \\
\hline $\boldsymbol{b}$ & 25,671 & 21,124 & 12,739 \\
\hline $\boldsymbol{c}$ & 0 & 0 & 0 \\
\hline $\boldsymbol{d}$ & 0,0966 & 0,0757 & 0,0563 \\
\hline
\end{tabular}

A função entre $A_{i}$ e $\frac{C_{12}}{C_{44}}$, está evidenciada pelas figuras $18 \mathrm{a}, \mathrm{b}, \mathrm{c}$ e d, que possibilita determinar o fator de contraste na reflexão $\bar{C}_{h 00}$ (Ungar et al., 1999). 


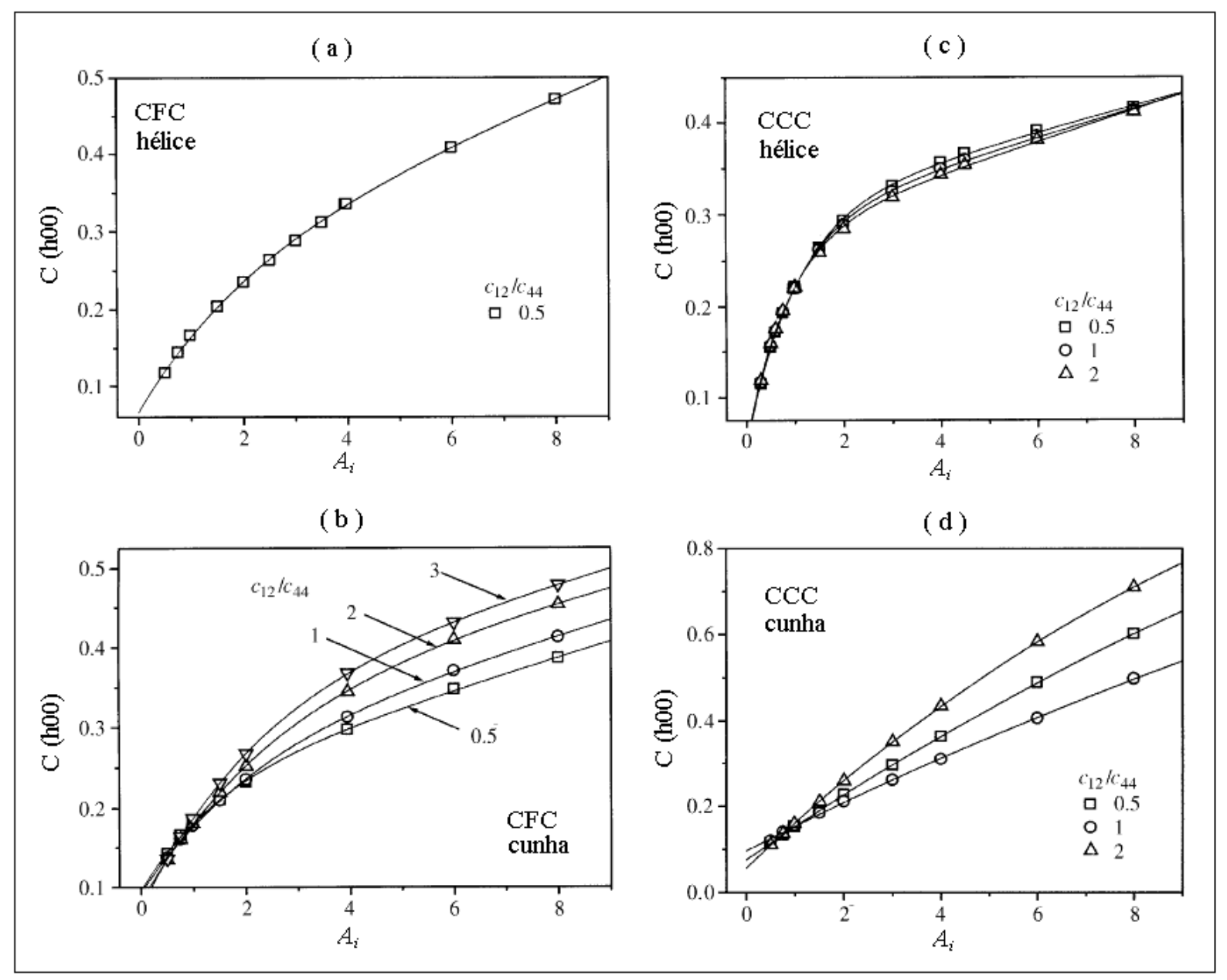

Figura 18: Fator de contraste correspondente a $\bar{C}_{h 00}$ para CFC hélice (a), CFC cunha (b), CCC hélice (c) e CCC cunha (d) na função da anisotropia elástica $A_{i}$ e em razão das constantes elásticas $\frac{C_{12}}{C_{44}}$ (Ungar e Borbély, 1996).

Da mesma forma com que fator de contraste na reflexão $\bar{C}_{h 00}$, foi parametrizado, o mesmo ocorre com o valor de $q$, aplicando a mesma equação:

$$
q=a\left[1-\exp \left(-\frac{A_{i}}{b}\right)\right]+c A_{i}+d
$$

Nas tabelas 4, 5 e 6 obtém-se os valores dos parâmetros a,b,c e d para os resultados de $q$ nas discordâncias do tipo cunha para o sistema CFC, do tipo hélice para o sistema CCC e tipo cunha em CCC respectivamente (Ungár et al., 1999). 
Tabela 4: Valores dos parâmetros $a, b, c$ e $d$ para os resultados de $q$ nas discordâncias do tipo cunha para sistema CFC

\begin{tabular}{|c|c|c|c|}
\hline & $\frac{C_{12}}{C_{44}}=\mathbf{0 . 5}$ & $\frac{C_{12}}{C_{44}}=\mathbf{1}$ & $\frac{C_{12}}{C_{44}}=\mathbf{2}$ \\
\hline$a$ & 4,0327 & 4,8608 & 5,8282 \\
\hline$b$ & 0,8846 & 0,8687 & 0,8098 \\
\hline$c$ & 0,0986 & 0,0896 & 0,0828 \\
\hline$d$ & $-2,8225$ & $-3,4280$ & $-4,297$ \\
\hline
\end{tabular}

Tabela 5: Valores dos parâmetros $a, b, c$ e $d$ para os resultados de $q$ nas discordâncias do tipo hélice para sistema CCC.

\begin{tabular}{|l|l|l|l|}
\hline & \multicolumn{1}{|c|}{$\frac{\boldsymbol{C}_{12}}{\boldsymbol{C}_{\mathbf{4 4}}}=\mathbf{0 , 5}$} & \multicolumn{1}{|c|}{$\frac{\boldsymbol{C}_{12}}{\boldsymbol{C}_{\mathbf{4 4}}}=\mathbf{1}$} & $\frac{\boldsymbol{C}_{12}}{\boldsymbol{C}_{44}}=\mathbf{2}$ \\
\hline $\boldsymbol{a}$ & 7,5149 & 8,6590 & 6,0725 \\
\hline $\boldsymbol{b}$ & 0,3818 & 0,3730 & 0,4338 \\
\hline $\boldsymbol{c}$ & 0,0478 & 0,0424 & 0,0415 \\
\hline $\boldsymbol{d}$ & $-4,9826$ & $-6,0740$ & $-3,5021$ \\
\hline
\end{tabular}

Tabela 6: Valores dos parâmetros a,b,c e $d$ para os resultados de $q$ nas discordâncias do tipo cunha para sistema CCC.

\begin{tabular}{|l|l|l|l|}
\hline & \multicolumn{1}{|c|}{$\frac{\boldsymbol{C}_{12}}{\boldsymbol{C}_{\mathbf{4 4}}}=\mathbf{0 , 5}$} & \multicolumn{1}{c|}{$\frac{\boldsymbol{C}_{12}}{\boldsymbol{C}_{\mathbf{4 4}}}=\mathbf{1}$} & $\frac{\boldsymbol{C}_{\mathbf{1 2}}}{\boldsymbol{C}_{\mathbf{4 4}}}=\mathbf{2}$ \\
\hline $\boldsymbol{a}$ & 5,3020 & 7,2361 & 8,8331 \\
\hline $\boldsymbol{b}$ & 1,0945 & 0,9285 & 0,8241 \\
\hline $\boldsymbol{c}$ & 0,1540 & 0,1359 & 0,1078 \\
\hline $\boldsymbol{d}$ & $-4,1841$ & $-5,7484$ & $-7,0570$ \\
\hline
\end{tabular}

Para determinar o parâmetro $q$ como uma função da anisotropia elástica $A_{i}$ e a razão da constante elástica $\frac{C_{12}}{C_{44}}$, observam-se os gráficos das condições relativas às tabelas 4,5 e 6 com a condição de se identificar o tipo de discordância (hélice ou cunha), conforme mostram as figuras 19a, b e c. 


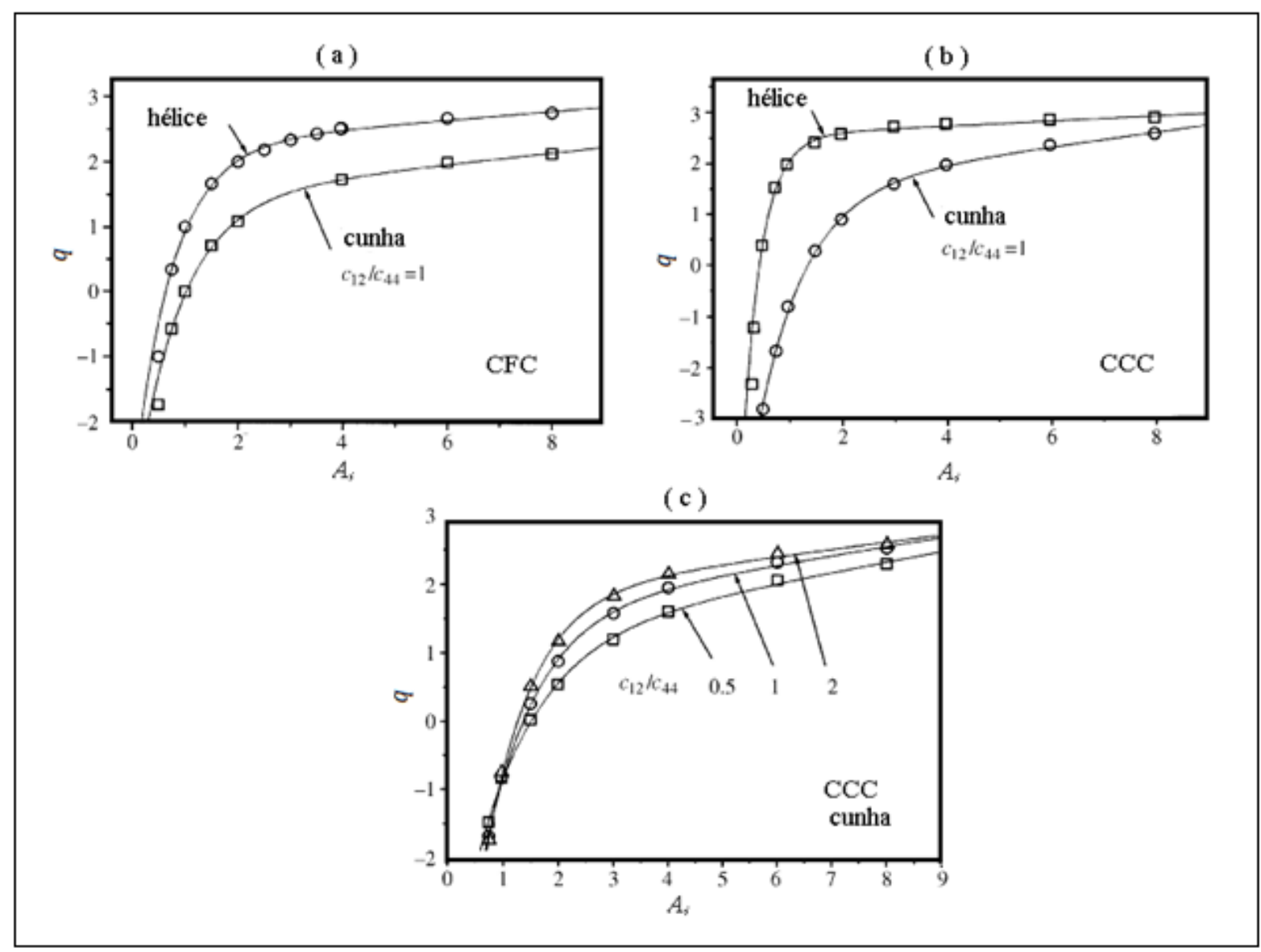

Figura 19: Parâmetro $q$ como função da anisotropia elástica $A_{i}$ e a razão da constante elástica $\frac{C_{12}}{C_{44}}$ : (a) no caso do sistema CFC nas discordâncias hélice e cunha em $\frac{C_{12}}{C_{44}}=1$; (b) no caso do sistema CCC nas discordâncias hélice e cunha em $\frac{C_{12}}{C_{44}}=1$; (c) no caso do sistema CCC na discordância cunha em diferentes razoes de $\frac{C_{12}}{C_{44}}$ (Ungar e Borbély, 1996).

Ungar e Borbély (1996) apresentaram uma análise de perfil em um aço ferrítico baseada nos procedimentos de Williamson-Hall . De acordo com a teoria, um aumento não linear em relação a ordem de difração é descrito pela anisotropia da tensão causada pelas discordâncias. A equação de Williamson-Hall modificada é expressa a seguir:

$$
\Delta K=\frac{0.9}{D}+\sqrt{\pi B^{2} \frac{b^{2}}{2}} * \sqrt{\rho}(k \sqrt{\langle C\rangle})+O(k \sqrt{\langle C\rangle})^{2}
$$

Onde $\Delta K$ é a largura integral no espaço $K$. Nesta equação, $D, \rho$ e $b$, são o tamanho do cristalito, a densidade de discordâncias e o vetor de Burgers, respectivamente; $B$ é um parâmetro que depende do raio de corte das discordâncias 
e $O$ representa um termo de ordem superior em $k \sqrt{\langle C\rangle}$. A variável $\langle C\rangle$ é um fator de contraste das discordâncias que depende das orientações relativas dos vetores de Burgers e linhas de discordâncias e o vetor de difração (Sato et al., 2013).

As figuras 20a 20b mostram os gráficos de Williamson-Hall e o modificado respectivamente para os perfis medidos experimentalmente por Sato et al. (2013). Observa-se que se propõe a assumir uma função linear em relação ao espaço $k$, a variação de $\Delta K$ em função de $K$ varia em forma zigue zague, causado pela anisotropia da tensão causada pela deformação. Contrastando a isto, aplicando-se a equação modificada, obtém uma curva suave, corrigindo a anisotropia com um fator de contraste. No caso particular ao trabalho de Sato, aplicado a uma amostra cilíndrica em análises a diferentes profundidades.

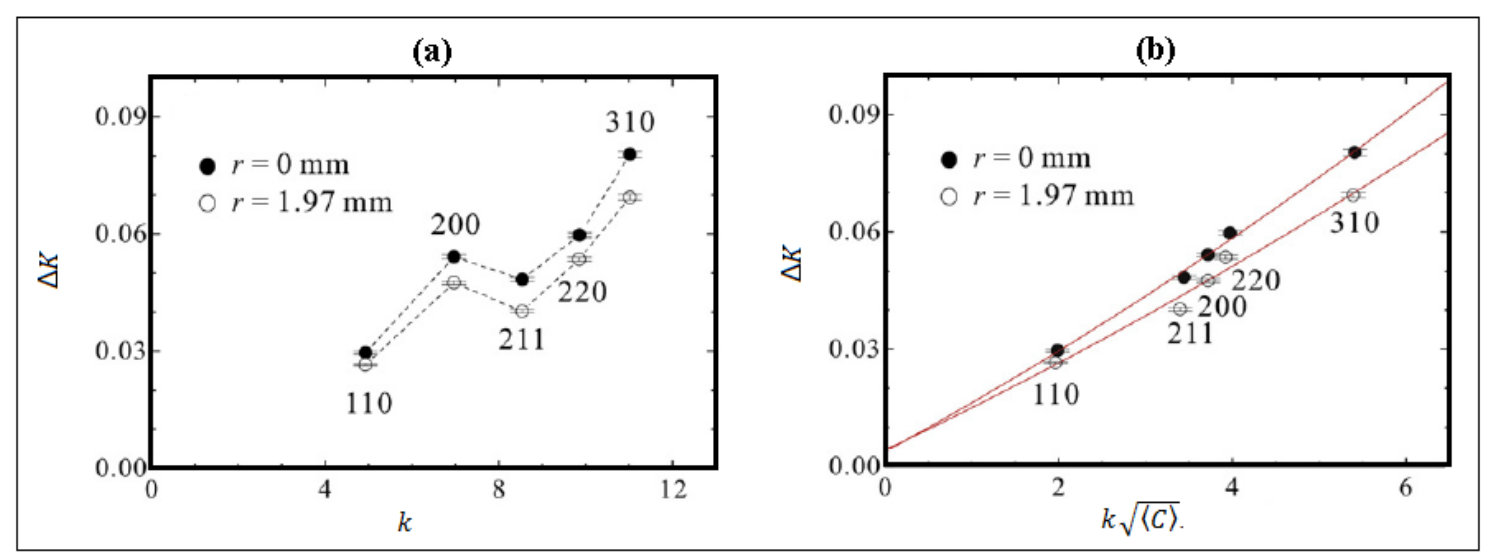

Figura 20: Gráfico aplicado a equação de Williamson-Hall (a) e Aplicado na equação modificada (b) (Sato et al., 2013).

Por meio destes gráficos é possível obter a informação sobre o fator de contraste das discordâncias $\langle C\rangle$ ao plotar os gráficos obtidos experimentalmente no decorrer do trabalho.

Toma-se a equação 48 na forma quadrática:

$$
\Delta K^{2}=\left(\frac{0.9}{D}\right)^{2}+\pi B^{2} \frac{b^{2}}{2} \rho K^{2} C \pm O\left(k^{4} C^{2}\right)
$$

Se $K=\frac{2 \operatorname{sen} \theta}{\lambda}$, portanto $\Delta K$ corresponde a largura do pico a meia altura, e substituindo os termos: 


$$
\frac{\left[(\Delta K)^{2}-\alpha\right]}{K^{2}} \cong \beta \bar{C}_{h 00}\left(1-q H^{2}\right)
$$

Pois $\alpha=\left(\frac{0.9}{D}\right)^{2}$ e $\beta=\frac{\pi M^{2} b^{2} \rho}{2}$

Na equação 68 , o valor de $q$ é obtido pela intersecção no eixo $x$ aplicada à função de $\Delta K^{2}$ em relação a $H^{2}$ para cada plano correspondente.

Esta função é representada pela figura 21, na reta correspondente do tipo $y=A+B x$ sendo o resultado, o valor de $x=\frac{1}{q}$

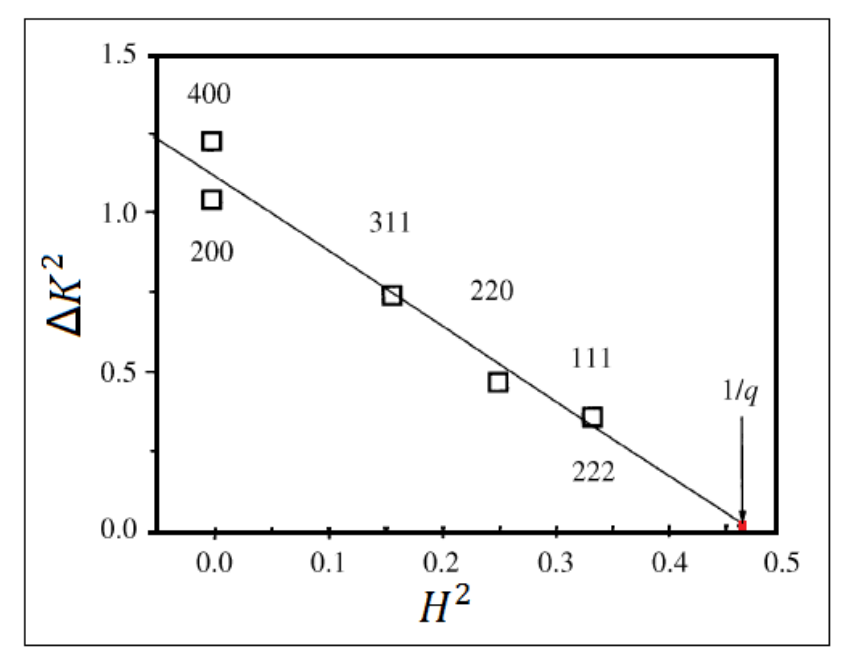

Figura 21: Gráfico da função para obtenção de $q$ em função de $\Delta K^{2}$ em relação a $H^{2}$.

Com o valor de $q$ torna-se possível distinguir se a discordância é do tipo cunha ou hélice, relacionado com a função da anisotropia elástica $A_{i}$ e a razão da constante elástica $\frac{C_{12}}{C_{44}}$ conforme as tabelas 4,5 e 6 e nas figuras $19 a$, b e c.

A obtenção dos valores da microdeformação da rede cristalina e do tamanho médio de cristalito se faz na construção de um gráfico na função de $K \sqrt{\bar{C}}$ por $\Delta K$ (x, y respectivamente). A inclinação corresponde à microdeformação da rede cristalina e o intercepto em y ao tamanho médio do cristalito do tipo $y=A+B x$, sendo para a microdeformação da rede cristalina, $\varepsilon=\frac{B}{2}$ e para o tamanho médio de cristalito, $D=0.9 \frac{\lambda}{A}$. 


\subsubsection{Série de Fourier}

Utilizando-se das relações de ortogonalidade das funções seno e cosseno que é aplicado ao perfil do pico obtido pela difração de raios- $x$, a série de Fourier é uma expansão de uma função periódica $f(x)$ em termos de uma soma infinita de senos e cossenos (http://mathworld.wolfram.com/FourierSeries.html) .

O cálculo e estudo da série de Fourier é conhecido como análise harmônica e utilizada como uma forma de determinar uma função periódica arbitrária em um conjunto de termos simples que podem ser conectados, resolvidos individualmente e então recombinados, obtendo a solução para o problema original ou uma aproximação para o mesmo.

Assim por definição, sendo $x$ um número real, chama-se exponencial complexa de $x$ o numero complexo.

$$
e^{i x}=\cos x+i \operatorname{sen} x
$$

Sendo que as exponenciais complexas são funções periódicas, de período igual a $2 \pi$ e afim de utilizá-las para obter funções periódicas com outros períodos, como por exemplo igual a $N$, nota-se que $e^{i 2 \pi n t / N}$ são funções periódicas de período $N$ para todo $n \in \mathbb{Z}$.

Portanto se uma função $f(x)$ com período $N$, então os coeficientes de Fourier $\left\{c_{n}\right\}$ de $f$ são definidos por:

$$
C_{n}=\frac{1}{N} \int_{0}^{N} f(x) e^{-i 2 \pi n x / N} d x
$$

Para todo $n$ inteiro.

Usando os coeficientes $\left\{c_{n}\right\}$, pode-se definir a série:

$$
f \sim \sum_{n=-\infty}^{+\infty} c_{n} e^{i 2 \pi n x / N}
$$

Denominada série de Fourier de $f$. 
Por meio das equações mostradas tem-se base para aplicar a transformada de Fourier, obtida por uma variável discreta $C_{n}$ por uma função contínua $f(x)$ para $N \rightarrow \infty$, alterando a somatória por uma integral.

Sendo uma função contínua $f(x)$, dependente de uma variável real $x$, a transformada de Fourier $f(x)$ poderá ser definida como:

$$
F(u)=\int_{-\infty}^{+\infty} f(x) e^{-i 2 \pi n x / N} d x
$$

Onde $u$ é considerada a variável de frequência. Se aplicar a fórmula de Euler na equação 54 obtém-se:

$$
F(u)=\int_{-\infty}^{+\infty} f(x)(\cos 2 \pi u x+i \operatorname{sen} 2 \pi u) d x
$$

Para calcular a função $f(x)$ aplica-se a transformada Inversa:

$$
f(x)=\int_{-\infty}^{+\infty} F(u) e^{-i 2 \pi n x} d u
$$

Aplicando a fórmula de Euler:

$$
f(x)=\int_{-\infty}^{+\infty} F(u)(\cos 2 \pi u x+i \operatorname{sen} 2 \pi u) d u
$$

Se $F(u)$ é a integral de um número real multiplicado por um número complexo obtemos:

$$
F(u)=A(u)+i B(u)
$$

Onde $A(u)$ é uma componente real e $B(u)$ é uma componente imaginária. Uma função $f(x)$ possuirá transformada direta e inversa desde que:

a) $\int_{-\infty}^{+\infty}|f(x)| d x$ exista;

b) Haja um número finito de descontinuidades; 
c) A função tenha variação finita. Uma condição suficiente é obedecer a condição de Lipschitz (Ichikawa, 2013).

No caso específico, a análise do perfil do pico de difração de raios-x se dá em valores discretos pelos intervalos regulares do ângulo de Bragg, sendo necessário a aplicação de uma função discreta, determinada pela transformada discreta de Fourier, dada por:

$$
F(u)=\frac{1}{N} \sum_{x=0}^{N-1} f(x) e^{-i 2 \pi u x / N}
$$

Onde, $u=0,1,2,3, \ldots N-1$,

A Transformada Inversa Discreta de Fourier é dada por:

$$
f(x)=\frac{1}{N} \sum_{x=0}^{N-1} F(u) e^{i 2 \pi u x / N}
$$

Substituindo a formula de Euler na equação 60 :

$$
F(u)=\frac{1}{N} \sum_{x=0}^{N-1} f(x)\left[\cos \left(\frac{2 \pi u x}{N}\right)+i \operatorname{sen}\left(\frac{2 \pi u x}{N}\right)\right]
$$

Onde:

$$
\begin{aligned}
& A(u)=\frac{1}{N} \sum_{x=0}^{N-1} f(x) \cos \left(\frac{2 \pi u x}{N}\right) \\
& B(u)=\frac{1}{N} \sum_{x=0}^{N-1} f(x) \operatorname{sen}\left(\frac{2 \pi u x}{N}\right)
\end{aligned}
$$

Onde $A(u)$ e $\mathrm{B}(u)$ são denominados coeficientes real e imaginário de Fourier respectivamente.

A próxima etapa é definir o produto de duas funções $f$ e $g$ em se proceder a convolução, dada como duas funções em um intervalo finito $[0, t]$, dado por: 


$$
[f * g](t) \equiv \int_{0}^{t} f(\tau) g(t-\mathcal{T}) d \tau
$$

Onde $[f * g]$ representa a convolução de $f$ e $g$.

A convolução também será dada em um intervalo infinito:

$$
[f * g](t) \equiv \int_{-\infty}^{+\infty} f(\tau) g(t-\mathcal{T}) d r=\int_{-\infty}^{+\infty} g(\tau) f(t-\mathcal{T}) d \tau
$$

Considerando o pico de difração como um sinal discreto, o sinal poderá ser definido como uma função matemática $f$ de uma variável independente $x \in \mathbb{Z}$.

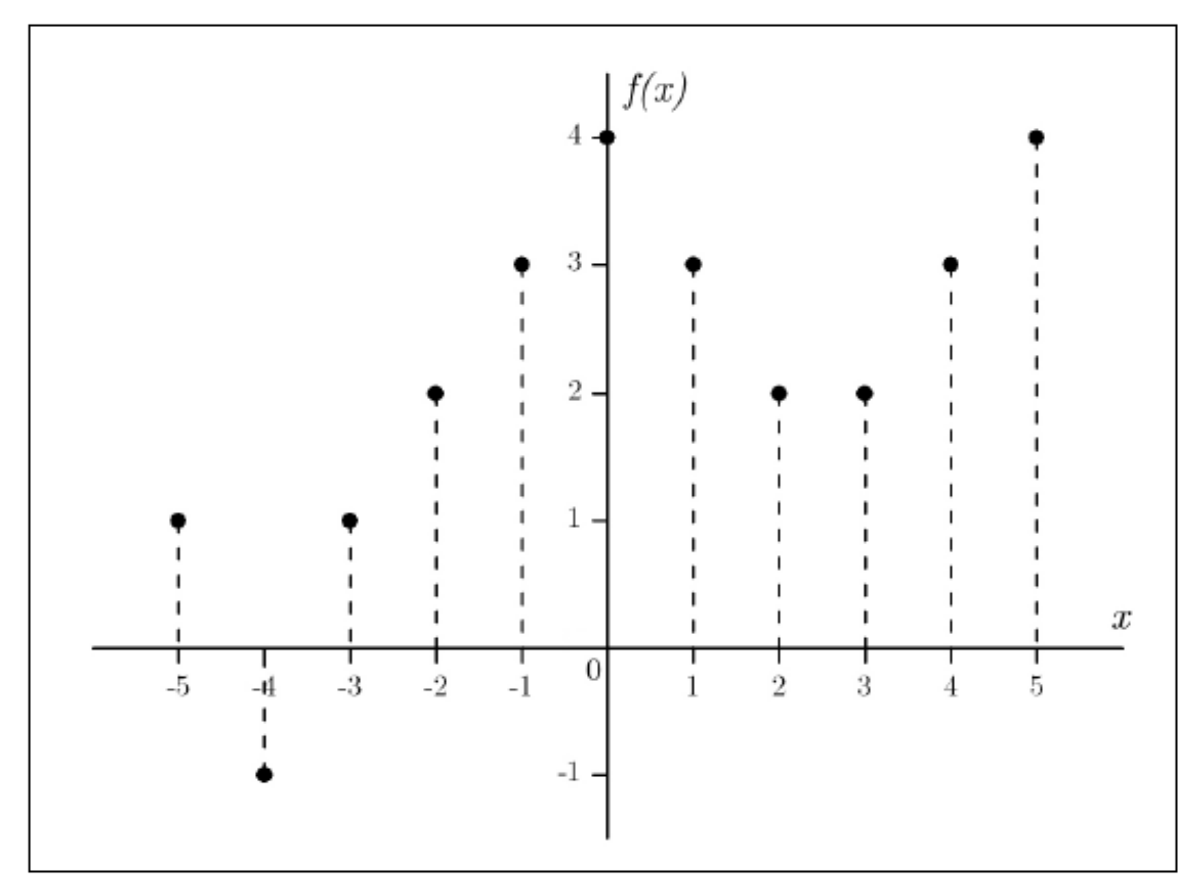

Figura 22: Exemplo de um sinal discreto (Ichikawa, 2013).

No caso de um perfil de difração de raios-x a intensidade é uma função de $\theta(I(2 \theta))$, onde $2 \theta>0$. Para desenvolver o algoritmo utilizado para o cálculo da transformada de Fourier discreta foi utilizado como um sinal não causal e calculado pela equação:

$$
F(u)=\frac{1}{N} \sum_{x=-\frac{N}{2}}^{x=\frac{N}{2}-1} f(x) e^{-i 2 \pi u x / N}
$$


O perfil apresentado por um pico de difração em um material policristalino livre de deformações e tamanho médio de cristalito grande tem por característica de ser estreito e em posição definida em $2 \theta$, porém ganha a contribuição de seu relativo alargamento devido a fatores instrumentais, cujo pico observado pode ser expressa pela equação 67 :

$$
h(x)=\int_{-\infty}^{+\infty} f(y) g(x-y) d y
$$

Onde $h(x)$ é a função que descreve o perfil observado, $g(x-y)$ é a função que descreve o perfil de uma amostra livre de efeitos que provoquem o alargamento do perfil, $f(y)$ é o perfil onde não há fatores instrumentais. Assim esta equação indica a convolução de duas funções no perfil apresentado: A primeira em relação a contribuição experimental e a segunda referente a um perfil puro livre dos fatores instrumentais.

\subsubsection{Estudo do perfil das difrações.}

A deformação de um metal produz uma rede de discordâncias que subdivide os grãos originais em pequenos domínios coerentes. A desorientação entre estes domínios causa espalhamento incoerente de raios-x de modo que cada domínio espalha como um pequeno cristal. As discordâncias que limitam os domínios produzem tensões que variam em escala microscópica, denominadas microtensões (Borges, 1985), sendo assim, a redução dos domínios coerentes de difração produzem o alargamento dos perfis de difração de raios- $x$, e tal efeito possibilita determinar as microtensões contidas. Além do alargamento produzido pela deformação, também é observado um deslocamento na posição do pico devido ao defeito de empilhamento introduzido pela deformação.

O difratograma obtido experimentalmente permite um estudo detalhado cujo propósito estabelecido neste trabalho é obter os valores da microdeformação da rede cristalina e do tamanho médio de cristalito nas várias regiões ao longo do material. Para este objetivo são utilizadas diversas funções para deconvoluir o perfil, separando os efeitos gerados pelos fatores instrumentais e defeitos da espécime 
usualmente utilizando as técnicas de Fourier. Entre os métodos propostos o mais utilizado no estudo do perfil das difrações aplicam-se às funções Cauchy (Lorentziana) e a Gaussiana. Para a função de Cauchy são previstos os efeitos onde os defeitos geométricos são pequenos, porém quando o perfil é decorrente de deformações da rede a aproximação será Gaussiana. O aumento das falhas depende da natureza das imperfeições, da forma e da distribuição do tamanho dos cristalitos, sendo assim necessária uma boa aproximação evidenciando a melhor representação obtidas pela convolução nas funções Lorentziana e Gaussiana e a curva formada neste caso é conhecido pela função de Voigt descrita a seguir:

$$
\beta=\frac{A}{I(0)}
$$

Onde $\beta$ é a amplitude integrada, $A$ é a área do perfil, $I(0)$ a altura do pico. Se considerar o tamanho do pico a meia altura, $2 w$ obtém se a relação $\frac{2 w}{\beta}$ e esta razão é o fator de forma. Isto pode ser exemplificado tendo como valores 0,63662 para a função integralmente Cauchy e 0,93949 se a função é totalmente Gaussiana, com valores intermediários para funções Voigt, cuja dedução se encontra na função $I(x)$ representada como a convolução das funções $m$ Cauchy e $n$ Gaussiana, cujos componentes estão descritos à Cauchy e Gaussiana, $c$ e $g$, respectivamente (Langford, 1978):

Convolução da função $m$ Cauchy:

$$
I_{c i}(x)=I_{c i}(0) \frac{w_{c i}^{2}}{w_{c i}^{2}+x^{2}}
$$

De área:

$$
A_{c i}=\pi w_{c i} I_{c i}(0)
$$

E a largura integral:

$$
\beta_{c i}=\pi w_{c i}
$$


Também a função Cauchy, dado por:

$$
I_{c}(x)=I_{c}(0) \frac{w_{c}^{2}}{w_{c}^{2}+x^{2}}
$$

Então:

$$
2 w_{c}=\frac{2}{\pi} \beta_{c}=2 \sum_{i=1}^{m} w_{c i}
$$

Portanto:

$$
A_{c}=\prod_{i=1}^{m} A_{c i}=\pi^{m} \prod_{i=1}^{m} w_{c i} I_{c i}(0)
$$

$E$ :

$$
I_{c i}(0)=\frac{A_{c}}{\pi w_{c}}
$$

Da equação 71 o fator de forma $\frac{2 w}{\beta}$ para uma função Cauchy é $\frac{2}{\pi}=0,63662$. Convolução da função $n$ Gaussiana:

$$
I_{g i}(x)=I_{g i}(0) e^{\left(\frac{-\pi x^{2}}{\beta_{g i}^{2}}\right)}
$$

De área:

$$
A_{g i}=I_{g i}(0) \beta_{g i}
$$

O pico à meia altura:

$$
2 w_{g i}=\frac{2 \beta_{g i} \sqrt{\left(\log _{e} 2\right)}}{\sqrt{\pi}}
$$

A função Gaussiana será dada por: 


$$
I_{g}(x)=I_{g}(0) e^{\left(\frac{-\pi x^{2}}{\beta_{g}^{2}}\right)}
$$

Então:

$$
\begin{aligned}
& \beta_{g}^{2}=\frac{\pi}{4 \log _{e} 2}\left(2 w_{g}\right)^{2}=\sum_{i=1}^{n} \beta_{g i}^{2} \\
& A_{g}=\prod_{i=1}^{n} A_{g i}=\prod_{i=1}^{n} \beta_{g i} I_{g i}(0)
\end{aligned}
$$

Portanto:

$$
I_{g}(0)=\frac{A_{g}}{\beta_{g}}
$$

Da equação 78 o fator de forma para uma função Cauchy é $\frac{2 \sqrt{\left(\log _{e} 2\right)}}{\sqrt{\pi}}=$ 0,93949 .

A função de Voigt possibilita a convolução das funções $m$ Cauchy e $n$ Gaussiana, desta forma:

$$
I(x)=\int_{-\infty}^{+\infty} I_{c}(u) I_{g}(x-u) d u
$$

A transformada de Fourier ficará:

$$
F_{c}(t)=\beta_{c} I_{c}(0) e^{\left(-2 \beta_{c} t\right)}
$$

$E$ :

$$
F_{g}(t)=\beta_{g} I_{g}(0) e^{\left(-\pi \beta_{g}{ }^{2} t^{2}\right)}
$$

Assim sendo, a transformada de $I(x)$ será: 


$$
F(t)=F_{c}(t) F_{g}(t)=\beta_{c} \beta_{g} I_{c}(0) I_{g}(0) e 0^{-\left(2 \beta_{c} t+\pi \beta_{g}{ }^{2} t^{2}\right)}
$$

O fator proporcional para a razão do alargamento integral $(k)$ é obtido:

$$
k=\frac{\beta_{c}}{\sqrt{\pi} \beta_{g}}
$$

Este fator possibilita a mostrar a contribuição que as funções Cauchy e Gaussiana inferem na composição da curva do difratograma. A tabela 7 mostra a relação entre a razão do alargamento do pico a meia altura $2 w$ com a largura integral $(\beta)$ e o fator proporcional das funções $(k)$.

Tabela 7: Relação da razão entre alargamento e integral do alargamento com a proporcionalidade entre as funções Cauchy e Gaussiana (Langford, 1978).

\begin{tabular}{|c|c|c|c|}
\hline $\mathbf{2 w} / \boldsymbol{\beta}$ & $\boldsymbol{k}(\mathbf{G x C})$ & $\mathbf{2 w / \beta}$ & $\boldsymbol{k}(\mathbf{G x C})$ \\
\hline 0,9349 & $0-1$ & 0,7099 & $1-1$ \\
\hline 0,8977 & $0-2$ & 0,7026 & $1-2$ \\
\hline 0,8628 & $0-3$ & 0,6961 & $1-3$ \\
\hline 0,8326 & $0-4$ & 0,6903 & $1-4$ \\
\hline 0,8079 & $0-5$ & 0,6854 & $1-5$ \\
\hline 0,7866 & $0-6$ & 0,6812 & $1-6$ \\
\hline 0,7530 & $0-7$ & 0,6774 & $1-7$ \\
\hline 0,7397 & $0-8$ & 0,6740 & $1-8$ \\
\hline 0,7282 & $0-9$ & 0,6709 & $1-9$ \\
\hline 0,7184 & $1-0$ & 0,6682 & $2-0$ \\
\hline
\end{tabular}

$\mathrm{Na}$ prática, os valores de $\frac{2 w}{\beta}$ são utilizados para o ajuste da curva experimental com a curva calculada, compondo a participação das funções no perfil.

Keijser et al, (1982) propuseram o uso da função de Voigt na análise do alargamento integrado, aplicado no perfil da difração de raios- $x$, obtendo resultados inerentes aos valores do tamanho médio de cristalito e da microdeformação da rede cristalina. 
Considerando que o perfil medido é $h$, cuja convolução é $g$ e o alargamento estrutural $f$ (Langford,1978):

$$
h_{C}=g_{C} f_{C} \quad \text { e } \quad h_{G}=g_{G} f_{G}
$$

Onde $C$ e $G$ denotam as componentes de Cauchy e Gaussiana dos respectivos perfis da função de Voigt.

Para ao alargamento integrado, de $f_{C}$ e $f_{G}$, serão dados por:

$$
\beta_{C}^{f}=\beta_{C}^{h}-\beta_{C}^{g} \text { e }\left(\beta_{G}^{f}\right)^{2}=\left(\beta_{G}^{h}\right)^{2}-\left(\beta_{G}^{g}\right)^{2}
$$

As constituintes dos componentes da Cauchy e Gaussiana podem ser obtidas pela razão $\frac{2 w}{\beta}$ pelos perfis de $h$ e $g$ gerando o comportamento mostrado na figura 23.

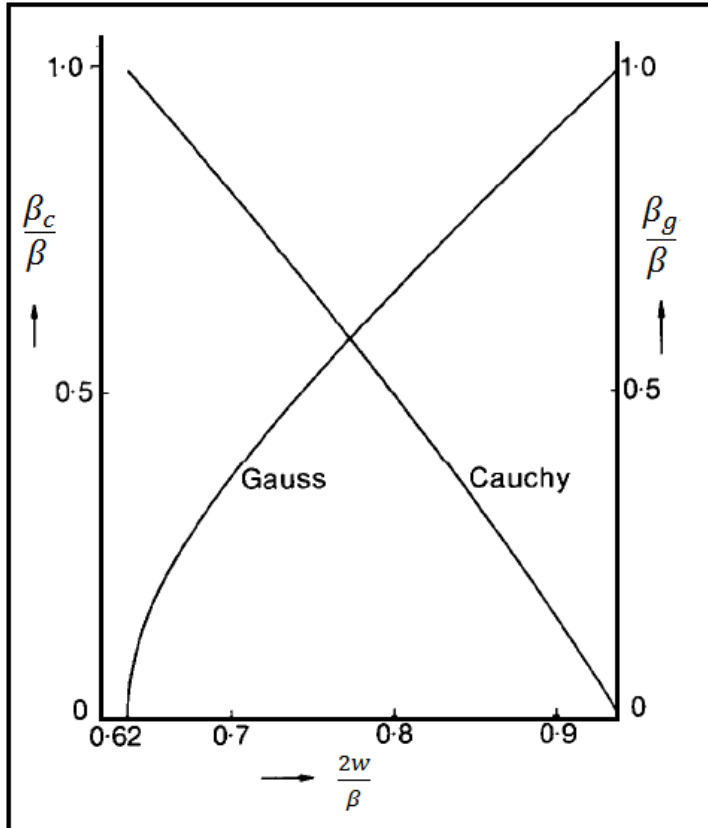

Figura 23: Razão do alargamento integrado das componentes de Cauchy e Gauss, $\frac{\beta_{C}}{\beta}$ e $\frac{\beta_{G}}{\beta}$, como função de $\frac{2 w}{\beta}$ (Langford, 1978)

Afim de identificar os efeitos relativos ao tamanho e deformação é necessário assumir que os perfis possuem formas particulares, e ambos podem ser 
determinados pela variação de $\beta_{C}^{f}$ e $\beta_{G}^{f}$ em relação a cada $h k l$, assumindo que a função Cauchy é unicamente devida ao tamanho de cristalito e a função Gaussiana está relacionada a deformação, dado por:

$$
D=\frac{\lambda}{\beta_{C}^{f} \cos \theta}
$$

Para o tamanho médio de cristalito e:

$$
\varepsilon=\frac{\beta_{G}^{f}}{4 \tan \theta}
$$

Para a microdeformação da rede cristalina.

\subsubsection{Método Warren-Averbach}

Em 1950, Warren \& Averbach desenvolveram um método de análise microestrutural para materiais policristalinos deformados e de acordo com os autores a distribuição da difração por unidade de comprimento de um cone de DebyeSherrer poderá ser expressa pela série de Fourier:

$$
P^{\prime}(2 \theta)=\frac{K N F}{\operatorname{sen}^{2} \theta} \sum_{n=-\infty}^{+\infty}\left(A_{L} \cos 2 \pi n h+B_{L} \operatorname{sen} 2 \pi n h\right)
$$

$P^{\prime}(2 \theta)$ é o perfil da difração medido ao longo de $2 \theta, c$ é o produto do fator de estrutura $(F)$, do fator angular $(K)$ e o número de celas unitárias do material analisado $(N)$.

O $n$ representa o número harmônico e $h$ é dado por:

$$
h=\frac{2 \operatorname{sen} \theta}{\lambda|\vec{B}|}=\frac{2|\vec{a}| \operatorname{sen} \theta}{\lambda}
$$

Onde: 


$$
\begin{aligned}
& A_{L}=N^{\prime}\left\langle\cos 2 \pi l Z_{n}\right\rangle \\
& B_{L}=-N^{\prime}\left\langle\operatorname{sen} 2 \pi l Z_{n}\right\rangle
\end{aligned}
$$

$N^{\prime}$ é o termo relacionado à média das colunas das celas unitárias e $Z_{n}$ é a distância entre os pares das celas unitárias que possuem um n-ésimo vizinho com o mesmo número de colunas e pode ser representado por $Z_{n}=\left\langle\epsilon_{L}\right\rangle$, onde $\left\langle\epsilon_{L}\right\rangle$ é a deformação média causada na rede cristalina na direção $\vec{a}$.

Tendo em conta que os efeitos do tamanho médio do cristalito e da microdeformação da rede cristalina alargam simetricamente o perfil da difração os coeficientes em seno $\left(B_{L}\right)$ da Série de Fourier não são considerados, dada a definição de que $Z_{-n}=-Z_{n}$, a somatória sobre seno (função impar) será nula. Desta forma a equação 95 ficará:

$$
P^{\prime}(2 \theta)=\frac{c}{\operatorname{sen}^{2} \theta} \sum_{n=-\infty}^{+\infty}\left(A_{L} \cos 2 \pi n h\right)
$$

Para definir os parâmetros da equação 96 , pode-se descrever um cristal constituído de colunas elementares na direção $a_{3}$, paralela ao vetor da difração, perpendiculares aos planos que difratam raios- $x$, (001), sendo $c$ uma constante, $h=2 \operatorname{asen} \theta / \lambda$.

Assim sendo, a intensidade de um pico de difração pode ser dada pelo coeficiente de Fourier $\left(A_{L}\right)$, que é um produto de dois termos, o primeiro dependente do comprimento das colunas das celas unitárias, assim relacionada ao tamanho médio dos cristalitos e o segundo relacionado à deformação da rede cristalina que por sua vez depende da ordem de reflexão do perfil analisado.

O coeficiente real de Fourier pode ser dado pela equação 34:

$$
A_{L}=A_{L}^{S} \cdot A_{L}^{D}
$$

$A_{L}^{S}$ é o termo relacionado com o tamanho do cristalito e $A_{L}^{D}$ é o termo relacionado à deformação da rede cristalina. Aplicando o logaritmo na equação 34 
possibilitará a separação dos dois termos, pois o termo relacionado à deformação depende da ordem de reflexão.

$$
l_{n}\left(A_{L}\right)=l_{n}\left(A_{L}^{S} A_{L}^{D}\right)=l_{n}\left(A_{L}^{S}\right)+l_{n}\left(A_{L}^{D}\right)
$$

Considerando $A_{L}^{S}$ dado por $\left\langle\cos 2 \pi l Z_{n}\right\rangle$ os valores muito pequenos para $l(l \rightarrow 0)$ a aproximação poderá ser feita em uma série de Taylor: (Van Berkum, et al., 1994.)

$$
\left\langle\cos 2 \pi l Z_{n}\right\rangle \approx 1-2 \pi^{2} l^{2}\left\langle Z_{n}^{2}\right\rangle
$$

Substituindo equação 98 na equação 97, obtém:

$$
l_{n}\left(A_{L}\right)=l_{n}\left(A_{L}^{S}\right)+l_{n}\left(1-2 \pi^{2} l^{2}\left\langle Z_{n}^{2}\right\rangle\right)
$$

Considerando que $l \rightarrow 0$, o segundo termo logarítmico da parte da direita pode ser aproximada para $-2 \pi^{2} l^{2}\left\langle Z_{n}^{2}\right\rangle$, então:

$$
l_{n}\left(A_{L}\right)=l_{n}\left(A_{L}^{S}\right)-2 \pi^{2} l^{2}\left\langle Z_{n}^{2}\right\rangle
$$

Sendo $\left\langle Z_{n}^{2}\right\rangle$ um termo relacionado à deformação quadrática média, relacionada a $L$

Desta forma, pode-se utilizar as múltiplas ordens de reflexão (no mínimo duas) para separar os dois coeficientes e obtendo um gráfico $l_{n}\left(A_{L}\right)$ por $l^{2}$. O coeficiente angular da reta permite obter o coeficiente relacionado a $A_{L}^{S}$, assim como os valores de $2 \pi^{2} l^{2}\left\langle Z_{n}^{2}\right\rangle$.

Os valores reais em tamanho médio de cristalito e microdeformação da rede cristalina somente serão possíveis de determinar considerando o tamanho que representa uma distância não deformada entre celas, também conhecido como comprimento de Fourier (grandeza $L$ ) calculada como:

$$
L=\frac{n \lambda}{2\left(\operatorname{sen} \theta_{2}-\operatorname{sen} \theta_{1}\right)}
$$


Onde $n$ é o número harmônico, $\theta_{1}$ e $\theta_{2}$ são os ângulos onde iniciam e terminam o pico analisado, e no caso onde haja uma deformação se calcula em termo de $\Delta L$ :

$$
\Delta L=\frac{Z_{n} \lambda}{2\left(\operatorname{sen} \theta_{2}-\operatorname{sen} \theta_{1}\right)}
$$

Portanto obtém-se a componente da deformação ao longo do eixo cristalográfico $\left(\varepsilon_{L}\right)$ calculado sobre $L$.

$$
\varepsilon_{L}=\frac{\Delta L}{L}
$$

O coeficiente angular da reta fornece a média dos valores da deformação quadrática $\left\langle\varepsilon_{L}^{2}\right\rangle$, utilizada para calcular a deformação quadrática média, e o tamanho médio de cristalito pode ser obtido a partir do gráfico $A_{L}^{S}$ por $L$, sendo $L \rightarrow 0$, pela intersecção da reta ajustada à inclinação inicial da curva no gráfico no eixo $L$.

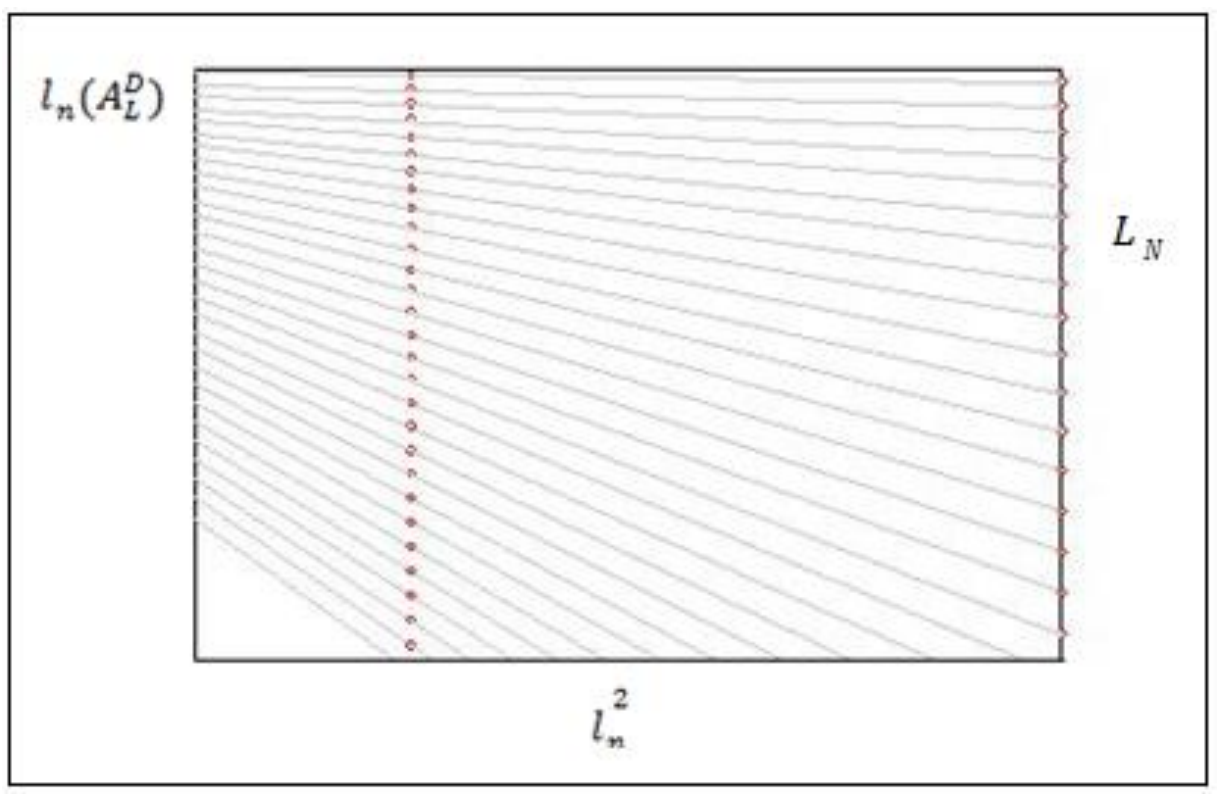

Figura 24: Gráfico baseado nos coeficientes de Fourier para obtenção da microdeformação na rede. 


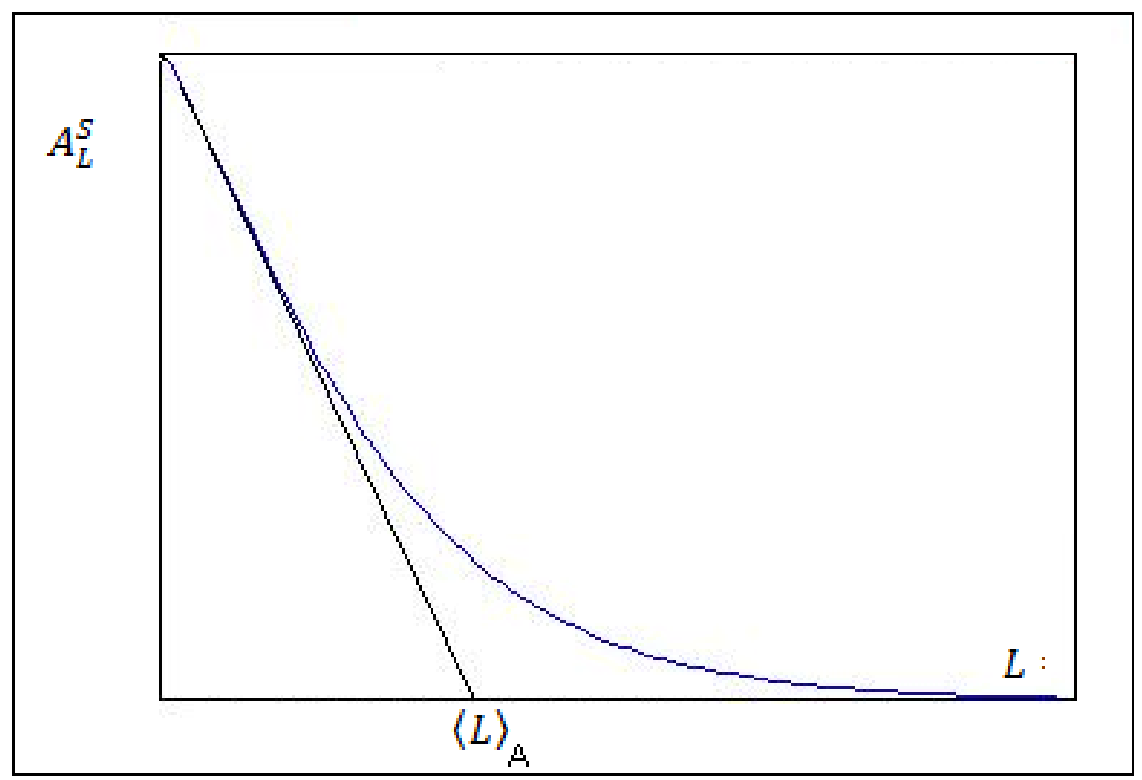

Figura 25: Gráfico dos coeficientes de Fourier $A_{L}^{S}$ em função de $L$, onde o intercepto da tangente fornece o tamanho médio do cristalito.

\subsection{Jateamento por granalhas}

Jateamento por granalhas é um processo de tratamento superficial que consiste no lançamento em alta velocidade de esferas de diversos materiais, tais como aço, cerâmica ou vidro sobre a superfície da peça a ser tratada causando um efeito análogo ao martelamento, gerando na superfície um alongamento, tendo como consequência a geração de tensão residual de compressão que proporciona aumento de resistência à fadiga, dureza e resistência à corrosão sob tensão (Bush, 1962; MIC, 2013; Schulze, 2006).

A utilização do termo jateamento por granalhas é universalmente aceito e decorre da intenção de caracterizar que não se trata de um simples jateamento, mas de um processo preciso, decorrente de uma série de fatores, o que o torna rigorosamente controlável e repetível (Camargo, 2007). 


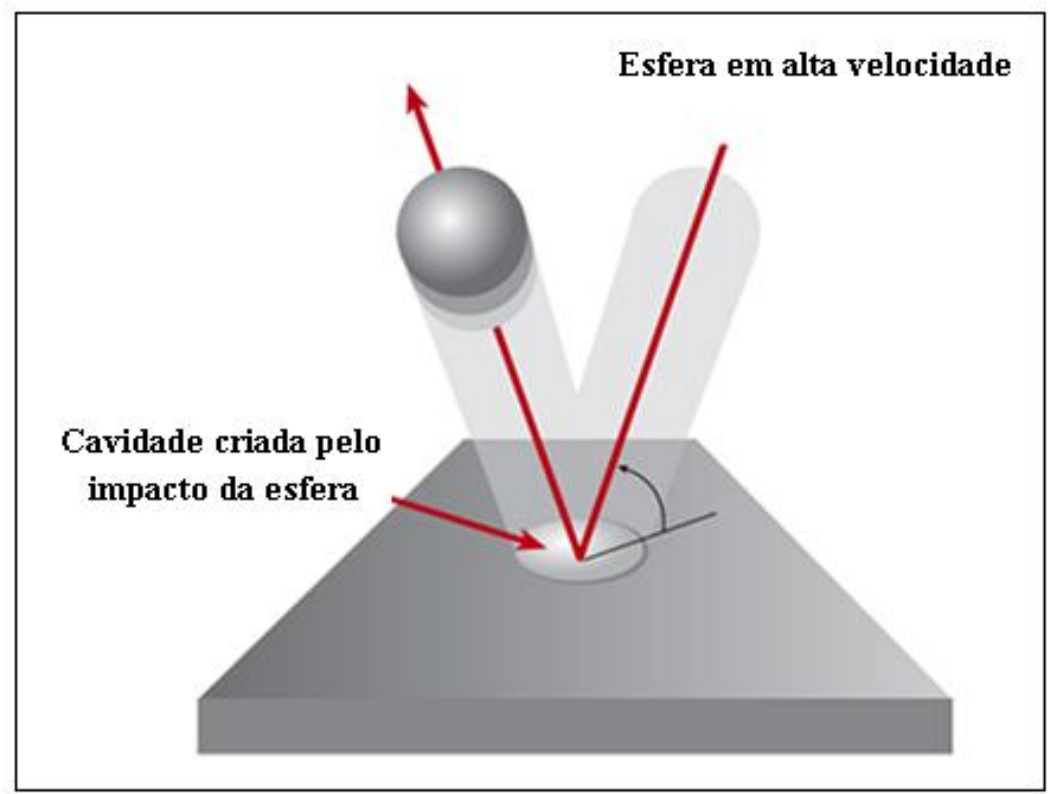

Figura 26: Demonstração do impacto da esfera sobre uma superfície (MIC, 2013)

O processo de jateamento por granalhas é largamente empregado e tem por característica a uniformização de tensões nas camadas superficiais, aumentando a resistência à fadiga, e eliminando porosidades além da obtenção de rugosidades controladas para criar interfaces, reter lubrificação e fixar desmoldantes, etc. (Torres e Voorwald, 2002; Guagliano e Vergani, 2004; Wang et al., 1998).

E. G. Herbert em 1927 publicou um trabalho sobre o jateamento por granalhas, cujo foco era sobre o aumento da dureza superficial, descrevendo a princípio dois métodos distintos para a aceleração das esferas. O primeiro é constituído de um sistema pressurizado, que utiliza ar comprimido para lançar as esferas sobre a superfície a ser tratada. As esferas, dispostas em um reservatório, mantida em atmosfera ambiente, posteriormente passando por uma câmara secundária onde é submetida à pressão e controlada por uma válvula cuja pressão interna é mantida equalizada com a pressão utilizada no bico de jateamento. A liberação das esferas para a linha de pressão, é controlada pela válvula situada na parte inferior da câmara secundária. Após o jateamento, as esferas são recolhidas no fundo da câmara de jateamento por uma esteira que as transporta de volta para o reservatório de esferas, o esquema simplificado desse processo pode ser visto na figura 27 (Poloar, 2016). 


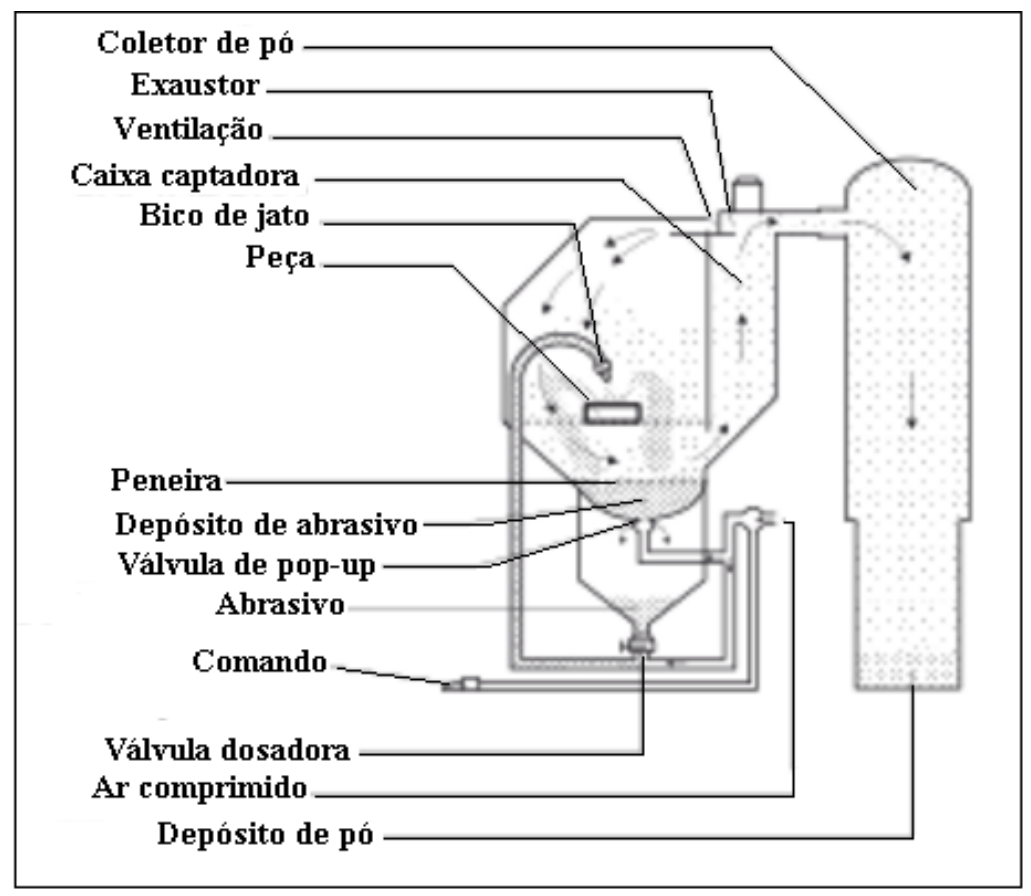

Figura 27: Sistema de jateamento pressurizado (Poloar, 2016).

O segundo processo utiliza a força centrífuga por meio de turbinas, alimentadas pelo centro da roda e as granalhas são lançadas pelas pás. Em geral, possuem sistemas automatizados para garantir melhores condições de cobertura, além de conferir melhor precisão com a possibilidade de jateamento de peças de geometria complexa e possibilitar o jateamento em peças de grandes dimensões, mostrado na figura 28 (Rosler, 2016). 


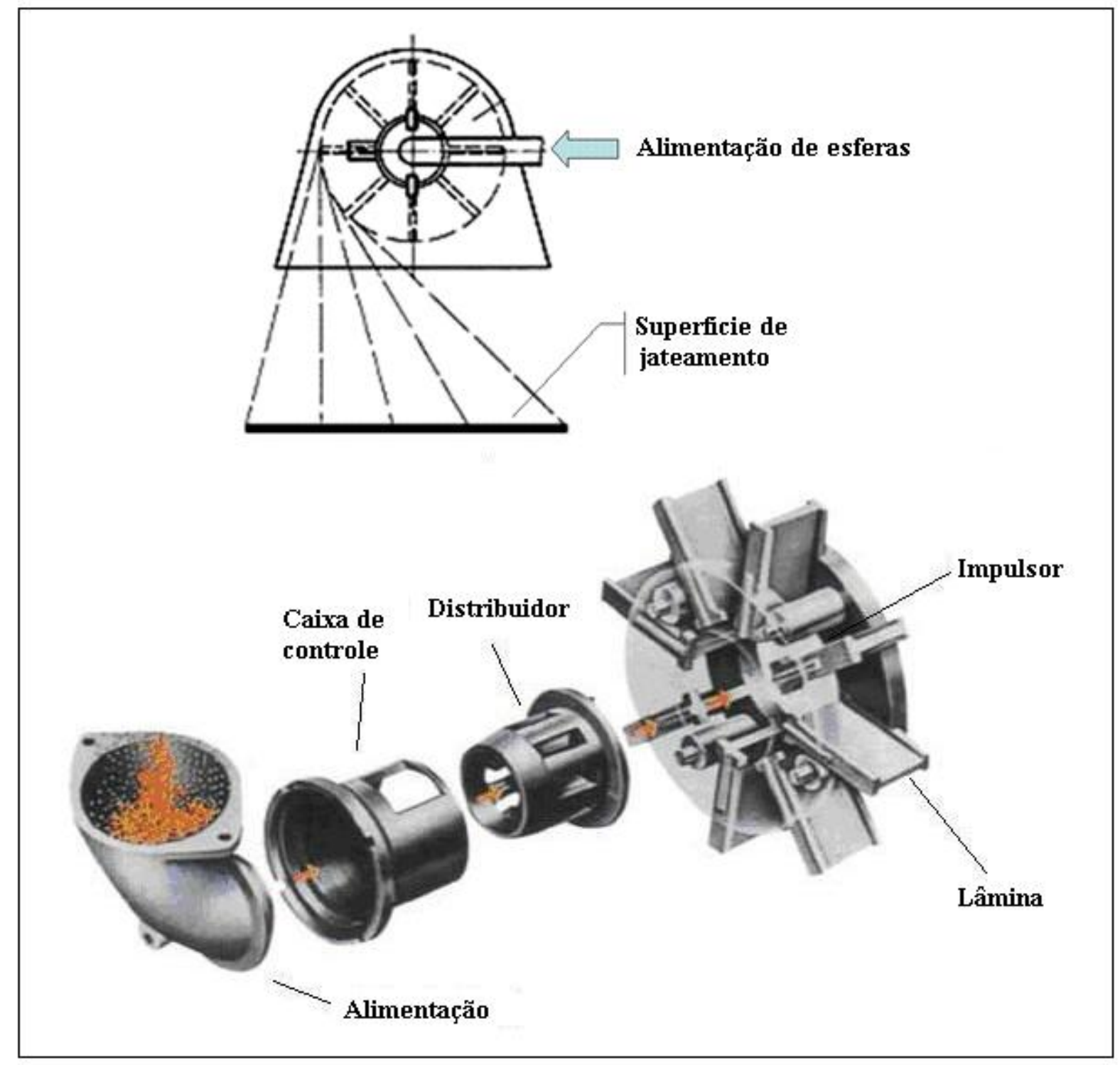

Figura 28: Sistema de jateamento centrífugo (Rosler, 2016).

Em termos práticos, as modificações na superfície induzidas pelo processo de jateamento por granalhas são a superfície rugosa, o aumento da dureza nas camadas superficiais e o perfil característico de tensão residual compressiva. Especificamente, a melhor condição do jateamento por granalhas para aumentar a resistência à fadiga depende de variáveis como o aumento das tensões residuais induzidas durante o processo; as condições de superfície criadas e a possibilidade do campo de tensões residuais compressivas (Torres e Voorwald, 2002).

De maneira geral, as tensões residuais compressivas, localizadas na superfície, são benéficas, pois retardam ou impedem a abertura e o avanço de trincas de fadiga (Song e Wen,1999). 
Após o impacto, o material é deformado plasticamente na região superficial, tendendo a alongar-se. Esta tendência ao alongamento é impedida pela parte inferior, que se deforma apenas elasticamente, gerando tensões de compressão nas camadas afetadas plasticamente (Diepart, 1994), conforme demonstrado na figura 29:

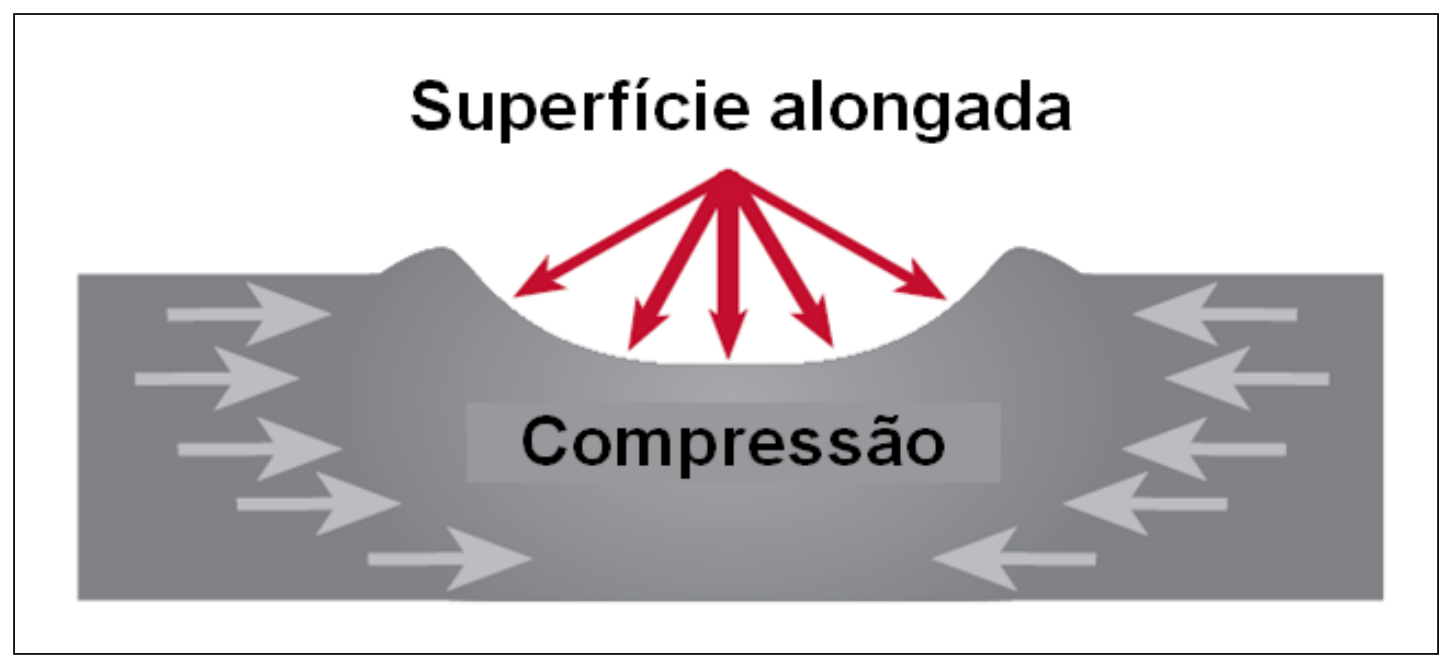

Figura 29: Distribuição de tensões após a aplicação do jateamento por granalhas (MIC, 2013)

A figura 30 apresenta um perfil típico de tensões induzidas pelo processo de jateamento por granalhas (Torres e Voorwald, 2002). 


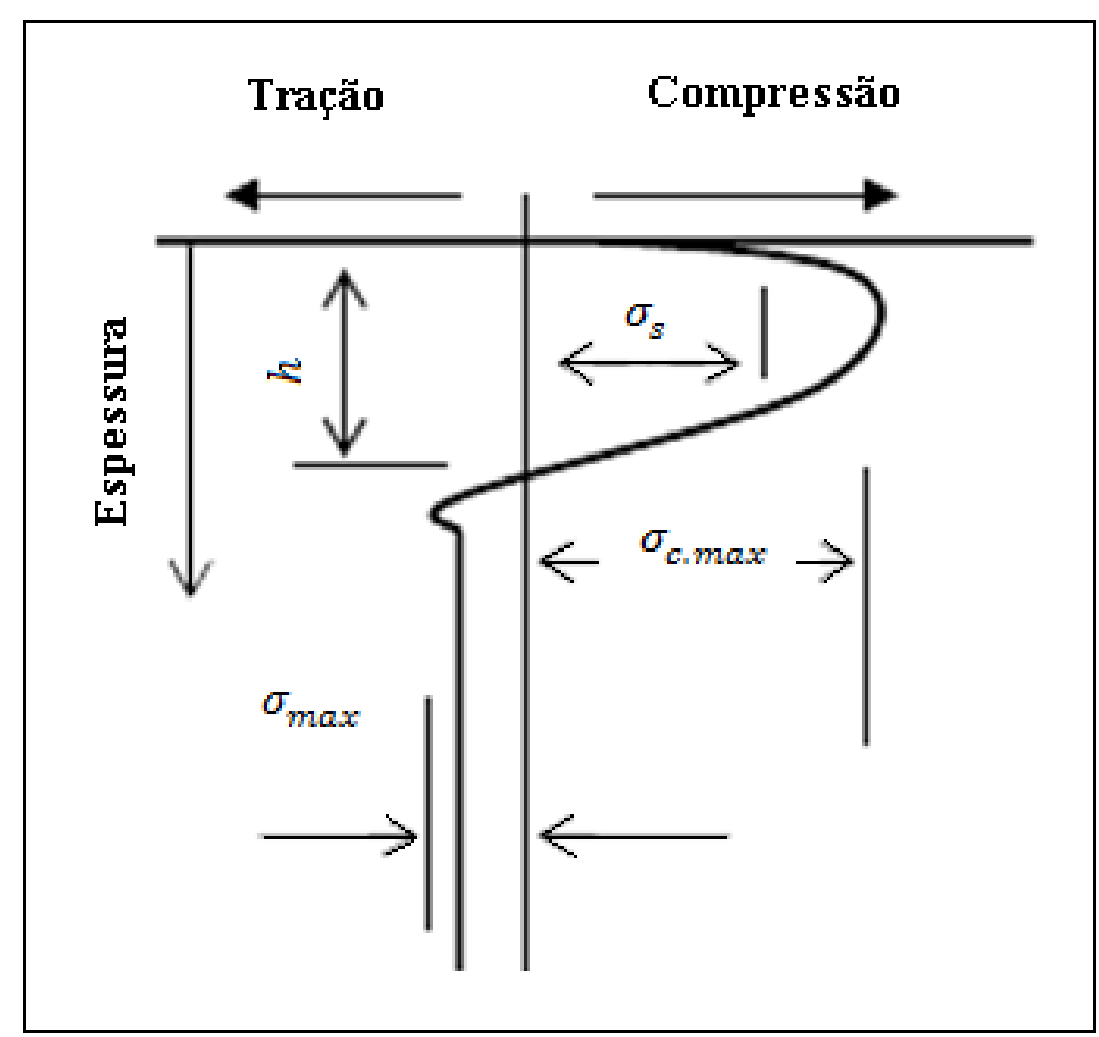

Figura 30: Perfil típico de tensões residuais (Torres e Voorwald, 2002).

Onde $\sigma_{s}$ é a tensão superficial, $\sigma_{\max }$ é a tensão máxima de tração; $\sigma_{c . m a x}$ é a tensão máxima de compressão e $h$ é a profundidade da região plástica.

Os parâmetros que influenciam na eficiência do processo de jateamento por granalhas podem ser divididos em três diferentes classes, cada uma delas associada às condições experimentais específicas:

1) Parâmetros do material: geometria e propriedades mecânicas.

2) Parâmetros de fluxo: propriedades da esfera (tipo, tamanho, material, massa específica, dureza, etc.), velocidade, ângulo de impacto, duração e distância do jateamento ao material tratado.

3) Parâmetros de contato: coeficiente de fricção e o coeficiente de restituição, que dependem da razão entre a dureza do material tratado e da esfera usada.

Entre as variáveis do processo é citado a superfície de cobertura, definida pela porcentagem de uma determinada área atingida pelas esferas, cuja relação entre cobertura e o número de ciclos de exposição pode ser expresso pela equação 103: (Torres e Voorwald, 2002):

$$
C_{n=1}-\left(1-C_{1}\right)^{n}
$$


Onde $C_{1}$ é a porcentagem de cobertura (decimal) após o $1^{\circ}$ ciclo (passe), $C_{n}$ é a porcentagem de cobertura (decimal) após $\mathrm{n}$ ciclos, onde $n$ é o número de ciclos do tratamento. Embora o valor limite para a cobertura seja de $100 \%$, na prática, devido às dificuldades de mensuração, adota-se o valor de $98 \%$ como cobertura total.

O controle da intensidade do jateamento por granalhas é realizado com a utilização das placas de Almen, produzidas em aço SAE 1070, que são colocadas ao lado do material tratado, recebendo o mesmo tratamento da peça submetida ao processo (Almen, 1963). O impacto das esferas induz tensões residuais nas placas, que se deformam, formando um pequeno arco. O valor da medida da flecha produzida na placa de Almen é comparado com uma tabela na qual se obtém a intensidade Almen, que é uma referência utilizada no controle do processo e seu valor torna-se apropriado para ajustar diversos parâmetros envolvidos.

Existem três padrões de placa Almen no uso corrente: N, A e C. A diferença de cada uma está na sua espessura. As relações das espessuras aproximadas entre elas são: $3 N=A=0,3 C$. $A$ especificação da intensidade Almen deve incluir tanto a deformação ocorrida na placa como o tipo de placa usada (Torres e Voorwald, 2002; Camargo, 2007).

O processo de jateamento por granalhas atinge uma situação de saturação, quando, a partir de certo tempo, a intensidade do jateamento pouco ou nada afeta a deformação causada na placa Almen. Esse ponto de saturação praticamente coincide com uma cobertura de $98 \%$.

Em algumas operações são exigidas coberturas de $150 \%$ ou $200 \%$, o que nada mais é do que utilizar tempos iguais a $1,5 \mathrm{t}$ ou $2 \mathrm{t}$ respectivamente (Torres $\mathrm{e}$ Voorwald, 2002).

Outro fator importante a se considerar no processo do jateamento por granalhas é o controle das esferas, sendo as mais utilizadas as de ferro fundido, que possuem uma dureza que varia de $58 \mathrm{HCR}$ a $68 \mathrm{HRC}$. Outros tipos são as de aço fundido com dureza entre $40 \mathrm{HRC}$ a $50 \mathrm{HRC}$ e as esferas de vidro e cerâmica, que são normalmente utilizadas para materiais que não podem ser contaminados pelo jateamento de partículas esféricas de aço ou ferro fundido. A dureza está entre $46 \mathrm{HRC}$ a $50 \mathrm{HRC}$ (vidro) e $58 \mathrm{HRC}$ a $63 \mathrm{HRC}$ (cerâmica), podendo ser usadas em processos úmidos e secos. 
O tamanho das esferas normalmente abrange um campo de $0,18 \mathrm{~mm}$ a 2,4 mm de diâmetro (Camargo, 2007).

As variações na dureza da esfera usada não afetam a intensidade do jateamento por granalhas, desde que sejam mais duras do que o elemento que receba o tratamento. Por outro lado, se a dureza do material a ser tratado for maior do que a da esfera, então pode haver uma diminuição na intensidade (Cao et al., 1995).

O aumento da velocidade das esferas faz com que aumente a intensidade do jateamento por granalhas. Porém o controle da velocidade é um fator necessário a fim de evitar o desgaste e/ou a quebra das esferas usadas no processo (Torres e Voorwald, 2002), além de proporcionar efeitos indesejáveis no resultado final na superfície da amostra.

O ângulo de impacto, por definição, é um ângulo de $90^{\circ}$ ou menor entre a superfície da peça tratada e a direção da rajada. Se o formato da peça não permitir um ângulo adequado de impacto, este deverá ser compensado, para a obtenção da intensidade desejada, através da variação de outros fatores, como o tamanho da esfera ou sua velocidade. Além disso, a distância entre o bico ejetor e a superfície da peça também exerce influência na intensidade do jateamento por granalhas. Quanto maior for à distância, menor serão a intensidade e a cobertura obtidas.

Um fator de grande importância no processo de jateamento por granalhas é a qualidade das esferas, pois conforme o uso constante, elas são danificadas e proporcionam perfis não aceitáveis, tornando o processo ineficiente e causando danos à superfície da peça. A figura 31 mostra exemplos de perfis aceitáveis e não aceitáveis das esferas:

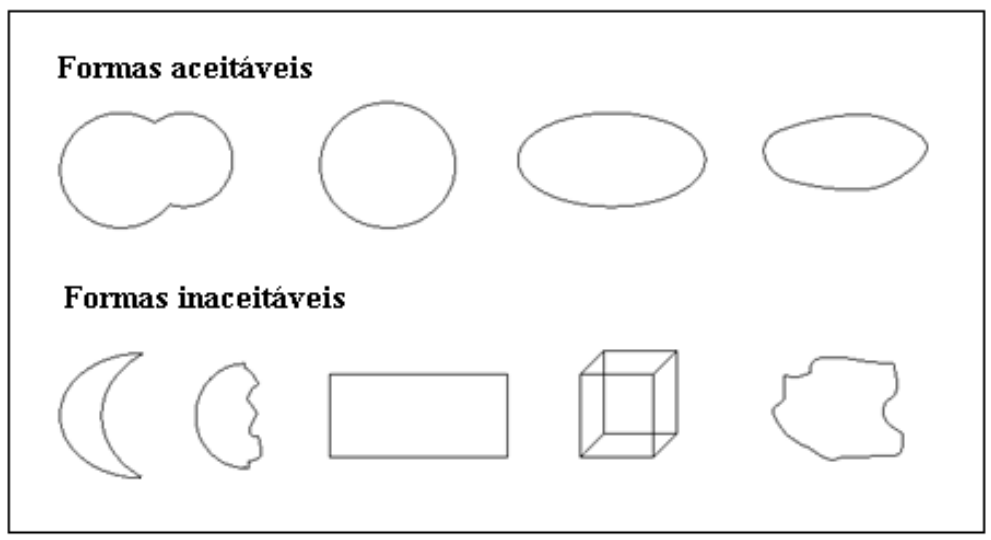

Figura 31: Padrão de formas para jateamento (MIC, 2013). 


\subsection{Tensão residual}

A tensão residual pode ser definida como qualquer tensão remanescente no volume de um material depois de cessada a aplicação de qualquer carga externa, (Almen e Back, 1963; Wulpi, 1985; James e Lu, 1996; Gurova at al., 2006).

Diferentemente da tensão aplicada externamente ao corpo cujo efeito pode ser facilmente visualizado, medido e calculado, a tensão residual no material dificilmente pode ser visualizada. A sua medição exige o uso de técnicas especiais e o cálculo ainda tem grau relativo de precisão. Um grão individual ou cristal em um corpo metálico reage à tensão aplicada seja ela externa ou interna ao corpo e mesmo com toda dificuldade de medição da tensão residual, ela deveria ser considerada durante a fase de projeto de um componente ou em análise de falha (Perini, 2008). Existem inúmeros processos cujo único propósito é induzir tensões residuais compressivas e dentre os principais processos, destacam-se o roleteamento, o jateamento por granalhas e o jateamento por laser e. No universo de processos que podem produzir tensões residuais de tração, as ocorrências estão na solda elétrica, processos de usinagem em geral, tratamentos térmicos e termoquímicos, a fundição e a conformação a frio e a quente (Wulpi, 1985).

A tensão residual é descrita em termos de tensões de tração e de compressão. Por convenção, a tensão de tração recebe o sinal positivo $(+\sigma)$ e a de compressão recebe o sinal negativo $(-\sigma)$. Para que ocorra o aparecimento da tensão residual, é necessário que o componente sofra alguma deformação plástica. Por exemplo, supondo que a barra ilustrada na figura 34a está apoiada sobre dois pontos fixos, desprezando-se a ação da gravidade e assumindo que ela esteja livre de qualquer tensão $(\sigma=0)$, aplica-se então uma força $(F)$ de igual valor em cada extremidade. Em qualquer ponto situado entre os apoios, a tensão nas fibras externas é constante, sendo de tração $(+\sigma)$ na parte superior e de compressão $(-\sigma)$ na parte inferior. No diagrama de tensão, à direita da figura 32a, é possível ver como a tensão varia ao longo da seção A-A', ela atinge seu valor máximo nas superfícies externas, decaindo a zero na linha neutra. Nessa situação, como a força aplicada à barra não foi suficiente para exceder o limite elástico do material, a barra retornara a sua condição inicial $(\sigma=0)$, assim que a força $(F)$ seja retirada. Imagine agora que 0 valor da força $(F)$ foi elevado até que a tensão na barra ultrapasse o limite de elasticidade do material, não somente nas fibras mais externas, mas a uma 
profundidade bem razoável (Perini, 2008). Então, ocorrerá o surgimento da deformação plástica, representado na figura 32b pela região hachurada. Contudo, nas fibras, próximo ao centro da barra, o limite de elasticidade ainda não foi excedido e a deformação nesse ponto é apenas elástica. Toda tensão acima da linha neutra, tanto a elástica como a plástica, são de tração $(+\sigma)$ e todas abaixo são de compressão $(-\sigma)$. Quando a força $(F)$ é removida, figura 32c, a tensão elástica contida na barra tenta se liberar forçando a barra a se auto-endireitar (Perini, 2008). Devido à presença da deformação plástica, a ação dessas forças internas não é suficiente para reduzir as tensões à zero, mas são suficientes para inverter a direção das tensões nas regiões deformadas plasticamente. Desse modo, as regiões que durante a ação da força $(F)$ estavam tracionadas $(+\sigma)$, estão agora comprimidas $(-\sigma)$ e as que estavam comprimidas $(-\sigma)$, estão tracionadas $(+\sigma)$, (Cullity e Stock, 2001). Esse princípio da inversão das tensões é utilizado por todos os processos mecânicos para tratamento de superfícies que visam aumentar a resistência à fadiga.

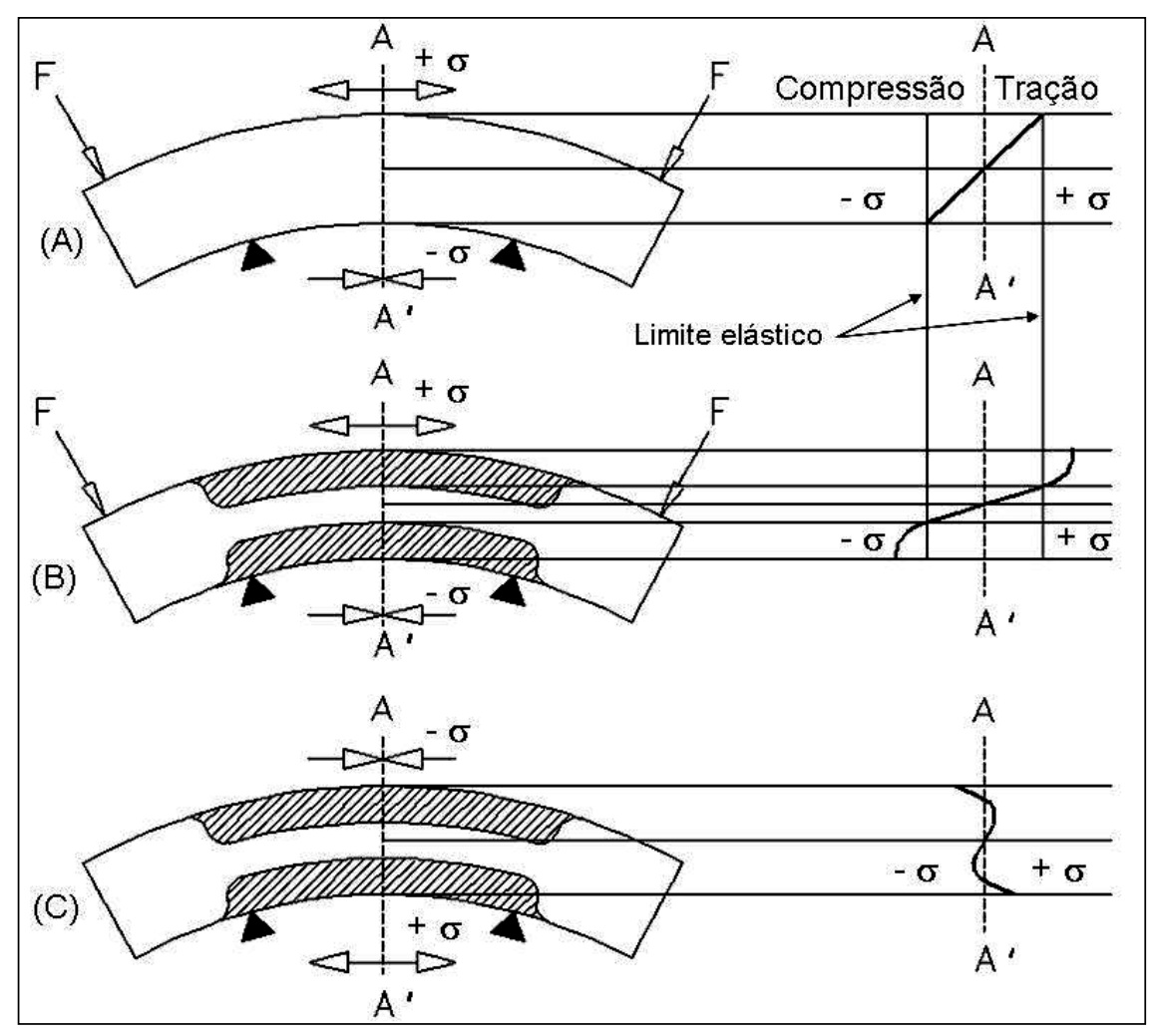

Figura 32: Tensão residual induzida pela deformação plástica (Cullity e Stock, 2001). 
A tensão residual atua em um sistema balanceado. Isso quer dizer, se uma parte do sistema sofre uma alteração, o resto do sistema se ajusta para manter o balanceamento. Esse ajuste resulta em distorções ou mudanças dimensionais no componente envolvido. A distorção é utilizada para estimar a sua magnitude e a sua direção. A tensão residual tem influência tridimensional nos corpos. Por exemplo, em um eixo, ela existe nas direções longitudinal, tangencial (também chamada de circunferencial) e radial (Perini, 2008). Em uma superfície plana, ela atua nas direções longitudinal, transversal e normal ao plano, (figura 33). Geralmente, as direções radiais e normais ao plano são desprezadas devido a sua baixa influência em causar danos ou benefícios (Wulpi, 1985).

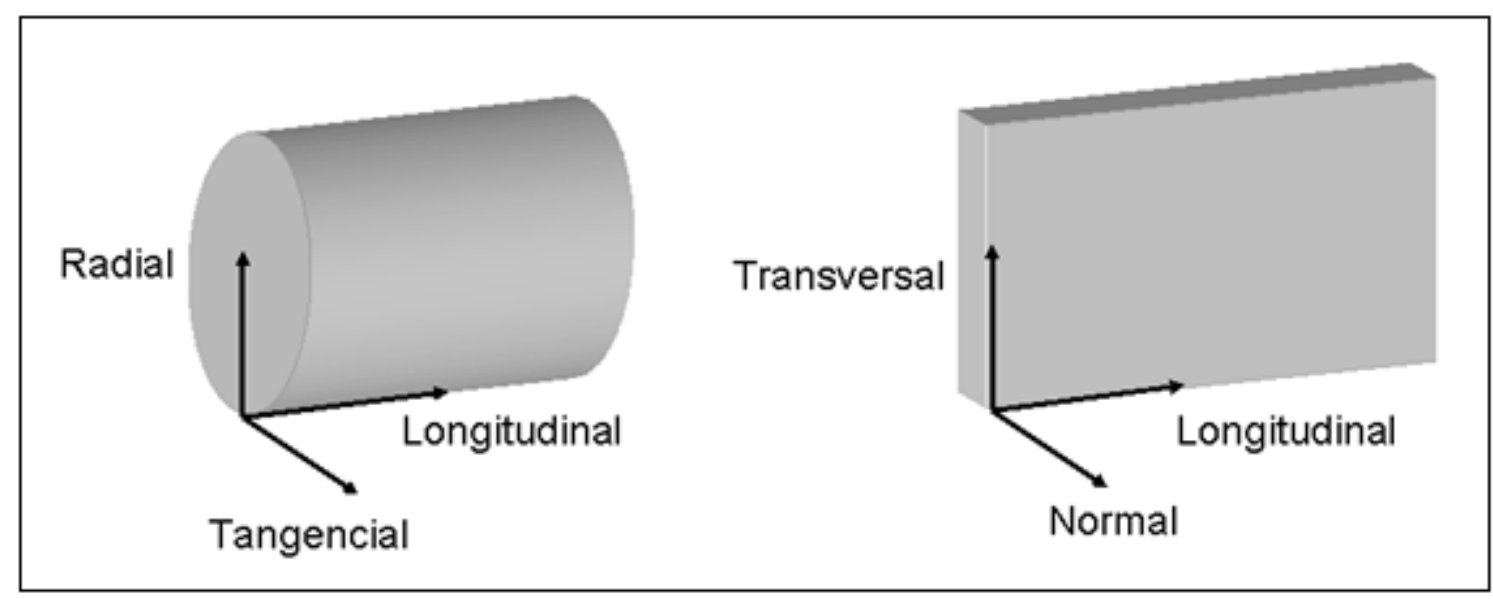

Figura 33: Nomenclatura das direções das tensões em eixos e chapas (Wulpi, 1985).

A tensão residual também pode ser classificada por três escalas de magnitude: macro, intergranular e atômica.

Macro: nessa escala está compreendida toda seção transversal da peça. Por exemplo, se existir tensão residual compressiva em uma área próxima a superfície, então, a área próxima ao centro haverá tensão residual de tração, para que haja um balanceamento de forças, (Wulpi, 1985).

Intergranular: essa escala é utilizada para tratar da tensão residual em um grão individual ou grupo de grãos. Os grãos são afetados pelo campo de atuação da macrotensão no qual estão localizados, mas cada grão está orientado aleatoriamente e seus micro-defeitos diferem dos grãos da vizinhança.

Atômico: cada grão do material é composto por uma rede tridimensional de átomos, que é utilizada como um tensor para o cálculo da tensão residual. A 
distorção nessa rede não pode ser medida individualmente, então ela é tratada estatisticamente pela média (Wulpi, 1985).

\subsubsection{Medidas de tensão residual por raios-x}

As medidas de tensão residual por raios-x são baseadas na alteração das distâncias interplanares do material cristalino, medidas pela posição angular dos feixes de raios-x difratados, sendo que a mudança fracional da distância interplanar é relacionada com a deformação a partir da qual a tensão pode ser calculada (Regone, 2000).

$\mathrm{Na}$ análise, a tensão pode ser medida em qualquer direção escolhida. Para realizar as medidas de tensão residual do material, o método da difração de raios-X apresenta a vantagem de ser um método rápido e não destrutivo.

A primeira medida de tensão residual utilizando a difração de raios- $x$ foi realizada em 1925, sendo os resultados gravados em películas fotográficas. Em 1953 foi feito um grande avanço quando se mostrou que a tensão interna poderia ser medida rapidamente por um difratômetro de raios-x onde as medidas são gravadas eletronicamente (Cullity,1978).

As macrotensões são calculadas quando a deformação elástica gera uma mudança na distância interplanar. Se o limite elástico exceder, a rede do cristal irá modificar-se formando as microtensões, mas não será um aumento adicional na tensão macroscópica. Ainda que as tensões internas resultem de uma deformação plástica não uniforme, todas as macrotensões internas permanecem quando o material atinge a deformação plástica (Regone, 2000).

Em um material policristalino (metal ou cerâmico) livre de tensão, o espaçamento interplanar $d_{0}$ para uma determinada família de planos não varia com a orientação desses planos (figura 34). Se o material é submetido a uma tensão, durante a deformação elástica, o espaçamento interplanar varia de acordo com a orientação dos planos, relativa à direção da tensão. A distância interplanar aumentará para os planos perpendiculares à direção da tensão aplicada e diminuirá para os planos paralelos a essa tensão, (figura 35). A tensão em um cristal pode ser definida pela variação do espaçamento interplanar $d-d_{0}$, medida pela posição dos picos de difração (François et al., 1996). 


$$
\varepsilon=\frac{d-d_{0}}{d_{0}}=\frac{\Delta d}{d_{0}}=\left(\theta-\theta_{0}\right) \operatorname{cotg} \theta_{0}=-\Delta \theta \operatorname{cotg} \theta_{0}
$$

Onde $\theta$ é a posição do pico de difração para o espaçamento interplanar $d$ (material sobre tensão) e $\theta_{0}$ é a posição correspondente para $d_{0}$ (material livre de tensão).

A rede cristalina (os planos cristalográficos) é utilizada como extensômetro que pode ser lido através de experimentos de difração. Como em qualquer método de extensometria a tensão pode ser calculada a partir da medição da deformação em varias direções mais a constante elástica do material (François et al., 1996).

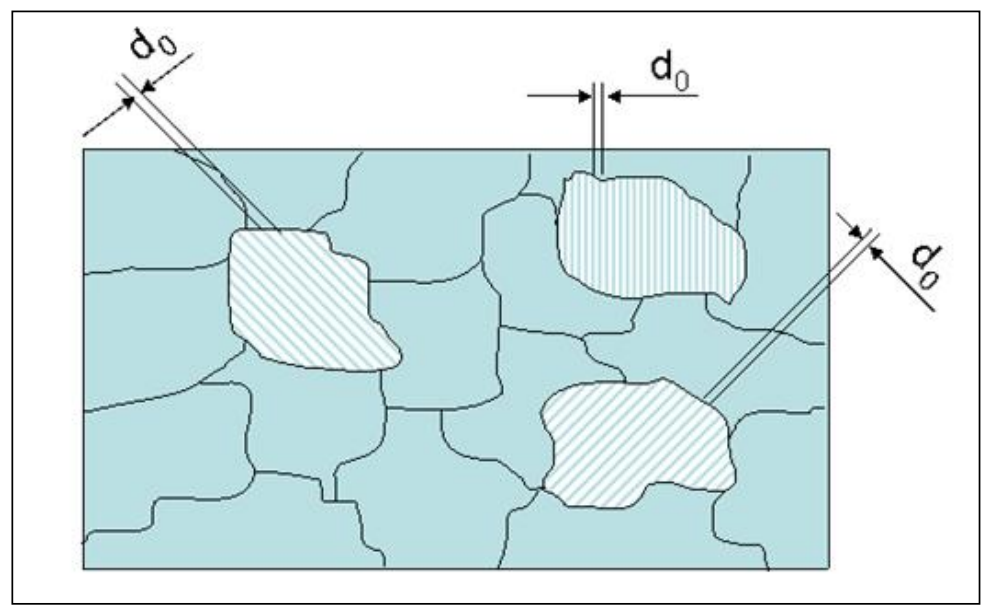

Figura 34: O espaçamento interplanar $\boldsymbol{d}_{\mathbf{0}}$ é o mesmo para todas as famílias de planos, em qualquer direção, quando o material está livre de tensões (François et al., 1996).

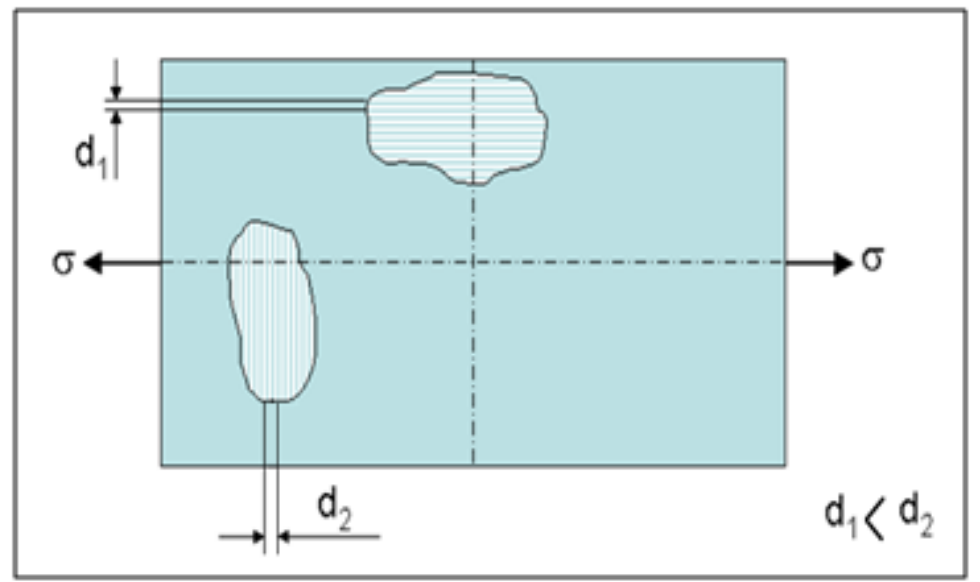

Figura 35: O espaçamento interplanar varia em todas as direções na presença de uma tensão (François et al., 1996). 
O cálculo da tensão residual utilizando a difratometria de raios-x baseia-se na determinação de duas componentes de deformação $\varepsilon_{\phi \psi 1}$ e $\varepsilon_{\phi \psi 2}$ nas direções determinadas pelos ângulos $\phi$ e $\psi$ de um sistema de coordenadas esféricas, (Assis at al, 2002; Perini, 2008). Definindo a relação entre o plano da tensão e a distorção da superfície da amostra, pode-se calcular a relação da tensão para um dado grau de inclinação da superfície da amostra. A inclinação do plano de difração e o plano da amostra são definidos como $\psi$. Tomando um ponto qualquer na superfície da amostra como foco da medição, pode-se definir $\sigma_{1}, \sigma_{2}$ e $\sigma_{3}$ como as tensões principais e $\varepsilon_{1}, \varepsilon_{2}$ e $\varepsilon_{3}$ como as deformações principais. Devido ao plano de tensão, o valor de $\sigma_{3}$ para o eixo Z é 0, (figura 36) (Rigaku, 2003).

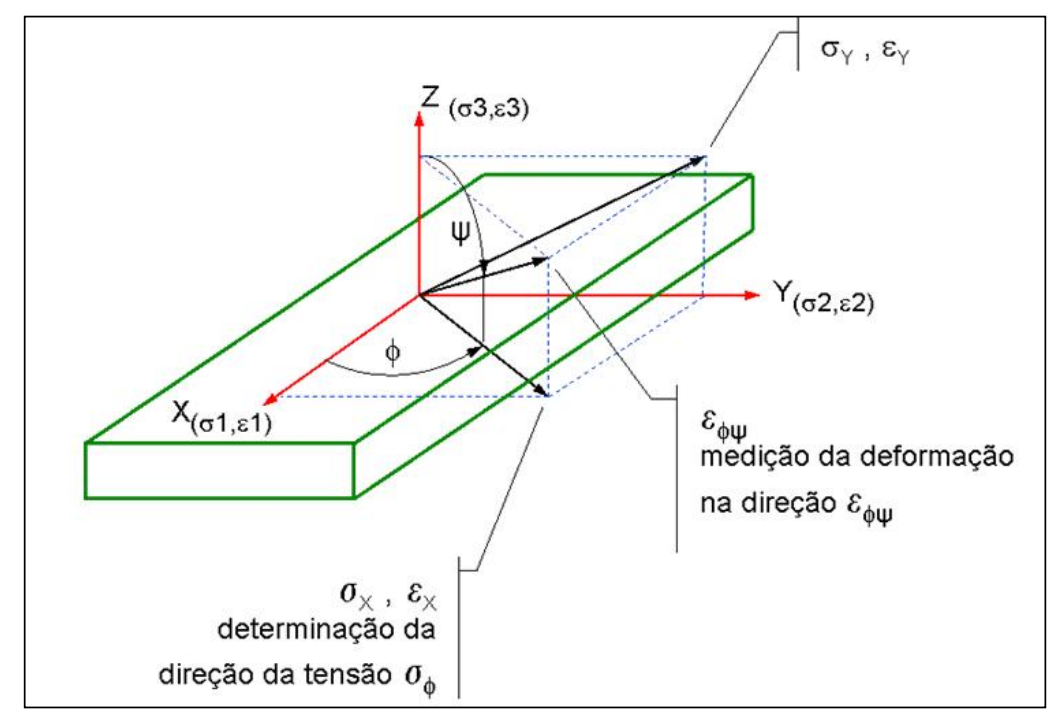

Figura 36: Direções da tensão e deformação principais (Rigaku, 2003).

A deformação $\varepsilon_{\phi \psi}$ pode ser determinada pela equação 105 da teoria da elasticidade para o estado biaxial de tensões, (Assis at al, 2002):

$$
\varepsilon_{\phi \psi}=\left(\frac{1+v}{E}\right) \sigma_{\phi} \operatorname{sen}^{2} \psi-\frac{v}{E}\left(\sigma_{1}+\sigma_{2}\right)
$$

Neste caso a diferença entre as duas componentes da deformação será:

$$
\varepsilon_{\phi \psi 2}-\varepsilon_{\phi \psi 1}=\left(\frac{1+v}{E}\right) \sigma_{\phi}\left(\operatorname{sen}^{2} \psi_{2}-\operatorname{sen}^{2} \psi_{1}\right)
$$


Onde $E$ (módulo de elasticidade) e $v$ (razão de Poisson) são as constantes elásticas do material, $\psi$ e $\phi$ são os ângulos polares e azimutais, $\sigma_{\phi}$ é a componente média da tensão, $\sigma_{1}$ e $\sigma_{2}$ as tensões principais. A componente $\sigma_{\phi}$ da equação 101 pode ser definida por:

$$
\sigma_{\phi}=\left(\frac{E}{1+v}\right) \frac{\varepsilon_{\phi \psi 2}-\varepsilon_{\phi \psi 1}}{\operatorname{sen}^{2} \psi_{2}-\operatorname{sen}^{2} \psi_{1}}
$$

Usando a lei de Bragg, a deformação $\varepsilon_{\phi \psi}$ pode ser determinada como:

$$
\varepsilon_{\phi \psi}=\frac{d_{\phi \psi}-d_{0}}{d_{0}}=-\operatorname{cotg} \theta_{0}\left(\theta_{\phi \psi}-\theta_{0}\right)
$$

Onde $d_{\phi \psi}, d_{0}$ e $\theta_{\phi \psi}, \quad \theta_{0}$ são as distâncias interplanares e os ângulos de difração para materiais com e sem tensão respectivamente. A equação final para o cálculo da componente de tensão $\sigma_{\phi}$ na direção escolhida é:

$$
\sigma_{\phi}=\frac{E}{2(1+v)} \frac{\pi}{180} \operatorname{cotg} \theta \frac{\delta(2 \theta)}{\delta\left(\operatorname{sen}^{2} \psi\right)}
$$

Para se obter resultados com maior precisão, é necessário que a medição do ângulo $\theta$ seja realizada em mais que duas posições $\psi\left(\psi_{1}, \psi_{2}, \psi_{3}, \psi_{N}\right)$. Os valores angulares de $\theta\left(\theta_{1}, \theta_{2}, \theta_{3}, \theta_{N}\right)$ correspondentes a cada ângulo $\psi_{N}$, são plotados em função de $\operatorname{sen}^{2} \psi$. O coeficiente angular de ajuste da função, $y=a x+b$.

Visto que $E, v$ e $\theta$ são valores conhecidos, formam uma constante $(k)$ :

$$
\sigma_{\phi}=-k \frac{\delta(2 \theta)}{\delta\left(\operatorname{sen}^{2} \psi\right)}
$$




\section{MATERIAIS E MÉTODOS}

\subsection{O material}

O material utilizado neste trabalho foi a liga de aço DIN 54SiCrV6 (SAE 9254+V) produzida pela Metalúrgica Gerdau S.A.,em lâminas de dimensões de 1300 $\mathrm{mm}$ de comprimento, $70 \mathrm{~mm}$ de largura e $13 \mathrm{~mm}$ de espessura e composição química de \% em massa, fornecida pelo fabricante, apresentada na tabela 8 :

Tabela 8: Composição química do material de \% de massa

\begin{tabular}{|l|l|l|l|l|l|l|l|l|l|l|l|l|l|}
\hline $\mathbf{C}$ & $\mathbf{S i}$ & $\mathbf{M n}$ & $\mathbf{P}$ & $\mathbf{S}$ & $\mathbf{C r}$ & $\mathbf{N i}$ & $\mathbf{M o}$ & $\mathbf{A l}$ & $\mathbf{C u}$ & $\mathbf{S n}$ & $\mathbf{T i}$ & $\mathbf{V}$ & $\mathbf{N b}$ \\
\hline 0,55 & 1,38 & 0,63 & 0,01 & 0,005 & 0,7 & 0,17 & 0,01 & 0,005 & 0,04 & 0,006 & 0,005 & 0,121 & 0,002 \\
\hline
\end{tabular}

Foi realizado pelo departamento de qualidade da Gerdau os ensaios de tamanho de grão e inclusões, apresentados na tabela 9:

Tabela 9: Análise microestrutural do material

\begin{tabular}{|l|c|}
\hline Tamanho de grão (ASTM E112) & 7 ASTM \\
\hline Inclusões (ASTM E45) & $\mathrm{AF}=0,5 / \mathrm{AG}=0,5 / \mathrm{BF}=0,0 / \mathrm{BG}=0,0$ \\
& $\mathrm{CF}=0,0 \mathrm{CG}=0,0 / \mathrm{DF}=0,5 / \mathrm{DG}=0,5$ \\
\hline
\end{tabular}

Os ensaios de dureza, estrutura e descarbonetação foram realizados pelo Laboratório Metalúrgico da Thyssenkrupp Bilsten Brasil e os resultados estão mostrados na tabela 10:

Tabela 10: Análise de dureza, estrutura e descarbonetação do material pela norma DIN e NBR.

\begin{tabular}{|l|c|}
\hline Dureza (DIN EN10089) & $321 \mathrm{HB}$ \\
\hline Estrutura & Perlita \\
\hline Descarbonetação (NBR 11299) & Global $(1+2+3)$ até $0,20 \mathrm{~mm}$ \\
Total $(1)$ até $0,03 \mathrm{~mm}$
\end{tabular}


Os parâmetros foram definidos em 3 condições, próximas às aplicadas na linha de produção das lâminas, sendo:

Sem tensionamento, granalha S330 (denominada TR1).

Com tensionamento, granalha S330 (denominada TR2).

Com tensionamento, granalha S390 (denominada TR3).

\subsection{Conformação do material}

Os materiais foram conformados na Thyssenkrupp Bilsten Brasil, por laminação à quente (figura 37) nas dimensões apropriadas para a utilização em suspensão veiculares por molas planas, com posterior enrolamento dos olhais nas extremidades, estampagem de furos e ressaltos e arqueamento.

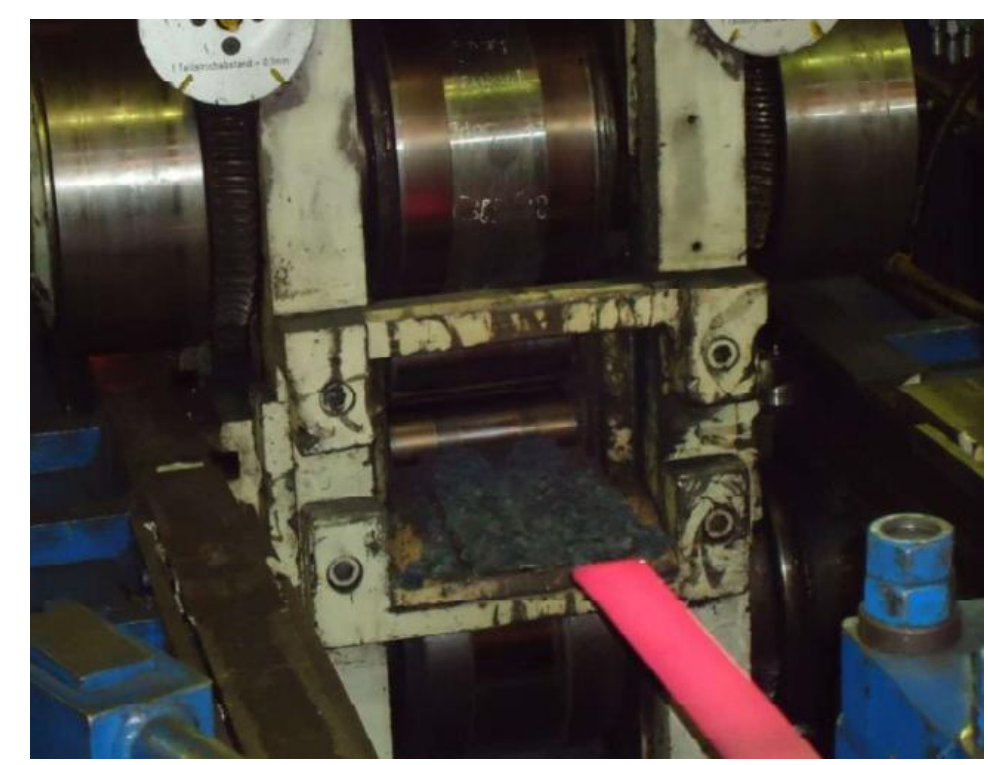

Figura 37: Conformação por laminação à quente (Thyssenkrupp Bilsten Brasil).

\subsection{Tratamento térmico}

O tratamento térmico consistiu na têmpera (aproximadamente a $920{ }^{\circ} \mathrm{C}$ ) (figura 38), e resfriamento em óleo (aproximadamente $70^{\circ} \mathrm{C}$ ) e posteriormente revenido $\left(350^{\circ} \mathrm{C} / 1\right.$ hora) (Scuracchio, 2012). 


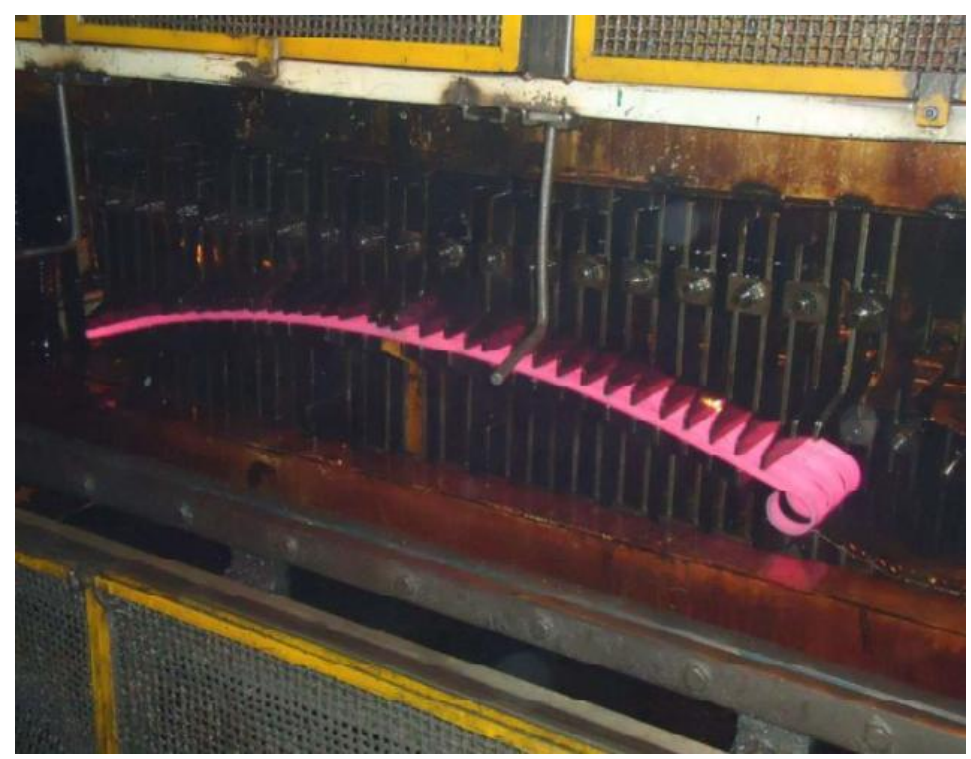

Figura 38: Tratamento térmico (Thyssenkrupp Bilsten Brasil)

\subsection{Aplicação do jateamento por granalhas.}

A definição das condições de tratamento mecânico superficial foi inicialmente distribuídas nas peças produzidas para o estudo, sendo necessárias 5 peças para o estudo de fadiga e 1 peça para os estudos de distribuição de tensão residual, tamanho médio de cristalito e microdeformação da rede cristalina. No total de 18 peças produzidas obtém-se 3 condições distintas em variáveis de processo, conforme os resultados obtidos durante a fase experimental em tamanho de granalhas e tensionamento das amostras. O tensionamento para a aplicação do jateamento por granalhas consiste no arqueamento da lâmina em 70 \% da tensão de escoamento da amostra.

Os materiais foram encaminhados para a empresa IKK do Brasil/WAbrasives para a aplicação do jateamento por granalhas. O procedimento foi realizado em um equipamento modelo Spinner Hanger, fabricado pela Metalcym-Metalblast Equipamentos e Máquinas S.A. (figura 39) com fluxo abrasivo de $79 \mathrm{~kg} / \mathrm{min}$ em 4 passagens em tempo total de 2 minutos de exposição e tamanho de granalhas S330 $(0,8382 \mathrm{~mm}$ de diâmetro) e $\mathrm{S} 390(0,9906 \mathrm{~mm}$ de diâmetro) e cobertura de $100 \%$.

Amostra não tensionada: S330.

Amostras tensionadas: S330 e S390. 
A preparação da amostras tensionadas foi realizada na Thyssenkrupp Bilsten do Brasil.

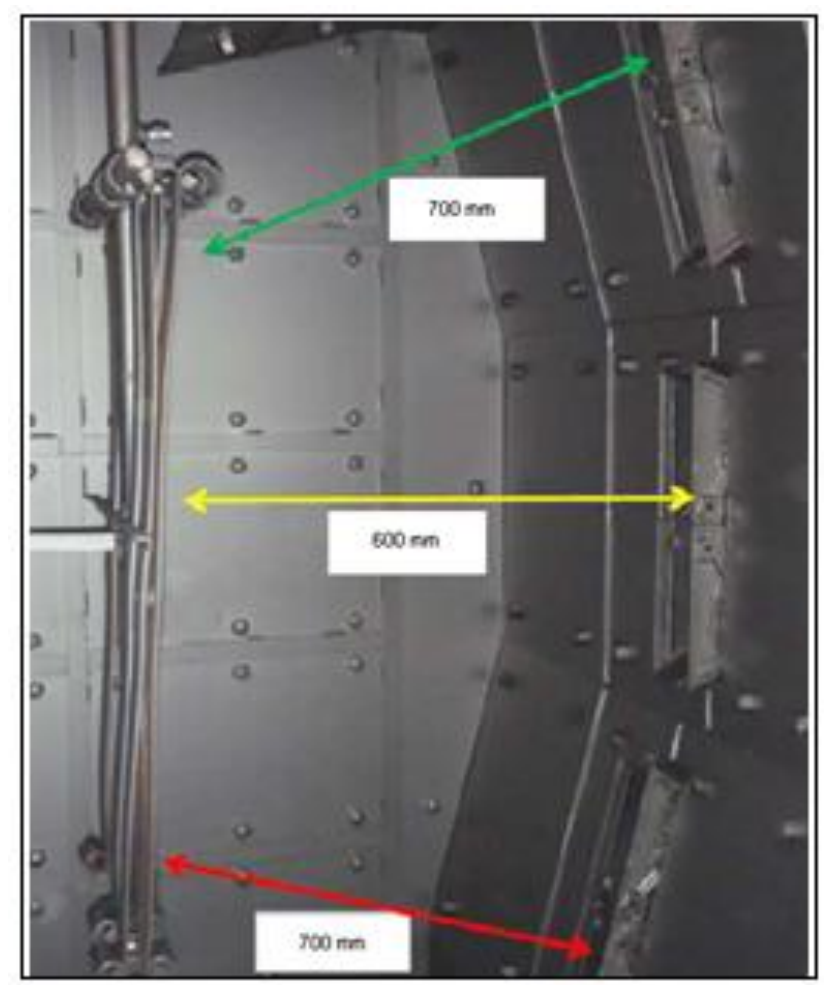

Figura 39: Aplicação do jateamento por granalhas (IKK do Brasil)

\subsection{Análise de tensão residual em profundidade ao longo da espessura}

A avaliação da distribuição da tensão residual ao longo da espessura do material foi realizada após a aplicação do jateamento por granalhas. Inicialmente o material foi cortado adequadamente às dimensões do porta amostras do difratômetro, sendo, em $15 \mathrm{~cm}$ de comprimento longitudinal e mantendo as dimensões de espessura e largura.

Como o desbaste mecânico pode ocasionar alterações nos valores de tensão residual, o método de remoção foi o de ataque químico, sendo utilizado $\mathrm{H}_{3} \mathrm{NO}_{4}$ diluído em $50 \%$ em $\mathrm{H}_{2} \mathrm{O}$ destilada. A medição da camada removida foi realizada com auxilio de um micrômetro.

Para a realização das análises de tensão residual foi utilizada um difratômetro de raios-x da marca Rigaku, modelo Rint 2000 (figura 40) com tubo de anodo de cromo em tensão de $40 \mathrm{kV}$ e corrente de $20 \mathrm{~mA}$. Para aplicação do método $\operatorname{sen}^{2} \psi$ foi utilizado a variação em $\psi$ de $-50^{\circ}$ a $+50^{\circ}$ com intervalos de $10^{\circ}$. A varredura em 
ângulo $2 \theta$ foi de $153,7^{\circ}$ a $157,5^{\circ}$ em referência ao plano (211), passo de $0,2^{\circ}$ em tempo fixo de 6 segundos.

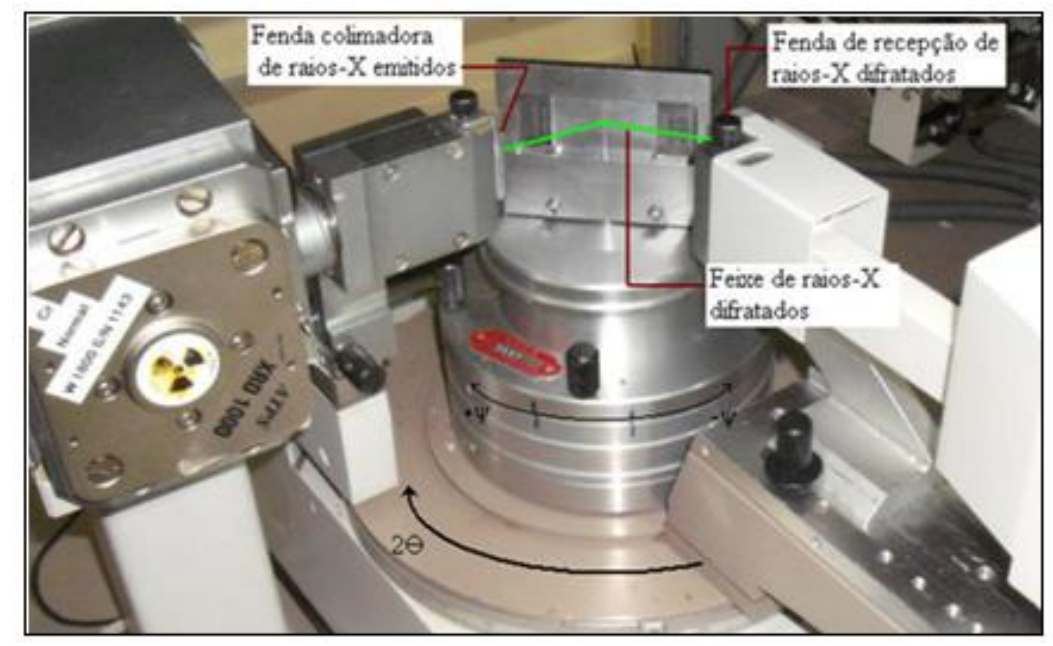

Figura 40: Difratômetro utilizado nas medidas de tensão residual (IPEN-CNEN/SP).

\subsection{Medidas de microdeformação e tamanho médio de cristalito}

A determinação da porcentagem da microdeformação na rede cristalina e do tamanho médio de cristalito teve por base a análise do perfil dos picos proporcionado pela difração de raios-x.

As medidas de difração de raios- $x$ foram realizadas por um difratômetro de raios-x da Rigaku, modelo Multiflex (figura 41) em condições de 40 kV de tensão, 20 $\mathrm{mA}$ de corrente, passo de $0,02^{\circ}$ em tempo de contagem de 6 segundos.

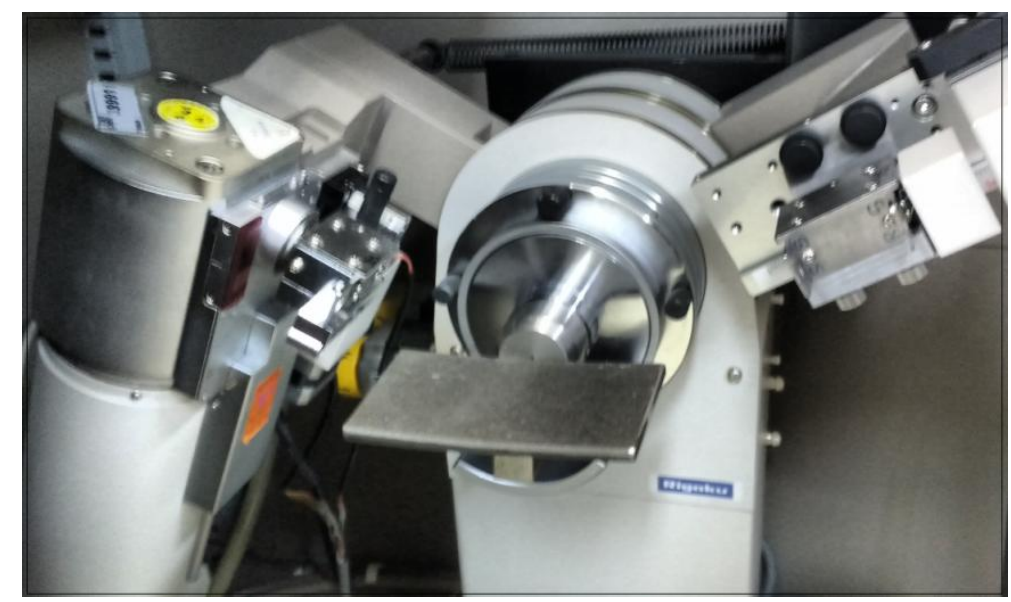

Figura 41: Difratômetro utilizado nas medidas de microdeformação da rede e tamanho médio de cristalito (IPEN-CNEN/SP). 
O perfil da difração de raios-x foram analisados pelo software GSAS (Larson \& VonDreele, 2004).

Pela posição e alargamento do pico determinaram-se a microdeformação da rede cristalina e o tamanho de cristalito pelos métodos de Williamson-Hall, WarrenAverbach e Single Line (Delhez et al, 1982) utilizando o software Winfit V1.2.

\subsection{Determinação do fator de concentração de tensão}

Os valores do fator de concentração de tensão foram determinados por meio da medição do diâmetro provocado pela indentação da granalha sobre a superfície da amostra em relação à profundidade média de penetração das granalhas. As medidas dos diâmetros foram obtidas por microscopia eletrônica de varredura, com a utilização do equipamento Phillips, modelo XL30. A profundidade média será obtida com a utilização do rugosímetro da Mitutoyo Sul Americana Ltda., modelo SJ301 pela norma ISO 1997.

O método para medição do fator de concentração de tensão (Kt) proposto por Li et al. (1992).

\subsection{Caracterização da seção transversal}

Esta caracterização teve por objetivo a avaliação da camada deformada pela aplicação do jateamento por granalhas com o objetivo de mensurar e avaliar a camada deformada possibilitando comparar a sua morfologia com os resultados das medições de tensão residual. As etapas para a preparação da amostra foram o corte, embutimento, lixamento e polimento da superfície normal à lâmina.

Para a realização do ataque químico foi utilizado Nital 5\% 


\subsection{Ensaio de fadiga}

Os ensaios de fadiga foram realizados na empresa Thyssenkrupp Bilstein Brasil com a frequência de $1 \mathrm{~Hz}$. As lâminas ensaiadas em fadiga tiveram o teste com frequência e amplitude constante cujos parâmetros estão mostradas na figura 42:

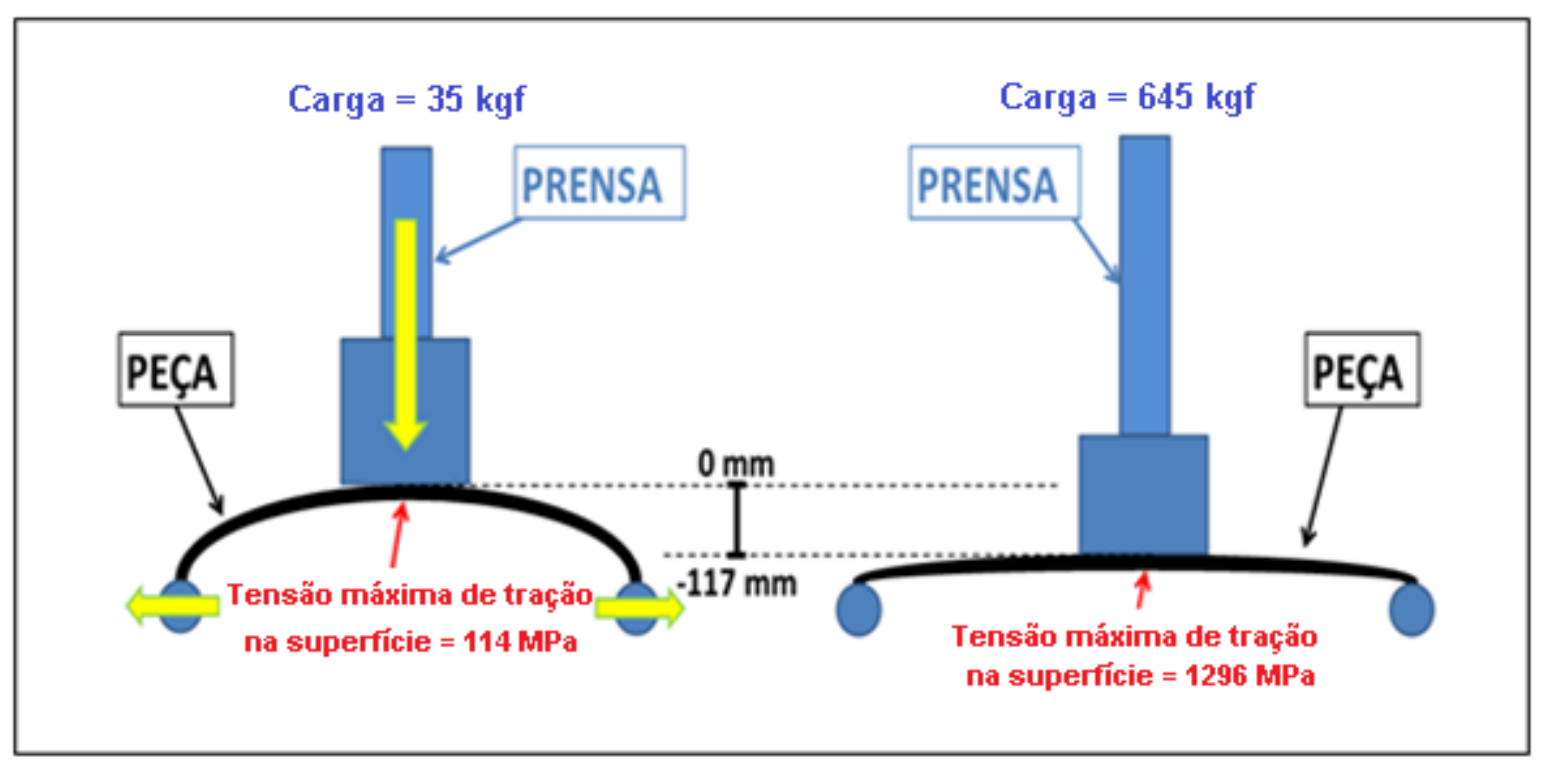

Figura 42: Parâmetros utilizados nos ensaios de fadiga (Scuracchio, 2012)

Estes parâmetros foram definidos pela montadora, e representam a carga mínima (rebound), carga nominal (design load), e carga máxima (jounce) em que a mola estará sujeita durante seu uso, e seus respectivos deslocamentos e tensões máximas. 


\section{RESULTADOS E DISCUSSÃO}

\subsection{Distribuição da tensão residual}

Os gráficos apresentados na figura 43 mostram a distribuição da tensão residual ao longo da espessura nas condições de jateamento, comparando o comportamento nas situações de tensionamento e diferentes granalhas. Os dados de tensão residual em profundidade foram ajustados com função polinomial de grau 6 e os respectivos valores se encontram na tabela 11:

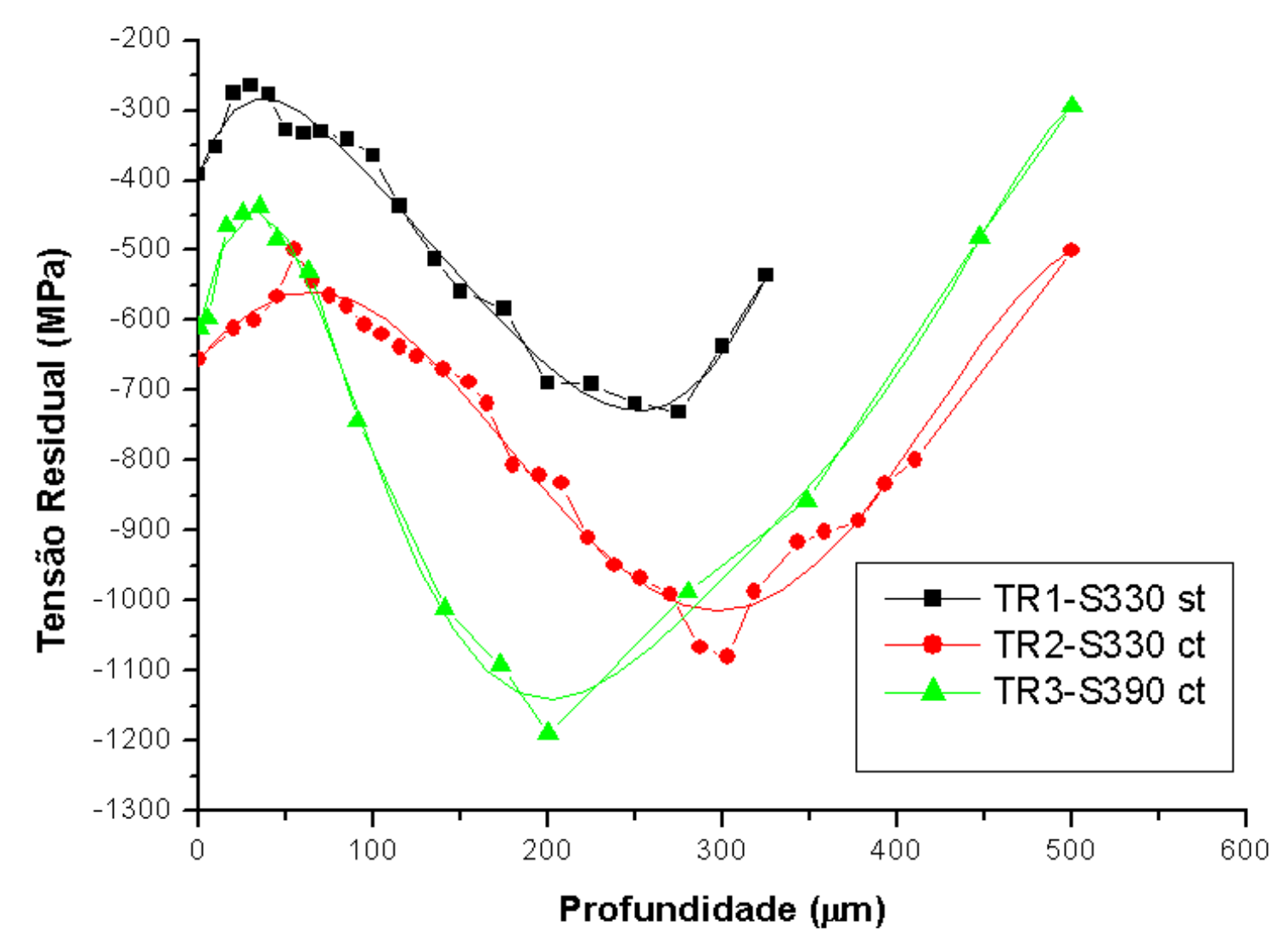

Figura 43: Distribuição de tensão residual da amostra jateada em granalhas S330 sem tensionamento (TR1), S330 com tensionamento (TR2) e S390 com tensionamento (TR3) 
Tabela 11: Resultados da tensão residual das amostras TR1, TR2 e TR3.

\begin{tabular}{|c|c|c|c|c|c|}
\hline \multicolumn{2}{|c|}{$\begin{array}{c}\text { S330 sem tensionamento } \\
\text { (TR1) }\end{array}$} & \multicolumn{2}{|c|}{$\begin{array}{c}\text { S330 com tensionamento } \\
\text { (TR2) }\end{array}$} & \multicolumn{2}{|c|}{$\begin{array}{c}\text { S390 com tensionamento } \\
\text { (TR3) }\end{array}$} \\
\hline $\begin{array}{l}\text { Profundidade } \\
\qquad(\mu \mathrm{m})\end{array}$ & $\begin{array}{c}\text { Tensão } \\
\text { residual } \\
(\mathrm{MPa})\end{array}$ & $\begin{array}{l}\text { Profundidade } \\
\qquad(\mu \mathrm{m})\end{array}$ & $\begin{array}{c}\text { Tensão } \\
\text { residual } \\
\text { (MPa) }\end{array}$ & $\begin{array}{l}\text { Profundidade } \\
\qquad(\mu \mathrm{m})\end{array}$ & $\begin{array}{c}\text { Tensão } \\
\text { residual } \\
(\mathrm{MPa})\end{array}$ \\
\hline 0 & -391 & 0 & -655 & 0 & -611 \\
\hline 10 & -352 & 20 & -611 & 5 & -597 \\
\hline 20 & -275 & 32 & -600 & 16 & -465 \\
\hline 30 & -264 & 45 & -566 & 25 & -447 \\
\hline 40 & -277 & 55 & -499 & 35 & -437 \\
\hline 50 & -328 & 65 & -544 & 45 & -483 \\
\hline 60 & -333 & 75 & -565 & 63 & -529 \\
\hline 70 & -331 & 85 & -580 & 91 & \begin{tabular}{|l|}
-743 \\
\end{tabular} \\
\hline 85 & $\begin{array}{l}-342 \\
\end{array}$ & 95 & -607 & 141 & -1011 \\
\hline 100 & -365 & 125 & -652 & 173 & -1092 \\
\hline 115 & -437 & 140 & -670 & 200 & -1189 \\
\hline 135 & -512 & 165 & -719 & 280 & $\begin{array}{l}-988 \\
\end{array}$ \\
\hline 150 & -559 & 195 & -822 & 348 & -857 \\
\hline 175 & $\begin{array}{l}-583 \\
\end{array}$ & 208 & -833 & 447 & -481 \\
\hline 200 & -690 & 223 & -911 & 500 & -294 \\
\hline 225 & -691 & 270 & -991 & & \\
\hline 250 & -719 & 287 & -1067 & & \\
\hline 275 & -731 & 303 & -1080 & & \\
\hline 300 & -637 & 343 & -917 & & \\
\hline \multirow[t]{3}{*}{325} & $\begin{array}{l}-536 \\
\end{array}$ & 393 & -834 & & \\
\hline & & 410 & -799 & & \\
\hline & & 500 & -500 & & \\
\hline
\end{tabular}

Conforme mostrado na tabela 11 , o valor de tensão residual máxima $\left(\sigma_{\max }\right)$ para o jateamento $S 330$ sem tensionamento foi de $-731 \mathrm{MPa}$, na profundidade de $275 \mu \mathrm{m}$. Quando este material é tensionado, a tensão residual máxima atinge um 
maior valor em compressibilidade de $-1080 \mathrm{MPa}$ na profundidade de $303 \mu \mathrm{m}$. As curvas das amostras jateadas com a granalha S330 possuem características semelhantes, obedecendo as proporções, aos acréscimos dos valores tanto em tensão residual quanto às profundidades onde ocorrem.

Ao aplicar o jateamento com a granalha S390 observam-se algumas alterações no comportamento do material em relação ao perfil da tensão residual. $O$ aumento da tensão residual compressiva se dá de forma mais contundente, visto pela maior inclinação verificada na curva TR3, entre $35 \mu \mathrm{m}$ a $200 \mu \mathrm{m}$ de profundidade, indicando uma maior eficiência no processo de jateamento pois a tensão residual máxima $\left(\sigma_{\max }\right)$ ocorre em profundidades menores e com maior compressibilidade (-1189 $\mathrm{MPa}$ ) comparando com a amostra jateada com a granalha S330 tensionada. Esta situação está diretamente ligada as variáveis da velocidade média das granalhas ao impactar com a amostra, que por sua vez está relacionada com a energia cinética e o momento aplicado.

A energia cinética é definida pela energia que o sistema possui em virtude do movimento e depende do valor de velocidade da partícula e da massa correspondente, neste caso as granalhas, sendo calculado:

$$
E_{c}=\frac{m v^{2}}{2}
$$

Sendo que $m$ é a massa individual da granalha e $v$ é a velocidade do jateamento

A quantidade de movimento linear, ou momento linear é definido pelo produto da massa e a velocidade do corpo da esfera de jateamento que nos permite definir a força resultante entre os dois sistemas.(esferas e amostra), calculado por:

$$
\vec{P}=m \vec{v}
$$

As especificações das granalhas estão descritos na tabela 12: 
Tabela 12: Especificação das granalhas (IKK do Brasil).

\begin{tabular}{|c|c|c|}
\hline Granalha & $\begin{array}{c}\text { Diâmetro } \\
(\mathbf{m m})\end{array}$ & $\begin{array}{c}\text { Massa } \\
\mathbf{( K g )}\end{array}$ \\
\hline $\mathbf{S 3 3 0}$ & 0,8382 & $2,25094 \times 10^{-6}$ \\
\hline $\mathbf{S 3 9 0}$ & 0,9906 & $3,71549 \times 10^{-6}$ \\
\hline
\end{tabular}

A tabela 13 mostra os valores obtidos da velocidade média, energia cinética e momento linear para o regime de jateamento:

Tabela 13: Relação das granalhas e pressão de jateamento para cálculo de energia cinética e momento linear

\begin{tabular}{|c|c|c|c|}
\hline Granalhas & $\begin{array}{c}\text { Velocidade média } \\
(\mathbf{m} / \mathbf{s})\end{array}$ & $\begin{array}{c}\text { Energia cinética } \\
(\mathbf{J})\end{array}$ & $\begin{array}{c}\text { Momento linear } \\
(\mathbf{k g} \cdot \mathbf{m} / \mathbf{s})\end{array}$ \\
\hline S330 & 90 & $9,1297 \times 10^{-3}$ & $2,025846 \times 10^{-4}$ \\
\hline S390 & 90 & $1,5049 \times 10^{-2}$ & $3,343941 \times 10^{-4}$ \\
\hline
\end{tabular}

Desta forma nota-se que o aumento da energia aplicada à superfície é capaz de alterar as características das curvas de tensão residual, fazendo com que os efeitos do jateamento ocorram de forma mais intensa, antecipando as tensões em relação a profundidade de ataque, além de aumentar a tensão residual compressiva.

Como ocorreram em todas as amostras, os valores iniciais em tensão residual decrescem (entre $30 \mu \mathrm{m}$ e $50 \mu \mathrm{m}$ ), cujo efeito pouco é relatado em trabalhos publicados, mas que podem ser vistos como um fator de grande importância nos estudos em resistência a fadiga. Tal efeito ocorre onde há a predominância de deformidades plásticas, conforme mostram as figuras 44a e 44b: 


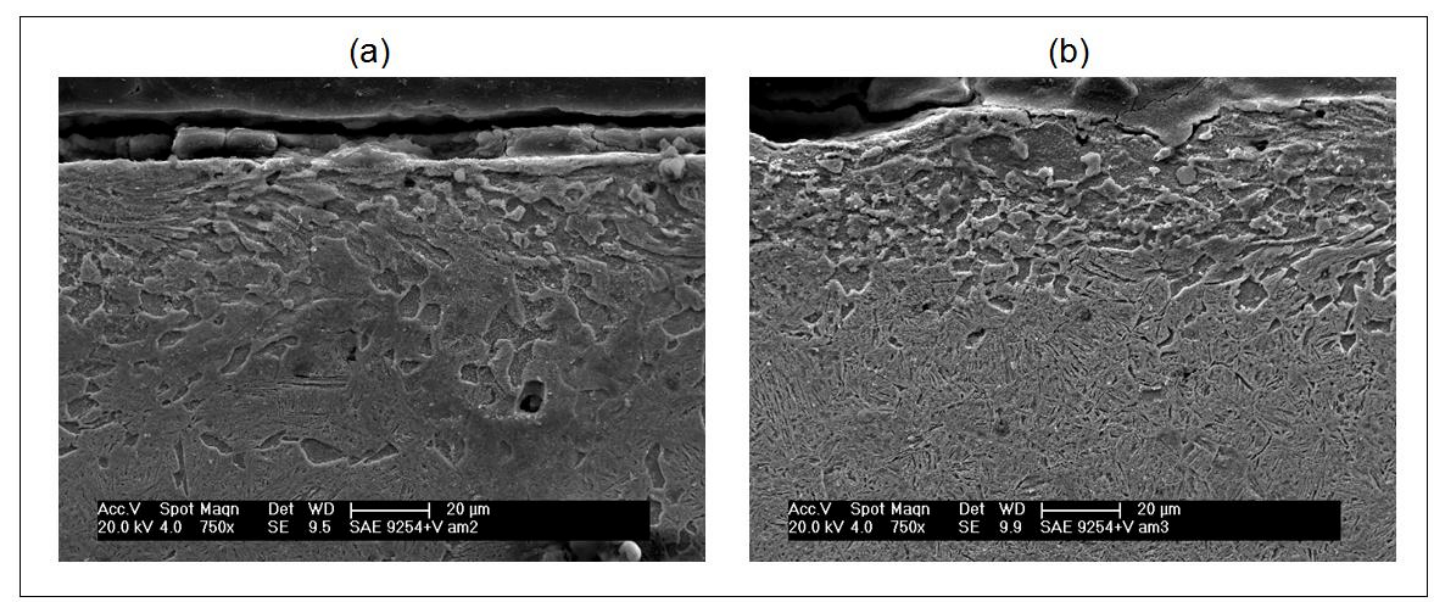

Figura 44: Micrografias utilizando Microscopia eletrônica de varredura das amostras TR2 (a) e TR3 (b) na região superficial jateada (IPEN/CNEN-SP)

Pela avaliação da imagem notam-se os efeitos causados na superfície da amostra, com o aspecto deformado da amostra jateada com as granalhas S330 e S390, que poderá resultar na diminuição da resistência a fadiga devido ao surgimento de micro trincas e formação de pontos de corrosão.

Meguid et al. (1998) propuseram uma simulação e modelamento pelo método de elementos finitos com o propósito de estudar o comportamento da curva de tensão residual em profundidade pelo jateamento de granalhas de aço em uma amostra. A tensão residual em profundidade foi calculada na linha de centro de uma esfera e na linha de centro entre as duas esferas $O$ modelamento foi conduzido considerando o efeito de duas granalhas onde as esferas encostam-se uma na outra $(\mathrm{C} / \mathrm{R}=1)$, que atingem o alvo simultaneamente, mostrado na figura 45.

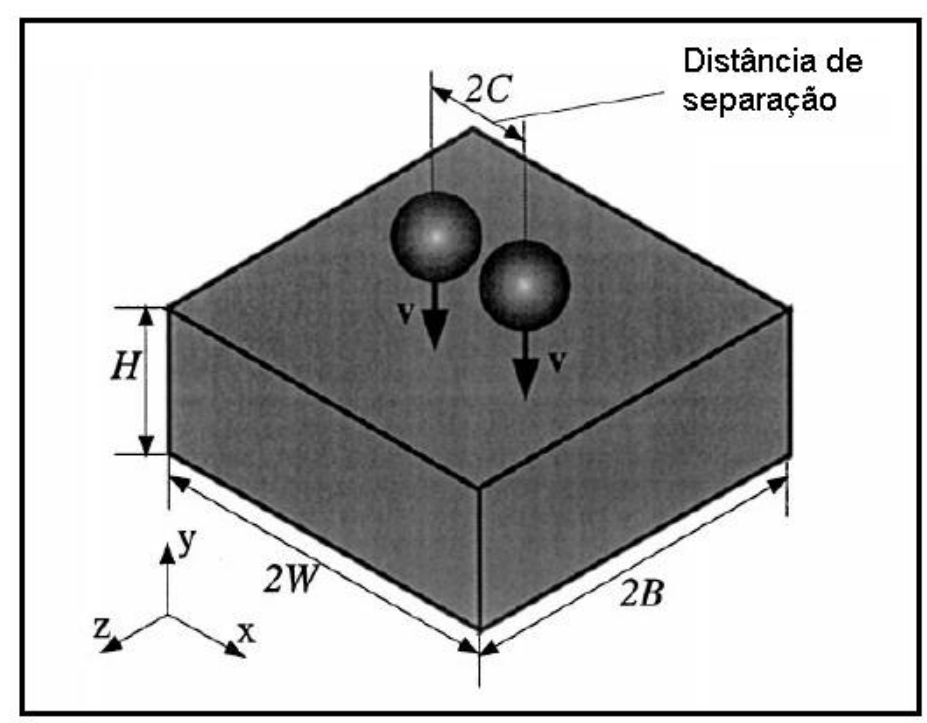

Figura 45: Modelamento para o estudo do efeito do jateamento (Meguid et al., 1998). 
Na figuras 46a e 46b são apresentados os resultados:

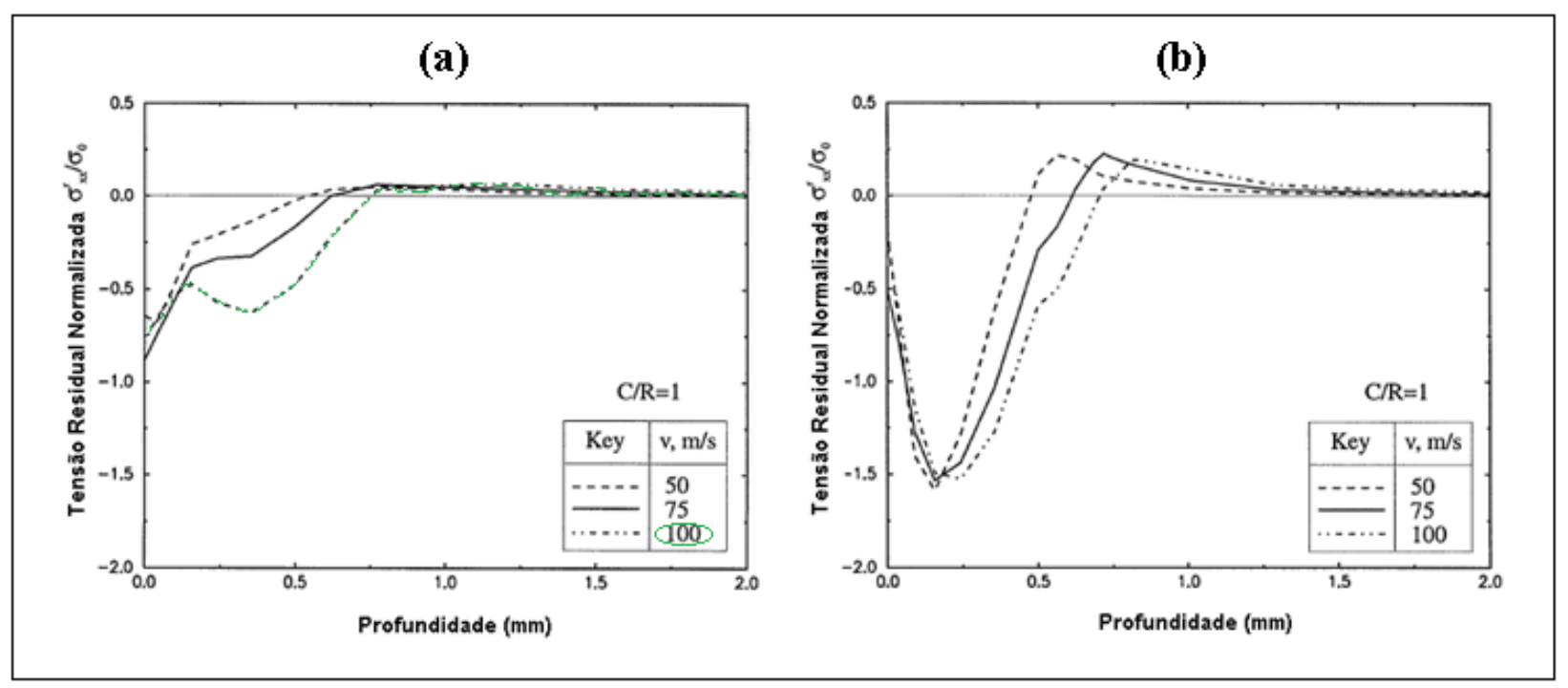

Figura 46: Resultado obtido por modelamento em jateamento com esfera de aço: analisado no centro das esferas (a) e analisado abaixo da linha de centro das esferas (b) (Meguid et al., 1998).

Assim sendo, verifica-se que a característica do perfil de tensão residual analisada no centro entre as esferas (46a) da amostra jateada com a velocidade de $100 \mathrm{~m} / \mathrm{s}$ é muito semelhante com as amostras do estudo deste trabalho. Abaixo da linha de centro das esferas (46b) o perfil de tensão residual apresenta um comportamento característico.

Nas amostras jateadas com as granalhas $S 330$ e S390 as medidas de tensão residual foram realizadas em regiões contínuas que englobam tanto os pontos referentes a linha de centro das granalhas quanto os pontos que estavam abaixo da linha, sendo que as medidas obtidas pela difração de raios-x são a composição de, ambas e dependentes da energia imposta pelas granalhas.

\subsection{Resultados do fator de concentração de tensão}

A avaliação do fator de concentração de tensão $\left(K_{t}\right)$ foi realizada por meio de informações das medidas de rugosidade, aplicando a média $\left(R_{z}\right)$, obtendo a profundidade média provocada pelas granalhas. Os valores de pico a pico (S) foram obtido por dados estatísticos medidos nas micrografias utilizando o microscópio eletrônico de varredura da superfície. Os resultados obtidos nas medidas de 
rugosidade média e diâmetro médio de indentação e os resultados do $\left(\mathrm{K}_{\mathrm{t}}\right)$ para as amostras S330 e S390 estão apresentadas na tabela 14. Para esta avaliação foram utilizadas somente as amostras pré tensionadas com jateamento com as granalhas S330 e S390:

Tabela 14: Resultados dos fatores de concentração obtidos em relação ao regime de pressão e carregamento das amostras jateadas com a S330 e S390.

\begin{tabular}{|c|c|c|c|}
\hline Granalha & $\begin{array}{c}\text { Rugosidade } \\
\text { média }-\mathbf{R}_{\mathbf{z}} \\
(\boldsymbol{\mu m})\end{array}$ & $\begin{array}{c}\text { Diâmetro médio } \\
\text { de indentação } \\
(\mathbf{m m})\end{array}$ & $\mathbf{K}_{\mathbf{t}}$ \\
\hline $\mathbf{S 3 3 0}$ & 30,344 & 0,354 & 1,180 \\
\hline $\mathbf{S 3 9 0}$ & 32,623 & 0,370 & 1,185 \\
\hline
\end{tabular}

As figuras $47 \mathrm{a}$ e $47 \mathrm{~b}$ apresentam como amostragem para a obtenção dos parâmetros necessários para o cálculo do fator de concentração de tensões das amostras jateadas com as granalhas S330 e S390 tensionadas, com as micrografias obtidas por MEV e nas figuras 48a e 48b os dados de rugosidade, aplicando o método proposto por Li et al. (1992).

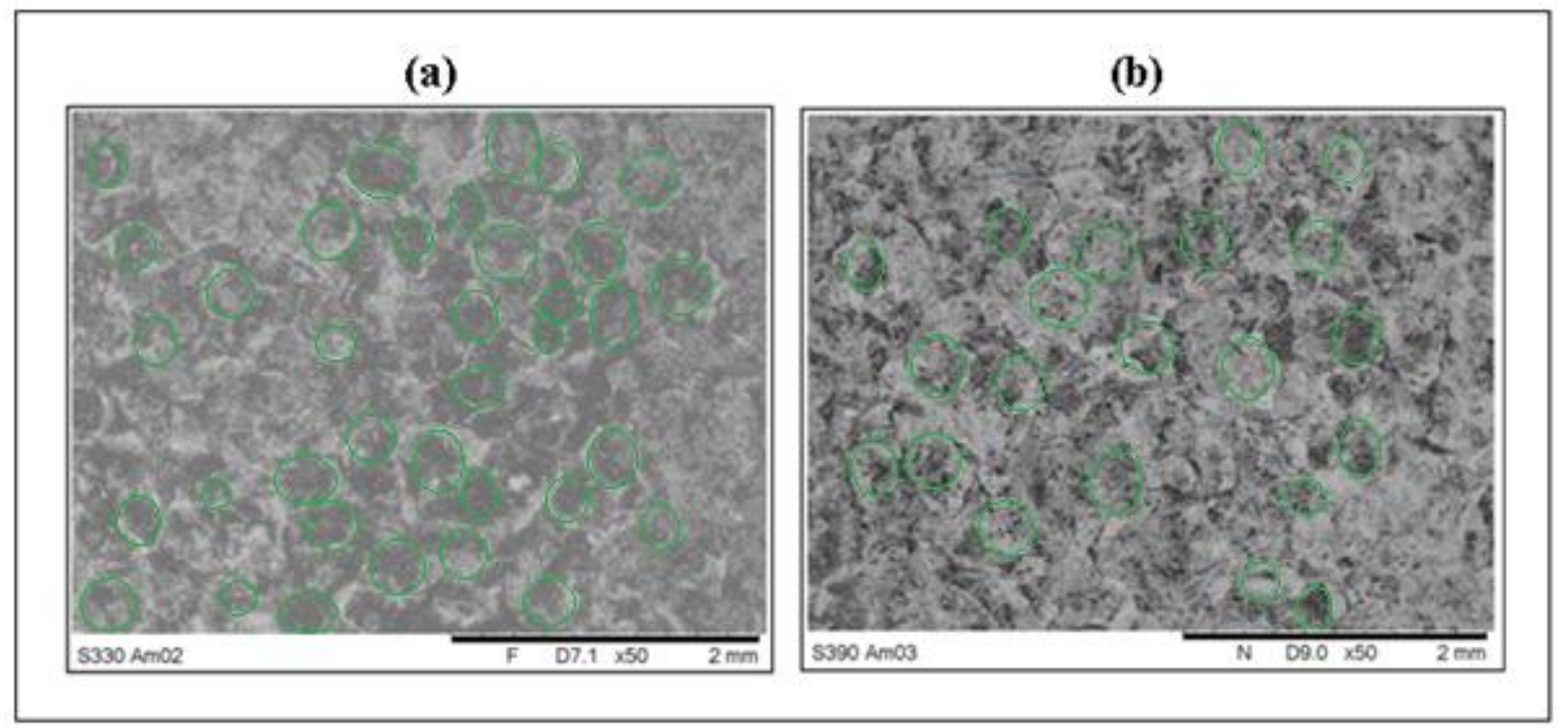

Figura 47: Micrografias representativas das regiões superficiais das amostras TR2 (a) e TR3 (b) (IPEN-CNEN/SP) 
(a)

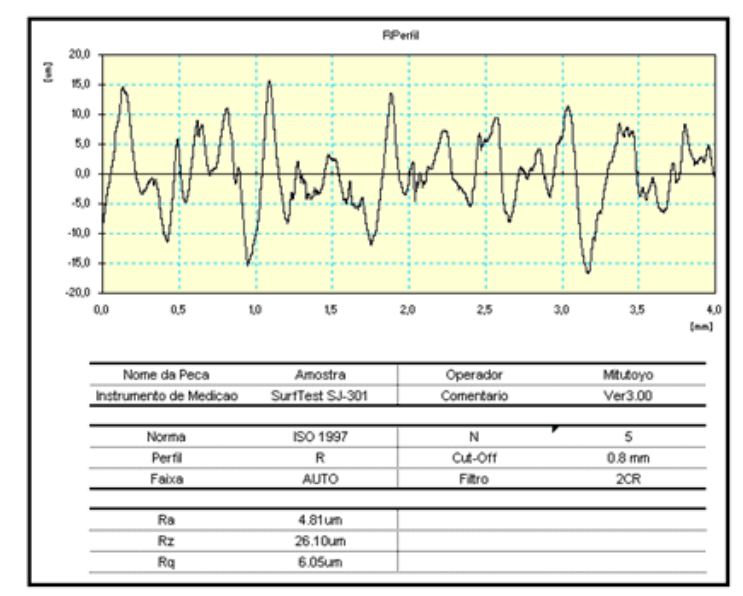

(b)

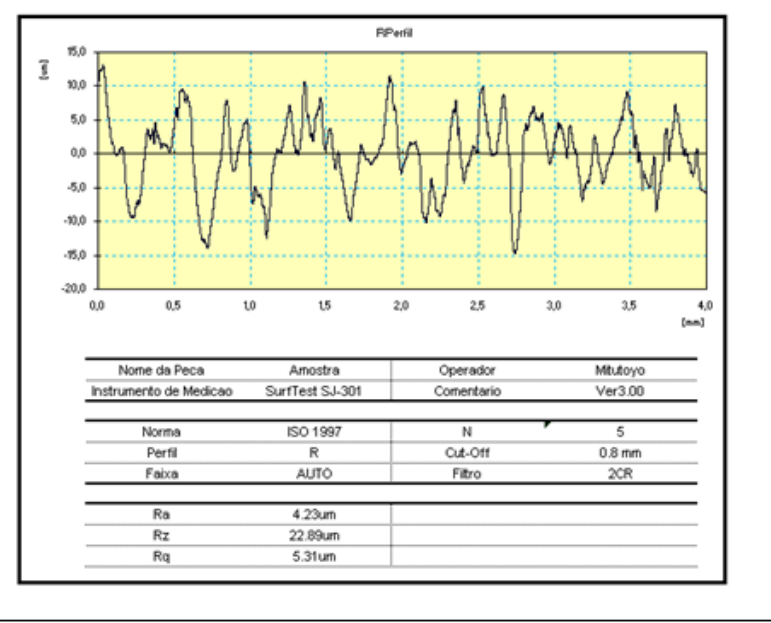

Figura 48 : Dados representativos obtidos no rugosímetro para obtenção do fator de concentração de tensão das amostras TR2 (a) e TR3 (b) (IPEN-CNEN/SP).

Os resultados dos fatores de concentração de tensão entre as amostras jateadas com a S330 e a S390 não apresentaram diferenças significativas, mostrando que a geometria das granalhas utilizadas, quando lançadas a uma velocidade constante não causam impressões diferenciadas, portanto não sendo esta a causa nos diferentes valores dos ciclos em fadiga. Somando a isso, o trabalho proposto por $\mathrm{Li}$ e colaboradores assumem que o fator de concentração de tensão proporciona uma forma de prever a resistência de fadiga que uma amostra suporta. Inicialmente os dados de rugosidade e dimensão de indentação foram coletados e analisados por um programa de análise automática de incrementação dinâmica não linear (ADINA) desenvolvido por Bathe (1981) com a finalidade de avaliar a concentração de tensão abaixo do ponto criado pelo jateamento por granalhas em uma superfície livre de um elemento finito como mostrado na figura 49. 


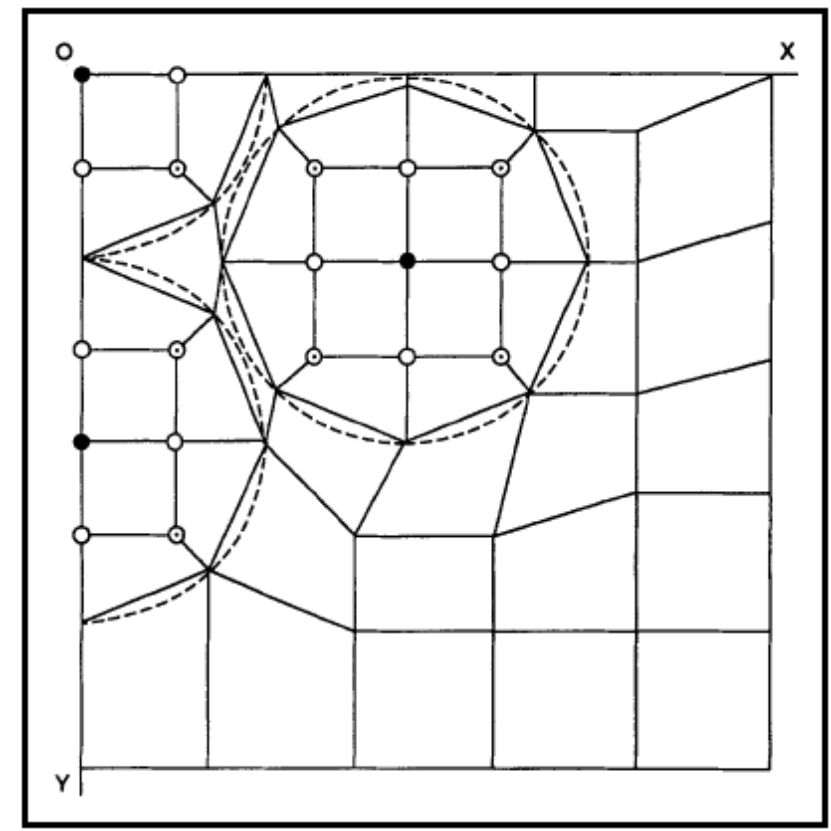

Figura 49: Vista vertical da idealização de um elemento finito mostrando a zona de indentação em uma superfície livre Li et al. (1992).

Pela fórmula de Goodman (1899) se aplica a uma amostra livre de imperfeições na superfície, considerando a tensão média $\left(\sigma_{m}\right)$, sendo:

$$
\sigma_{a}=m\left(\sigma_{b}-\sigma_{m}\right)
$$

Onde $m$ é um coeficiente relacionado a resistência de fadiga considerando uma superfície livre de imperfeições. $\sigma_{a}$ é a tensão de amplitude do ensaio de fadiga e $\sigma_{b}$ a tensão final suportada pelo material.

Porém, para uma amostra jateada por granalhas a rugosidade e a tensão residual devem ser considerados, sendo assim ocorre a necessidade em modificar a fórmula de Goodman introduzindo elementos característicos gerados pelo jateamento.

Assim sendo, a fórmula de Goodman modificada poderá ser expressa como:

$$
K \sigma_{a}=m\left[\sigma_{b}-\left(K \sigma_{m}+\bar{\sigma}_{r}\right)\right]
$$

Para $K$, o fator de concentração de tensões e $\bar{\sigma}_{r}$ a tensão residual.

Na prática o valor de tensão máxima da resistência de fadiga será: 


$$
\sigma_{\max }=\frac{2 m}{[(1-R)+(1+R) m] K}\left(\sigma_{b} \bar{\sigma}_{r}\right)
$$

Sendo $R$, a razão tensão do teste de fadiga.

Os resultados obtidos no trabalho de Li e seus colaboradores indicaram uma aproximação semelhante aos resultados práticos mostrando a capacidade deste método em prever a resistência de fadiga suportada pelo material analisado.

\subsection{Microdeformação da rede cristalina e tamanho médio de cristalito.}

Foram analisados os difratogramas após cada remoção por ataque químico no material, revelando o padrão de difração do perfil em profundidade. Desta forma foi possível avaliar a distribuição do tamanho médio de cristalito e a porcentagem de deformação da rede cristalina no perfil da amostra. No refinamento pelo método Rietveld foi utilizado o programa GSAS, possibilitando melhor definição do alargamento dos perfis de difração $(\Delta 2 \theta)$.

Com os dados do difratograma foi realizado o refinamento referente aos planos (110), (200), (211), (220) e (310) mostrado como exemplo na figura 50.

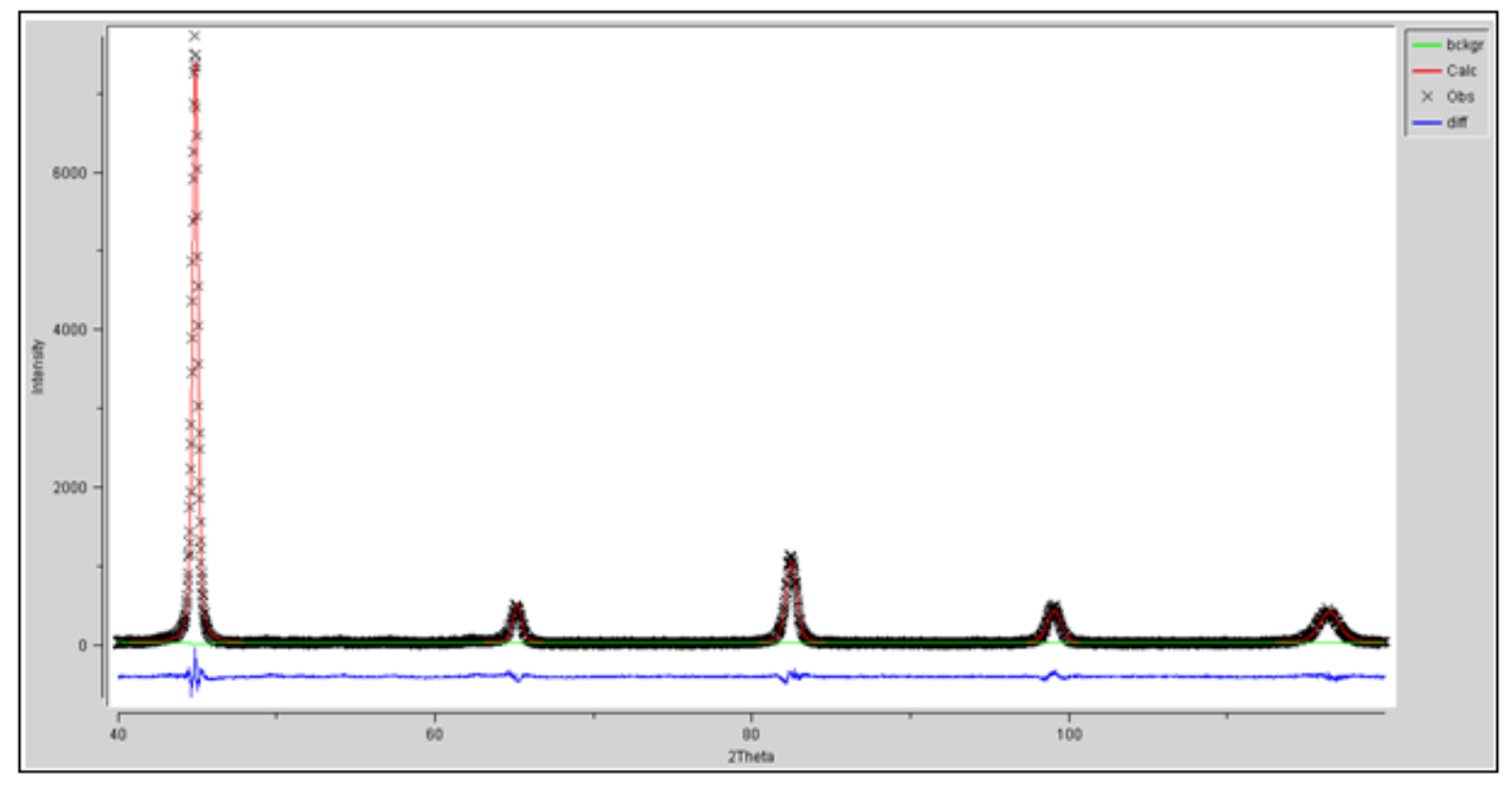

Figura 50: Refinamento do padrão de difração da amostra 1, jateada com granalha $\$ 330$ sem pré tensionamento. 
Neste caso em particular, apresentado na figura 49, o difratograma se refere a amostra jateada com a granalha S330 sem o tensionamento e medido na superfície.

Com o perfil de alargamento, realizado com o refinamento pelo GSAS, cada pico referente ao plano foi analisado, conforme a largura do pico à meia altura. Estes resultados permitiram utilizar o procedimento proposto por Williamson-Hall, plotando para cada plano os valores de $(\Delta 2 \theta) \cos \theta$ por $\operatorname{sen} \theta$ para os resultados do tamanho médio de cristalito e microdeformação da rede cristalina. A correção instrumental foi realizada utilizando o padrão de silício, correlacionando a posição $2 \theta$ para os planos em relação a amostra experimental, no caso a ferro CCC. O ajuste dos alargamentos estão apresentados no gráfico da figura 51.

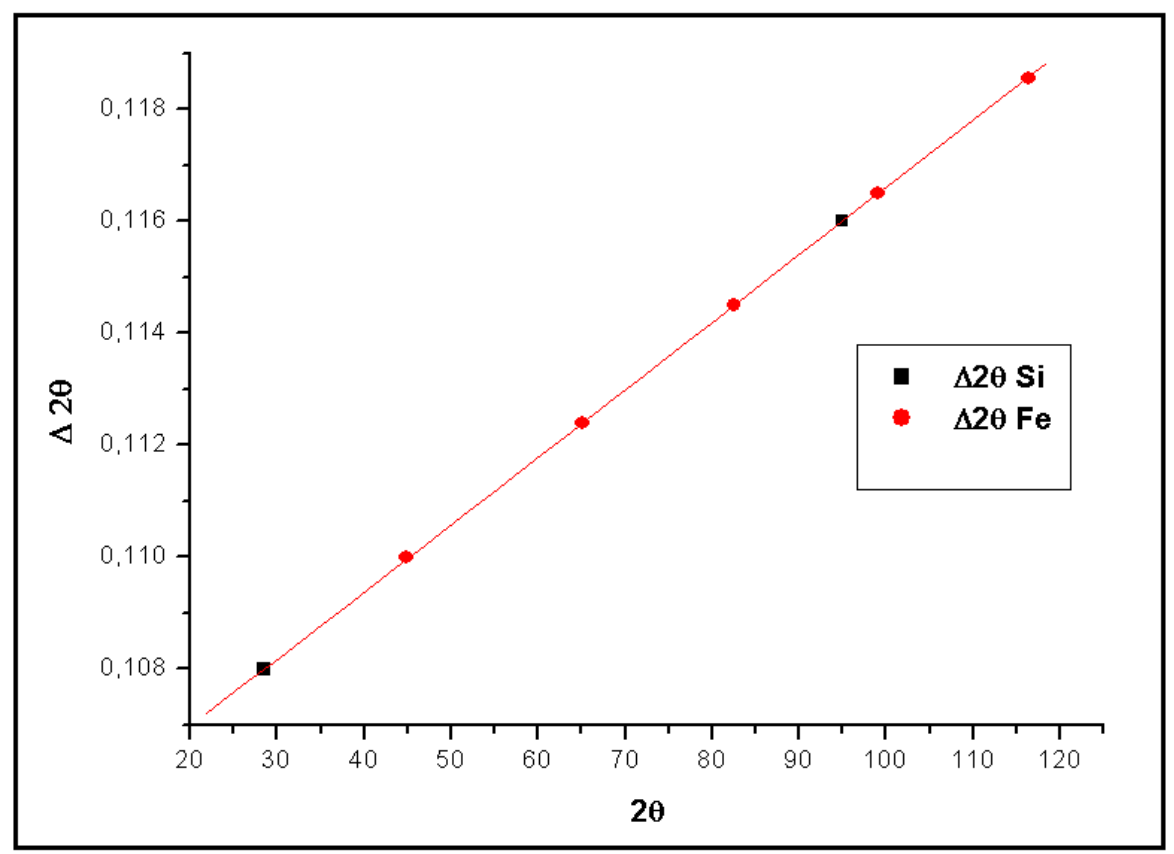

Figura 51: Gráfico de aproximação do alargamento instrumental do pico padrão de Si para determinação do alargamento $\mathrm{Fe}$ - CCC.

Tabela 15: Alargamento dos picos a meia altura referentes aos planos do padrão de difração do $\mathrm{Fe}$ CCC

\begin{tabular}{|l|l|l|l|l|l|}
\hline$(\mathbf{h k l})$ & $(110)$ & $(200)$ & $(211)$ & $(220)$ & (310) \\
\hline$(\boldsymbol{\Delta} \mathbf{2 \theta})$ & 0,1100 & 0,1124 & 0,1145 & 0,1165 & 1,1186 \\
\hline
\end{tabular}


Desta forma, o gráfico gerado se encontra representado como exemplo na figura 52 :

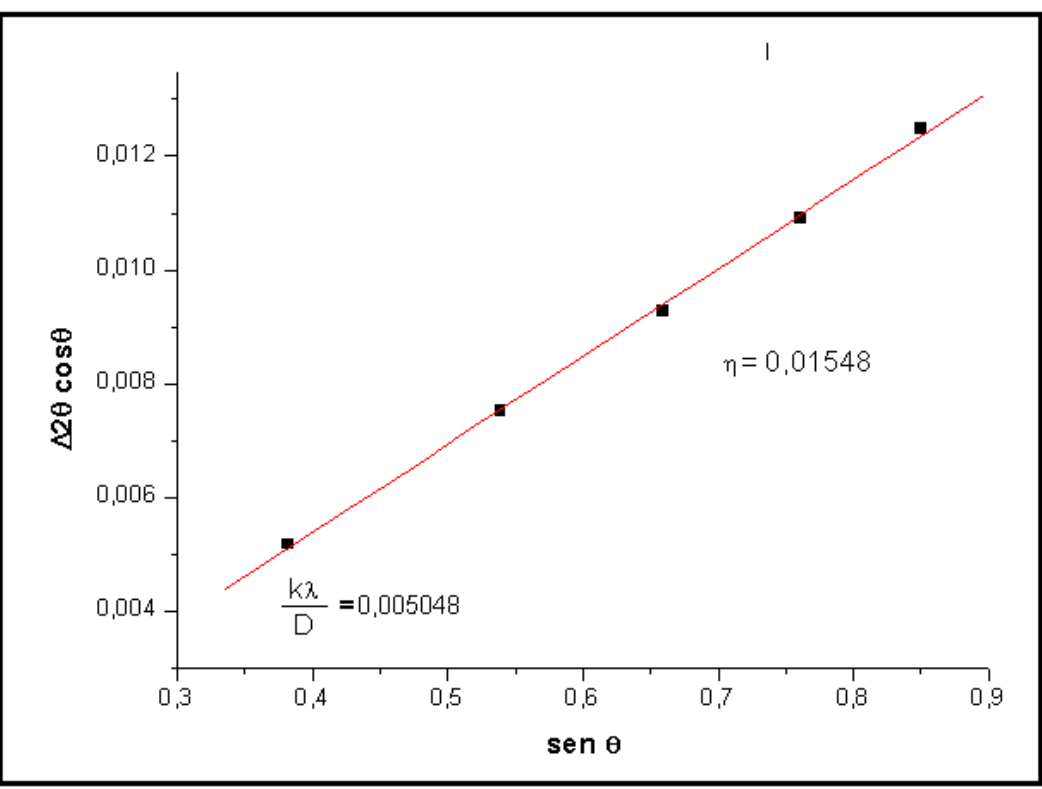

Figura 52: Gráfico para a determinação da microdeformação e tamanho médio de cristalito da amostra 1 jateada com granalha $\$ 330$ sem pré tensionamento.

Este gráfico nos permite avaliar os valores do tamanho médio de cristalito e da microdeformação da rede cristalina pelo resultado dos parâmetros $A$ e $B$, respectivamente, o intercepto no eixo das ordenadas e o coeficiente angular da reta.

Sendo assim, o cálculo da microdeformação será:

$$
\varepsilon=\frac{B}{2}
$$

E do tamanho médio de cristalito:

$$
D=\frac{0,9 \cdot \lambda}{A}
$$

Os resultados para esta condição foram: $D=274 \AA$ e $\varepsilon=0,774 \%$.

O método analítico do qual opera o GSAS baseia-se com a distribuição estatística e correção de posicionamento de um perfil de difração, que em determinadas particularidades podem ocultar erros isolados. Tais particularidades se referem ao posicionamento e aos valores de intensidade dos picos ao realizar o 
refinamento do difratograma completo. Nos casos de alterações nos valores de intensidade, o programa possibilita a correção por meio de comandos relacionados a orientações cristalográficas conforme a simetria, ordem esférica harmônica e ângulos. No caso do posicionamento em relação a $2 \theta$ ocorre uma correção da qual o padrão medido se ajusta ao perfil calculado.

A presença da microdeformação devido as discordâncias e falhas de empilhamento produzem pequenos deslocamentos e mudanças na forma e no posicionamento nos perfis de difração. Quando, devido a susceptibilidade de um plano deformar-se mais do que outro ocorre a anisotropia cristalográfica da qual um pico desloca-se independente do outro. Na figura 53 é mostrado um esquema de deslocamento de perfis de difração em um material CCC com a presença de falhas de empilhamento.

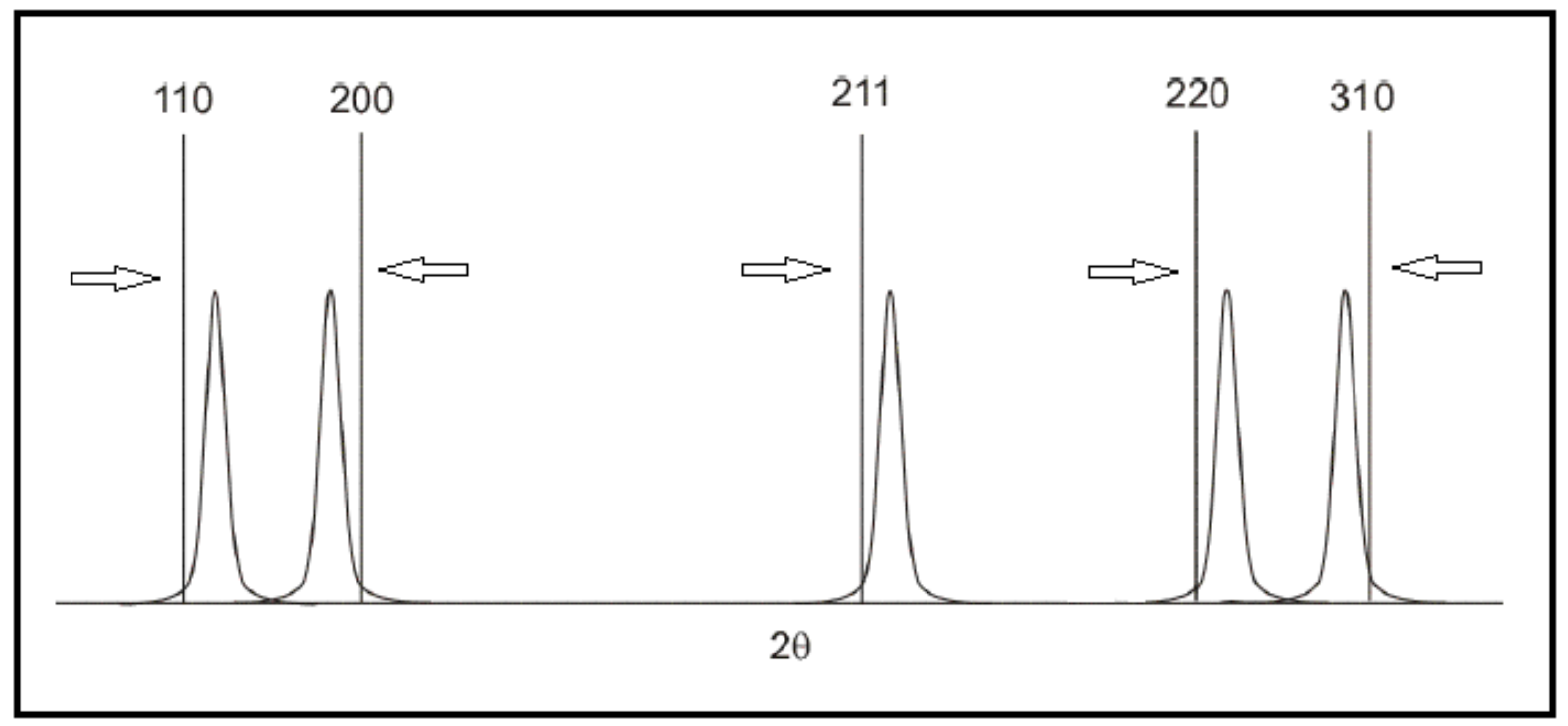

Figura 53: Deslocamento dos perfis de difração de um material CCC na presença de falhas de empilhamento

Ao ampliar o padrão da difração da figura 50 observa-se que o material analisado apresenta um deslocamento no pico referente ao plano (200) conforme mostra a figura 54, onde o perfil calculado e o perfil medido não sobreposicionam na posição $2 \theta$. 


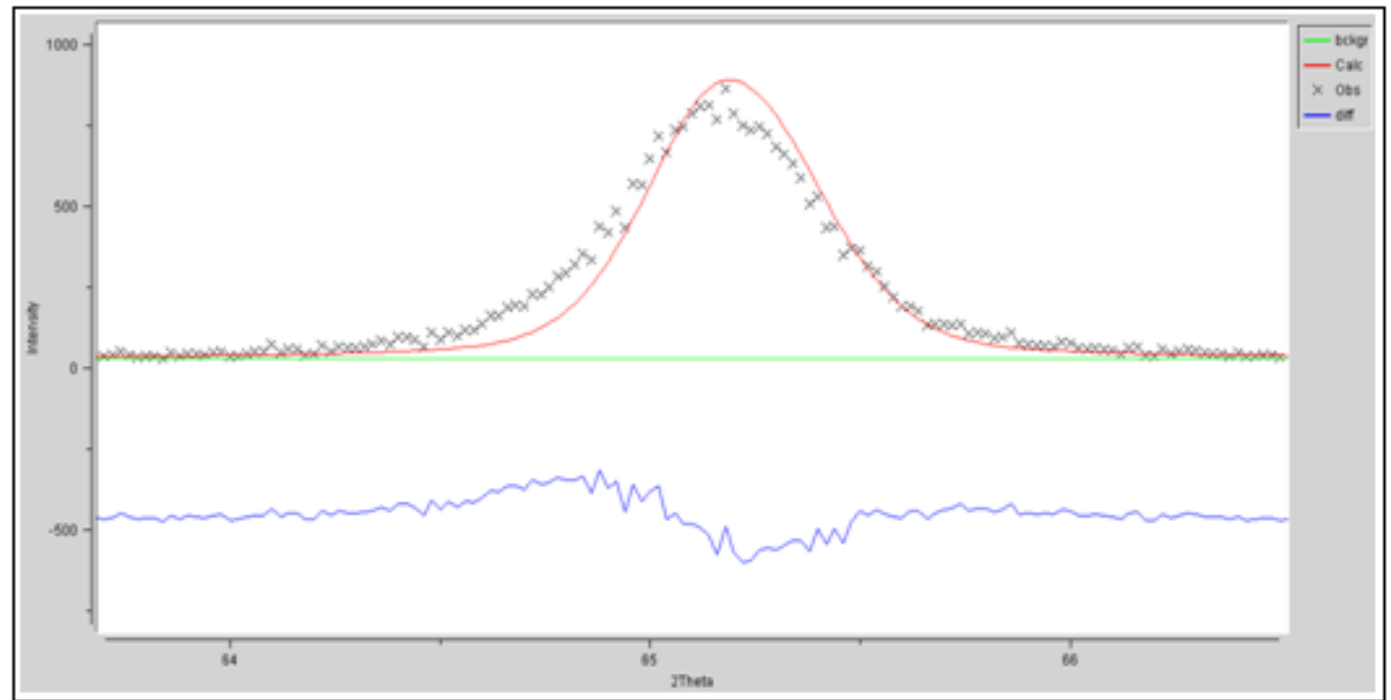

Figura 54: Refinamento do pico 200 da amostra jateada com granalhas S330 sem tensionamento ampliada da figura 50 .

Em função das deformações ocorridas devido ao jateamento por granalhas nota-se que este deslocamento não se iguala a um padrão JCPDS, em consequência, à lei de Bragg, em relação aos outros picos do padrão de difração, ou seja, a relação do parâmetro de rede dos planos ( $h k l)$ e a distância interplanar são diferentes em relação a outros picos.

Desta forma foi proposto o refinamento do perfil experimental para cada plano com medições na velocidade de $0,02^{\circ}$ por minuto em 8 segundos de passo cuja variação foi de:

Tabela 16: Planos individuais analisados por difração de raios-x.

\begin{tabular}{|c|c|}
\hline Varredura $(2 \theta)$ & Planos (hkI) \\
\hline $41^{\circ}$ a $47^{\circ}$ & (110) \\
\hline $61^{\circ}$ a $68^{\circ}$ & (200) \\
\hline $80^{\circ}$ a $85^{\circ}$ & (211) \\
\hline $96^{\circ}$ a $102^{\circ}$ & (220) \\
\hline $113^{\circ}$ a $117^{\circ}$ & $(310)$ \\
\hline
\end{tabular}

Com as medições plano a plano foram obtidos os valores dos alargamentos $(\Delta 2 \theta)$ e seu respectivo alinhamento na posição $(2 \theta)$, evitando que a correção estatística fosse distribuída a todo o difratograma de forma generalizada. 


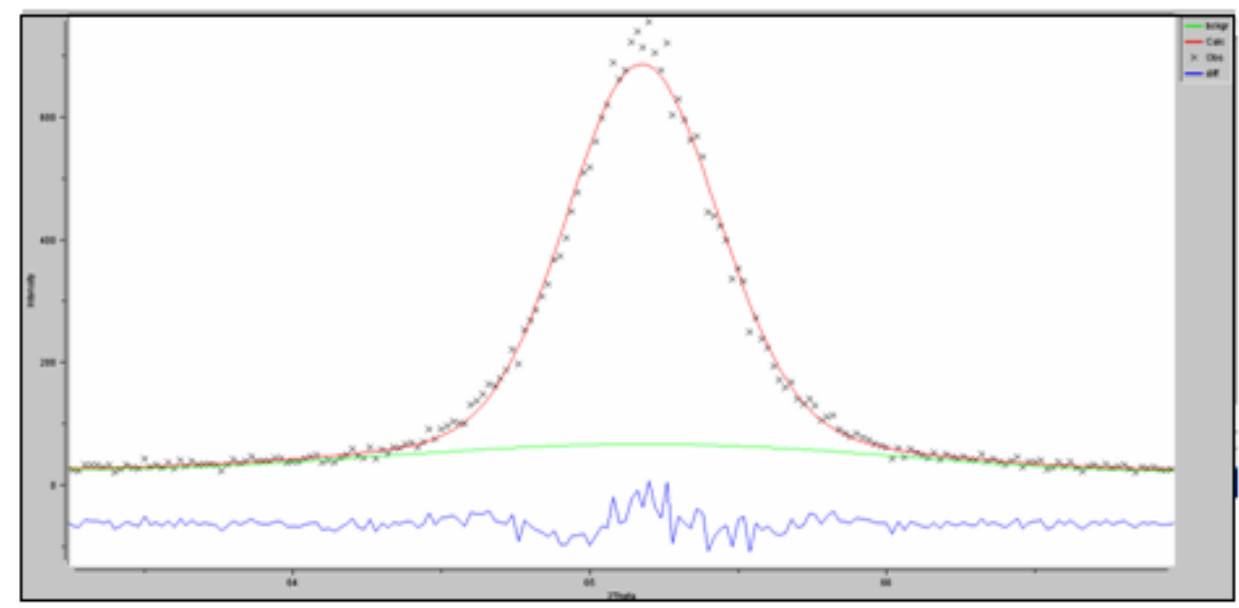

Figura 55: Refinamento do pico 200 da amostra jateada com S330 sem tensionamento.

Com o resultado dos refinamentos dos planos cristalográficos, considerando os valores atuais de alargamento $(\Delta 2 \theta)$ e posicionamento $2 \theta$ foi aplicado o método Williamson-Hall, obtendo um gráfico não linear, conforme mostra a figura 56 :

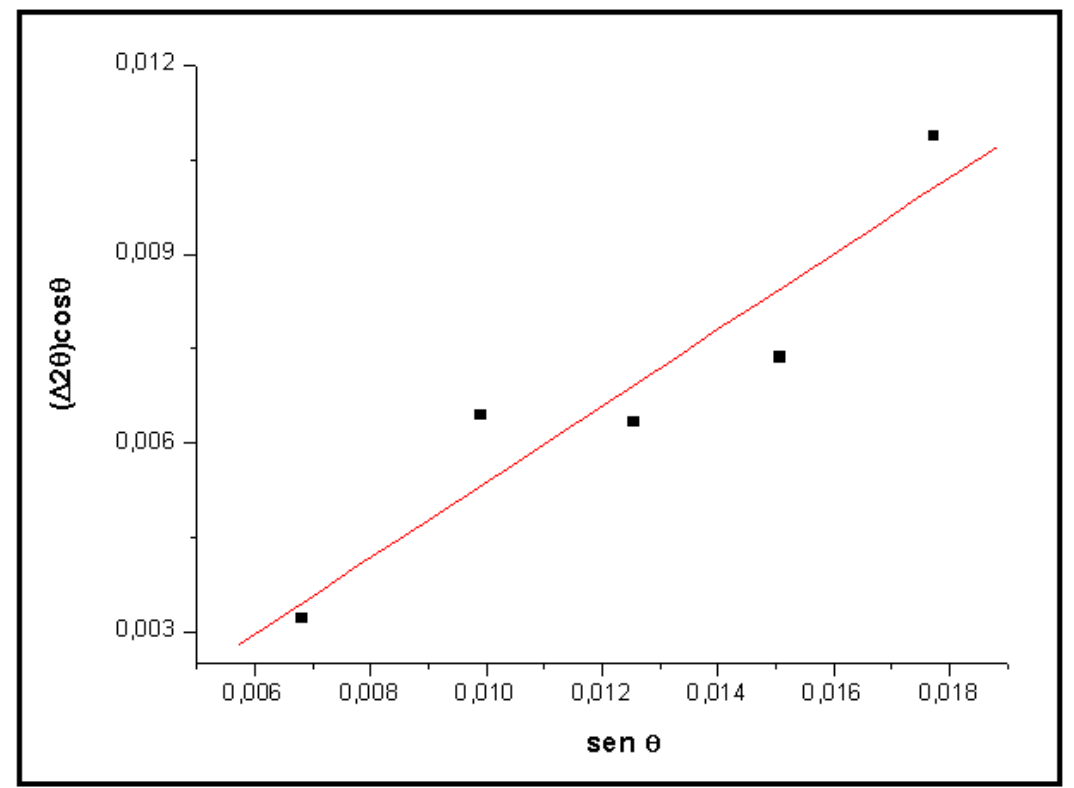

Figura 56: Gráfico para a determinação da microdeformação e tamanho médio de cristalito da amostra jateada com a granalha S330 na superfície.

O resultado deste gráfico não apresenta condições em se obter os parâmetros necessários para a determinação da microdeformação ou do tamanho médio de cristalito, visto a não linearidade entre os pontos. Tal ocorrência se encontra no fato da presença da anisotropia das tensões entre os planos, os defeitos de empilhamento e a densidade das discordâncias no material. 
Conforme já foi apresentado, o método Willianson-Hall consiste na relação entre $(\Delta 2 \theta) \cos \theta$ e $\operatorname{sen} \theta$, que por consequência $K=\frac{2 \operatorname{sen} \theta}{\lambda}$ e $\Delta K=\frac{2 \cos \theta \Delta \theta}{\lambda}$.

A modificação proposta por Ungar e Borbély (1996) da equação de Willianson e Hall (equação 48) leva em consideração os valores de tamanho de cristalito, densidade de discordâncias, o vetor de Burgers e além de uma variável descrita por $\langle C\rangle$, denominado fator de contraste das discordâncias.

Assim sendo ocorre a necessidade de encontrar $\sqrt{\langle C\rangle}$, sabendo que:

$$
\bar{C}=\bar{C}_{h 00}\left(1-q H^{2}\right)
$$

$\bar{C}$ depende de $H$, que por sua vez depende de (hkl). Assim sendo:

$$
H^{2}=\frac{h^{2} k^{2}+h^{2} l^{2}+l^{2} k^{2}}{h^{2}+k^{2}+l^{2}}
$$

Os resultados se encontram na tabela 17:

Tabela 17: Valores de $H^{2}$ para os planos (hkl) - CCC

\begin{tabular}{|c|l|}
\hline Plano & \multicolumn{1}{|c|}{$\boldsymbol{H}^{\mathbf{2}}$} \\
\hline $\mathbf{1 1 0}$ & 0,25 \\
\hline $\mathbf{2 0 0}$ & 0 \\
\hline $\mathbf{2 1 1}$ & 0,25 \\
\hline $\mathbf{2 2 0}$ & 0,25 \\
\hline $\mathbf{3 1 0}$ & 0,09 \\
\hline
\end{tabular}

Considerando que $\bar{C}_{h 00}$ é dependente das constantes elásticas $C_{11}, C_{12}$ e $C_{44}$, respectivamente: $237 \mathrm{GPa}, 141 \mathrm{GPa}$ e $116 \mathrm{GPa}$, o fator de anisotropia $\left(A_{i}\right)$ é definido por:

$$
A_{i}=\frac{2 C_{44}}{C_{11}-C_{12}}
$$


E a relação:

$$
\frac{C_{12}}{C_{44}}=1,2
$$

Deve-se ter em conta que para obter $q$, será necessário encontrar $\Delta K^{2}$, sabendo-se que:

$$
\Delta K^{2}=\left[\frac{\frac{\left(\Delta 2 \theta-\Delta 2 \theta_{\text {inst }}\right) \pi}{180}}{\tan \left(\theta \frac{\pi}{180}\right)}\right]^{2}-\left[\frac{0,9 \lambda}{2 D \operatorname{sen}\left(\theta \frac{\pi}{180}\right)}\right]^{2}
$$

Para identificar $q$, uma relação de $\frac{B}{A}$, cujos valores são obtidos no gráfico da figura 57, plotando $\Delta K^{2}$ versus $H^{2}$, onde $H^{2}=\frac{1}{q}$.

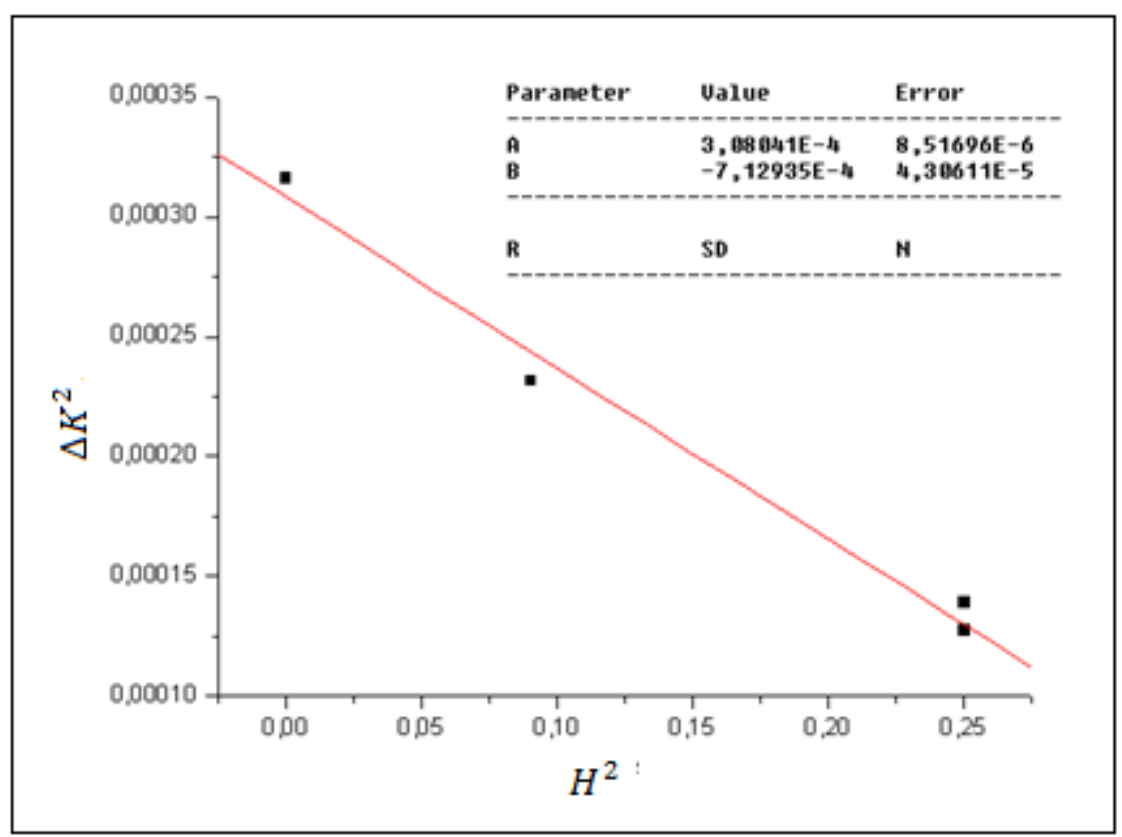

Figura 57: Gráfico para a determinação de $q$ da amostra jateada com a granalha $\$ 330$ na superfície

Sabendo que o valor de $\frac{1}{q}$ corresponde a $\Delta K^{2}=0$, sendo este gráfico $\mathrm{y}=\mathrm{a}+\mathrm{b} . \mathrm{x}$, ou seja $\mathrm{y}=\mathrm{a}+\mathrm{b} . \mathrm{x}$, sendo $\operatorname{assim} \frac{1}{q}=\frac{-3,0804 \cdot 10^{-4}}{-7,12935 \cdot 10^{-4}}$, em particular, o resultado de $q=2,314$. 
Se $A_{i}=2,41$ e $\frac{C_{12}}{C_{44}}=1,2$, portanto, $\bar{C}_{h 00} \sim 0,3$

Os resultados de $q$ obtidos neste trabalho variam de 2,10 a 2,64 e conforme o gráfico proposto por Ungàr e Borbély (1996), na figura 19b, a maior parte das discordâncias são do tipo hélice.

Sequencialmente, obtêm-se o valor de $C$ do qual permite obter 0 valor de $K \sqrt{\langle C\rangle}$. Sabendo-se que:

$$
K \sqrt{\langle C\rangle}=\frac{2 \operatorname{sen} \theta}{\lambda} \sqrt{\langle C\rangle}
$$

e:

$$
\Delta K=2 \cos \theta \frac{\pi}{180} \frac{\left(\Delta 2 \theta-\Delta 2 \theta_{\text {inst }}\right) \pi}{180}
$$

Então é possível obter os valores de $\varepsilon$ e $D$ possibilitando a montagem de um gráfico $K \sqrt{\langle C\rangle}$ versus $\Delta K$ (figura 58):

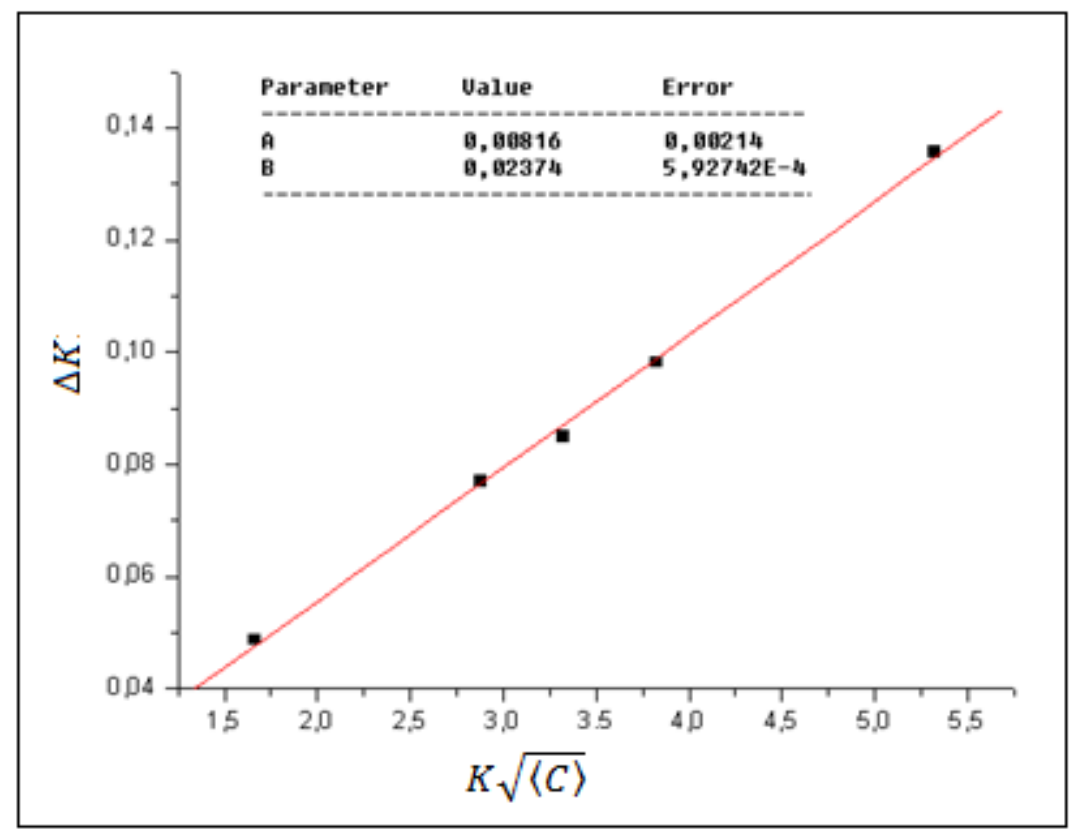

Figura 58: Gráfico para a determinação da microdeformação e tamanho médio de cristalito pelo método de Willianson-Hall modificado.

Desta forma, se torna possível obter os valores da microdeformação da rede cristalina e do tamanho médio do cristalito. Os resultados da microdeformação da rede cristalina obtidos utilizando a equação de Willianson-Hall modificada estão expressos na tabela 18, com as seguintes variáveis: granalha S330 sem 
tensionamento (amostra 1), S330 com tensionamento (amostra 2), e S390 com tensionamento (amostra 3), ambas distribuídas conforme o ataque em profundidade.

Tabela 18: Resultados em porcentagem da deformação na rede cristalina

\begin{tabular}{|c|c|c|c|c|c|}
\hline \multirow{2}{*}{\multicolumn{2}{|c|}{ Amostra 1}} & \multirow{2}{*}{\multicolumn{2}{|c|}{ Amostra 2}} & \multirow{2}{*}{\multicolumn{2}{|c|}{ Amostra 3}} \\
\hline & & & & & \\
\hline $\begin{array}{l}\text { Prof. } \\
(\mu \mathrm{m})\end{array}$ & $\begin{array}{c}\mathcal{E} \\
(\%)\end{array}$ & $\begin{array}{l}\text { Prof. } \\
(\mu \mathrm{m})\end{array}$ & $\begin{array}{c}\varepsilon \\
(\%)\end{array}$ & $\begin{array}{l}\text { Prof. } \\
(\mu \mathrm{m})\end{array}$ & $\begin{array}{c}\mathcal{\varepsilon} \\
(\%)\end{array}$ \\
\hline 0 & 1,11708 & 0 & 1,21975 & 0 & 1,21444 \\
\hline 10 & 0,92279 & 20 & 1,1044 & 5 & 0,90046 \\
\hline 20 & 0,84876 & 32 & 0,99396 & 18 & 0,78265 \\
\hline 30 & 0,92042 & 45 & 0,97278 & 25 & 0,90365 \\
\hline 40 & 0,92099 & 55 & 1,02922 & 35 & 0,90602 \\
\hline 50 & 0,92156 & 85 & 1,05532 & 45 & 0,90807 \\
\hline 60 & 1,00869 & 95 & 1,05614 & 63 & 0,99642 \\
\hline 85 & 1,11545 & 105 & 1,05941 & 91 & 1,08723 \\
\hline 100 & 1,12077 & 125 & 1,0635 & 141 & 1,09205 \\
\hline 135 & 1,01703 & 155 & 1,10825 & 173 & 1,09541 \\
\hline 150 & 0,96852 & 85 & 1,05532 & 200 & 1,13426 \\
\hline 175 & 0,93105 & 180 & 1,11283 & 220 & 1,14277 \\
\hline 225 & 0,92934 & 195 & 1,1188 & 280 & 1,13263 \\
\hline 250 & 0,92827 & 238 & 1,21296 & 348 & 1,13222 \\
\hline 275 & 0,91322 & 287 & 1,17623 & 402 & 1,11627 \\
\hline 300 & 0,91297 & 358 & 1,16576 & 447 & 1,00035 \\
\hline 325 & 0,91199 & \begin{tabular}{|l|}
378 \\
\end{tabular} & 1,14195 & 503 & 0,94971 \\
\hline \multirow[t]{3}{*}{1000} & 0,58084 & 410 & 1,12322 & 630 & 0,90995 \\
\hline & & 750 & 0,92983 & 1000 & 0,55179 \\
\hline & & 1000 & 0,64546 & & \\
\hline
\end{tabular}

A figura 59 mostra os gráficos da distribuição da microdeformação em relação a profundidade. 


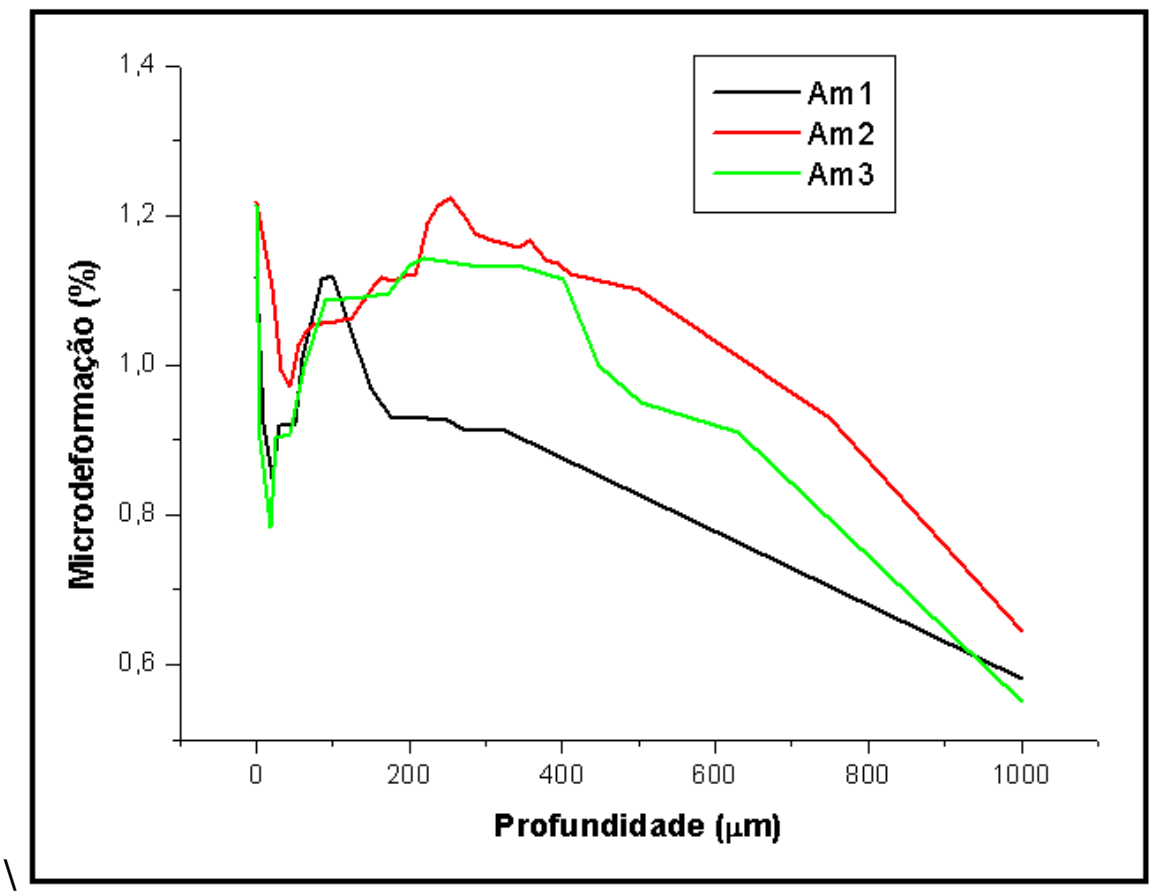

Figura 59: Gráficos da distribuição da microdeformação em relação a profundidade das amostras 1, 2 e 3 pelo método de Willianson-Hall modificado.

Ao sobrepor os perfis das microdeformações com as curvas da distribuição da tensão residual observa-se uma notável semelhança em relação a compressibilidade inserida na amostra com gerada pelo jateamento.

Em geral, nas distâncias iniciais ao processo de desbaste químico, os valores de microdeformação decrescem aos valores mínimos em $20 \mu \mathrm{m}$ para a amostra 1 (S330 sem tensionamento), $45 \mu \mathrm{m}$ para a amostra 2 (S330 com tensionamento) e 18 $\mu \mathrm{m}$ para a amostra 3 (S390 com tensionamento), da mesma forma com que as medidas inicias da tensão residual possuem no momento em que ocorre o maior alívio de compressão, em $30 \mu \mathrm{m}$ para a amostra 1, $55 \mu \mathrm{m}$ para a amostra 2 e $35 \mu \mathrm{m}$ para a amostra 3.

As figuras 60, 61 e 62 mostram o gráfico relacionado ao comportamento da microdeformação em comparação a tensão residual das amostras 1,2 e 3, respectivamente. 


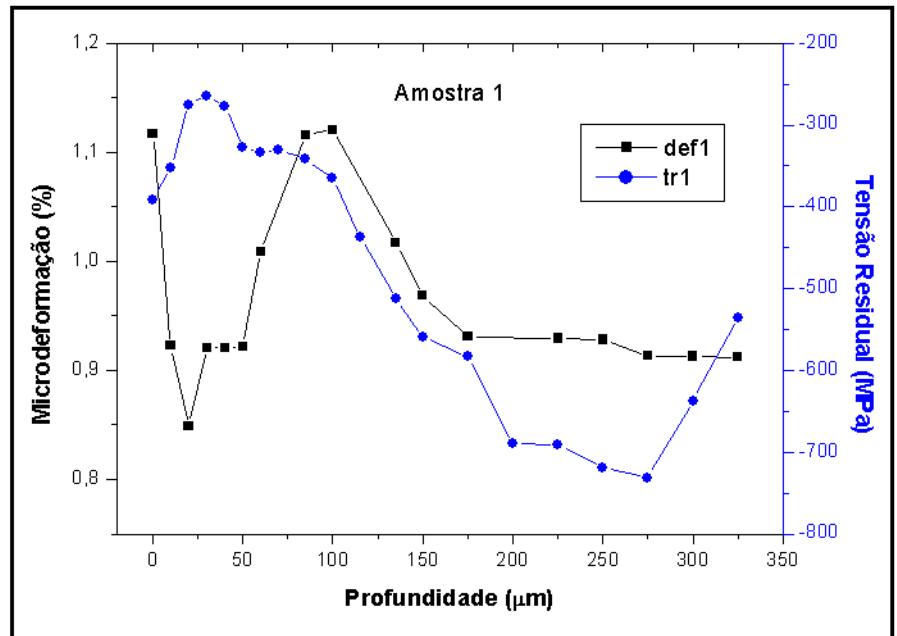

Figura 60: Gráfico comparativo entre a tensão residual e a microdeformação da rede da amostra 1 pelo método Willianson-Hall modificado.

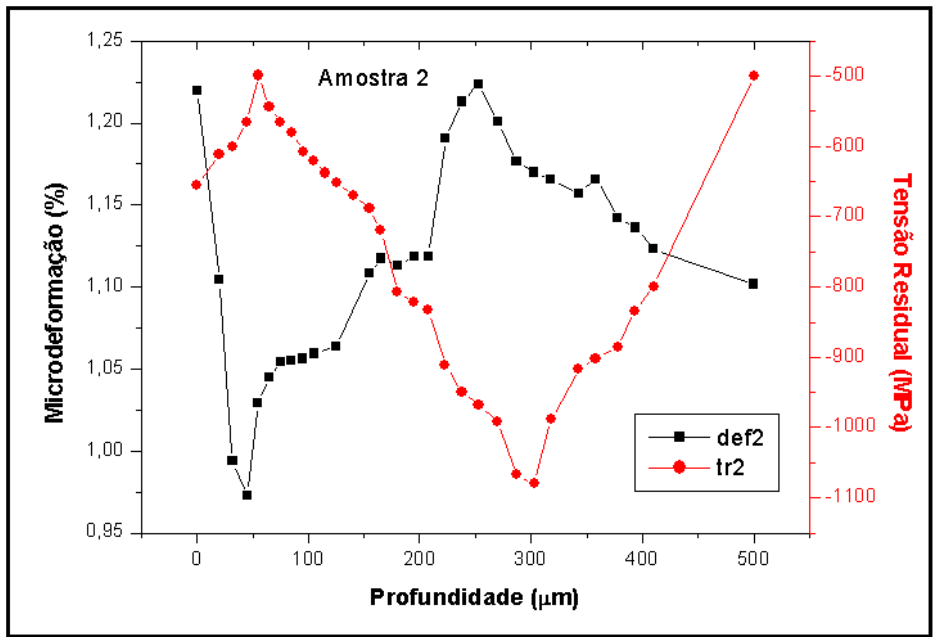

Figura 61: Gráfico comparativo entre a tensão residual e a microdeformação da rede da amostra 2 pelo método Willianson-Hall modificado.

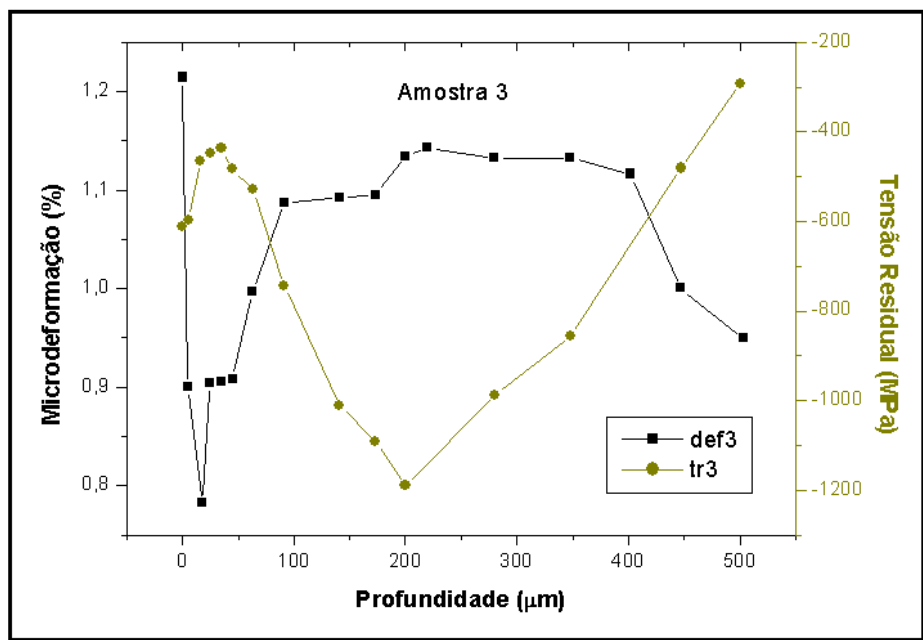

Figura 62: Gráfico comparativo entre a tensão residual e a microdeformação da rede da amostra 3 pelo método Willianson-Hall modificado. 
Desta forma pode se deduzir que a microdeformação correspondente ao deslocamento dos átomos na posição de equilíbrio, do qual consome a energia oriunda do jateamento por granalhas e outra parte fica para a tensão residual. A figura 63 mostra o comportamento dos átomos quando sujeitos a tensão residual e a microdeformação.

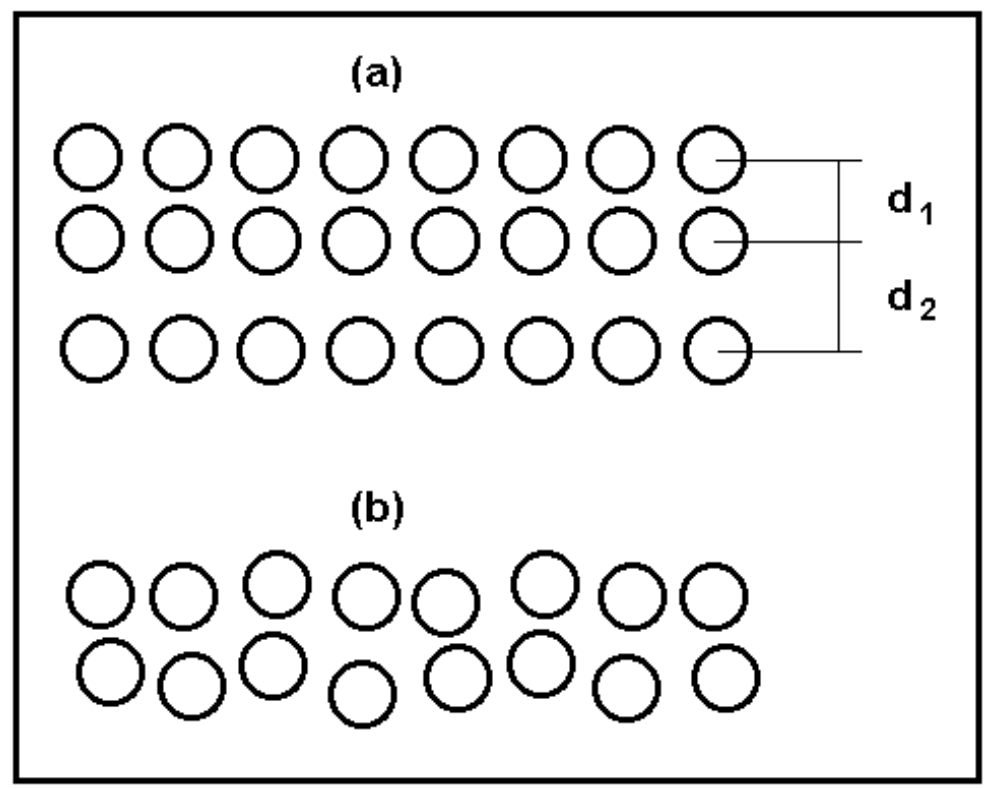

Figura 63: Deslocamentos dos átomos em relação a tensão residual (a) e a microdeformação da rede cristalina (b).

Desta forma torna-se possível relacionar o comportamento da curva de distribuição de tensão residual conjugadas aos valores de microdeformação da rede cristalina, ou seja o que infere às influências da macrotensão e da microtensão, pois conforme ocorre o alívio da tensão residual, a microdeformação decresce ao mesmo ponto na profundidade da amostra, o que demonstra que a microdeformação diminui quando o posicionamento dos átomos torna-se regular. Com o objetivo de proporcionar maior embasamento para este estudo, outras técnicas de análise do perfil de difração foram utilizadas.

$O$ uso das funções relacionadas ao alargamento dos picos obtidos pela difração de raios-x proporcionam uma série de estudos relacionados a estrutura do material dentre outros os relativos às microtensões da rede cristalina.

Pelo método Single Line (Delhez et al, 1982) os dados obtidos pela difração foram analisados pela razão entre a largura do pico a meia altura $2 w$ e a sua integral $\beta$, cujos valores foram processados pelo software Winfit!1.2. Foram 
selecionadas as amostras 2 e 3 (S330 e S390, respectivamente) jateadas com tensionamento. Neste método os dados de entrada foram os perfis dos planos (110), (200) e (220). Os resultados estão apresentados nos gráficos da figura 64 (amostra 2) e figura 65 (amostra 3)

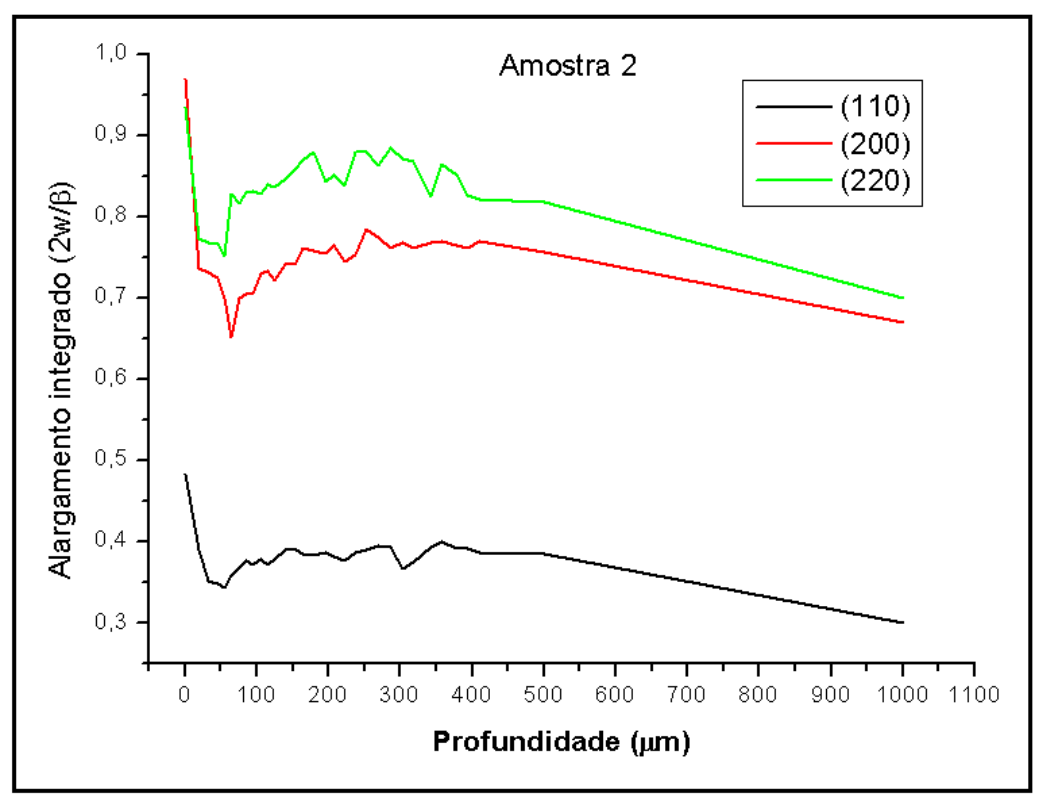

Figura 64: Gráficos da distribuição do alargamento integrado em relação a profundidade da amostra 2.

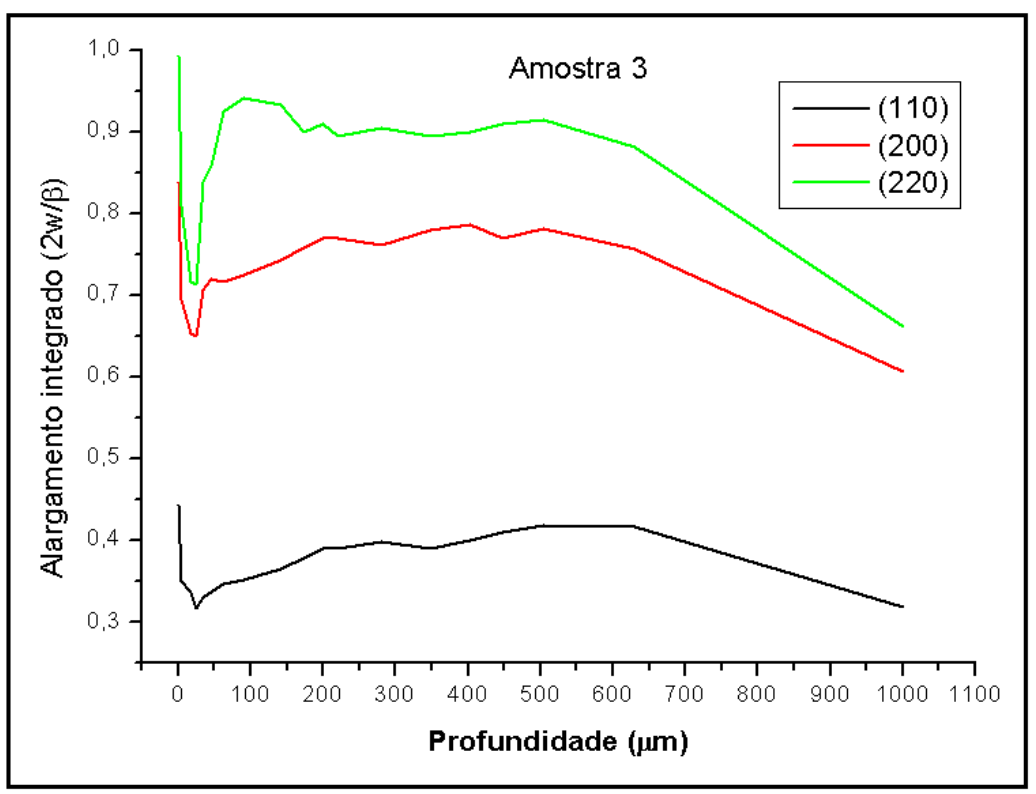

Figura 65: Gráficos da distribuição do alargamento integrado em relação a profundidade da amostra 3. 
Esta análise tem por base uma avaliação da variação da microdeformação e do tamanho de cristalito na amostras visto que ambos estudos baseiam-se na variação do alargamento do pico difratado. Neste sentido, a princípio nota-se que para cada plano a faixa de variação ocorreu em diferentes valores, o que deduz que as microtensões atuam distintamente em diferentes planos devido as susceptibilidades das deformações e planos de escorregamento.

Observando as camadas iniciais das amostras, o mesmo comportamento é descrito pela análise utilizando o método de Williamson-Hall modificado em que a variação tende a um decréscimo até a profundidade aproximada de $50 \mu \mathrm{m}$ na amostra 2 e $30 \mu \mathrm{m}$ na amostra 3 , que por sua vez conferem uma notável semelhança com a região da queda de compressibilidade das análises de tensão residual.

As figuras 66 e 67 mostram a comparação do comportamento entre as curvas de distribuição da tensão residual e a variação do alargamento pelo método Single Line das amostras 2 e 3 , respectivamente.

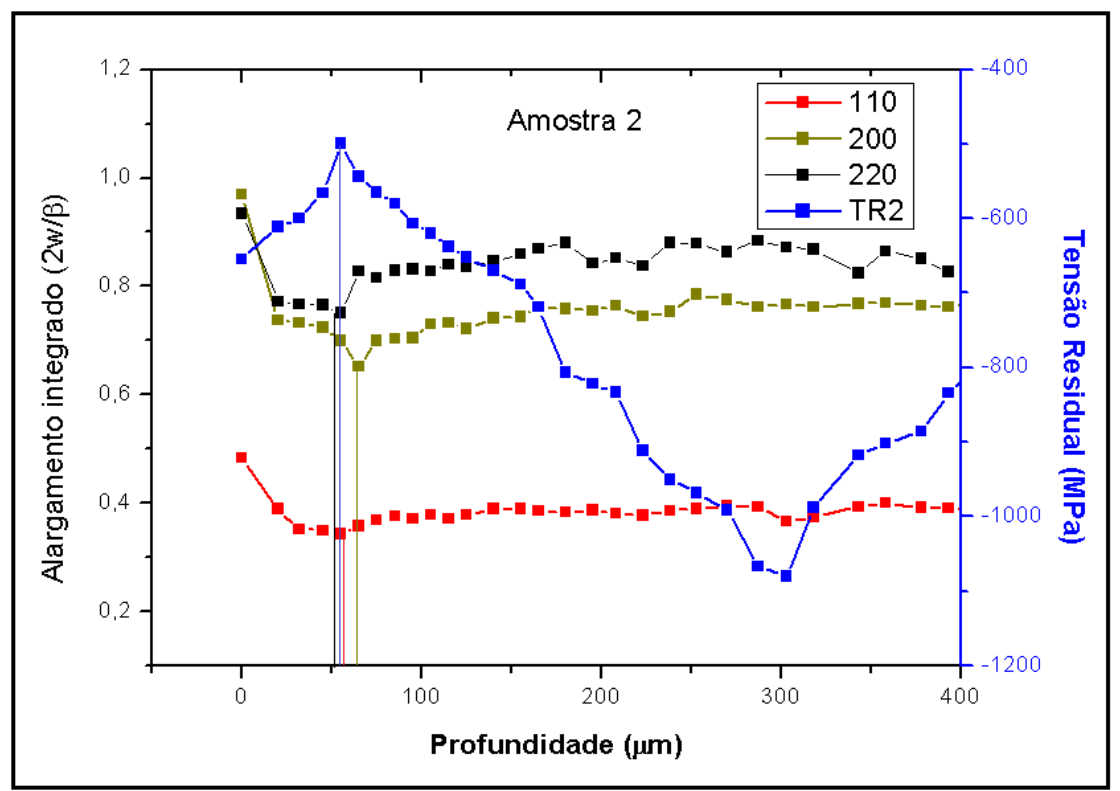

Figura 66: Gráfico comparativo entre a tensão residual e o alargamento integrado da amostra 2. 


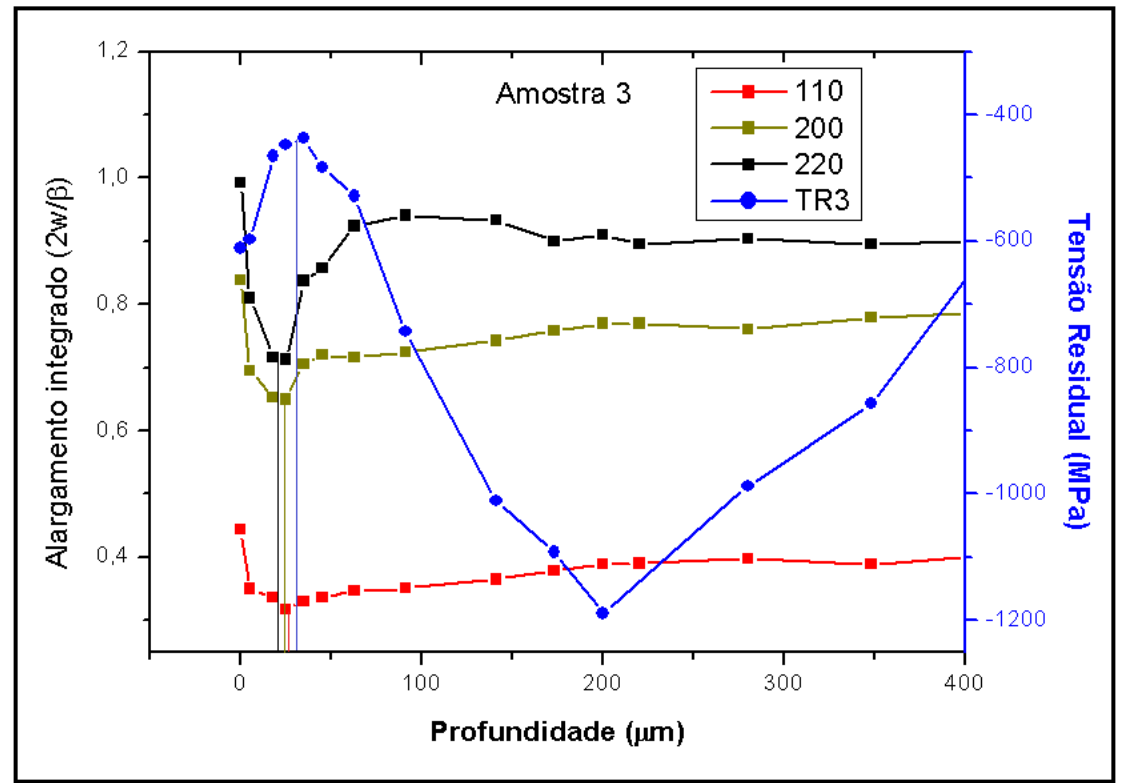

Figura 67: Gráfico comparativo entre a tensão residual e o alargamento integrado da amostra 3.

Nota-se o comportamento do perfil da tensão residual com o comportamento relativo com as microtensões e tamanho de cristalito nas camadas iniciais onde o ponto de máximo alivio de tensão residual compressiva se compara a profundidade onde o alargamento integrado é menor (próximo de $50 \mu \mathrm{m}$ na amostra 2 e $30 \mu \mathrm{m}$ na amostra 3).

Segue assim o estudo das microdeformações da rede cristalina aplicada aos perfis das difrações utilizando as funções Cauchy e Gaussiana (Langford et al., 1978, Keijser et al., 1982).

Os resultados estão demonstrados pelas figuras 68 e 69 das amostras 2 e 3 respectivamente, supondo que o tamanho médio de cristalito seja fixo. 


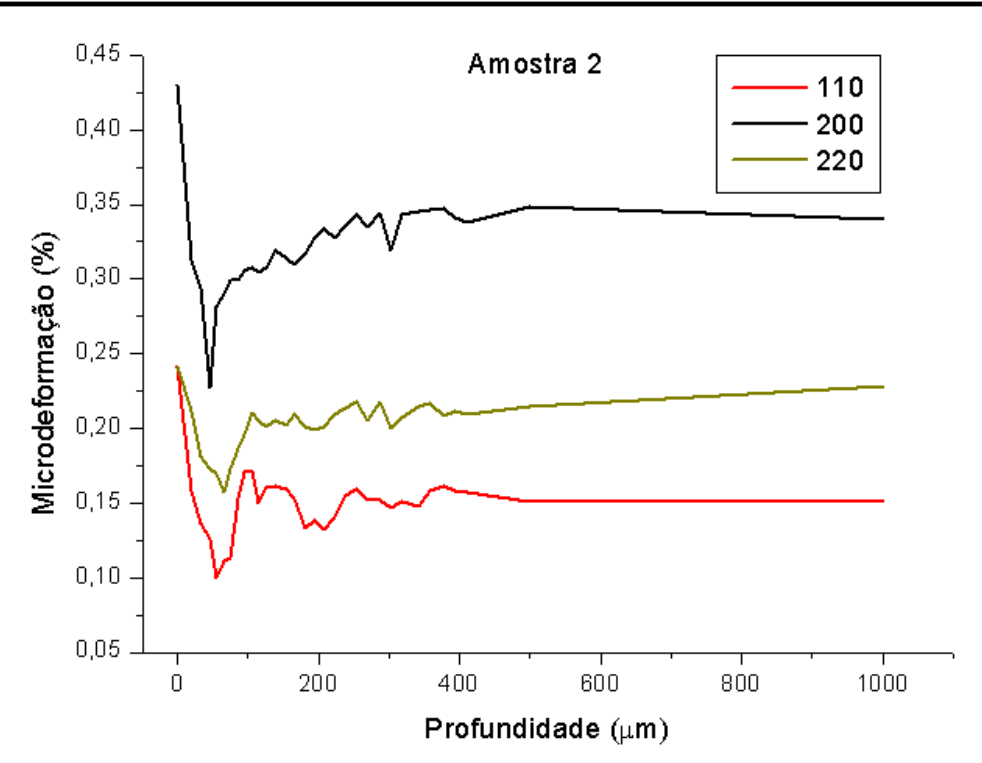

Figura 68: Gráficos da distribuição da microdeformação da rede cristalina em relação a profundidade da amostra 2 pelo método Single Line por distribuição.

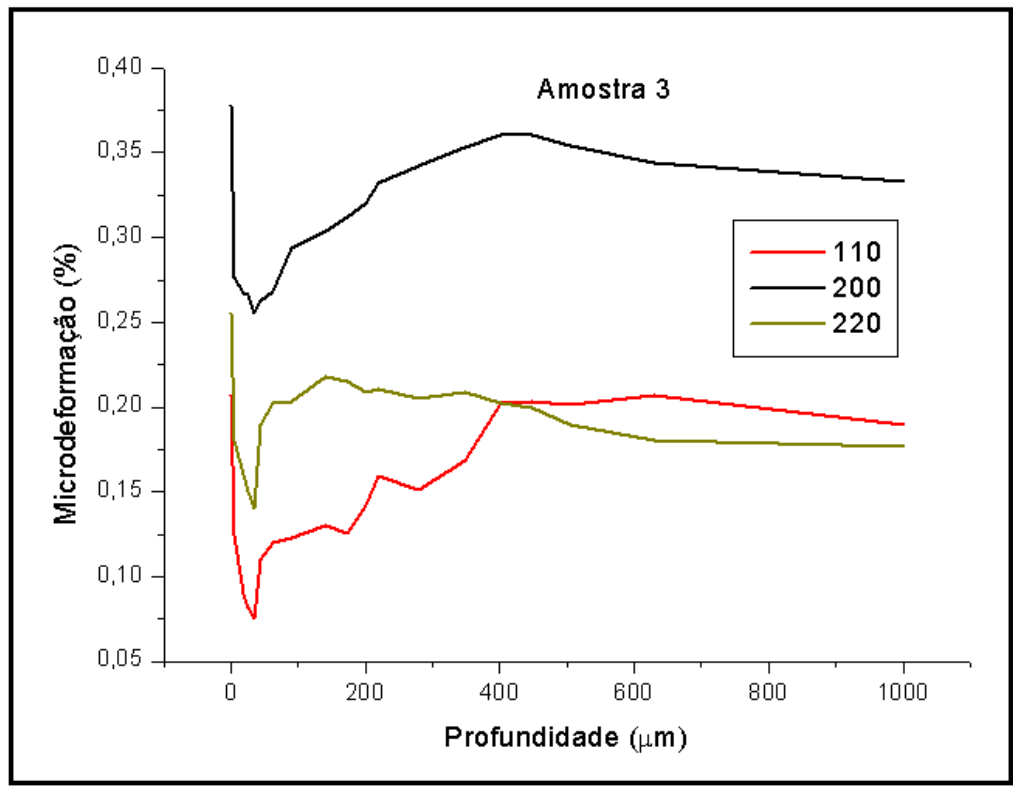

Figura 69: Gráficos da distribuição da microdeformação da rede cristalina em relação a profundidade da amostra 3 pelo método Single Line por distribuição.

Os resultados das distribuições das microdeformações pelo método Single Line possuem grande semelhança com os resultados proporcionados pelo método Willianson-Hall modificado com a diminuição dos valores de deformação na profundidade de $50 \mu \mathrm{m}$ na amostra 2 e $30 \mu \mathrm{m}$ na amostra 3, com o comportamento comparável a distribuição de tensão residual nas camada próximas à superfície, mostrado nas figuras 70 e 71 . 


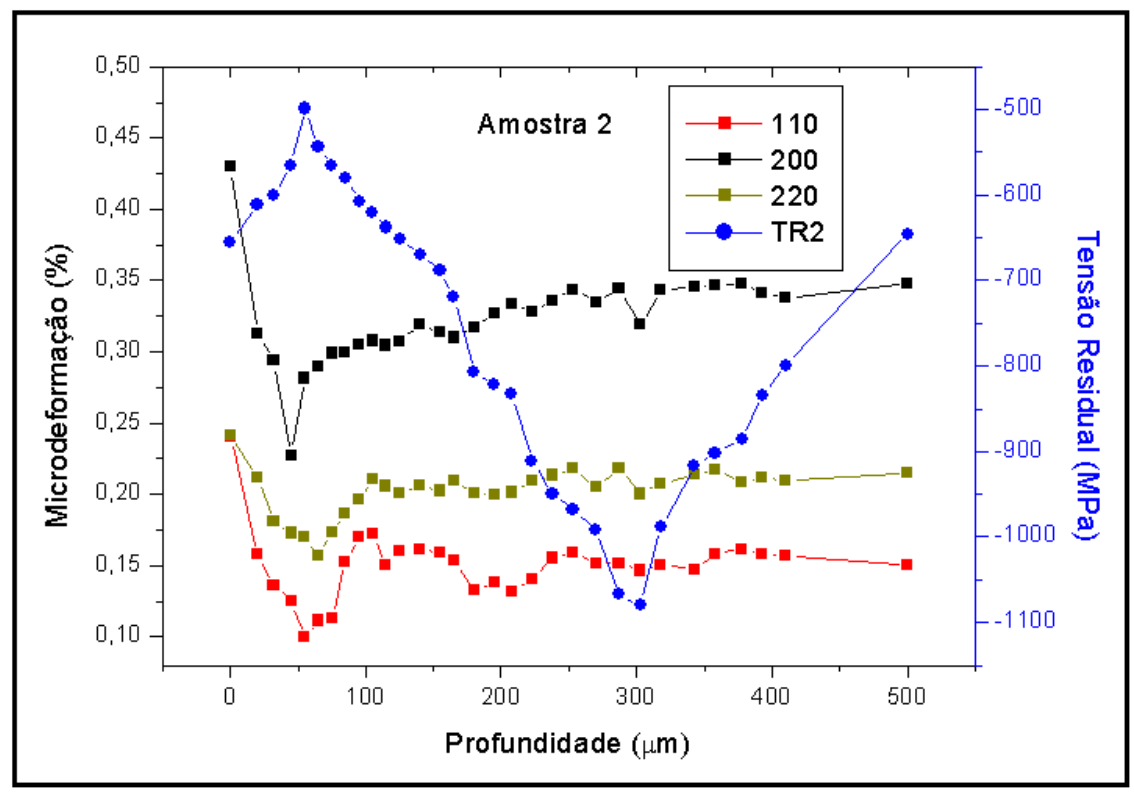

Figura 70: Gráfico comparativo entre a tensão residual e a microdeformação da rede cristalina da amostra 2 pelo método Single Line por distribuição.

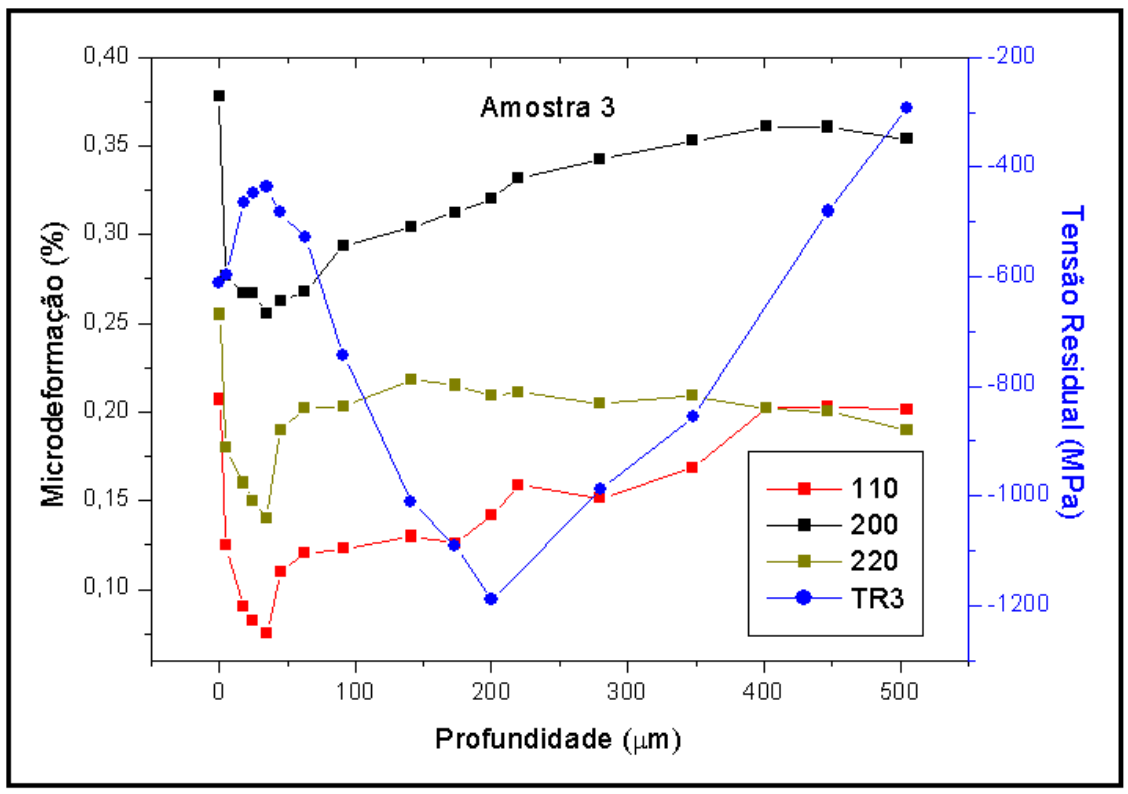

Figura 71: Gráfico comparativo entre a tensão residual e a microdeformação da rede cristalina da amostra 2 pelo método Single Line por distribuição.

A seguir, o perfil das difrações de raios-x foram analisadas pelo método de Warren Averbach por distribuição, utilizando os planos paralelos (110) e (220), e o resultado das amostras 2 e 3 se encontram nos gráficos apresentados nas figuras 72 e 73 , respectivamente. 


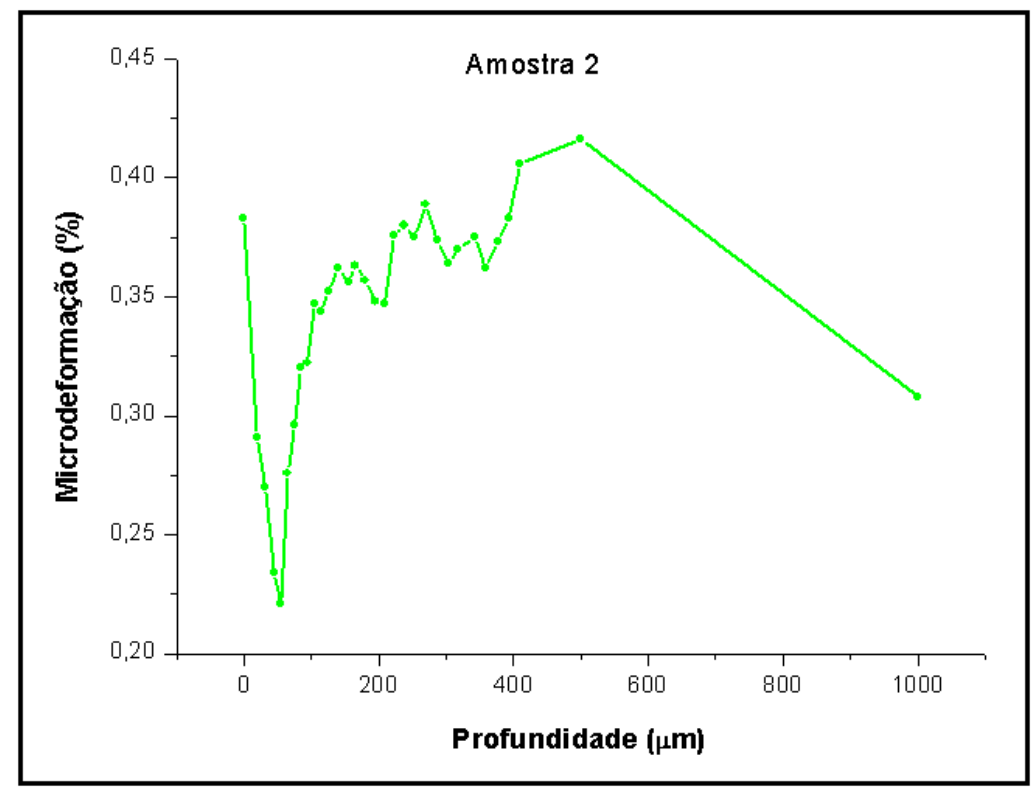

Figura 72: Gráfico da distribuição da microdeformação em relação a profundidade da amostra 2 pelo método Warren-Averbach por distribuição.

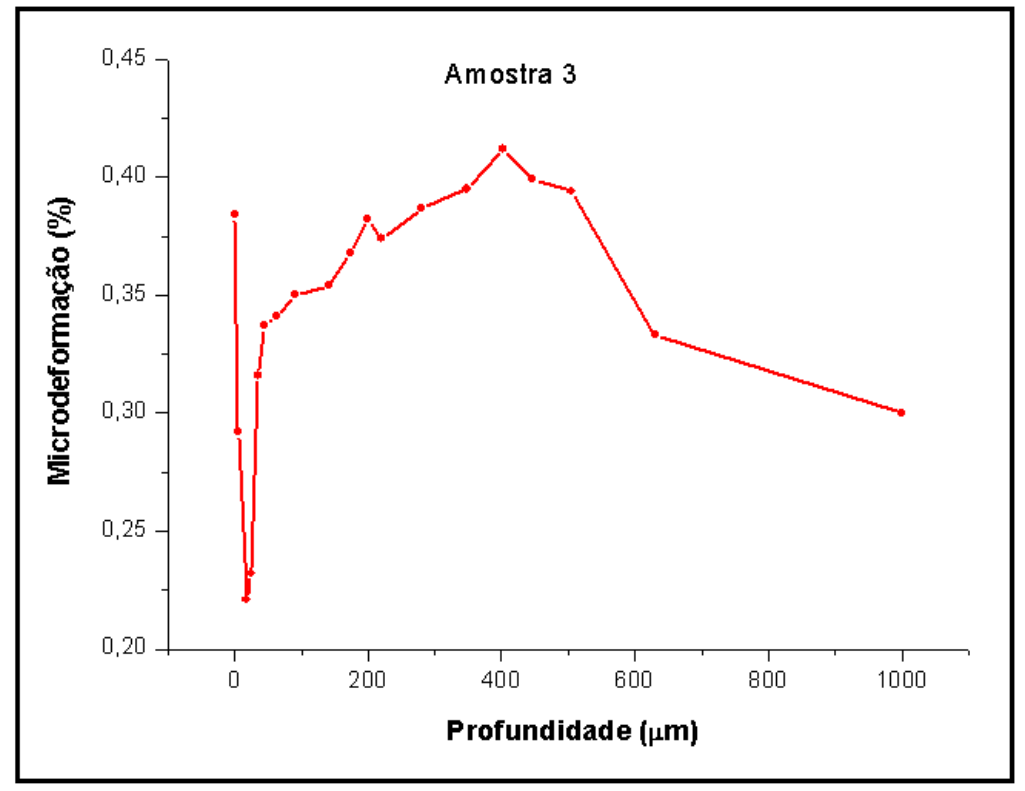

Figura 73: Gráfico da distribuição da microdeformação em relação a profundidade da amostra 3 pelo método Warren-Averbach por distribuição

Assim como apresentado na figuras 67 e 68, similarmente, o comportamento da curva de distribuição da microdeformação da rede cristalina obtida pelo método Warren-Averbach pode ser comparada com a relação da distribuição da tensão residual na amostra. A visualização poderá ser feita por meio da sobreposição dos perfis da microdeformação e da tensão residual, mostrada na figuras 74 e 75 : 


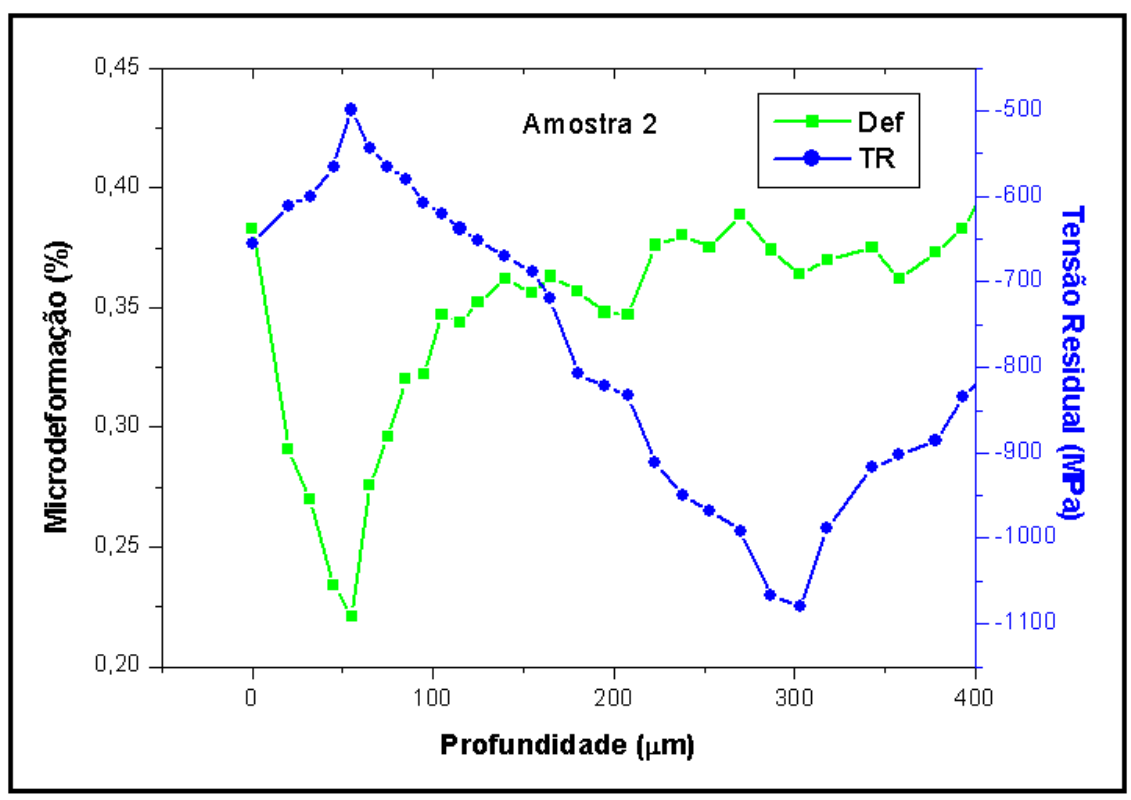

Figura 74: Gráfico comparativo entre a tensão residual e a microdeformação da rede da amostra 2 pelo método Warren-Averbach por distribuição.

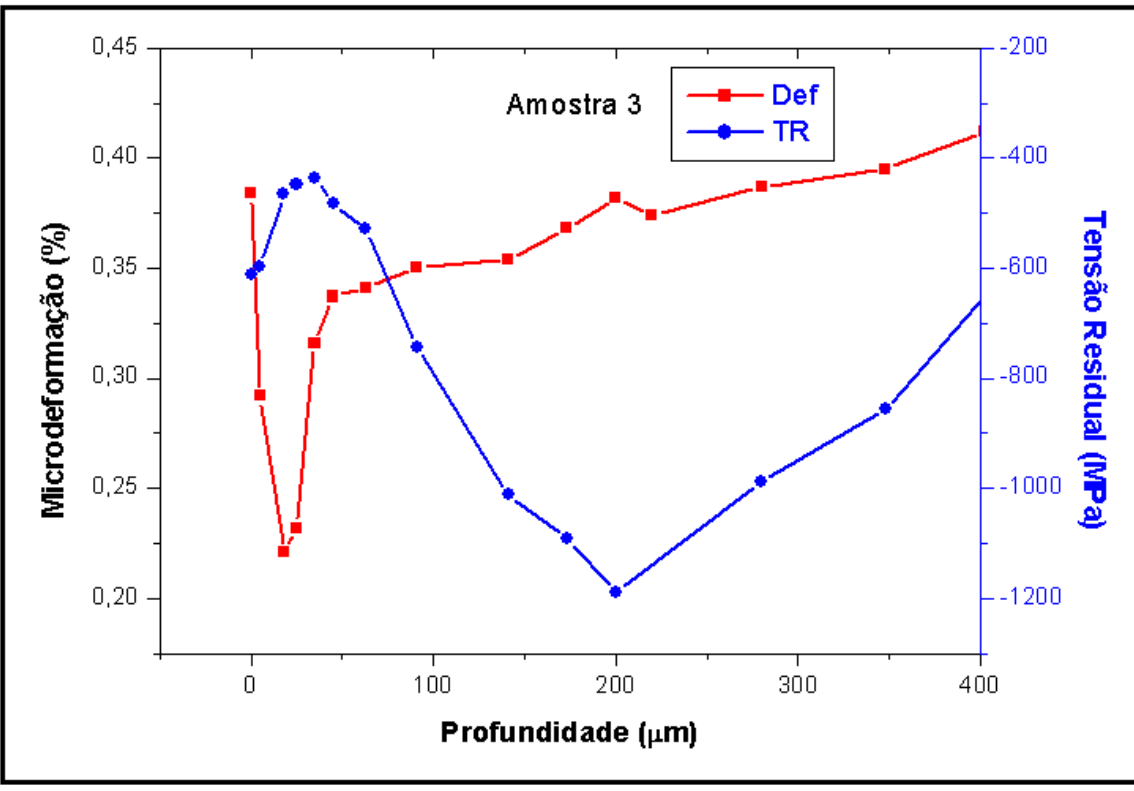

Figura 75: Gráfico comparativo entre a tensão residual e a microdeformação da rede da amostra 3 pelo método Warren-Averbach por distribuição

Seguindo a ordem dos métodos analisados, os resultados se mantiveram com o mesmo comportamento visto anteriormente nos métodos de Williamson-Hall e o Single Line, observando que no método Warren-Averbach os pontos iniciais ocorreram com a melhor definição da curva pela diminuição da microdeformação da rede, o que facilita a determinação do estudo do efeito comparativo com o perfil de tensão residual pelo fato de se aplicar duas ordens de reflexão nos planos paralelos (110) e (220). 
Pelo método Single Line os perfis de difração de raios-x foram analisados para a obtenção do tamanho médio de cristalito nas amostras 2 e 3, utilizando o software Winfit!1.2, calculando os dados obtidos pelo perfil da difração dos planos (110), (200) e (220) na distribuição pela profundidade das amostras. O tamanho médio de cristalitos se dá na intersecção da reta extrapolada à inclinação inicial na curva do gráfico no eixo que representa o domínio do tamanho de cristalito, dado em angstrons, em relação ao coeficiente real de Fourier $\left(A_{n}\right)$. Na figura 76, é mostrado como exemplo o gráfico obtido para a amostra 2 , em análise na profundidade de 20 $\mu \mathrm{m}$, no plano (110).

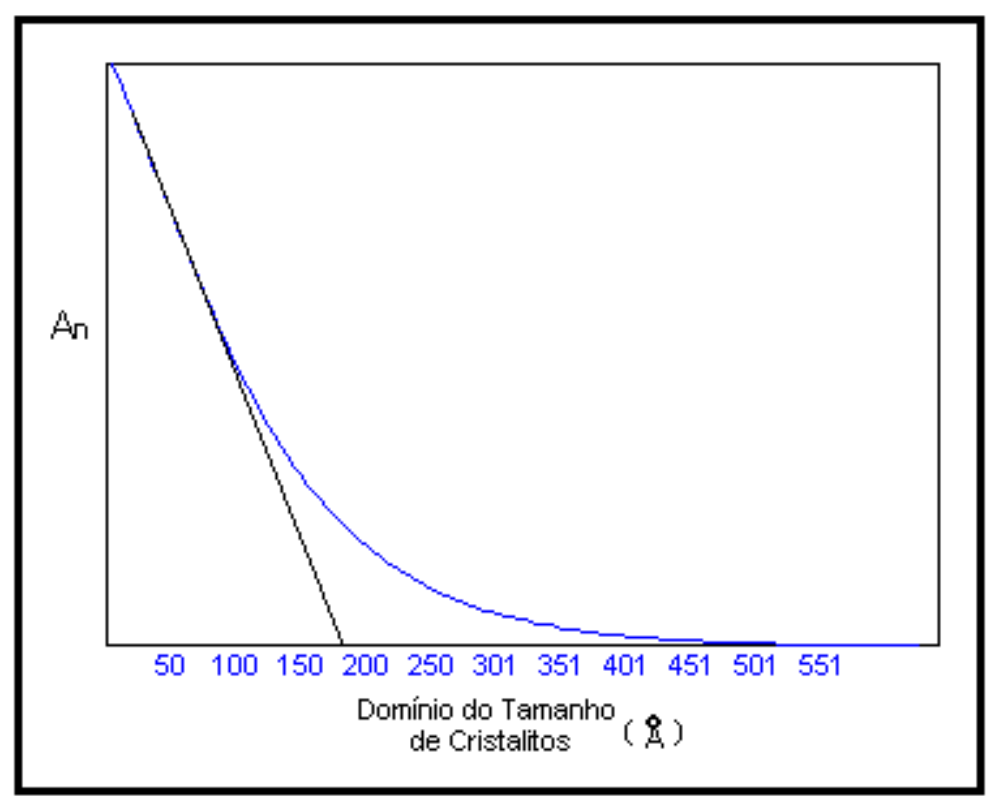

Figura 76: Gráfico para obtenção dos valores do tamanho médio do cristalito obtidos pelo método Single Line pela inclinação

Pelo intercepto no eixo x obtém-se os valores dos tamanhos médios dos cristalitos e o resultado da distribuição das amostras 2 e 3 são mostradas nos gráficos das figuras 77 e 78. 


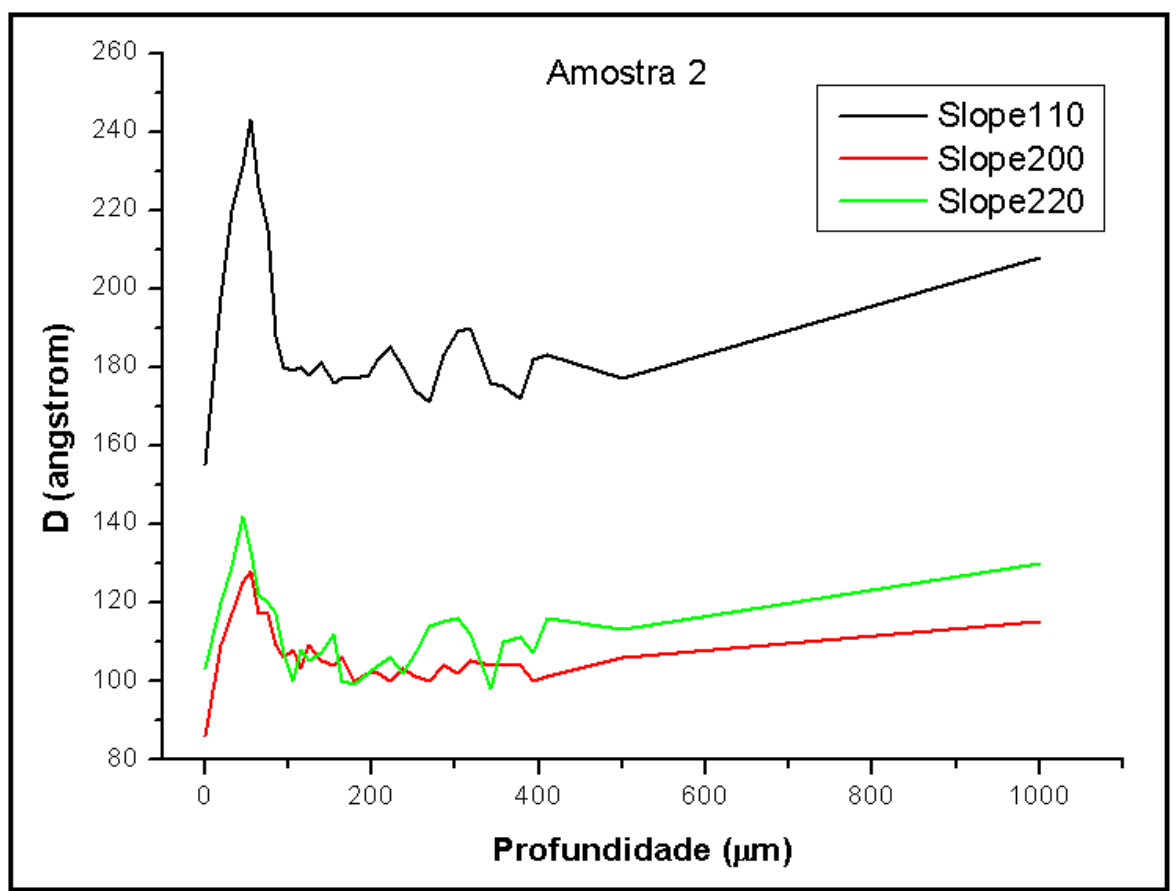

Figura 77: Gráficos da distribuição do tamanho médio dos cristalitos em relação a profundidade da amostra 2 pelo método Single Line pela inclinação.

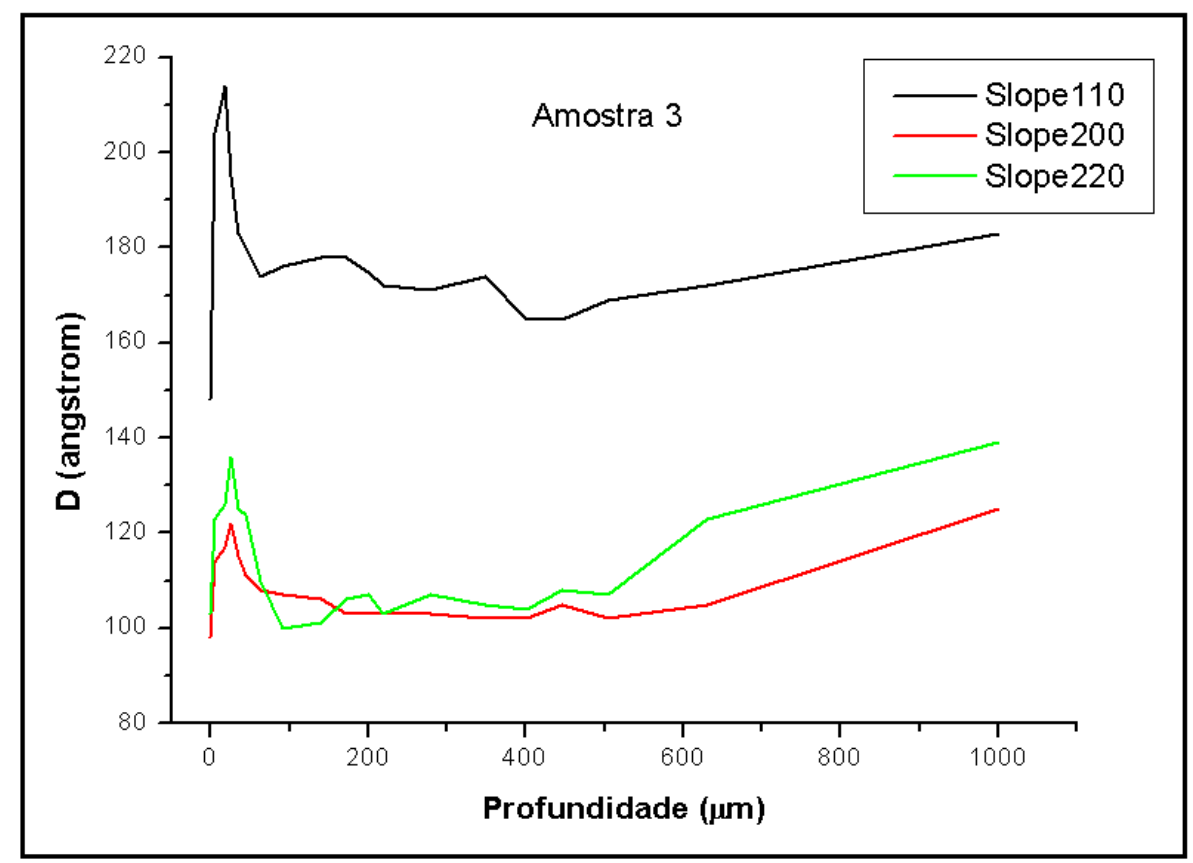

Figura 78: Gráficos da distribuição do tamanho médio dos cristalitos em relação a profundidade da amostra 3 pelo método Single Line pela inclinação.

Contudo, observa-se a proporcionalidade, porém de forma inversa do tamanho de cristalito em relação a microdeformação da rede, observados nas figuras 72 e 73, visto que é de conhecimento que existe uma relação direta entre ambos, se acompanhar os pontos iniciais das análises em profundidade, os pontos 
de maior tamanho de cristalitos se encontram próximos aos pontos de alívio na tensão residual, ou seja, $50 \mu \mathrm{m}$ para a amostra 2 e $20 \mu \mathrm{m}$ na amostra 3, sendo que por estas informações, fica evidente a influência da microdeformação da rede, do tamanho de cristalito no valor da tensão residual, que por sua vez está ligada com as propriedades da resistência à fadiga. Nota-se que o tamanho de cristalito possui valores diferentes para cada plano cristalográfico, conforme já comentado, refere-se as diferenças da susceptibilidade de cada plano à deformação. Assim como foi realizado em outras análises, pode-se fazer um comparativo demonstrado graficamente entre as o perfil da tensão residual e do tamanho de cristalito, conforme as figuras 79 e 80 , respectivamente às amostras 2 e 3 .

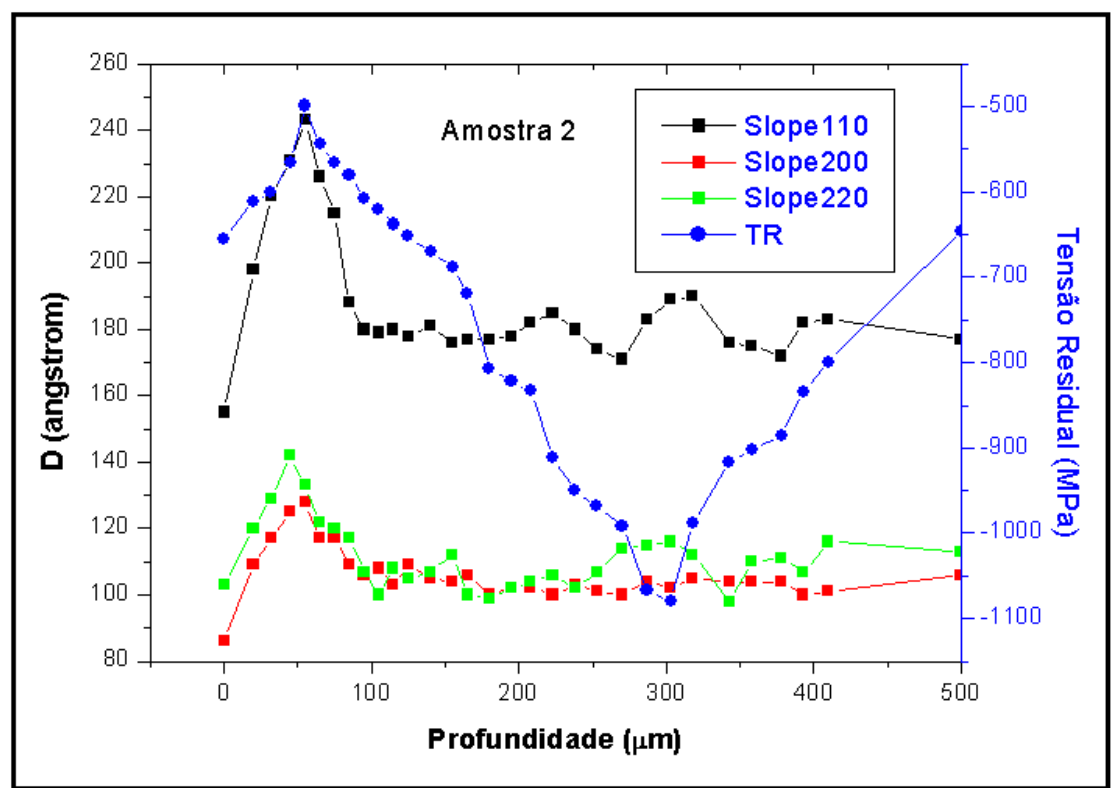

Figura 79: Gráficos comparativos entre a tensão residual e tamanho de cristalitos da amostra 2 pelo método Single Line pela inclinação 


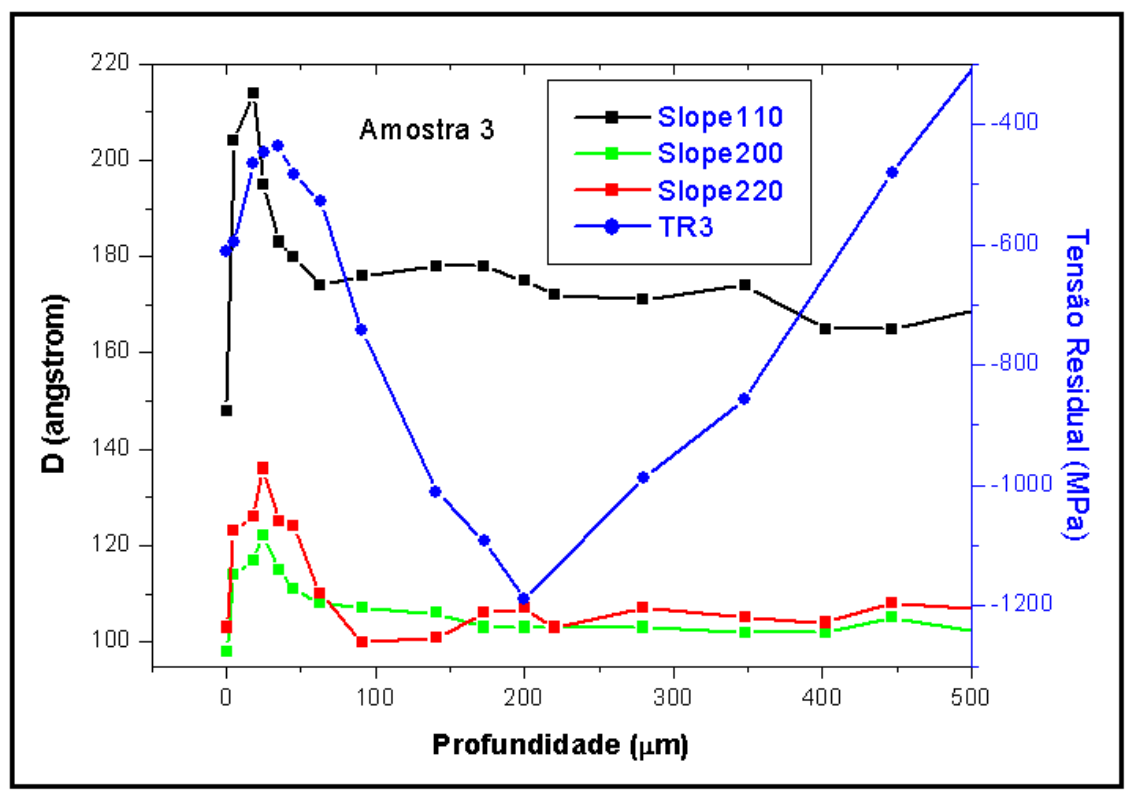

Figura 80: Gráficos comparativos entre a tensão residual e tamanho de cristalitos da amostra 3 pelo método Single Line pela inclinação

A intersecção da reta extrapolada do coeficiente real de Fourier permite a avaliação do tamanho de cristalito pelo método Warren-Averbach. Os dados coletados pelo Winfit!1.2 são mostrados pelo gráfico gerado na figura 81 , no exemplo, a expansão dos valores dos coeficientes de Fourier e seu conjugado da intersecção no eixo dos cristalitos da amostra 2 em ataque à profundidade de $20 \mu \mathrm{m}$.

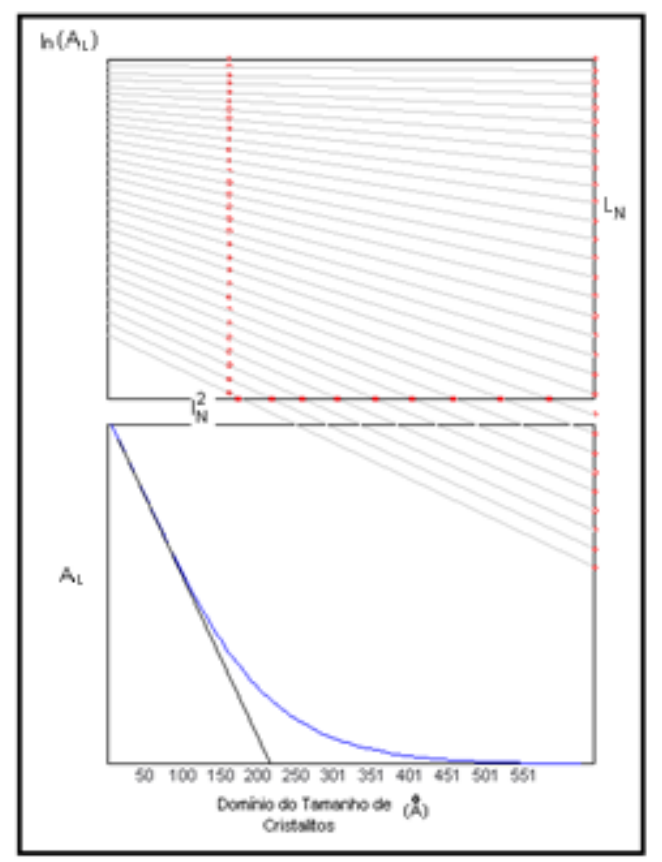

Figura 81: Gráfico para obtenção dos valores do tamanho médio do cristalito obtidos pelo método Warren-Averbach pela inclinação 
Os resultados das análises pelo método Warren-Averbach para as amostras 2 e 3 foram obtidos nas medições do perfil nas profundidades (figuras 82 e 83).

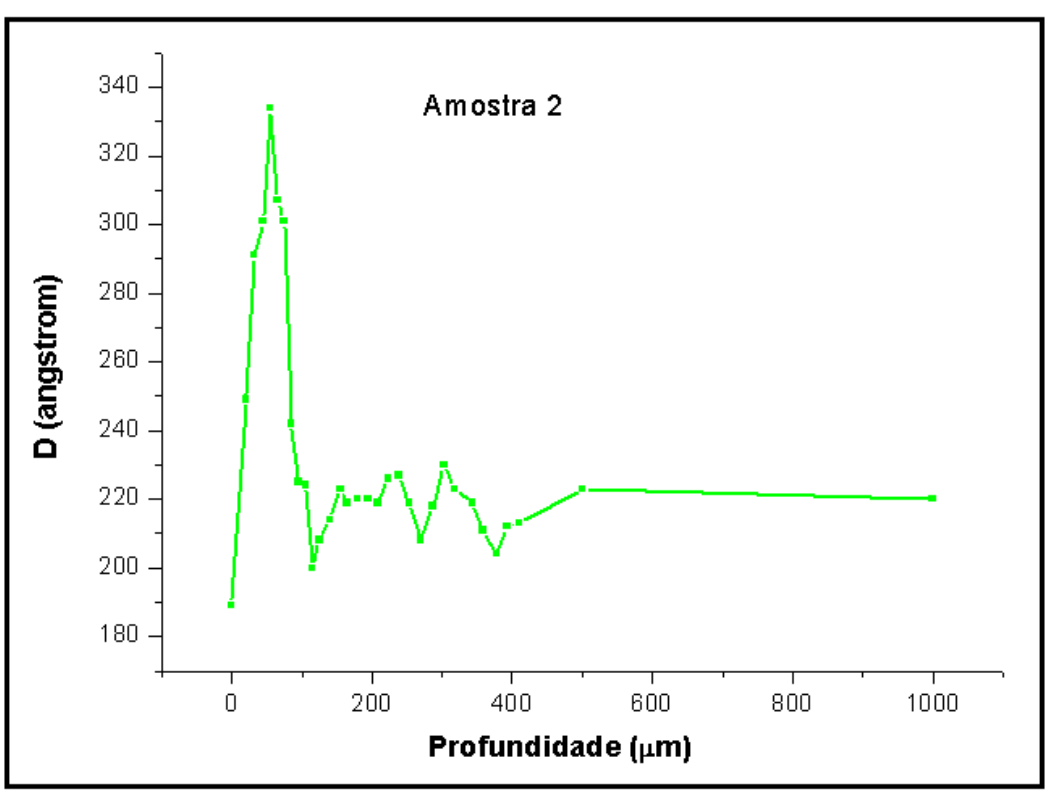

Figura 82: Gráfico da distribuição do tamanho médio dos cristalitos em relação a profundidade da amostra 2 pelo método Warren-Averbach pela inclinação.

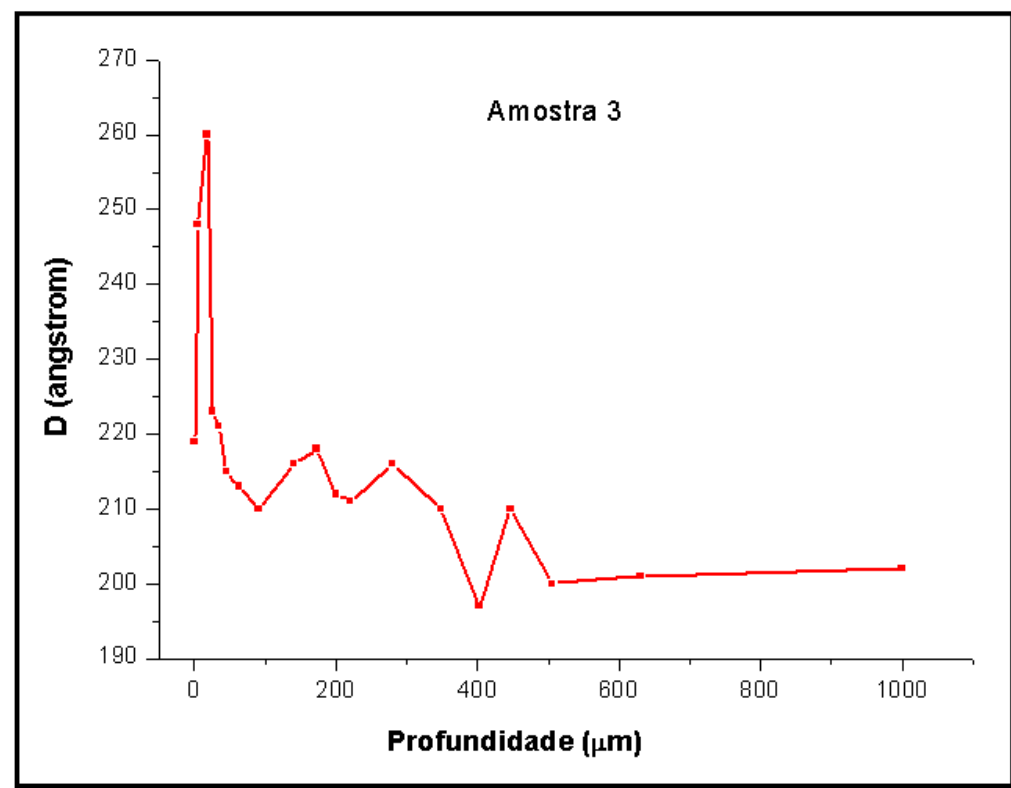

Figura 83: Gráfico da distribuição do tamanho médio dos cristalitos em relação a profundidade da amostra 3 pelo método Warren-Averbach pela inclinação.

A comparação das curvas com o perfil de tensão residual obteve a similaridade com os resultados apresentados pelo método Single Line. O que se observa é o fato da existência da diferença entre as forças correspondentes ao deslizamento em cada plano cristalino, que pode ser notado pelos diferentes valores 
encontrados tanto nas análises de microdeformação quanto no tamanho de cristalito. As figuras 84 e 85 mostram a distribuição do tamanho de cristalito em relação ao perfil de tensão residual das amostras 2 e 3 , respectivamente:

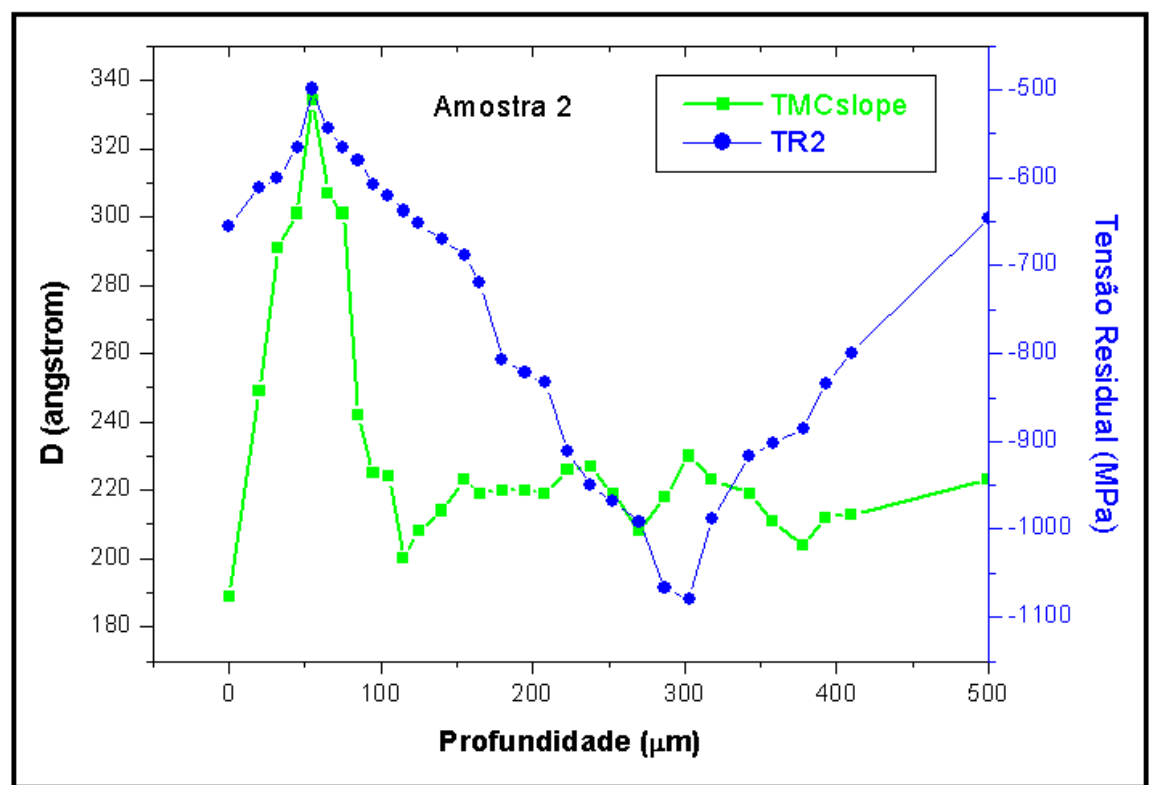

Figura 84: Gráfico comparativo entre a tensão residual e tamanho de cristalitos da amostra 2 pelo método Warren-Averbach pela inclinação

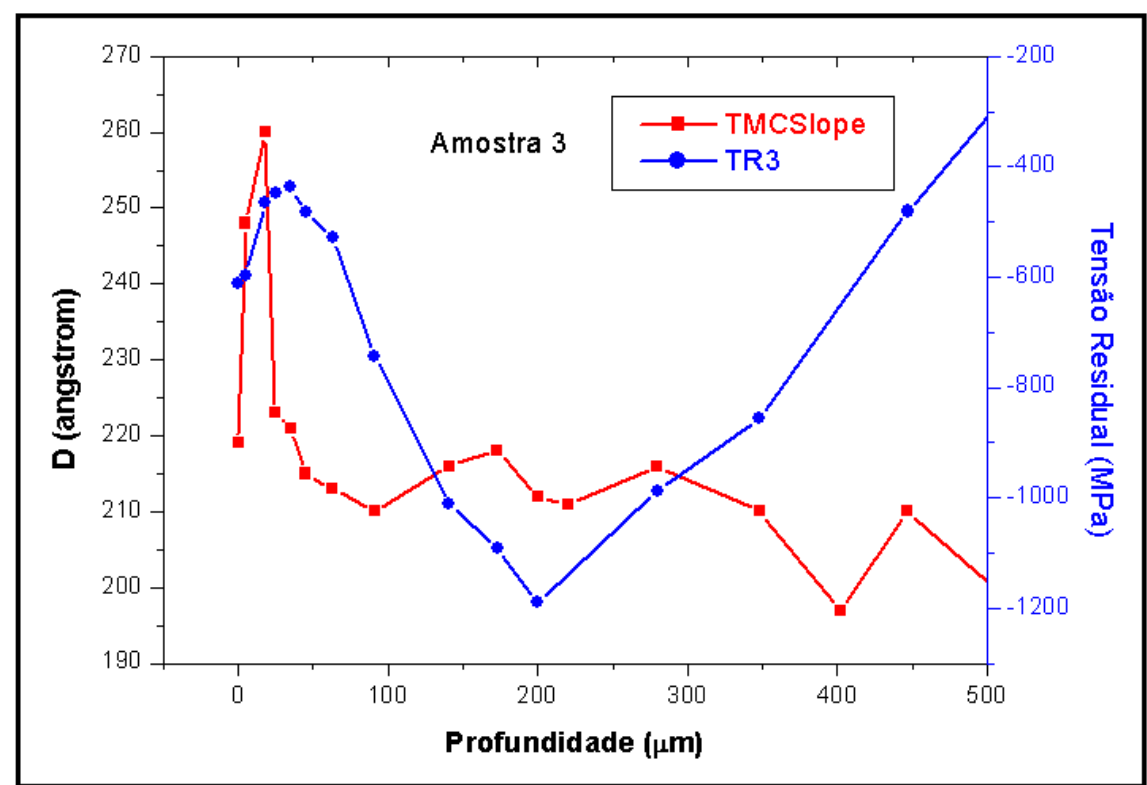

Figura 85: Gráfico comparativo entre a tensão residual e tamanho de cristalitos da amostra 3 pelo método Warren-Averbach pela inclinação

Os valores encontrados no pico de maior tamanho de cristalito e alívio de tensão residual nas camadas próximos à superfície são muito semelhantes em cada 
amostra, do que requer maior atenção nos possíveis efeitos que podem ser causados nas propriedades mecânicas do material em estudo.

Por outro lado, o software Winfit!1.2 oferece por meio do método Single Line outra forma de avaliação do tamanho de cristalito utilizando a curva da distribuição do tamanho de cristalito relativo e cumulativo da análise de Fourier, demonstrado pelo gráfico da figura 86 .

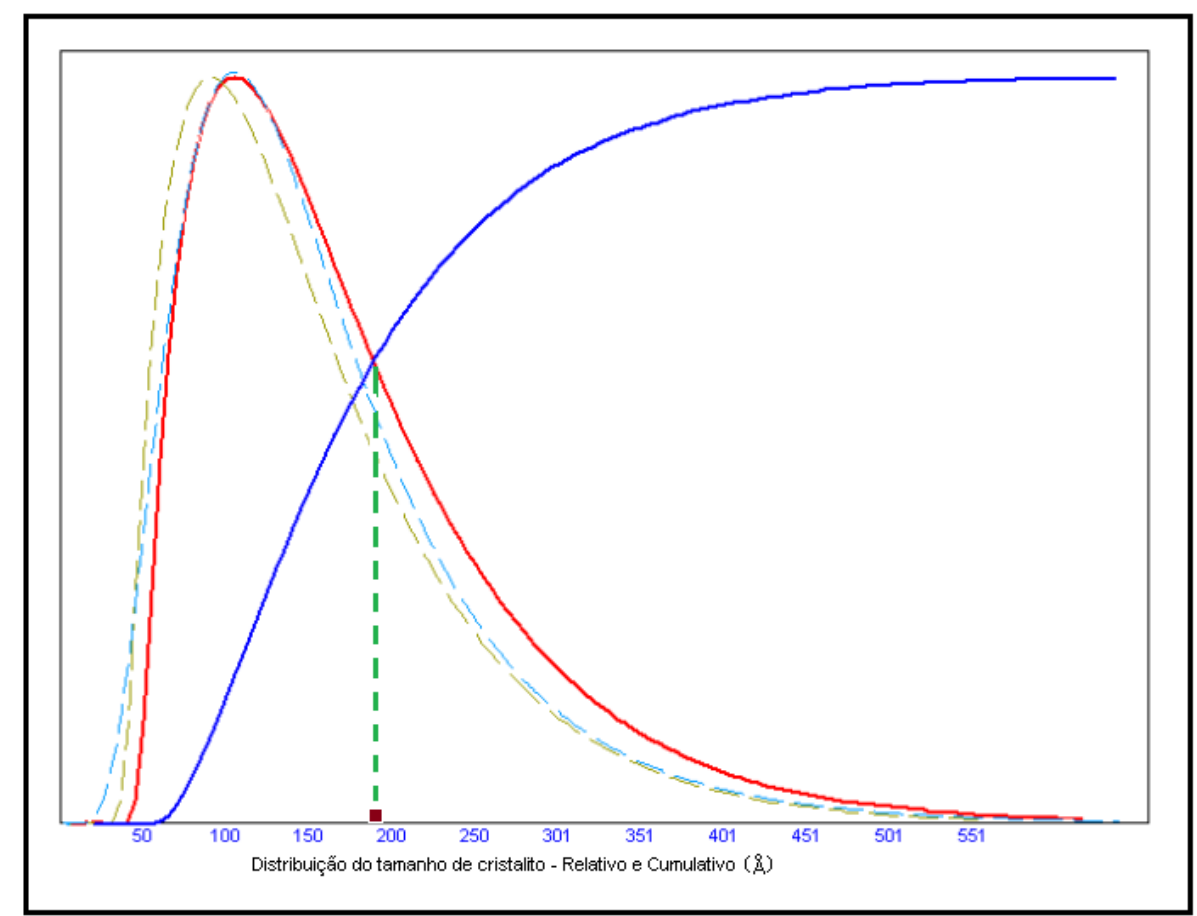

Figura 86: Gráfico para obtenção dos valores do tamanho médio dos cristalitos pelo método Single Line por distribuição.

Onde o cruzamento das linhas, no intercepto do eixo horizontal fornece o valor do cristalito, neste caso, da amostra 2 no plano (110) em $20 \mu \mathrm{m}$ de profundidade do ataque. $O$ resultado das análises estão representados nas figuras 87 e 88 , para as amostras 2 e 3 , respectivamente. 


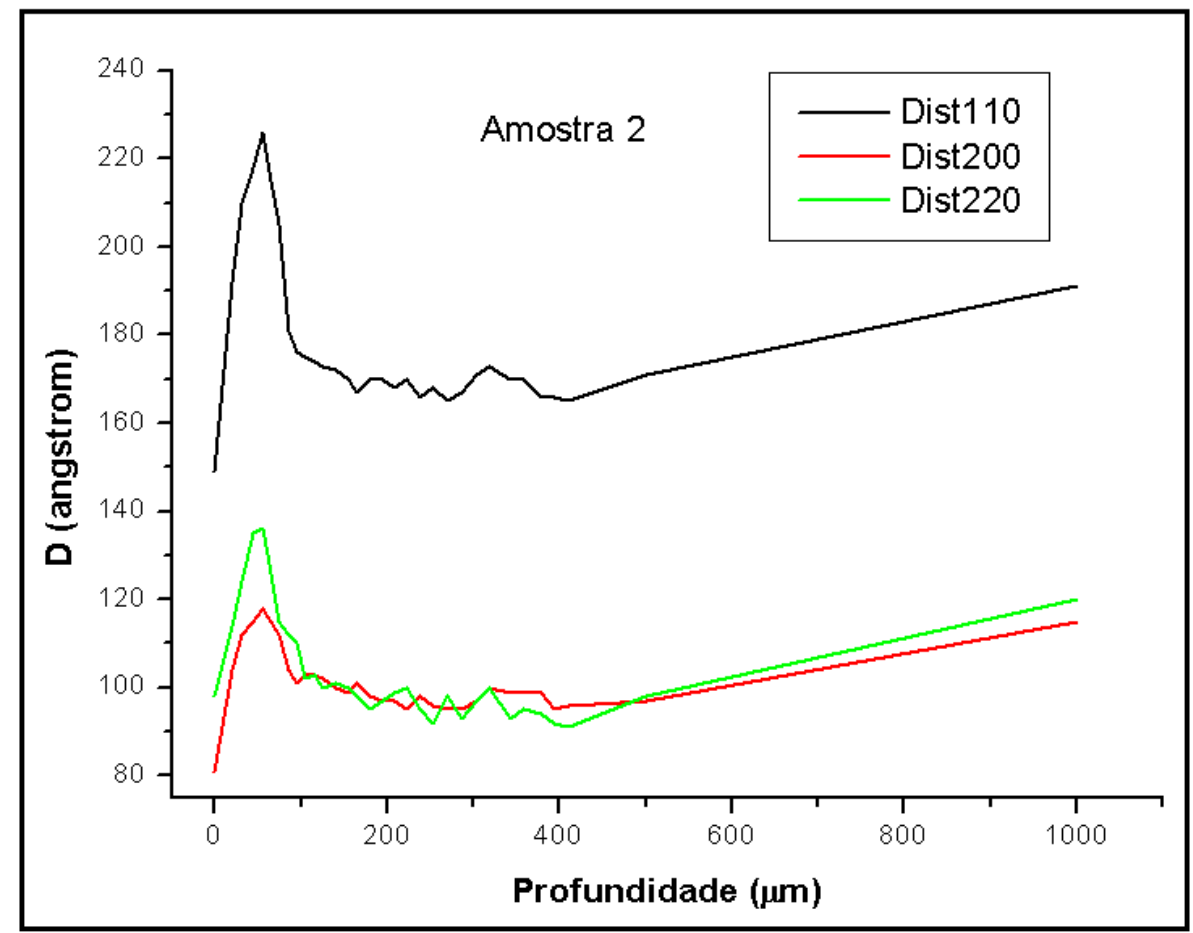

Figura 87: Gráficos da distribuição do tamanho médio dos cristalitos em relação a profundidade da amostra 2 pelo método Single Line pela distribuição.

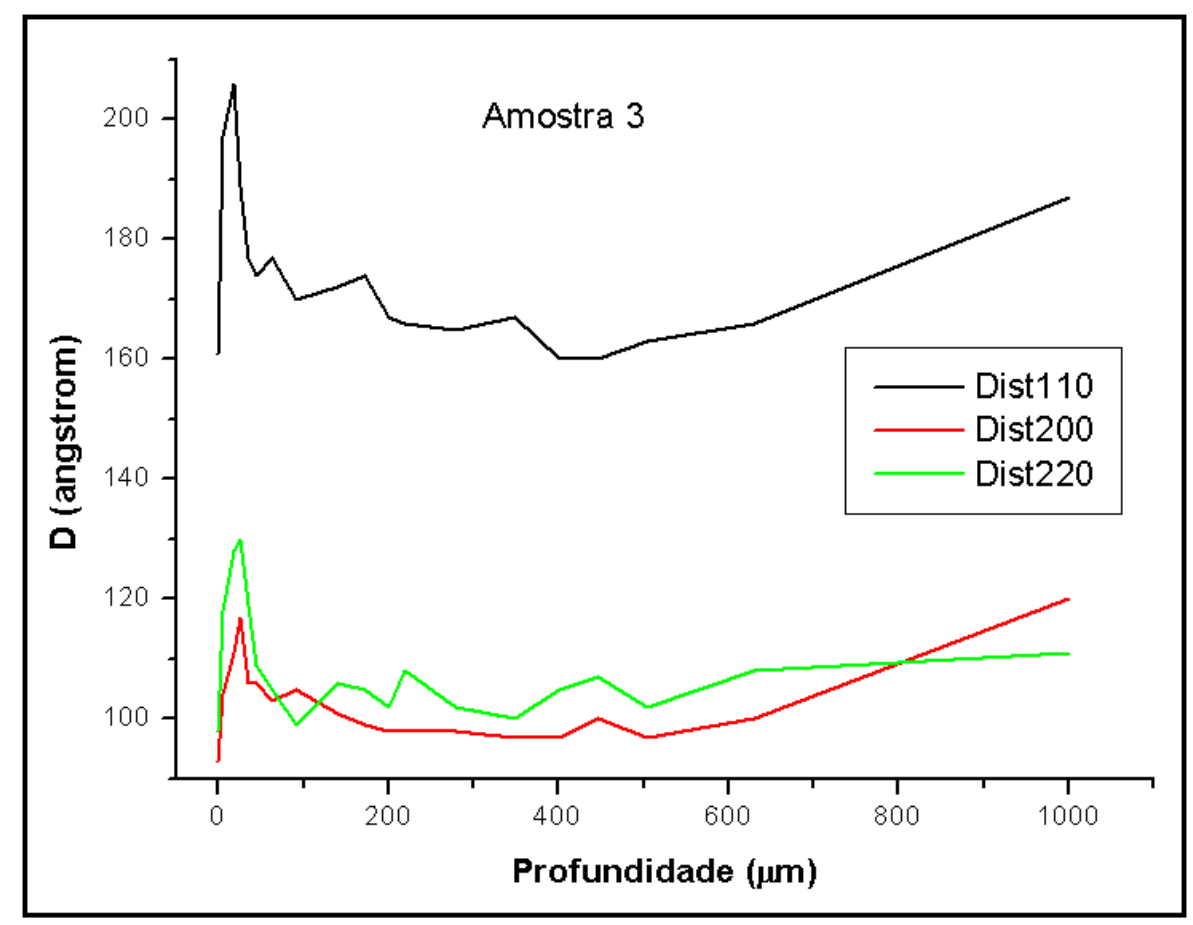

Figura 88: Gráficos da distribuição do tamanho médio dos cristalitos em relação a profundidade da amostra 3 pelo método Single Line pela distribuição.

Ao realizar a comparação com os dados resultantes da tensão residual obtemos os gráficos mostrados nas figuras 89 e 90, das amostras 2 e 3 respectivamente: 


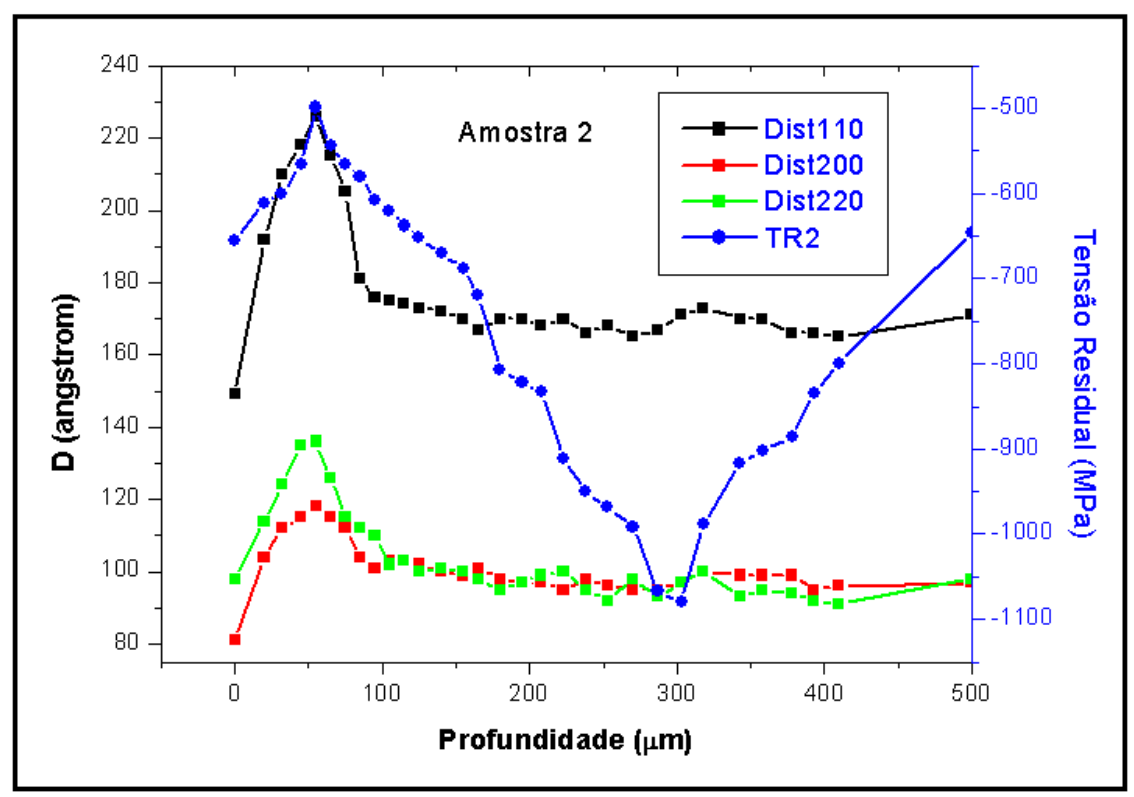

Figura 89: Gráficos comparativos entre a tensão residual e tamanho de cristalitos da amostra 2 pelo método Single Line por distribuição.

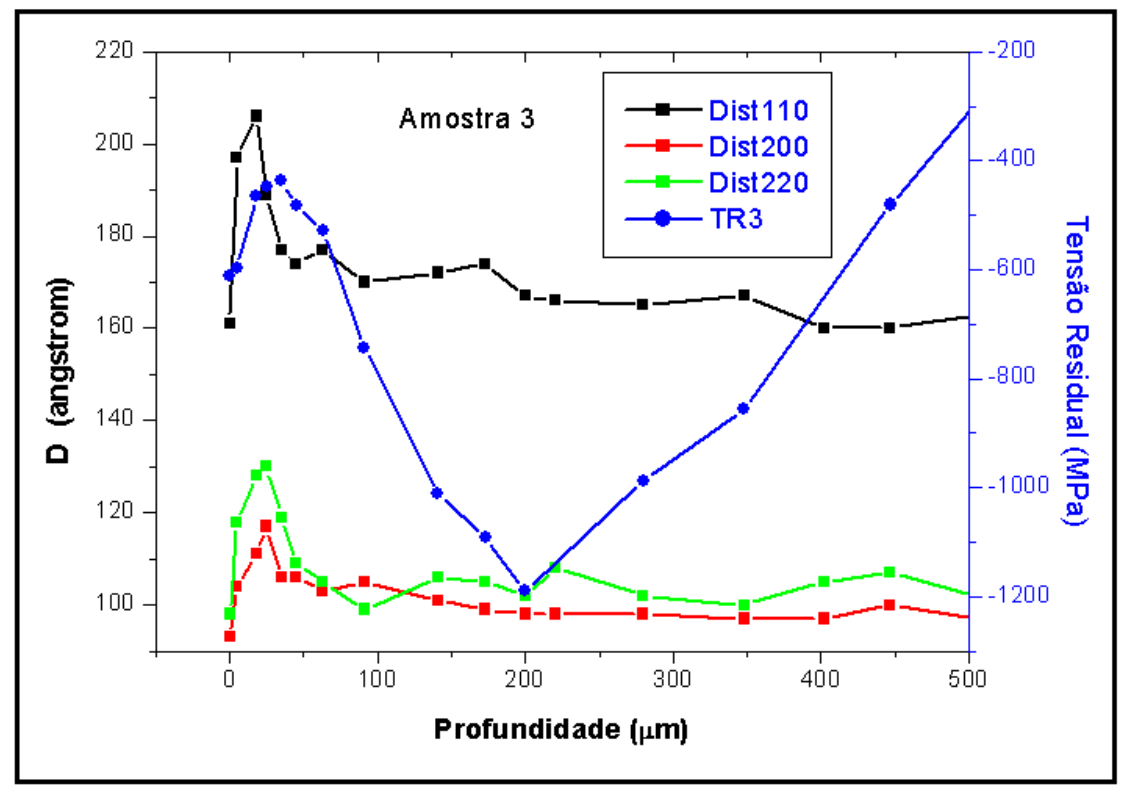

Figura 90: Gráficos comparativos entre a tensão residual e tamanho de cristalitos da amostra 3 pelo método Single Line por distribuição.

Conforme os resultados anteriores nota-se que os valores em tensão residual, nas profundidades inicias seguem o mesmo comportamento na variação do tamanho de cristalito, na faixa de $50 \mu \mathrm{m}$ para a amostra 2 e de aproximadamente $30 \mu \mathrm{m}$ para a amostra 3.

Por ultimo os resultados dos perfis das difrações de raios- $x$ foram analisados pelo método de Warren-Averbach pela distribuição cumulativa e relativa pela análise 
de Fourier e os resultados estão mostrados graficamente na figura 91 e 92, para as amostras 2 e 3 respectivamente.

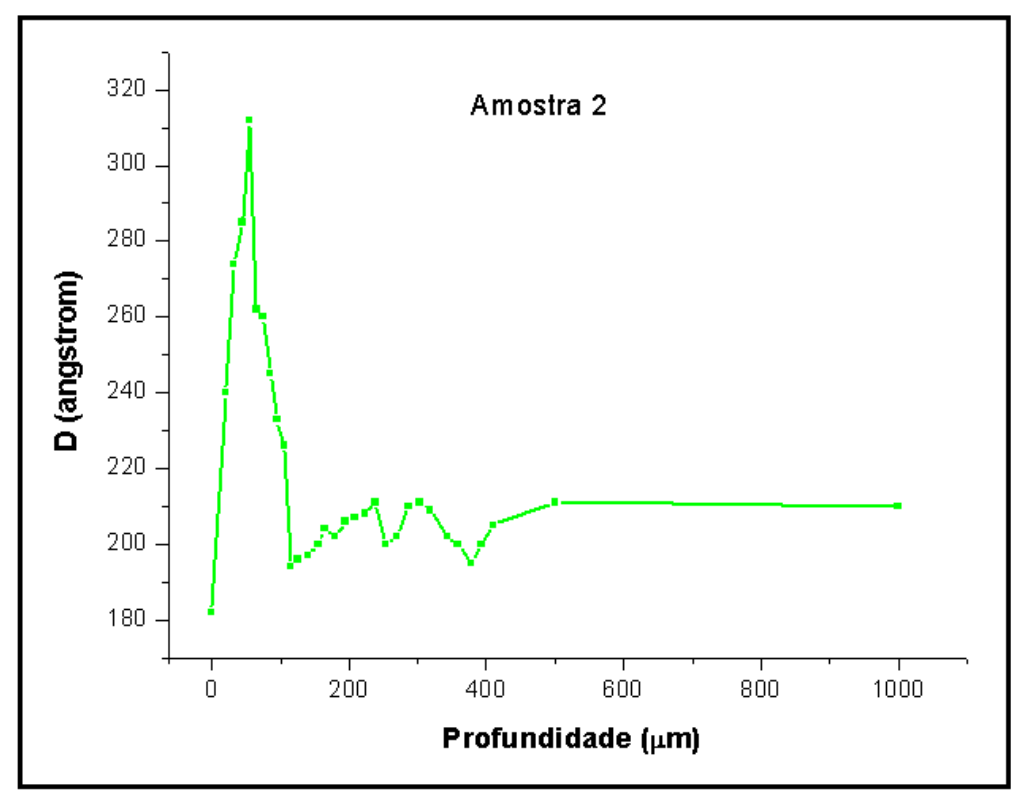

Figura 91: Gráfico da distribuição do tamanho médio dos cristalitos em relação a profundidade da amostra 2 pelo método Warren-Averbach por distribuição.

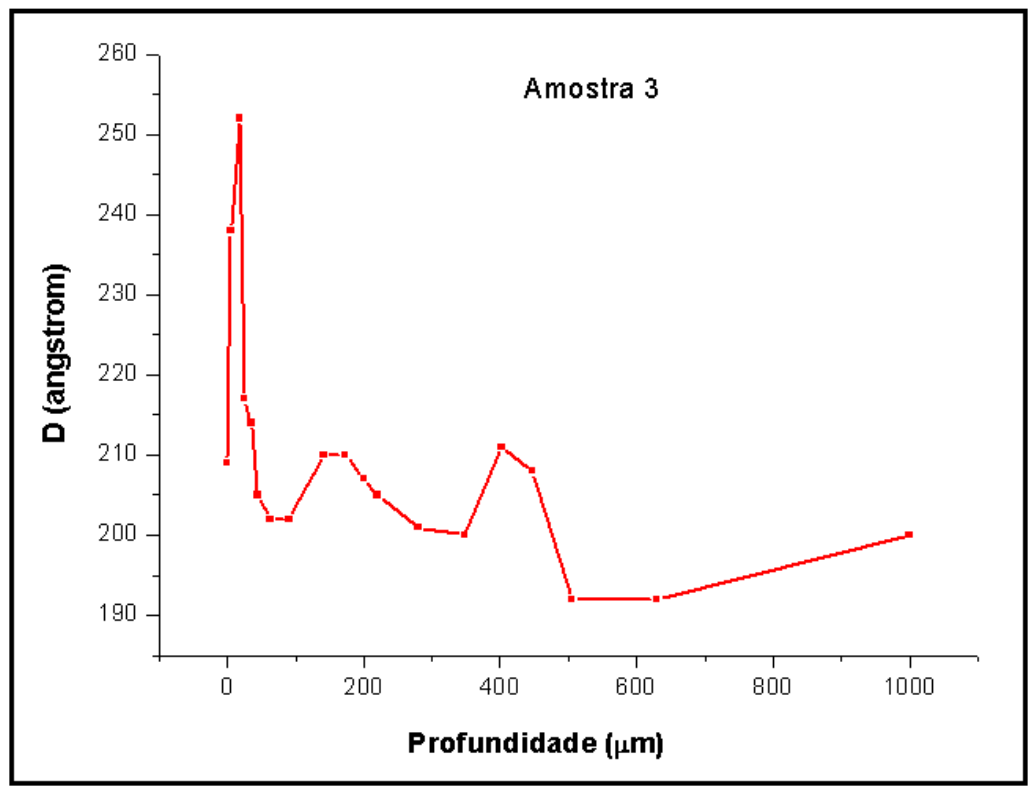

Figura 92: Gráfico da distribuição do tamanho médio dos cristalitos em relação a profundidade da amostra 3 pelo método Warren-Averbach por distribuição.

Ao fazer a comparação dos gráficos da distribuição dos tamanhos médios de cristalitos com o perfil da distribuição da tensão residual, observa-se que os pontos correspondentes às regiões deformadas possuem comportamentos similares, demonstrando que em condições de grandes deformações a curva de tensão 
residual perde compressibilidade nas camadas iniciais para posteriormente assumir o comportamento normal, já descrito pelos métodos anteriores.

Os comparativos estão descritos pelos gráficos das figuras 93 e 94 para as amostras 2 e 3 , respectivamente.

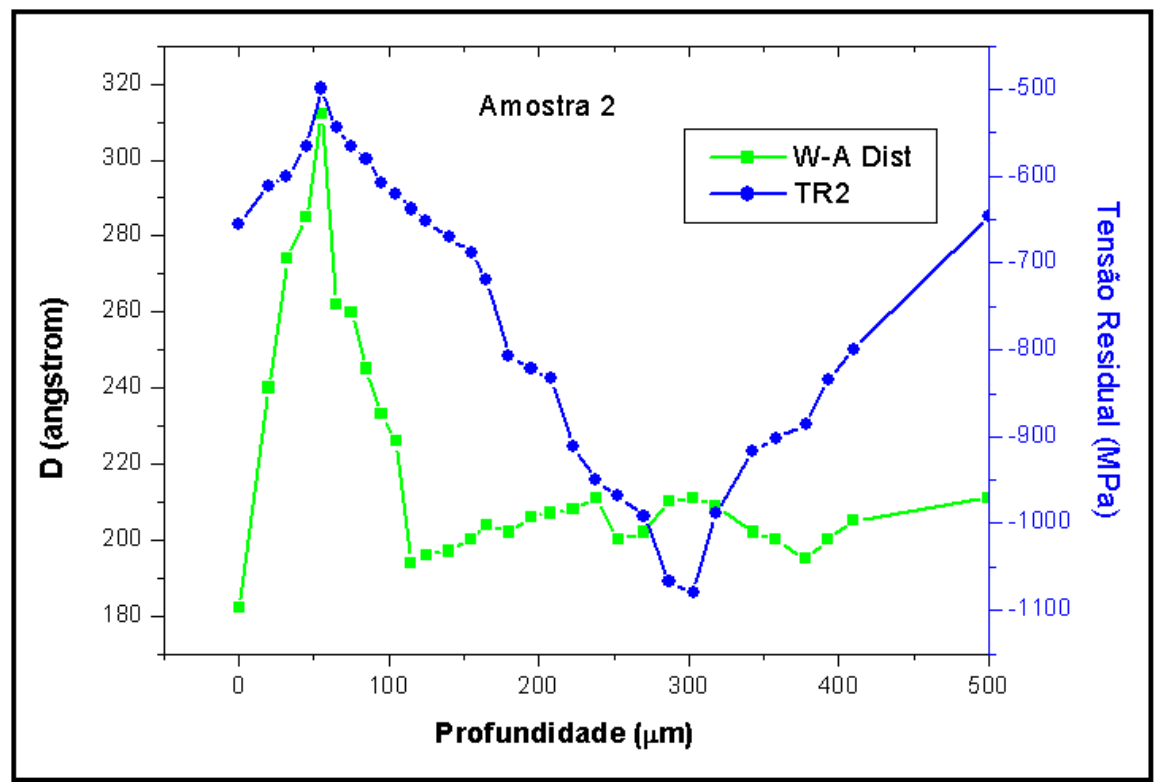

Figura 93: Gráficos comparativos entre a tensão residual e tamanho de cristalitos da amostra 2 pelo método Warren-Averbach por distribuição

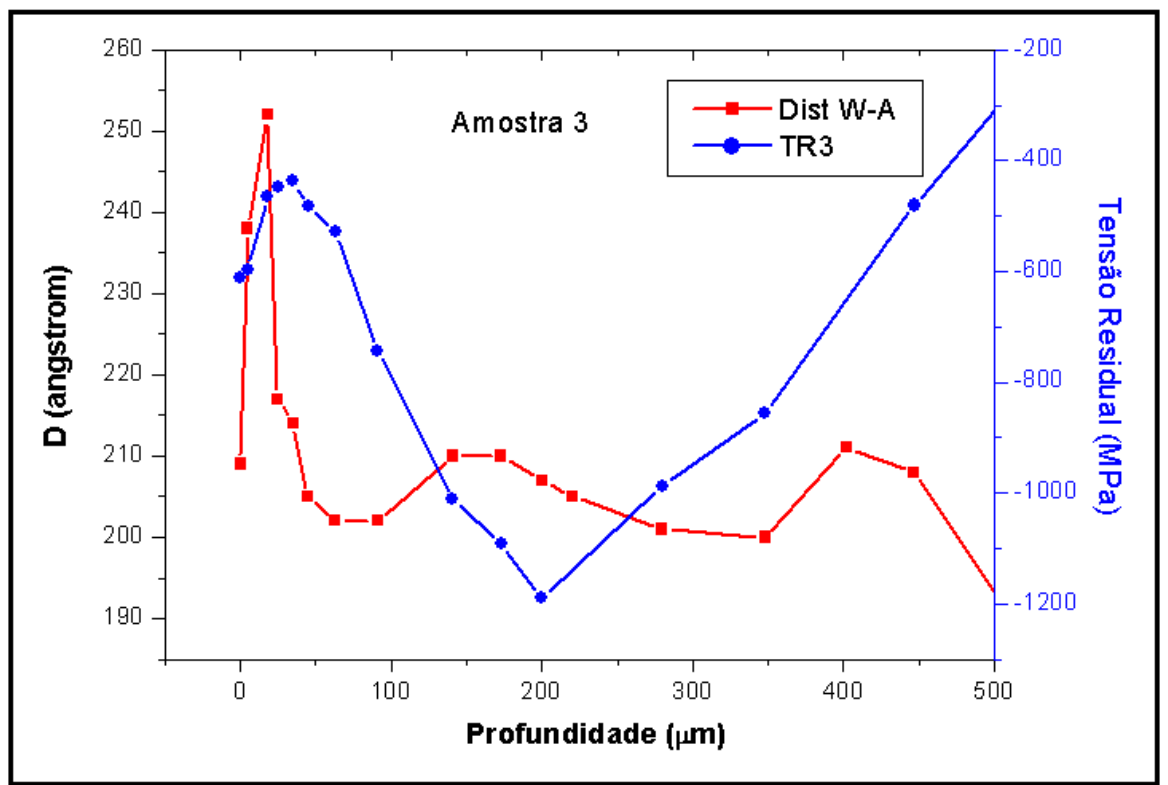

Figura 94: Gráficos comparativos entre a tensão residual e tamanho de cristalitos da amostra 3 pelo método Warren-Averbach por distribuição

Portanto, seja qual for o método utilizado, sempre apresentará um aumento no tamanho de cristalito decrescendo conforme aumenta a profundidade de ataque, 
acompanhando o perfil das tensões residuais, até manter-se estável, na proporção inversa da microdeformação de rede cristalina. A hipótese mais convincente de se detalhar este comportamento está na quantidade da deformação plástica encontrada na superfície do material. Quando a energia de impacto transfere para o interior da peça, encontrando a componente elástica, transmitindo a força no sentido contrário. Neste momento a força contrária encontra menor resistência devido a deformação plástica e transfere o alívio de forma gradual em sentido à superfície de tal maneira que o perfil da distribuição da tensão residual toma a forma de uma parábola.

Com a proposta de avaliar a distribuição da tensão residual de uma forma mais efetiva, toma-se os valores em $2 \theta$ medidos em paralelo à superfície, os seja, as medidas realizadas em $\psi=0^{\circ}$.

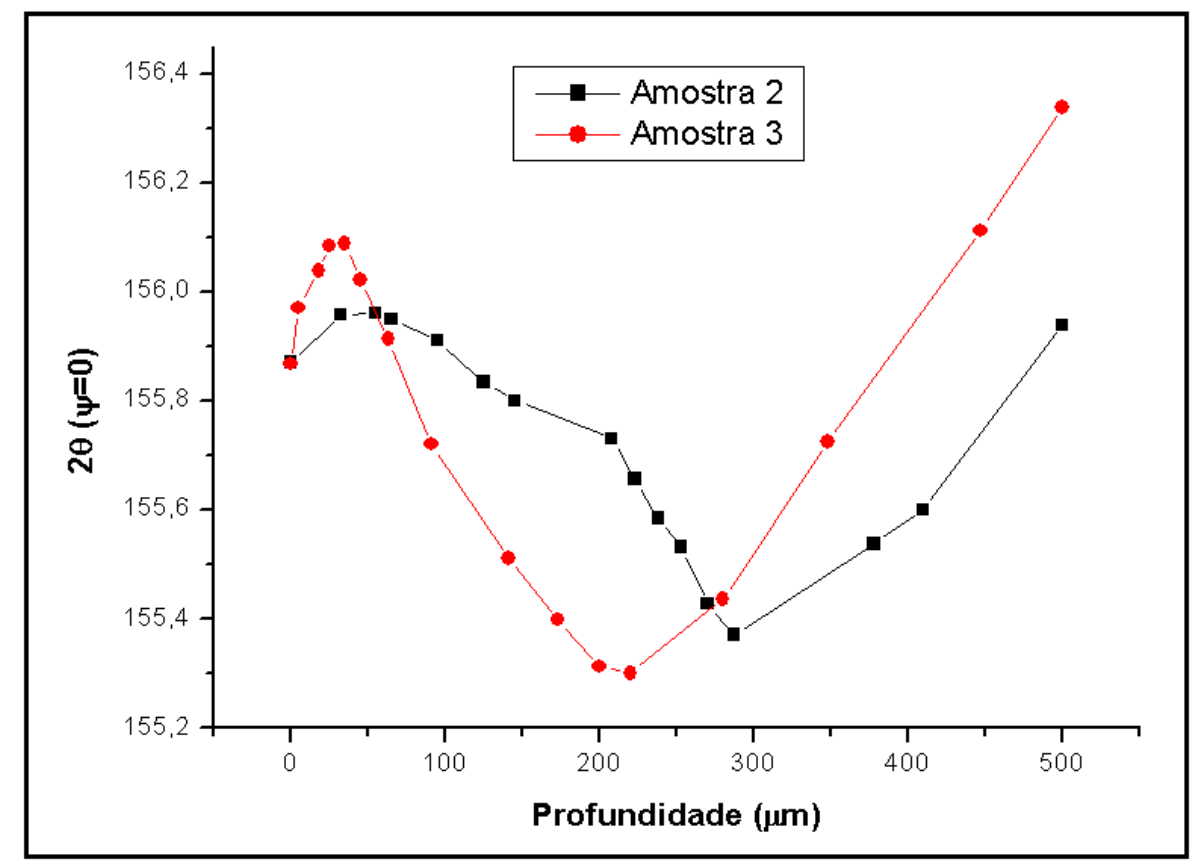

Figura 95: Posições em $2 \Theta$ para $\Psi=0^{\circ}$ das amostras 2 e 3.

Os resultados podem ser visualizados pela tabela 19. 
Tabela 19:Distribuição das posições em $2 \Theta$ para $\Psi=0^{\circ}$ das amostras 2 e 3

\begin{tabular}{|l|l|l|l|}
\hline \multicolumn{2}{|c|}{ Amostra 2 } & \multicolumn{2}{c|}{ Amostra 3 } \\
\hline $\begin{array}{c}\text { Profundidade } \\
(\boldsymbol{\mu m})\end{array}$ & $\mathbf{2} \boldsymbol{\Theta}$ & $\begin{array}{c}\text { Profundidade } \\
(\boldsymbol{\mu m})\end{array}$ & $\mathbf{2} \boldsymbol{\theta}$ \\
\hline 0 & 155,87 & 0 & 155,867 \\
\hline 32 & 155,957 & 5 & 155,97 \\
\hline 55 & 155,961 & 18 & 156,038 \\
\hline 65 & 155,95 & 25 & 156,084 \\
\hline 95 & 155,911 & 35 & 156,088 \\
\hline 125 & 155,834 & 45 & 156,022 \\
\hline 145 & 155,8 & 63 & 155,913 \\
\hline 208 & 155,73 & 91 & 155,72 \\
\hline 223 & 155,656 & 141 & 155,511 \\
\hline 238 & 155,584 & 173 & 155,399 \\
\hline 253 & 155,532 & 200 & 155,313 \\
\hline 270 & 155,427 & 220 & 155,3 \\
\hline 287 & 155,371 & 280 & 155,436 \\
\hline 378 & 155,537 & 348 & 155,725 \\
\hline 410 & 155,6 & 447 & 156,112 \\
\hline 500 & 155,939 & 500 & 156,338 \\
\hline
\end{tabular}

Observa-se que a curva gerada pela medições da deformação dos espaçamentos em $\Psi=0^{\circ}$ assemelha-se com a curva de distribuição de tensão residual, compreendendo que esta variação na distância interplanar segue a uma lógica quanto aos efeitos que ocorrem quando leva-se em conta a quantidade de discordâncias causadas pelo jateamento. Com este argumento pode-se deduzir que ao constatar o aumento da distância interplanar e mantida a quantidade de discordâncias ocorre a diminuição de sua densidade, obtendo 0 aspecto característico na curva de distribuição da microdeformação da rede. O mesmo acontece com o perfil da distribuição dos tamanhos de cristalitos das amostras. $O$ fato de ocorrer o alívio nas tensões a partir da superfície infere no aumento das distâncias interplanares e como consequência no aumento do tamanho dos cristalitos. Como forma de definir estas colocações, toma-se o comparativo entre as curvas da distribuição de tensão residual com a curva das medidas realizadas em $\Psi$ $=0^{\circ}$ das amostras 2 e 3 , apresentadas pelos gráficos das figuras 96 e 97. 


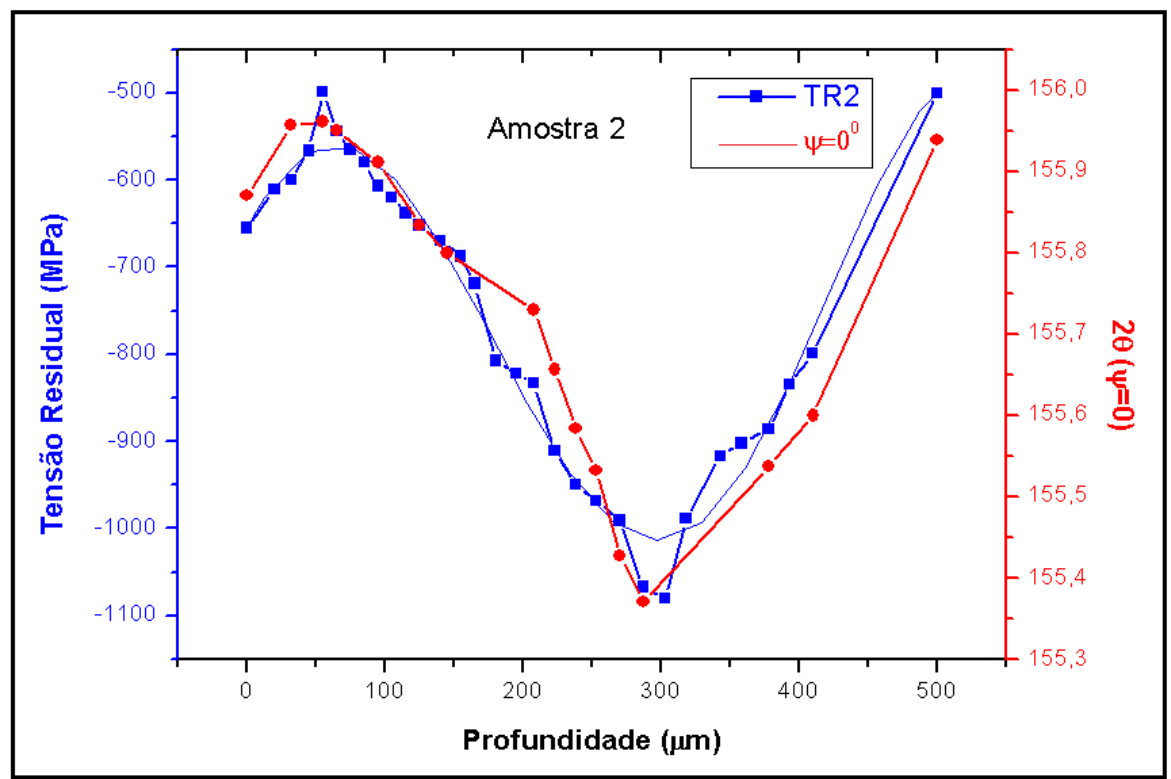

Figura 96: Comparativo entre a tensão residual e os parâmetros em $\Psi=0^{\circ}$ da amostra 2.

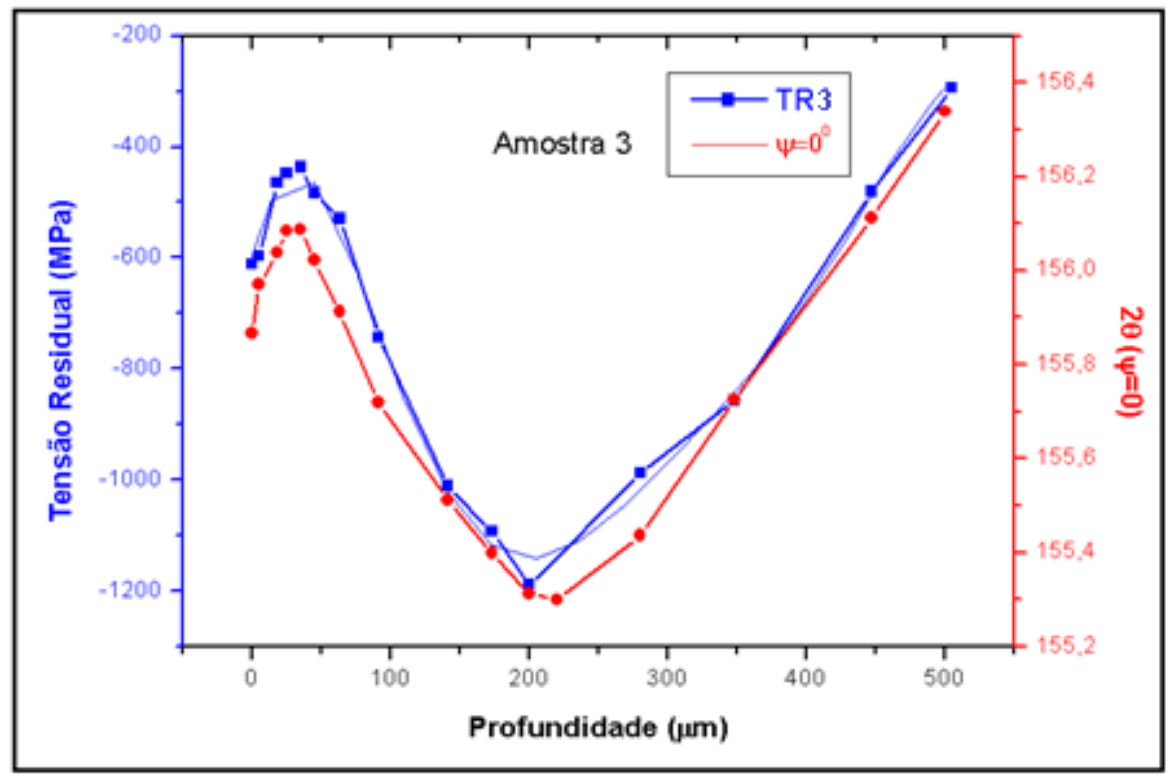

Figura 97: Comparativo entre a tensão residual e os parâmetros em $\Psi=0^{\circ}$ da amostra 3 .

Desta forma, pode-se resumir que a deformação na rede cristalina e o tamanho de cristalitos estão diretamente ligados às alterações nas distâncias interplanares no perfil da profundidade da amostra, que por sua vez gera a distribuição da tensão residual, cujo perfil da curva ocorre devido a quantidade de deformações plásticas conjugadas ao componente elástico do material jateado.

Como forma de promover o estudo deste trabalho, toma-se um comparativo entre as técnicas de análise do perfil obtido pela difração de raios-x, tendo cada qual a sua especificidade e denotando a sua aplicação na circunstância da qual é exigida. 
A análise do perfil pelo método Williamson-Hall modificado utiliza-se de dados inerentes ao material em suas constantes elásticas, além de ser aplicado a todos os picos obtidos em um padrão de raios- $x$, sendo assim, contém uma resposta gerada de uma análise completa do padrão da difração de raios-x. Os valores das microdeformações variaram de $0,78 \%$ a $1,21 \%$, os maiores valores encontrados quando comparado a outros métodos analíticos.

Também foram utilizadas outras técnicas que se baseiam no estudo do alargamento proporcionado pela difração de raios-x. A partir dessas técnicas obtémse os valores da microdeformação da rede cristalina e do tamanho médio de cristalito, cujo perfil pode ser separado aplicando-se a série de Fourier com as funções Gaussiana e Lorentziana, por deconvolução, definindo assim as partes inerentes a microdeformação e ao tamanho médio de cristalito contidos no perfil estudado.

Para a obtenção da distribuição da microdeformação da rede cristalina, o método Single Line foi utilizado. A variação da microdeformação foi de $0,07 \%$ a $0,42 \%$, valores estes bem inferiores aos obtidos pelo método Willianson-Hall modificado, porém com uma particularidade que é a de descrever a susceptibilidade da deformação dos planos cristalográficos individualmente. Neste estudo constatouse que o plano que mais deformou foi o (200), tanto da amostra 2 (entre $0,22 \%$ a $0,42 \%)$ quanto da amostra $3(0,26 \%$ a $0,37 \%)$. Os planos (110) e (220) estiveram em $0,10 \%$ a $0,23 \%$ na amostra 2 e $0,07 \%$ a $0,26 \%$ na amostra 3 . Pelo fato de possibilitar o estudo em planos individuais, constatou-se que a maior deformação do plano (200) coincide com a análise obtida pelo GSAS em referência ao deslocamento em $2 \theta$ (figura 54).

Pelo método Warren-Averbach obteve-se valores das microdeformações em torno de $0,22 \%$ a $0,43 \%$ para ambas as amostras ( 2 e 3 ), observando o estreitamento da faixa dos valores. Este fato pode ser explicado pelo uso dos dois planos paralelos (110) e (220), com valores muitos próximo se observados nos resultados obtidos em outros métodos.

De qualquer forma, independentemente dos resultados obtidos, a distribuição da microdeformação da rede cristalina nas amostras apresentaram características semelhantes, cujos valores apresentaram um decréscimo na camadas superficiais, coincidindo com a perda da compressão da tensão residual, o que caracteriza a relação entre a macrotensão com a microtensão e que existe a influência entre um e 
outro e a relação direta do espaçamento interplanar com a quantidade de discordâncias e falhas de empilhamento ocasionados pelo jateamento por granalhas está relacionada com a densidade destas ocorrências.

Em se tratando de quantidade de defeitos, a relação da densidade de discordâncias e falhas de empilhamento com as distâncias interplanares na região coerente da difração estão de certa forma ligados, pela diminuição da microdeformação com o aumento do tamanho médio dos cristalitos.

Sendo assim, os métodos utilizados possibilitaram fazer uma comparação confirmando a relação microdeformação-tamanho de cristalitos-tensão residual.

Nas medidas de tamanho médio de cristalito pelo método Single Line foram utilizadas duas formas de interpretação: por inclinação extrapolada ao eixo da ordenadas em relação ao coeficiente de Fourier e por distribuição relativa e cumulativa (páginas 118 e 124). Os valores de ambos ficaram muito próximos, e ao contrário da microdeformação, o tamanho de cristalito aumentou nas camadas iniciais das amostras.

Utilizando planos independentes, os resultados da amostra 2 no plano (110) foram de $155 \AA$ a $242 \AA$ e da amostra 3 no plano (110) nos valores de $150 \AA$ a $227 \AA$ mostraram que o tamanho médio de cristalito também sofre alterações conforme as forças atuantes nos distintos planos. Nos planos (200) e (220) o tamanho de cristalitos foi menor. Na amostra 2 variou de $80 \AA$ a $138 \AA$ e na amostra 3 de $92 \AA$ a $130 \AA$ A. Além disso cabe a observação que o plano (220) deveria ter o tamanho de cristalito em maiores proporções, visto que a deformação foi menor, fato que não ocorreu, cujas causas ainda deverão ser estudadas.

Ao utilizar o método Warren-Averach, encontraram-se valores ainda superiores para os tamanhos de cristalitos tanto pela inclinação como pela distribuição (páginas 121 e 126). Para a amostra 2 por inclinação o tamanho médio de cristalito fica em torno de $184 \AA$ a $332 \AA$, muito semelhante ao método pela distribuição, sendo os valores encontrados de $180 \AA$ a $310 \AA$. Ao observar os resultados da amostra 3 dos dois métodos (inclinação e distribuição), verifica-se que os valores são inferiores à amostra 2, e muito semelhantes entre os métodos (inclinação e por distribuição), com os valores de $196 \AA$ a $260 \AA$ e com os valores de $191 \AA$ a $253 \AA$, respectivamente.

No intuito de finalizar este tema, cabe a observar que tanto o decréscimo da microdeformação quanto o aumento do tamanho médio do cristalito nas 
profundidades inicias da amostra se relacionam com a queda da compressibilidade na tensão residual, gerada pela deformação plástica abaixo da superfície com o jateamento por granalhas de aço.

\subsection{Ensaio de fadiga.}

Os ensaios de fadiga foram realizados nas dependências da Thyssenkrupp Bilstein Brasil, para as amostras 1 (S330 sem tensionamento), amostra 2 (S330 com tensionamento) e amostra 3 (S390 com tensionamento), com 5 amostras para cada condição e os resultados em ciclos estão descritos na tabela 20:

Tabela 20: Resultados em ciclos para o ensaio de fadiga das amostras 1, 2 e 3:

\begin{tabular}{|c|c|c|}
\hline Amostra 1 & Amostra 2 & Amostra 3 \\
\hline 41233 & 93000 & 82568 \\
\hline 41428 & 59342 & 115557 \\
\hline 42600 & 74282 & 60433 \\
\hline 39147 & 110443 & 81572 \\
\hline 32416 & 77421 & 83637 \\
\hline
\end{tabular}

Para a análise destes ensaios foi aplicado a distribuição de Weibull, considerando o valor de ciclos característicos onde 50\% das amostras irão sobreviver, denominada de B50, padronização mais utilizada pela indústria automotiva, e um intervalo de confiabilidade de $90 \%$.

Utilizando o software Weibull 1.0, os gráfico gerados para as amostra 1, 2 e 3 (figuras 98,99 e 100, respectivamente) foram: 


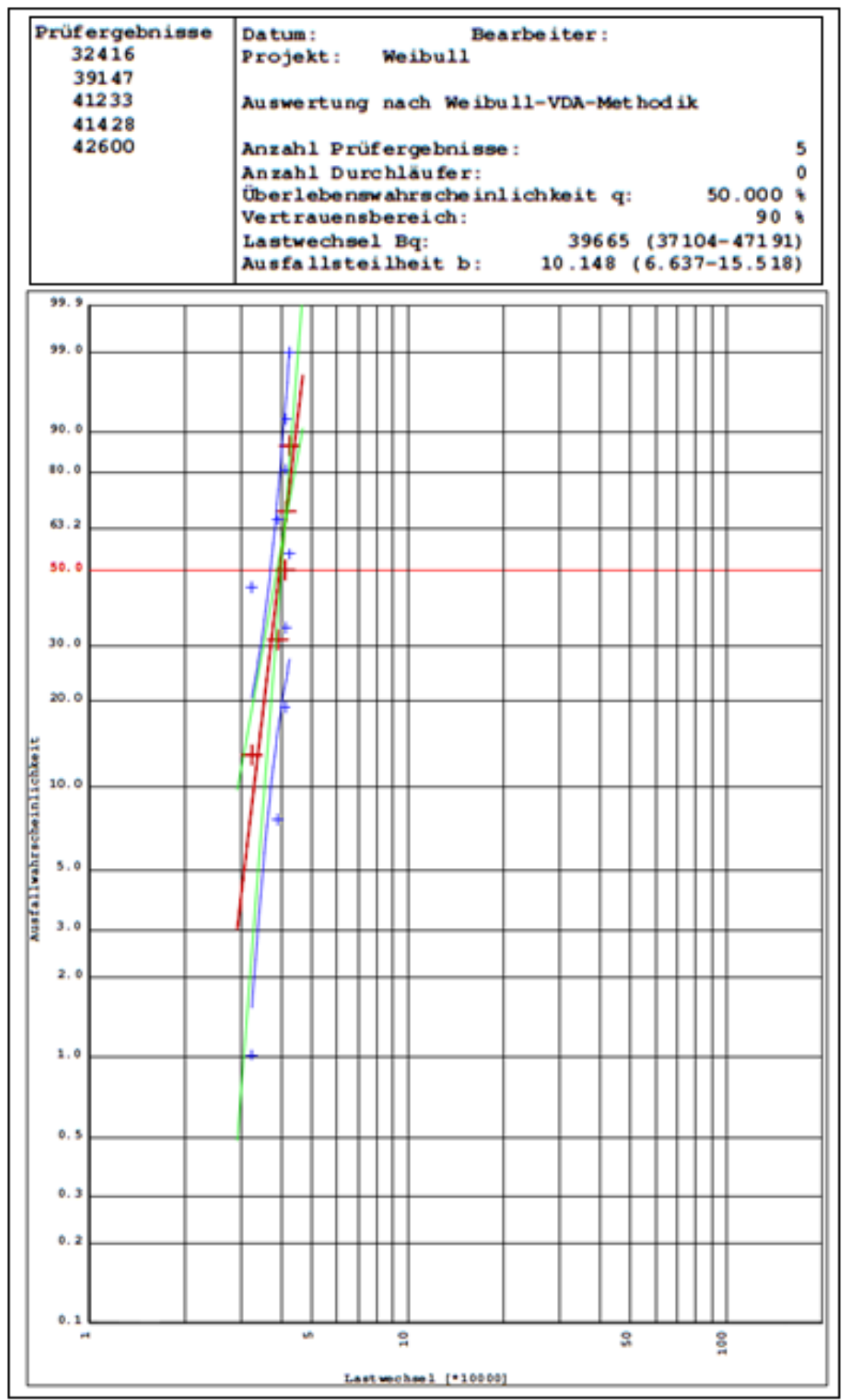

Figura 98: Gráfico gerado pela análise de Weibull da amostra 1. 


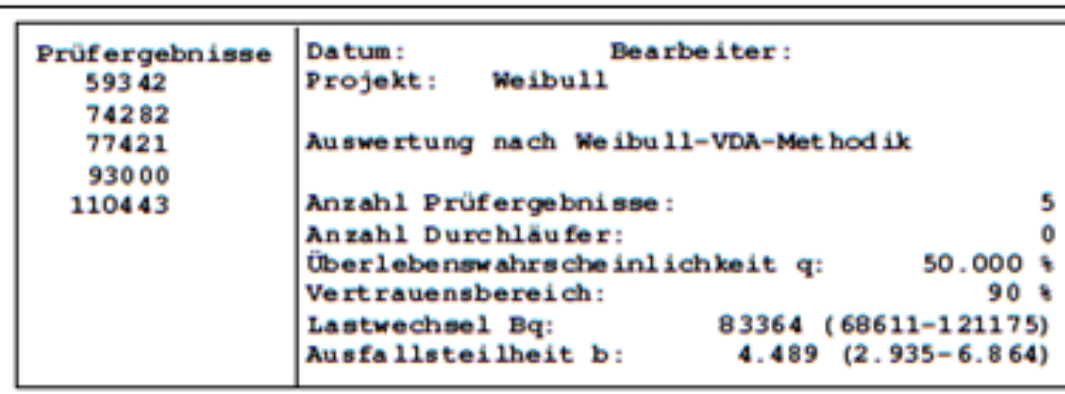

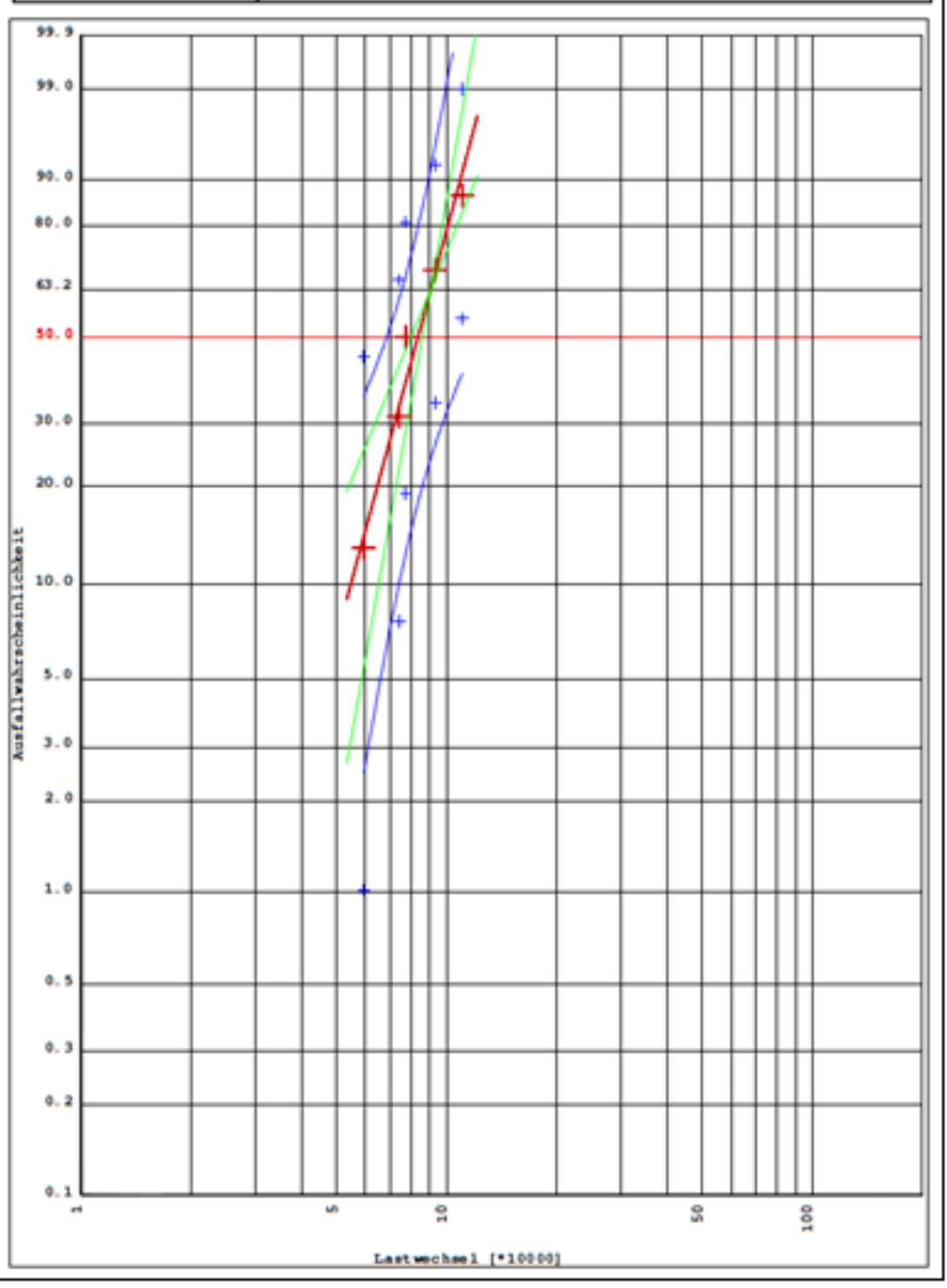

Figura 99: Gráfico gerado pela análise de Weibull da amostra 2. 


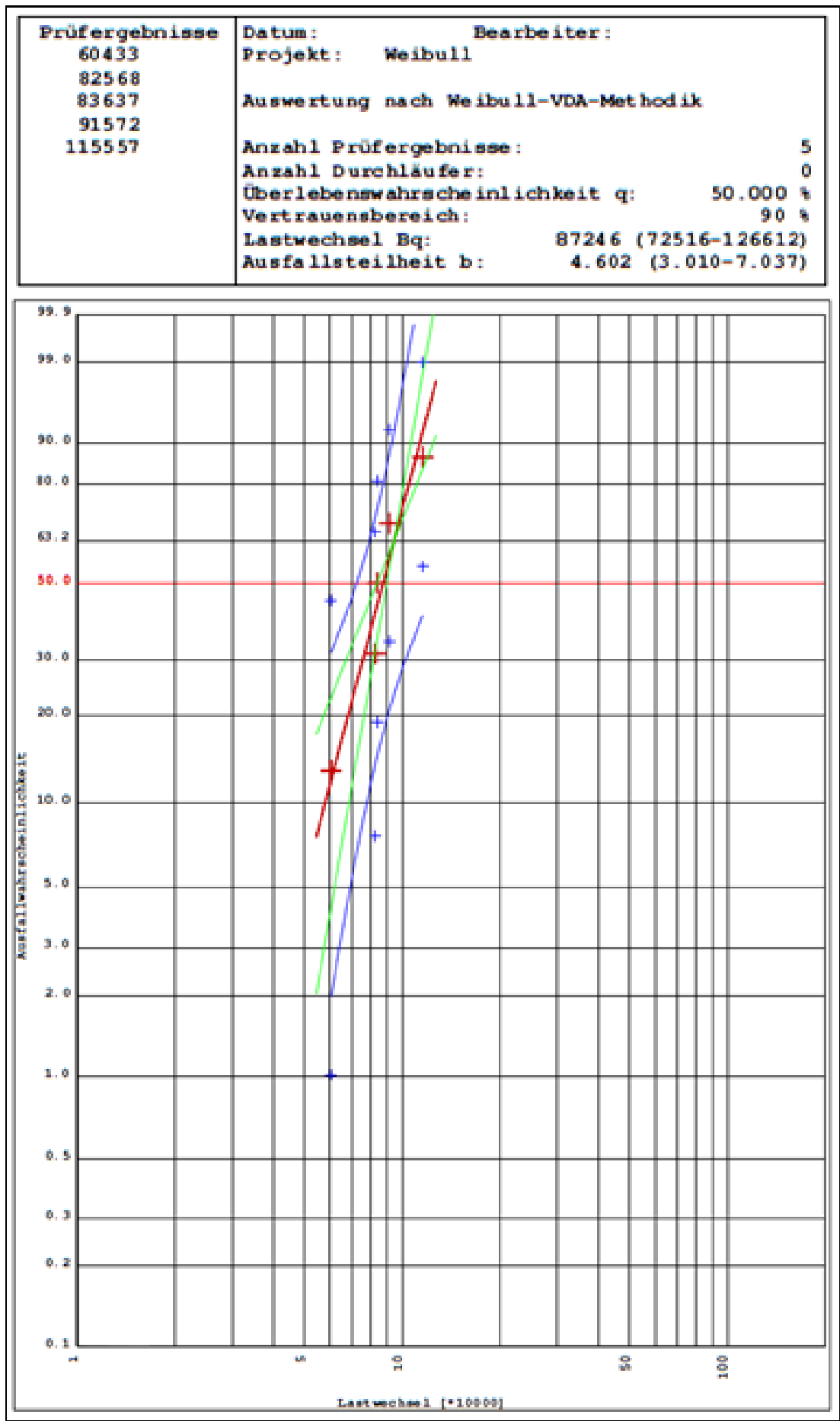

Figura 100: Gráfico gerado pela análise de Weibull da amostra 3.

Estes resultados possibilitam definir os valores limite da vida em fadiga nas condições $\mathrm{B} 50$, e os valores de forma $\beta$ para cada condição de jateamento. Estes valores estão descritos na tabela 21. 
Tabela 21: Vida em fadiga B50 das amostras e valores de $\beta$

\begin{tabular}{|l|c|c|}
\hline & Valores limite da vida em fadiga B50 & $\boldsymbol{\beta}$ \\
\hline Amostra 1 & $39665(37104-47191)$ & 10,148 \\
\hline Amostra 2 & $83364(68611-121175)$ & 4,489 \\
\hline Amostra 3 & $87246(72516-126612)$ & 4,602 \\
\hline
\end{tabular}

A se considerar pelos resultados afirma-se que a vida fadiga aumentou com o tensionamento da peça, e que neste caso o tamanho da granalha não teve influência considerável. $\mathrm{O}$ mesmo se aplica ao parâmetro $\beta$ de Weibull, que representa a dispersão dos resultados de fadiga, sendo as maiores dispersões para as amostras 2 e 3, conforme o coeficiente da inclinação da reta gerada. E conforme os valores de $\beta$ os parâmetros utilizados no jateamento não acarretarão em falhas prematuras do material em fadiga. No caso de ambas as amostras, os resultados dos fatores de concentração de tensão na superfície não tiveram interferência nos valores dos ciclos em fadiga, ainda assim pela proximidade dos resultados obtidos. 


\section{CONCLUSÕES}

Os valores de microdeformação obtidas pelos métodos Williamson-Hall modificado, Warren-Averbach e Single Line possuem valores absolutos diferentes, mas relativamente apresentam o mesmo comportamento.

$\mathrm{O}$ jateamento por granalhas com a amostra tracionada aumenta a vida em fadiga e os valores em tensão residual.

O jateamento por granalhas, dependendo da energia imposta pelas granalhas, provoca no material uma camada plasticamente deformada que induz um perfil de tensão residual em profundidade que apresenta um pico de alívio de tensão, seguido do aumento da tensão residual compressiva.

A distribuição da microdeformação da rede cristalina da região plasticamente deformada assume comportamento semelhante a perda de compressibilidade da tensão residual.

A distribuição do tamanho médio de cristalitos na região plasticamente deformada assume comportamento inverso da compressibilidade da tensão residual.

A microdeformação da rede cristalina e o tamanho médio de cristalito possuem diferentes valores para cada plano cristalográfico.

Pela variação da distância interplanar é possível verificar a variação da densidade de discordâncias.

O jateamento por granalhas produz discordâncias do tipo hélice no aço SAE 9254+V.

A variação do valor do fator de concentração de tensão segue similaridade com os valores de resistência à fadiga.

Nas condições de jateamento de granalhas S330 e S390 não ocorrerá falha catastrófica.

Nos métodos Single Line e Warren-Averbach as formas de interpretação (por inclinação extrapolada ao eixo da ordenadas em relação ao coeficiente de Fourier e por distribuição relativa e cumulativa) apresentam similaridade para cada método.

No aço SAE 9254+V o plano de maior deformação é o (200). 


\section{BIBLIOGRAFIA}

ALMEN, J.O.; BACK, P.H.; Residual stresses and fatigue in metals. Mc Graw-Hill, cap. 6, p. 61-62, apêndice A-12, p. 200-201, New York, 1963.

AMERICAN SOCIETY FOR TESTING AND MATERIALS. Standard test methods for determining average grain size. Philadelphia. 2006. (ASTM E112).

AMERICAN SOCIETY FOR TESTING AND MATERIALS. Standard practice for determining the inclusion content of steel. Philadelphia 1987. (ASTM E45).

AMERICAN SOCIETY FOR TESTING AND MATERIALS,. Standard Practice for Conducting Constant-Amplitude Axial Fatigue Tests of Metallic Materials. p. 539-43,1989. Philadelphia, 1989. (ASTM E 466)

AMERICAN SOCIETY FOR TESTING AND MATERIALS. Philadelphia. Standard Test Method for Measurement of Fracture Toughness. 1999. (ASTM E1820).

AMERICAN SOCIETY FOR TESTING AND MATERIALS. Standard Terminology Relating to Fatigue and Fracture Testing. Philadélfia. p.20, 1996. (ASTM E-1823)

ANDERSON, T. L.; Fracture Mechanics Fundamentals and Applications. 3ㄹ Ed., Taylor e Francis Group. New York. 2005.

ASSIS, J. T.; MONIN, V. I.; SOUZA, P. S.; WEIDLICH, M. C.; GUROVA, T.; TEODOSIO, J. R. Processamento dos dados de difração de raios-X para medição de tensões. Disponível em: < http: //www.sbmac.org.br /bol/ boletim_2002/ assis-monim-souza-weidlich- 4emc.pdf >. Acesso em: 20 set. 2013.

BARNES, P.; JACQUES, S.; VICKERS, M. Determination of size and strain. A hypertext book of crystallographic space group diagrams and tables. Birbeck College. University of London. Disponível em $<$ http : // pd.chem.ucl.ac.uk /pdnn/peaks/ sizedet.htm> acesso em 24 nov 2015.

BATHE, K., J.; A finite element program for automatic dynamic incremental nonlinear analisys. Massachusetts Institute of Technology. Cambrige, Massachusetts, 1981.

BLOM, A. F.; HEDLUND, A.; ZHAO, W.; FATHULLA, A., WEISS, B., STICKER E. R. Short fatigue crack growth behaviour in Al 2024 and Al 7475. In: Miller KJ, de los Rios ER, editors. The behaviour of short fatigue cracks. MEP; p. 37-66. 1986.

BORGES, J. F. A. Determinação da energia de defeito de empilhamento em metais e ligas com estrutura CFC por difração de raios-X. 1985. Dissertação (Mestrado). Instituto de Pesquisas Energéticas e Nucleares. São Paulo.

BUSH, G. F.; ALMEN, J. O.; DANSE, L. A.; HEISE, J. P. How, when and by who was mechanical prestressing discovered: Society of Automotive Engineers ISTC, Div. 20 meeting. SAE. Colorado Springs. Colorado, p. 14. 1962. 
CAGLIOTI, G.; PAOLETTI, A.; RICCI, F. P.; Choice of collimators for a crystal spectrometer for neutron diffraction; Nuclear Instruments; Roma; 223-228. 1958.

CALLISTER, W., D., Jr.; Fundamentals of Materials Science and Engineering. John Wiley \& Son Inc. New York. 2001.

CAMARGO, J.A.M. A influência do jateamento por granalhas e das anodizações crômica, sulfúrica e dura sobre a resistência à fadiga da liga 7050t7451 de uso aeronáutico. 2007. Tese (doutorado). Faculdade de Engenharia de Guaratinguetá. UNESP.

CAO, W.; FATHALLAH, R.; CASTEX, L. Correlation of Almen arc height with residual stresses in jateamento por granalhas process. Materials Science and Technology. v.11, p. 967-973. 1995.

CANAAN, G. L.; Influência da adição de vanádio nas propriedades mecânicas de aços médio teor de carbono para beneficiamento. 2007. Dissertação (mestrado). UFMG, Belo Horizonte.

COLOSIMO, E. A.; GIOLO, S. R. Análise de Sobrevivência Aplicada. Editora Edgard Blucher. 2006.

COTTRELL, A.H.; HULL, D. Extrusion and intrusion by cyclic slip in copper. Proc R Soc London. A 242:211-3. 1957.

CROWTHER, D. N.; GREEN, M.J.W.; MITCHELL, P.S. Microalloying in Steels, p. 469-476. 1998.

CULLITY, B. D. Elements of X-ray diffraction. Addison-Wesley Publishing Company Inc. 2 ${ }^{\mathrm{a}}$ Ed. Reading, Massachusetts, USA. 1978.

CULLITY, B.D.; STOCK, S.R.; Elements of $x$-ray difraction. $3^{\text {th }}$ ed. Prentice Hall, cap 15, p.435-469. Upper Saddle River. New Jersey. 2001.

CURTIS, S.A.; ROMERO, J.S.; de los RIOS, E.R.; RODOPOULOS, C.A. and LEVERS, A.; Predicting the interfaces between fatigue crack growth regimes in 7150 - T651 aluminum alloy using the fatigue damage map. International Journal of Fatigue. 25 - p. 59-66. 2003.

de los Rios E. R.; NAVARRO, A. Considerations of grain orientation and work hardening on short-fatigue-crack modeling. Phil. Mag. 1990.

DEARDO, A. J. Metallurgical Basis for Thermomechanical Processing of Microalloyed Steels. Ironmaking and Steelmaking, vol. 28, n. 2, p. 138-144. 2001.

DIEPART, C.P. Modeling of jateamento por granalhas residual stresses. Practical applications. Materials Science Forum, v. 163-165, p. 457-464, Stafa, Zurich, 1994. 
DIETER, G. E. Metalurgia Mecânica. 2.ed., Rio de Janeiro. Cap. 12. Fadiga dos metais. p.344-484. 1981.

EI HADDAD, M. H.; DOWLING M. E.; TOPPER T. H.; SMITH Jr., K. N. J.; Integral applications for short-fatigue-crack modelling. Int J Fracture; 16:15-30; 1980.

EUROPEAN STANDARD. Hot Rolled Steels for Quenched and Tempered Springs, 2003. (DIN EN10089).

FORREST, P.G.. Fatigue of Metals, Pergamon Press, Oxford, 1970.

FORSYTH, P.J.E. Slip band damage and extrusion. Proceeding of the Royal Society. London; A242: 198 - 202, 1957.

FRANÇOIS, M.; SPRAUEL, J. M.; DEHAN, C. F.; JAMES, M. R.; CONVERT, F.; LU, J.; LEBRUN, J. L.; LI, N.; HENDRICKS, R.W.; X-Ray difraction method. In: Handbook of measurement of residual stresses. Society for Experimental Mechanics; Fairmont Press,. cap. 5. Lilburn, GA, 1996.

FROHBERG, G.; GRAF, H. Stahl und Eisen, 80, p. 539; 1960.

FUCHS, H. O.; STEPHENS, R. I. Metal Fatigue in Engineering, $2^{a}$ edição, Willey Library, 2000.

GALLEGO, J.; MORALES, E. V.;KESTENBACH, H. J.; Estudo quantitativo do endurecimento por precipitação em aços microligados ao vanádio. $57^{\circ}$ Congresso Anual da ABM, São Paulo, 2002.

GLODOWSKI, R.J. Vanadium in medium and high carbon steels. Vanadium Application Technology, The Use of Vanadium in Steel. Paper Presented at The Vanitec International Symposium. Guilin, China. 6th November 2000.

GONZALES, A.,C.; BARRIOS, D.,B.;LIMA, N.,B.; GONÇALVES, E.; Importance of considering a material micro-failure criterion in the numerical modeling of the jateamento por granalhas process applied to parabolic leaf springs. Latin American Journal of Solids and Structures. Pag 21, 2009.

GOODMAN, J.; Mechanics Applied to Engineering. Longman, Green e Company. London, 1899.

GRIFFITH, A. A.; The Phenomena of Rupture and Flow in Solids. Philosophical Transactions, p. 163-198 Series A, Vol. 221, 1920.

GROMA, I.; UNGÁR, T.; WILKENS, M.; Asymmetric X-ray line broadening of plastically deformed crystals. I. Theory. J. Appl. Cryst. 21, pp 47-53. 1988.

GUAGLIANO, M., VERGANI, L.; An approach for prediction of fatigue strength of shot peened components. Engineering Fracture Mechanics. v. 21.171, p. 501-512, 2004. 
GUROVA, T.; QUARANTA, F.; ESTEFEN, S. Monitoramento do estado das tensões residuais durante a fabricação de navios. In: 21 Congresso Nacional de Transportes Marítimos, Construção Naval e Offshore, 27.11-01.12.2006, p.1-9, Rio de Janeiro, RJ, 2006.

HERBERT, E. G.; Work hardening of steel by abrasion. Journal Iron and Steel Institute, No. 11, pp. 116-22, 1927.

HERZOG, R., ZINN, W., SCHOLTES, B., WOHLFAHRT, H.; The significance of Almen intensity for the generation of jateamento por granalhas residual stresses. In: International Conference on Jateamento por granalhas. p. 270-281. São Francisco,CA, 1996.

HE, J.H.; SHOENUNG, J.M.; Nanostrutured coatings. Materials Science e Engineering. Value 336, p. 282-284, 25 set 2002.

HONEYCOMBE, R. W. K.;. The Plastic Deformation of Metals; London: Edward Arnold; pp. 106-107. 1984.

HONEYCOMBE, R.W.K., Carbide Precipitation in HSLA Steels, Proc. Microalloyed HSLA Steels, Chicago, pp. 1-13, 1988.

IRWIN, G. R.; Onset of Fast Crack Propagation in High Strength Steel and Aluminum Alloys. Sagamore Research Conference Proceedings, Vol. 2, p. 289305, 1956.

ICHIKAWA, R. U.; Aplicações do método Warren-Averbach de análises de perfis de difração. Dissertação de mestrado: IPEN-USP. São Paulo. SP.2003

JAMES, M.R.; LU, J.; INTRODUCTION. IN: Handbook of measurement of residual stresses; Society for Experimental Mechanics; Fairmont Press; cap. 1; dez. 1996.

JEFFERY, J.W. Methods in x-ray crystallography. Academic Press, London e New York. P. 33, 1971.

JENKINS, R.; SNYDER, R.L.; Anisotropic distortions of the diffraction pattern. Introduction to $X$ ray powder diffraction. USA: Wiley Interscience, Chap. 3: Diffraction Theory, vol. 138, p. 85, 1996.

KEIJSER, Th. H.; LANGFORD, J. I.; MITTEMEIJER, e. J.; VOGELS, B. P.; Use of Voigt function in a Single Line method for the analysis of $x$-ray diffraction line broadening. J. Appl Cryst; 15, pp308-314, 1982.

KITAGAWA, H.; TAKAHASHI, S.; Applicability of fracture mechanics to very small cracks or cracks in the early stage. In: The Second International Conference on Mechanical Behaviour of Materials, ICM2. Ohio: ASM Metal Park; p. 627-31. 1976. 
KLIMANEK, $\mathrm{P} . ; \mathrm{KUZEL}, \mathrm{R}$. Jr; X-ray diffraction line broadening due to dislocations in non-cubic crystalline materials. III. Experimental results for plastically deformed zirconium. J. Appl. Cryst; 2, pp 299-307. 1989.

KRIVOGLAZ, M. A.; X-ray and Neutron Diffraction in Nonideal Crystals. Berlin: Springer-Verlag, pp. 357-420. 1996.

LANGFORD, J. I.; A rapid method for analyzing the breadths of diffraction and spectral lines using Voigt function. J. Appl Cryst; 11, pp10-14, 1978.

LATROCHE, M.; RODRIGUEZ-CARVAJAL, J.; PERCHERON-GUÉAN, A.; BOUREÉ-VIGNERON, Structural studies of $L_{a N i} C_{1} D_{6.11}$ and $\mathrm{LaNi}_{3.55} \mathrm{Mn}_{0.4} \mathrm{Al}_{0.3} \mathrm{Co}_{0.75} \mathrm{D}_{5.57}$ by means of neutron powder diffraction J.; Alloys Comp. 218, pp. 64-72. 1995.

LI, J.K.,YAO,M.,WANG, D.,WANG, R. An analysis of stress concentrations caused by jateamento por granalhas and its application in predicting fatigue strength. Fatigue Fracture Engineering Materials Structure. 15(12), p. 1271, 1992.

MADAYAG, A. F.; Metal fatigue: Theory and Design. New York. Wiley, 425p. 1969.

MALCHER, L.; Um modelo para determinação da resistência à fadiga multiaxial para carregamento de flexão e torção combinados, fora de fase e com amplitude constante com base no critério do invariante do tensor. Dissertação de mestrado, Universidade de Brasília, 2006.

MEYERS, M. A.; CHAWLA, K. K.; Endurecimento por precipitação ou dispersão princípios de metalurgia mecânica. 1.ed. São Paulo: Edgard Blücher Ltda, Cap.11., p-328-358, 1982.

MIC; Jateamento por granalhas applications. Metal Improvement Company - 9a ed., 62p. Disponível em: <http://www.metalimprovement.com /premium /PDF/greenbook_v9/english/MIC\%20Green\%20Book\%20-\%209th\%20edition\%20\%20 Com plete\%20Book.pdf> Acesso em: 15 dez. 2013.

MILLER, K. J.; Materials Science Perspective of Metal Fatigue Resistance; Materials Science and Technology, v.9, p.453-462, June 1993.

MITCHELL, P.S.; The use of Vanadium. Vanitec, Winterton House, High Street, Westerham, Kent, TN16 1AQ, England, 2001.

MODENESI, P.J.; MARQUES, P.V.;SANTOSD.B.; Introdução à Metalurgia da Soldagem. UFMG; Belo Horizonte, 2012.

MORRIS, W. L.; BUCK, O.; Crack closure load measurements for microcracks developed during the fatigue of Al 2219-T851. Metall Trans;A8:597-601. 1977.

NAVARRO A.; de los Rios E. R.; Fatigue crack growth modelling by successive blocking of dislocations. Proc. R. Soc., A437;1992 
NBR 11299; Aço: Determinação da Profundidade de Descarbonetação, 1990.

O'HARA, P. Superfinishing and jateamento por granalhas of surfaces to optimize roughness and stress. In: Brebbia CA, Kenny JM, editors. Surface treatment IV. Wessex, UK: WIT Press; p. 321-30. 1999.

OHTANI, H.; HILLERT, M.; A thermodynamic assessment of the Fe-N-V system. Calphad, , vol 15, p. 25. ISSN: 0364-5916 DOI: 10.1016/0364-5916(91)90023-D.Elsevier Science. 1991.

PERINI, R.; $O$ uso de raios-x para determinação da tensão residual induzida pelo processo de roleteamento de uma camisa de cilindro de motor diesel. Dissertação (mestrado). Instituto de Pesquisas Energéticas e Nucleares. São Paulo, SP, 2008.

POPA, N. C.; The (hkl) Dependence of Diffraction-Line Broadening Caused by Strain and Size for all Laue Groups in Rietveld Refinement; J. ApplCryst. 31, pp. 176-180. 1998.

REGONE, N. N.; Determinação de Tensão Residual em Camadas Superficiais. Dissertação (Mestrado). Universidade Estadual de Campinas. Campinas, SP., 2000.

RÉVÉSZ, A.; UNGÁR, T.; BORBÉLY, A.;LENDVAI, J.; Dislocation and grain size in ball milled iron power; Nanostr. Mater. 7, PP 779-788. 1996

RIGAKU. Residual stress data process program 2 (ver. 2.0) d/max-2000 instruction manual, Rigaku Corporation, 10ํㅡㄹ. 2006.

RONNIGER, C.; Reliability Analysis with Weibull, disponível em: http://www.crgraph.com/Weibull11e.pdf. Acesso em 25 de novembro de 2012.

RUCHERT, C. O. F. T.; Estudo da interferência de carregamento em histórias de vôos simulados na liga de alumínio aeronáutico SAE 7475 T7351. USP, Tese de doutorado, São Carlos, SP, 2007.

SATOH, H.; $37^{\text {st }}$ Mechanical Working and Stell. Processing Conference Proceedings, p. 911. 1999.

SATO, S. K. W.;KUMAGAI, M.; IMAKUFU, M.; TASHIRO, H.; KAJIWARA, K.; SHOBU, T.; Relationship between dislocations and residual stresses in colddrawn pearlitic steel analyzed by energy-dispersive X-ray diffraction. Materials Characterization, p 152-160; 2013.

SCARDI, P.; X-ray Powder Diffraction Analysis of Real Structure of Materials; edited by H.-J. Bunge; J. Fiala; R. L. Snyder. IUCr. Oxford University Press. 1998.

SCHERRER, P.;Nachr. Gesellschaft der Wissenschaften zu Göettingen. Math. Phys. $\mathrm{KI}$ 2, 98, 1918. 
SCHULZE, V.; Modern mechanical surface treatment: states, stability, effects: Weinheim: Wiley-VCH; cap. 1-3, 2006

SCURACCHIO, B. G.; Tensões residuais induzidas por jateamento por granalhas e durabilidade de molas em lâminas. Tese de doutorado. Escola Politécnica-USP. São Paulo, 2012.

SONG, P. S., WEN, C. C., Crack closure and crack growth behavior in shot peened fatigued specimen. Engineering Fracture Mechanics. v. 63, p. 295-304, 1999.

STEPHENS, P. W.; Phenomenological model of anisotropic peak broadening in powder diffraction; J. Appl. Cryst.; 32, pp. 281-289. 1999.

SUORTTI, P.; The Rietveld Method; IUCr Monographs on Crystallography, Oxford University Press. Vol. 5, pp. 167-185. 1993.

SURYANARAYANA, C.; NORTON, M.G. X-ray diffraction - a practical approach. Plenun Press. p. 207-218. New York, 1998.

TORRES, M. A. S.; Uma avaliação do efeito do jateamento por granalhas na vida em fadiga do Aço ABNT $4340 \mathrm{com}$ e sem revestimento de cromo duro. Tese (Doutorado) - FEG/UNESP, Guaratinguetá, SP, 2002.

TORRES, M. A. S.; VOORWALD, H. J. C.; An evaluation of jateamento por granalhas, residual stresses and relaxation on the fatigue life. International Journal of Fatigue, v.24, pp 877-866, 2002.

TURNBULL, A.; de los Rios, E.R.; TAIT, R.B., LAURANT, C.; BOABAID, J.S. Improving the fatigue resistance of wasp alloy by shot Peening. Fatigue Fract Eng Mater Struct; 21:1513-24. 1998.

UNGÁR, T.; BORBÉLY, A.; The effect of dislocation contrast on $x$-ray line broadening: a new approach to line profile analysis. Appl Phys Lett; 69:3173-5. 1996.

UNGÁR, T.; DRAGOMIR, I.;RÉVÉSZ, Á.; BORBÉLY, A.;The contrast factors of dislocations in cubic crystals: the dislocation model of strain anisotropy in practice Appl Phys Cryst.; 32; 992-1002. 1999.

UNGÁR, T.; TICHY, G.; The Effect of Dislocation Contrast on X-Ray Line Profiles in Untextured Polycrystals. Phys. Status Solidi, Wiley-VCH, Germany 171, pp 425434. 1999.

VAN BERKUM, J. G. M.; VERMEULEN, A. C.; DELHEZ, R.; DE KEIJSER,T.H.; MITTEMEIJER, E. J.; Applicabilities of the Warren-Averbach analysis and an alternative analysis for separation of size an strain broadening. J. Appl. Cryst., V. 27, 345-357, 1994.

VAN VLACK, L. H.;Princípio de ciência dos materiais. Editora Edgard Blücher Itda, 13ª edição, São Paulo, SP, p.157, 2000. 
WAGNER, L.; LÜTJERING, G.; Influence of jateamento por granalhas on the fatigue behaviour of Ti-alloys. In: Jateamento por granalhas. Oxford: Pergamon Press; p. 453-60. 1981.

WANG, S.; YAO, M.; WANG, R.; Fatigue limits of shot peened metals. Journal of Materials Processing Technology. v. 73, p. 57-63, 1998.

WARREN, B. E.; X-ray studies of deformed metals; Prog.in Metal Phys. Pergamon Press, London; 8; pp. 147-202. 1959.

WARREN, B. E.; AVERBACH, B. L; The separation of cold-work distortion and particle size broadening in $x$-ray patterns; J. Appl. Phys. (1952); 23, 497.

WEISSTEIN, E. W.; "Fourier Series"; Disponível em: http ://mathworld. wolfram. com/FourierSeries.html. Acesso em 15/06/2016.

WILKENS, M.; The determination of density and distribution of dislocations in deformed single crystals from broadened $X$-ray diffraction profiles. Phys. Status Solidi, 1970. A, 2, pp 359-370.

WILLIAMSON, G. K.; HALL, W. H.; X-ray line broadening from filed aluminium and wolfram; Acta Metall. 1; pp 22-31. 1953.

WILLIANSOM, G., K.; SMALLMAN R. E.; Dislocation densities in some annealed and cold-worked metals from measurements on the X-ray debye-scherrer spectrum. Philos. Mag. 1; pp 34-46. 1955.

WOODHEAD, J. H. The physical metallurgy of vanadium steels. Vanadium Application Technology, The Use of Vanadium in Steel. Paper Presented at The Vanitec International Symposium. Guilin, China. 6th November 2000.

WU, E.; MAC, A.; GRAY, E.; KISI, E. H.; J. Appl. Cryst. Modelling DislocationInduced Anisotropic Line Broadening in Rietveld Refinements Using a Voigt Function. I. General Principles. 31, pp 356-362; 1998.

WULPI, D. J.; Understanding how components fail, ASM American Society for Metal. cap. 7, Metals Park, OH, 1985. 